\title{
Design and co-simulation of a seasonal solar thermal system for a Canadian single-family detached house
}

\author{
by \\ Adam D. Wills, B.A.Sc., Mechanical Engineering \\ University of Windsor

\begin{abstract}
A thesis submitted to the
Faculty of Graduate and Postdoctoral Affairs

in partial fulfillment of the requirements for the degree of
\end{abstract}

Master of Applied Science in Sustainable Energy

Department of Mechanical and Aerospace Engineering

Carleton University

Ottawa, Ontario

May, 2013

(C)Copyright

Adam D. Wills, 2013 
Library and Archives

Canada

Published Heritage

Branch

395 Wellington Street

Ottawa ON K1A ON4

Canada
Bibliothèque et

Archives Canada

Direction du

Patrimoine de l'édition

395 , rue Wellington

Ottawa ON K1A ON4

Canada
Your file Votre référence

ISBN: 978-0-494-94625-1

Our file Notre référence

ISBN: 978-0-494-94625-1
NOTICE:

The author has granted a nonexclusive license allowing Library and Archives Canada to reproduce, publish, archive, preserve, conserve, communicate to the public by telecommunication or on the Internet, loan, distrbute and sell theses worldwide, for commercial or noncommercial purposes, in microform, paper, electronic and/or any other formats.

The author retains copyright ownership and moral rights in this thesis. Neither the thesis nor substantial extracts from it may be printed or otherwise reproduced without the author's permission.
AVIS:

L'auteur a accordé une licence non exclusive permettant à la Bibliothèque et Archives Canada de reproduire, publier, archiver, sauvegarder, conserver, transmettre au public par télécommunication ou par l'Internet, prêter, distribuer et vendre des thèses partout dans le monde, à des fins commerciales ou autres, sur support microforme, papier, électronique et/ou autres formats.

L'auteur conserve la propriété du droit d'auteur et des droits moraux qui protege cette thèse. $\mathrm{Ni}$ la thèse ni des extraits substantiels de celle-ci ne doivent être imprimés ou autrement reproduits sans son autorisation.
In compliance with the Canadian Privacy Act some supporting forms may have been removed from this thesis.

While these forms may be included in the document page count, their removal does not represent any loss of content from the thesis.
Conformément à la loi canadienne sur la protection de la vie privée, quelques formulaires secondaires ont été enlevés de cette thèse.

Bien que ces formulaires aient inclus dans la pagination, il n'y aura aucun contenu manquant. 


\section{Abstract}

For the 2009 residential sector in Ontario, Canada, $81.5 \%$ of the secondary energy consumed was for space heating and domestic hot water preparation. The majority of domestic space heating and hot water systems in Ontario are natural gas-fired systems, which generated $16.1 \mathrm{Mt}$ of $\mathrm{CO}_{2 e}$ in 2009. Working towards reductions of greenhouse gas emissions from this sector, there may be potential in alternative energy technologies. One potential candidate is solar "combisystems", which supply both space heating and domestic hot water. This type of system has received considerable attention recently as an alternative to conventional heating systems.

The challenge of using solar energy is the intermittence of the solar resource and the mismatch between supply and demand of solar energy. Solar availability is typically highest at noon and during the summer months. For Canadian climates however, thermal demands are normally highest during the winter. To address this seasonal mismatch, past researchers have proposed the use of seasonal thermal energy storage to carry over summer solar collection for winter use and dampen out periods of low solar availability.

This work was carried out as part of the Carleton Research and Innovation in Sustainable Energy (C-RISE) project at Carleton University. The C-RISE project is a test facility for innovative residential technologies. The focus of this thesis was the design and simulation of the seasonal solar thermal energy system for a single house scale application. To carry out the analysis, a numerical representation of the C-RISE house was developed in the ESP-r simulation tool. A literature review and "best practices" were used to develop a layout of a two-tank water-based seasonal solar thermal energy system. A $300 \mathrm{~L}$ diurnal tank was specified to supply domestic hot water and a buried concrete water tank seasonal storage with variable volume was specified to supply space heating to the C-RISE house. To simulate the performance of the solar thermal system, a model was created in the TRNSYS simulation tool. Interaction between the ESP-r and TRNSYS models was then facilitated by the use 
of a co-simulation tool called the "Harmonizer."

Several parametric and sensitivity analyses were carried out using co-simulation. The annual performance of varying combinations of seasonal storage volumes, solar collector areas, and seasonal storage insulation levels were examined. It was found that when a fixed collector area was used, increases in seasonal storage volume initially improved annual performance up to a critical point. Beyond that point further increases in storage volume decreased annual performance. It was also found that the annual performance of the solar thermal system was sensitive to the level of stratification in both the diurnal and seasonal tanks. Finally, to assess the two-tank system configuration, a "selected case" was analyzed. This system contained $34.5 \mathrm{~m}^{2}$ of collector area and a $80 \mathrm{~m}^{3}$ buried seasonal storage with $45 \mathrm{~cm}$ of extruded polystyrene insulation. The results from the co-simulation found that this system could provide $89.2 \%$ of the space heating and domestic hot water thermal demands of the C-RISE house. 
For my parents, who were always by my side 


\section{Acknowledgments}

I would first like to thank my supervisors, Dr. Ian Beausoleil-Morrison and Dr. Cythia Cruickshank. I could not have asked for better team to get me through this journey. Your wealth of knowledge and experience was an incredible asset. Our meetings were always filled with laughter and your approach to academia and life will continue to provide an example for me in the future.

I would also like to acknowledge the funding and support of the Natural Sciences and Engineering Research Council of Canada (NSERC) as well as the NSERC Smart Net-zero Energy Buildings strategic Research Network (SNEBRN). A special thanks to Patrice Pinel who authored the ground conduction model used in this work and his knowledge, experience, and friendship helped to bring this work to completion. I would also like to acknowledge Dr. Liam O'Brien for sharing his lab's resources to aid in the completion of this work.

I would like to extend a special thank-you to Courtney Edwards, John Kopf, and Andrea Pietila for helping me settle into life at Carleton University. You helped me scale the ESP-r learning cliff and introduced me to the wonders of tea. I would also like to thank my lab mates Ahmed Alnabelseya, Sébastien Brideau, Skai Edwards, Ifaz Haider, and of course Steve McMurtry. Your support and friendship made it easy to come into work every day. Thank-you to my friends and colleagues b, Chris Baldwin, Evan Boucher, Ryan Dickinson, Phil Drouillard, Geoff Johnson, and David Ouellette. The lunch and coffee breaks we had gave me much needed escape from my work and helped me retain my sanity.

Lastly, I would like to thank my family. Your enduring love and support gave me the strength and confidence to complete this work. When I doubted myself, you believed in me and reminded me of the wonderful friends and family I have to get me through any ordeal. 


\section{Table of Contents}

Abstract $\quad$ iii

$\begin{array}{ll}\text { Acknowledgments } & \text { vi }\end{array}$

Table of Contents vii

List of Tables $\quad$ xii

List of Figures xiv

$\begin{array}{ll}\text { Nomenclature } & \text { xvii }\end{array}$

1 Introduction 1

1.1 Background ......................... 1

1.2 Solar Thermal Systems . . . . . . . . . . . . . . . . . . . 3

1.3 Solar Availability . . . . . . . . . . . . . . . 5

1.4 C-RISE Project . . . . . . . . . . . . . . . 7

1.5 Research Objectives . . . . . . . . . . . . . 7

1.6 Thesis Outline . . . . . . . . . . . . . . . 8

2 Literature Review $\quad 10$

2.1 Introduction . . . . . . . . . . . . . . . . . 10

2.2 Thermal Energy Storage . . . . . . . . . . . . . . . 10

2.2.1 Thermal Energy Storage Mechanisms and Concepts . . . . . 11

2.2.2 Water Based Sensible Storage . . . . . . . . . . . . . 13

2.3 Past Projects and Studies . . . . . . . . . . . . . 23

2.3.1 Experimental Facilities .............. 24

2.3 .2 Simulation Studies . . . . . . . . . . . . . 28 
2.4 Performance Indices $\ldots \ldots \ldots \ldots \ldots$

2.4.1 System Performance . . . . . . . . . . . . . 30

2.4 .2 Storage Performance . . . . . . . . . . . . . 31

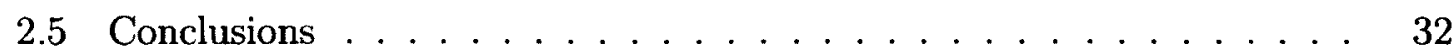

3 Whole-Building Energy Simulation using ESP-r 33

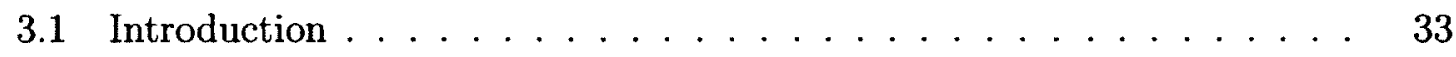

3.2 Building Thermal Domain . . . . . . . . . . . . . 34

3.2 .1 Discretization of System . . . . . . . . . . . . 35

3.2.2 Formation of Finite Volume Equations . . . . . . . . 35

3.2 .3 Simultaneous Solution Method . . . . . . . . . . . . . 39

3.3 Building Air Flow $\ldots \ldots \ldots \ldots \ldots \ldots$

3.3.1 Scheduled Flow . . . . . . . . . . . . . . . . . 41

3.3 .2 Air Flow Networks . . . . . . . . . . . . . . . 41

3.3 .3 AIM 2 Model . . . . . . . . . . . . . . . . . . 42

3.4 Plant Network Domain . . . . . . . . . . . . . . . . . 43

4 Solar Thermal System Simulation using TRNSYS 45

4.1 Introduction . . . . . . . . . . . . . . . 45

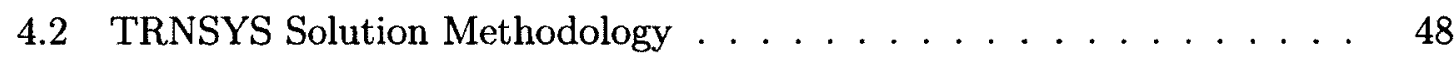

4.3 Models in TRNSYS . . . . . . . . . . . . . . . . . . . 49

4.3.1 Flat-plate Solar Collector . . . . . . . . . . . . . 49

4.3.2 Stratified Storage Tank . . . . . . . . . . . . . . . 53

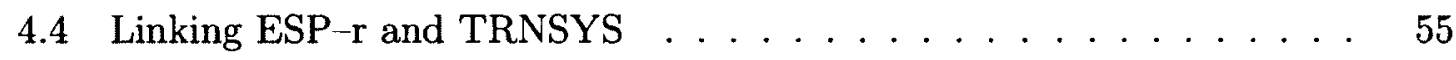

4.5 Closing Remarks $\ldots \ldots \ldots \ldots \ldots$. . . . . . . . . 57

5 Modelling of Building Physics and Hydronic Floor Heating for the C-RISE House $\quad 59$

5.1 Building Geometry $\ldots \ldots \ldots \ldots \ldots \ldots$

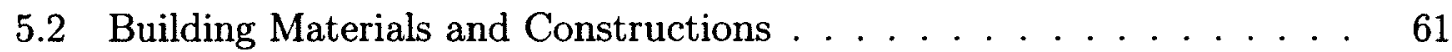

5.3 Building Air Flow $\ldots \ldots \ldots \ldots \ldots$

5.3 .1 Infiltration . . . . . . . . . . . . . . . 64

5.3 .2 Ventilation . . . . . . . . . . . . . . 65

5.3.3 Inter zonal Air Exchange $\ldots \ldots \ldots \ldots \ldots 6$

5.4 Hydronic Heating Floor $\ldots \ldots \ldots \ldots 6$ 
5.4 .1 Hydronic Floor Design . . . . . . . . . . . . . . 67

5.5 Boundary Conditions and Internal Gains $\ldots \ldots \ldots \ldots \ldots$

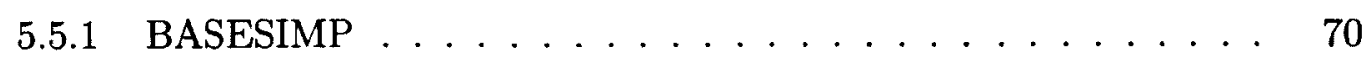

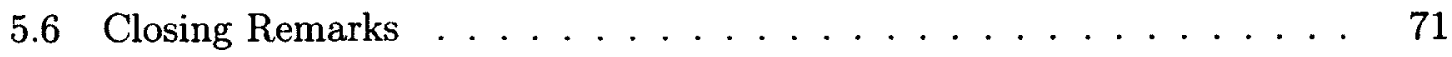

6 Modelling and Co-simulation of the Seasonal Solar Thermal System 72

6.1 Seasonal Solar Thermal System _. . . . . . . . . . . 73

6.1.1 Thermal Management Strategy . . . . . . . . . . 74

6.1 .2 Diurnal Tank . . . . . . . . . . . . . . . . 77

6.1 .3 Seasonal Storage Tank . . . . . . . . . . . . . 80

6.1.4 Solar Thermal Collectors . . . . . . . . . . . . . . . . 84

6.1.5 Secondary Components of the Solar Thermal System . . . . 87

6.2 Hydronic Slab Control and Operation . . . . . . . . . . . . . 89

6.3 Closing Remarks . . . . . . . . . . . . . . . . . . 93

7 Results and Discussion $\quad 94$

7.1 Space Heating and DHW Loads . . . . . . . . . . . . . 95

7.2 Numerical Sensitivity Analysis . . . . . . . . . . . . . . . . . 96

7.2.1 Diurnal Tank Discretization _. . . . . . . . . . . . 97

7.2 .2 Seasonal Tank Discretization . . . . . . . . . . . . 99

7.2 .3 Summary of Findings . . . . . . . . . . . . . 101

7.3 Parametric Study . . . . . . . . . . . . . . . . . . . . . . 101

7.3.1 Summary of Findings . . . . . . . . . . . . . . . . . 109

7.4 Analysis of "Selected Case" . . . . . . . . . . . . . . . . . . 109

7.4 .1 Solar Collectors . . . . . . . . . . . . . . . . . 111

7.4 .2 Seasonal Tank . . . . . . . . . . . . . . . . . . 113

7.4 .3 Diurnal Tank . . . . . . . . . . . . . . . . . 114

7.4.4 Hydronic Slab Operation . . . . . . . . . . . . . 115

7.4.5 "Selected Case" Sensitivity Analysis . . . . . . . . . . . 118

7.4 .6 Summary of Findings . . . . . . . . . . . . . . 122

8 Conclusions and Recommendation 124

8.1 Conclusions . . . . . . . . . . . . . . . . . . . 124

8.2 Recommendations and Future Work . . . . . . . . . . . . . 128

$\begin{array}{ll}\text { List of References } & 131\end{array}$ 
A.1 Collector Discretization Study . . . . . . . . . . . . . . . 143

A.2 Temporal Discretization Study . . . . . . . . . . . . . 145

A.3 Ground Conduction Model Discretization Study . . . . . . . . . . 146

A.3.1 Mesh Generation . . . . . . . . . . . . . . . . 147

A.3.2 Distance to Farfield Sensitivity _ . . . . . . . . . . 150

A.3.3 Nodes to Farfield Sensitivity . . . . . . . . . . . . 150

A.3.4 Nodes Along Side of Tank Sensitivity . . . . . . . . . . . 151

A.3.5 Nodes Between Tank Bottom and Water Table Sensitivity . . 152

A.3.6 Final Parameters used in Ground Conduction Model . . . . . 152

A.4 Inter-zonal Air Exchange Study . . . . . . . . . . . . . 153

Appendix B Parametric Study Data 156

B.1 Combined Space Heating and DHW Solar Fraction . . . . . . 156

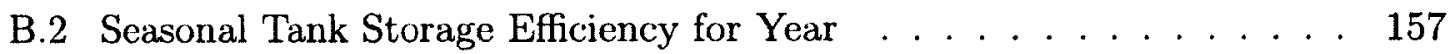

B.3 Annual Solar Energy Collected . . . . . . . . . . . . . . 158

Appendix C ESP-r Building Constructions $\quad 160$

C.1 Exterior Walls . . . . . . . . . . . . . . . . . . . 161

C.2 Hydronic Floors . . . . . . . . . . . . . . . . . . 162

C.3 Ceiling and Glazing Constructions . . . . . . . . . . . . . 163

Appendix D Simulation Input Files $\quad 165$

D.1 Harmonizer Input File $\ldots \ldots \ldots \ldots \ldots \ldots$

D.2 ESP-r Input Files . . . . . . . . . . . . . . . . . . . 167

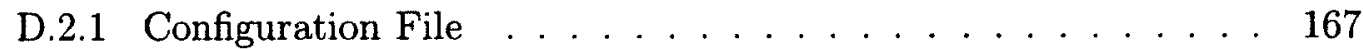

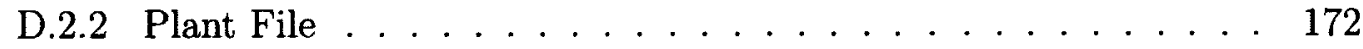

D.2.3 AIM-2 Input File . . . . . . . . . . . . . . . . 174

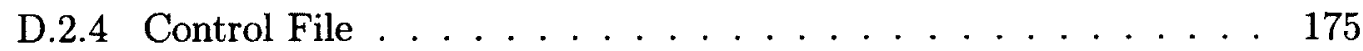

D.2.5 Ventilation Input File . . . . . . . . . . . . . 175

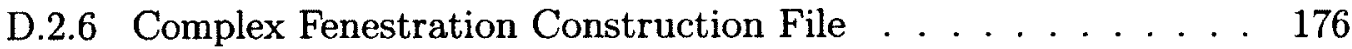

D.2.7 BASESIMP Input Files . . . . . . . . . . . . . . . . . 178

D.3 TRNSYS Input File . . . . . . . . . . . . . . . . . . . . . . 179

D.3.1 TRNSYS Control Cards . . . . . . . . . . . . . . . . 179

D.3.2 Weather Reader Type $15 \ldots \ldots \ldots \ldots$ 
D.3.3 Flat-Plate Collector Type $539 \ldots \ldots 182$

D.3.4 Diurnal Tank Type 534 . . . . . . . . . . . . . . . . . 182

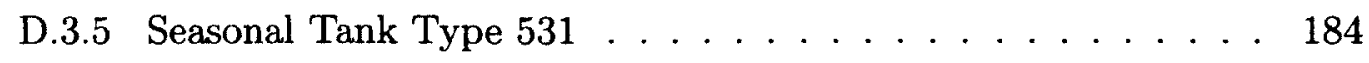

Appendix E Hydronic Slab Model in ESP-r $\quad 186$

E.1 Assumptions and Modelling . . . . . . . . . . . . 186

E.2 Modification to the Source Code . . . . . . . . . . . . . 190

$\begin{array}{lll}\text { Appendix F } & \text { Custom TRNSYS Types } & 193\end{array}$ 


\section{List of Tables}

5.1 C-RISE air infiltration . . . . . . . . . . . . 65

5.2 Radiant floor parameters . . . . . . . . . . . . . . . 68

6.1 Basic soil properties assumed for the research . . . . . . . . . 84

6.2 Outdoor reset control parameters _. . . . . . . . . . . 91

7.1 System parameters used for the numerical sensitivity study . . . . . 97

7.2 System parameters used for the parametric study . . . . . . . . 102

7.3 Variation of seasonal tank fluid height in relation to insulation thickness 103

$7.4 \Im_{\text {total }}$ results for the $45 \mathrm{~cm}$ insulation case $\ldots \ldots \ldots \ldots \ldots . \ldots 105$

7.5 System parameters of the "selected case" . . . . . . . . . . . 110

A.1 System parameters used for the numerical sensitivity study . . . . . 146

A.2 Ground conduction model base parameters . . . . . . . . . . . . 149

A.3 Ground conduction final discretization parameters . . . . . . . . 153

B.1 $30 \mathrm{~cm}$ seasonal storage insulation $\ldots \ldots \ldots \ldots \ldots \ldots \ldots$

B.2 $45 \mathrm{~cm}$ seasonal storage insulation $\ldots \ldots \ldots \ldots \ldots \ldots$

B.3 $60 \mathrm{~cm}$ seasonal storage insulation $\ldots \ldots \ldots \ldots \ldots \ldots \ldots$

B.4 $80 \mathrm{~cm}$ seasonal storage insulation $\ldots \ldots \ldots \ldots \ldots \ldots$

B.5 $30 \mathrm{~cm}$ seasonal storage insulation $\ldots \ldots \ldots \ldots \ldots \ldots \ldots$

B.6 $45 \mathrm{~cm}$ seasonal storage insulation $\ldots \ldots \ldots \ldots \ldots \ldots \ldots$

B.7 $60 \mathrm{~cm}$ seasonal storage insulation $\ldots \ldots \ldots \ldots \ldots \ldots$

B.8 $80 \mathrm{~cm}$ seasonal storage insulation $\ldots \ldots \ldots \ldots \ldots \ldots \ldots$

B.9 $30 \mathrm{~cm}$ seasonal storage insulation $\ldots \ldots \ldots \ldots \ldots \ldots \ldots$

B.10 $45 \mathrm{~cm}$ seasonal storage insulation $\ldots \ldots \ldots \ldots \ldots . \ldots . \ldots 159$

B.11 $60 \mathrm{~cm}$ seasonal storage insulation $\ldots \ldots \ldots \ldots \ldots \ldots$

B.12 $80 \mathrm{~cm}$ seasonal storage insulation $\ldots \ldots \ldots \ldots \ldots \ldots$

C.1 Exterior Brick Wall . . . . . . . . . . . . . . . . . . . . 161

C.2 Exterior Siding Wall . . . . . . . . . . . . . . . . 161

C.3 Roof Construction . . . . . . . . . . . . . 162 
C.4 Main zone hydronic floor construction . . . . . . . . . . . 163

C.5 Second zone hydronic floor construction . . . . . . . . . . 163

C.6 Ceiling construction between attic and second floor . . . . . 163

C.7 Glazing frame construction . . . . . . . . . . . . . . . 164

C.8 Triple pane double low-e argon glazing . . . . . . . . . . . 164 


\section{List of Figures}

1.12009 secondary energy use in Ontario by sector . . . . . . . . . . 2

1.22009 residential sector secondary energy use . . . . . . . . . . . 2

1.3 Examples of active and passive solar thermal systems . . . . . . . . 4

1.4 Cycle and intermittence of solar energy availability . . . . . . . 6

1.5 Seasonal offset of solar availability and space heating in Northern climates 6

2.1 Volumes required to store $6.7 \mathrm{MJ} \ldots \ldots . \ldots . \ldots . . \ldots 12$

2.2 Simple solar hot water tank . . . . . . . . . . . . . 14

2.3 Indirect charging of sensible TES . . . . . . . . . . . . . . 15

2.4 Effective volume of water in tank . . . . . . . . . . . . 15

2.5 Different levels of thermal stratification . . . . . . . . . . . . 16

2.6 Multi-tank thermal storage system . . . . . . . . . . . 18

2.7 Buried and bermed storage tanks . . . . . . . . . . . . . 20

2.8 One dimensional water tank models . . . . . . . . . . . . . . 22

2.9 Seasonal hot water storage in Hannover . . . . . . . . . . . . . 25

2.10 System schematic of the Drake Landing Solar Community . . . . . 26

3.1 Handshaking of solver domains in ESP-r . . . . . . . . . . . 34

3.2 ESP-r discretization and energy flowpaths in a modelled building zone 36

3.3 ESP-r discretization of an external opaque wall . . . . . . . . 36

3.4 Control-volume heat balance at homogeneous layer in construction . 37

3.5 Simple illustration of a building air flow network . . . . . . . . . . 42

3.6 Simple illustration of an ESP-r plant network . . . . . . . . . . 44

4.1 Illustration of stair-step effect . . . . . . . . . . . . . 46

4.2 TRNSYS type and networking . . . . . . . . . . . . . 48

4.3 TRNSYS solution method . . . . . . . . . . . . 49

4.4 Cross-section of simple flat-plate collector . . . . . . . . . 50

4.5 One dimensional discretization of a solar thermal collector . . . . . 52

4.61 -D discretization of a stratified tank . . . . . . . . . . . 54 
4.7 Control volume for tank node $i \ldots \ldots \ldots \ldots \ldots$

4.8 Illustration of different co-simulation techniques for modelling of a simple plant . . . . . . . . . . . . . 56

5.1 Wireframe and rendered C-RISE building model . . . . . . . 60

5.2 Different representations of glazing and framing . . . . . . . . 61

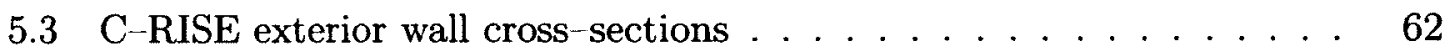

5.4 Air flowpaths in the C-RISE building model . . . . . . . . . . 64

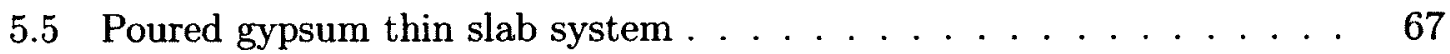

5.6 Hydronic floor cross-section $\ldots \ldots \ldots \ldots \ldots$

5.7 Single hydronic floor with two circuits $\ldots \ldots \ldots \ldots$

5.8 C-RISE Foundation Layout $\ldots \ldots \ldots \ldots \ldots \ldots$

6.1 Seasonal solar thermal system considered in the research $\ldots \ldots .73$

6.2 Solar loop control logic . . . . . . . . . . . . . 76

6.3 TRNSYS Type 2 control logic $\ldots \ldots \ldots \ldots \ldots \ldots \ldots$

6.4 Inlet and Outlet Port Locations for the DHW Tank . . . . . . . 78

6.5 Seasonal tank elevation section $\ldots \ldots \ldots \ldots \ldots . \ldots . \ldots . \ldots$

6.6 Cross-sectional plan view of the ground conduction model . . . . . 83

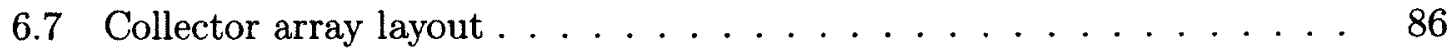

6.8 TRNSYS / ESP-r co-simulation of the space heating loop . . . . . 89

6.9 Outdoor reset curve and offset-modulation . . . . . . . . . 90

6.10 Hydronic floor recirculation valve control logic $\ldots \ldots \ldots . . . . .992$

7.1 Annual results of the diurnal tank discretization study . . . . . . 98

7.2 Annual results of the seasonal tank discretization study . . . . . . 99

$7.330 \mathrm{~cm}$ insulation on the seasonal tank . . . . . . . . . . . . . 104

$7.445 \mathrm{~cm}$ insulation on the seasonal tank . . . . . . . . . . . . . . 104

$7.560 \mathrm{~cm}$ insulation on the seasonal tank . . . . . . . . . . . 104

$7.680 \mathrm{~cm}$ insulation on the seasonal tank . . . . . . . . . . . . 104

7.7 Sensitivity of $\Im_{\text {total }}$ to $t_{\text {Seas,ins }}$ for the 12 collector and $120 \mathrm{~m}^{3}$ system 108

7.8 Sensitivity analysis for $45 \mathrm{~cm}$ seasonal tank insulation and 12 collector case . . . . . . . . . . . . . . . . . . . . . . 108

7.9 Energy supplied to and delivered by the "selected case" seasonal solar thermal system . . . . . . . . . . . . . . . . 111

7.10 Instantaneous efficiencies of the solar collectors . . . . . . . . . . 112

7.11 Inlet temperatures of the solar collectors $\ldots \ldots \ldots \ldots . \ldots 113$ 
7.12 "Selected case" annual seasonal tank temperatures . . . . . . . . . . 114

7.13 "Selected case" annual diurnal tank top temperatures . . . . . . . . 115

7.14 Temperatures and internal gains of the main floor zone . . . . . . 116

7.15 Temperatures and internal gains of the main floor zone for Jan $27^{\text {th }}$ to

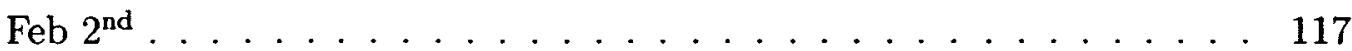

7.16 Seasonal storage length, width, and height definitions . . . . . . 118

7.17 Seasonal storage H/D ratio sensitivity study . . . . . . . . . . 119

7.18 Seasonal storage $\mathrm{L} / \mathrm{W}$ ratio sensitivity study . . . . . . . . . . . . 120

7.19 Collector slope sensitivity . . . . . . . . . . . . . . 121

A.1 Annual results of the collector discretization study . . . . . . . . . . 144

A.2 Annual results of the temporal discretization study . . . . . . . . 145

A.3 Plan view of ground conduction model and quarter of buried tank . . 147

A.4 Elevation view of ground conduction model and quarter of buried tank 148

A.5 Annual losses of the buried seasonal storage for the distance to farfield sensitivity study . . . . . . . . . . . . . . . 150

A.6 Annual losses of the buried seasonal storage for the $N_{\text {farfield }}$ sensitivity study . . . . . . . . . . . . . . . . . . 151

A.7 Annual losses of the buried seasonal storage for the $N_{x}$ and $N_{z}$ sensi-

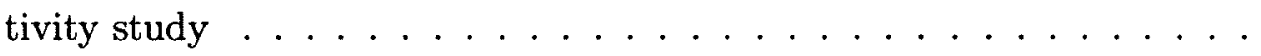

A.8 Annual losses of the buried seasonal storage for the $N_{B o t}$ sensitivity study . . . . . . . . . . . . . . . . .

A.9 RMSD of basement zone temperatures with increasing air flow between the basement and main zone . . . . . . . . . . . . . . . . . 154

A.10 RMSD of second zone temperatures with increasing air flow between the main and second zone . . . . . . . . . . . . . . 155

E.1 Hydronic floor calculation domain . . . . . . . . . . . . . 187

E.2 Energy balance for tube element . . . . . . . . . . . . . . . . . 189

E.3 Simple 2 zone hydronic floor example model . . . . . . . . . . . . . . 190

E.4 Temperature of node receiving flux from hydronic floor model using

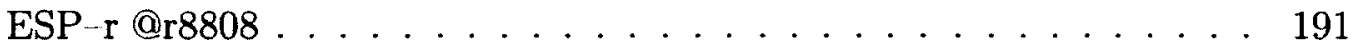

E.5 Temperature of node receiving flux from hydronic floor model using

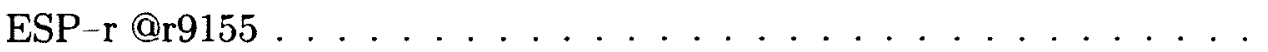




\section{Nomenclature}

\begin{tabular}{|c|c|c|}
\hline$\Im$ & Solar fraction & {$[\%]$} \\
\hline$A$ & Area & {$\left[\mathrm{m}^{2}\right]$} \\
\hline$A^{\prime}$ & Differential area & {$\left[\mathrm{m}^{2}\right]$} \\
\hline $\mathrm{ACC}$ & Air coupling component & \\
\hline $\mathrm{ACH}$ & Volumetric flow rate of room air in air changes per hour & \\
\hline AIM-2 & Alberta air infiltration model & \\
\hline$A F N$ & Air-flow network & \\
\hline $\mathrm{A} / \mathrm{V}$ & Area-to-volume ratio & \\
\hline BPS & Building performance simulation & \\
\hline BTES & Borehole thermal energy storage & \\
\hline$C$ & Flow coefficient & {$\left[m^{3} /\left(s \cdot P a^{n}\right)\right]$} \\
\hline \multirow[t]{2}{*}{ C RISE } & Carleton Carleton Research and & \\
\hline & Innovation in Sustainable Energy & \\
\hline$C_{\text {coll }}$ & Combined thermal capacitance of the fluid and collector & {$[\mathrm{J} / \mathrm{K}]$} \\
\hline$c_{p}$ & Specific heat capacity & {$[\mathrm{J} / \mathrm{kg} \mathrm{K}]$} \\
\hline $\mathrm{CFC}$ & Complex fenestration construction & \\
\hline CFD & Computational fluid dynamics & \\
\hline CSHPSS & central solar heating plants with seasonal storage & \\
\hline
\end{tabular}




\section{Nomenclature}

CTF Conduction transfer function

$\mathrm{CV} \quad$ Control volume

CWEC Canadian Weather year for Energy Calculation

DHW Domestic hot water

DLL Dynamic-link library

DLSC Drake Landing Solar Community

EPS Expanded polystyrene

ETC Evacuated tube solar collector

$F^{\prime} \quad$ Collector efficiency factor

$F_{R} \quad$ Unitless heat removal factor $\quad[-]$

$f_{\text {sav,therm }}$ Extended fractional thermal energy savings [\%]

G Gain

$\begin{array}{lll}G_{T} & \text { Total incident solar flux on surface } & {\left[\mathrm{W} / \mathrm{m}^{2}\right]}\end{array}$

GHG Greenhouse gas

GUI Graphical user interface

$h \quad$ Height

[m]

H/D Height-to-diameter ratio

HCC Hydronic coupling component

HRV Heat recovery ventilator

HVAC Heating, ventilation and air-conditioning

IAM Incidence angle modifer

$\begin{array}{lll}k & \text { Conductivity } & {[\mathrm{W} / \mathrm{m} \mathrm{K}]}\end{array}$

$\Delta k \quad$ Additional conductivity $\quad[\mathrm{W} / \mathrm{m} \mathrm{K}]$ 


\section{Nomenclature}

\begin{tabular}{|c|c|c|}
\hline$L$ & Length & {$[\mathrm{m}]$} \\
\hline Low-e & Low-emissivity & \\
\hline$\dot{m}$ & Mass flow rate & {$[\mathrm{kg} / \mathrm{s}]$} \\
\hline$\dot{m}^{\prime}$ & Specific mass flow rate & {$\left[\mathrm{kg} / \mathrm{s} \mathrm{m}^{2}\right]$} \\
\hline MLC & Multi-layer construction & \\
\hline$N$ & Number of nodes & \\
\hline$n$ & Flow exponent & {$[-]$} \\
\hline ORC & Outdoor reset control & \\
\hline$P$ & Pressure & {$[\mathrm{Pa}]$} \\
\hline$P_{b}$ & Perimeter of basement & {$[\mathrm{m}]$} \\
\hline PEX & Cross-linked polyethylene & \\
\hline PV & Photovoltaic & \\
\hline$Q$ & Energy & {$[\mathrm{J}]$} \\
\hline$\dot{Q}$ & Heat flow & {$[\mathrm{W}]$} \\
\hline$\dot{Q}^{\prime}$ & Heat flow per length & {$[\mathrm{W} / \mathrm{m}]$} \\
\hline$\dot{Q}^{\prime \prime}$ & Heat flux & {$\left[\mathrm{W} / \mathrm{m}^{2}\right]$} \\
\hline$\dot{Q}^{\prime \prime \prime}$ & Heat source & {$\left[\mathrm{W} / \mathrm{m}^{3}\right]$} \\
\hline$r$ & Radius & {$[\mathrm{m}]$} \\
\hline$R S I$ & Thermal resistance in SI units & {$\left[\mathrm{m}^{2} \mathrm{~K} / \mathrm{W}\right]$} \\
\hline$S$ & Solar flux & {$\left[\mathrm{W} / \mathrm{m}^{2}\right]$} \\
\hline$S F D H$ & Single-family detached house & \\
\hline SHGC & Solar heat gain coefficient & \\
\hline SLC & Solar loop controller & \\
\hline
\end{tabular}




\section{Nomenclature}

SSTS Seasonal solar thermal system

$\begin{array}{lll}T & \text { Temperature } & {\left[\mathrm{K} \text { or }{ }^{\circ} \mathrm{C}\right]} \\ t & \text { Time } & {[\mathrm{hr} \text { or s] }} \\ t_{\text {Seas,ins }} & \text { Insulation thickness on seasonal storage } & {[\mathrm{m}]} \\ \Delta T & \text { Deadband temperature difference } & {\left[\mathrm{K} \text { or }{ }^{\circ} \mathrm{C}\right]} \\ \text { TES } & \text { Thermal Energy Storage } & \\ \text { TMC } & \text { Transparent materials construction } & \\ \text { U-value } & \text { Heat transfer coefficient } & {\left[\mathrm{W} / \mathrm{m}^{2} \mathrm{~K}\right]} \\ U A & \text { Overall heat transfer coefficient } & {[\mathrm{W} / \mathrm{K}]} \\ U_{L / T} & \text { Quadratic loss coefficient } & {\left[\mathrm{W} / \mathrm{m}^{2} \mathrm{~K}^{2}\right]} \\ V & \text { Volume } & {\left[\mathrm{m}^{3}\right]} \\ \dot{V} & \text { Volumetric flow rate } & {\left[\mathrm{m}^{3} / \mathrm{s}\right]} \\ W & \text { Width or spacing } & {[\mathrm{m}]} \\ \text { XPS } & \text { Extruded polystyrene } & \end{array}$

\section{Greek symbols}

$\begin{array}{ll}\alpha & \text { Absorptivity } \\ \beta & \text { Collector slope } \\ \eta & \text { Efficiency } \\ \kappa & \text { Soil coefficient } \\ \rho & \text { Density } \\ \tau & \text { Transmittance or time constant }\end{array}$

$[-]$

$\left[{ }^{\circ}\right]$

$[\%]$

$[-]$

$\left[\mathrm{kg} / \mathrm{m}^{3}\right]$

[unitless or s] 


\section{Chapter 1}

\section{Introduction}

\subsection{Background}

In 2007, the Ontario provincial government announced its goal of a $15 \%$ reduction in greenhouse gas (GHG) emissions by 2020 (compared to 1990 levels) [1]. To meet these targets, the provincial government looked to phase-out coal-fired power generation by 2014 and replace it with cleaner, renewable sources such as wind, solar, biomass, and hydroelectric [1]. In 2009, the installed wind power capacity in the province had grown to 1,162 MW [1] and by the end of 2010 Ontario had closed four coal-fired plants [2]. Nonetheless, as of 2013 Ontario Power Generation [3] still operated four coal-fired plants and one dual-fueled oil and natural gas plant. In 2010, these plants generated 12.2 TWh of electricity [4] and emitted $13 \mathrm{Mt}$ of $\mathrm{CO}_{2}$ equivalent $\left(\mathrm{CO}_{2 e}\right)$ [5]. Continuing to work towards GHG reductions, there is benefit in identifying which sectors in the province represent a large portion of energy consumption. For Ontario in 2009 , the residential sector accounted for $20.2 \%$ of the province's secondary energy use [6], illustrated in Figure 1.1.

In 2009, the majority of residential energy consumption was attributed to space heating and domestic hot water (DHW) preparation. These end-uses accounted for $67.4 \%$ and $18.3 \%$ of secondary energy ${ }^{1}$ consumed in existing Ontario homes respectively. This is shown graphically in Figure 1.2a. The space heating of dwellings in Ontario was primarily accomplished using natural gas, illustrated in Figure 1.2b. The use of natural gas for space heating resulted in 12.1 $\mathrm{Mt}$ of $\mathrm{CO}_{2 e}$ emissions in 2009 [6].

\footnotetext{
${ }^{1}$ Secondary energy can be considered as refined or processed energy such as electricity which is derived from a primary source such as nuclear
} 


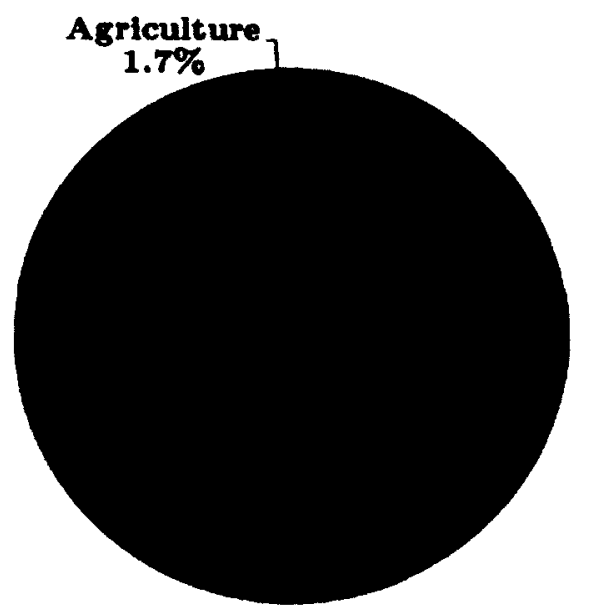

Figure 1.1: 2009 secondary energy use in Ontario by sector, adapted from NRCan [6]

For residential DHW preparation in Ontario, $87.3 \%$ of secondary energy consumed was from natural gas resulting in $4.0 \mathrm{Mt}$ of $\mathrm{CO}_{2 e}$ emissions in 2009 [6]. The Canadawide residential GHG emissions due to space and hot water heating in 2009 was 50.4 $\mathrm{Mt}$ of $\mathrm{CO}_{2 e}$, representing $81.7 \%$ of the total $\mathrm{GHG}$ emissions for the sector (including electricity consumption) [6].

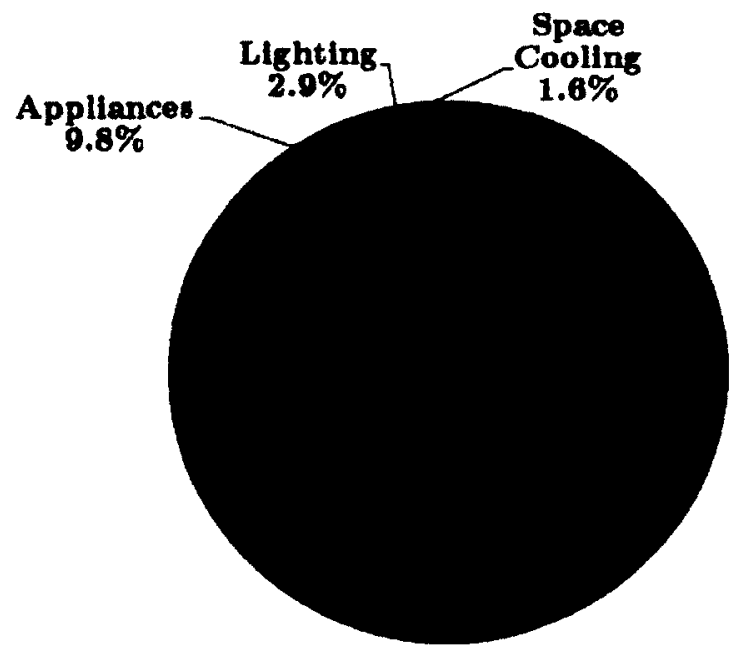

(a) Residential secondary energy end-use

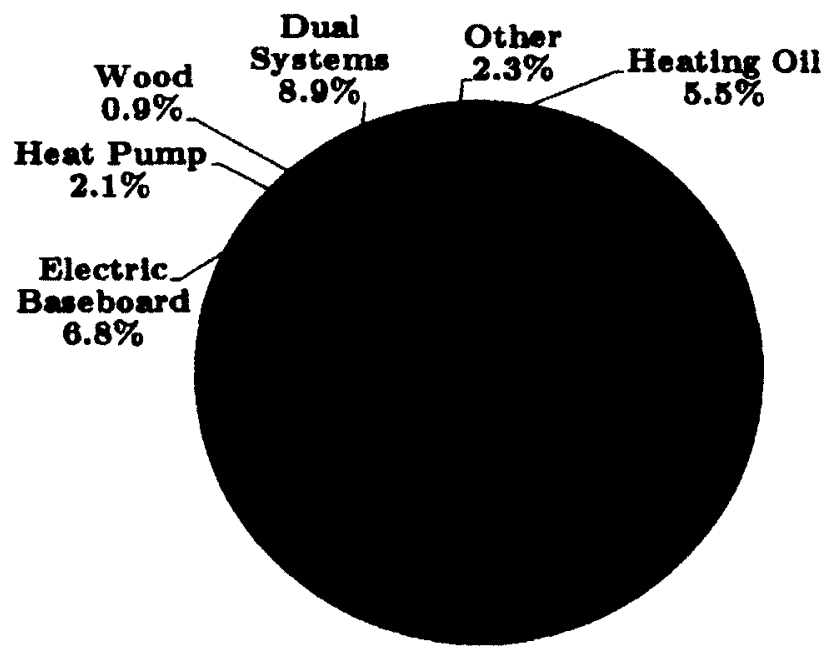

(b) Residential secondary energy use for space heating by energy source

Figure 1.2: 2009 residential sector secondary energy use, adapted from NRCan [6] 


\subsection{Solar Thermal Systems}

There are many alternative technologies and strategies to reduce GHG emissions from residential space heating and DHW preparation. Solar thermal systems are one option for meeting these domestic demands. It has already seen a large adoption in regions such as China, which had $60.1 \%$ of the global solar thermal operating capacity at the end of 2010, and Europe which represented $18.4 \%$ of installed capacity [7]. According to Weiss [8], the solar radiation incident on earth exceeds the global primary energy demand by 10,000 times. Pinel et al. [9] noted that the solar radiation on a typical home exceeds its energy consumption annually. The majority of solar thermal systems operate at low to medium temperatures of approximately 40 to $120^{\circ} \mathrm{C}[10]$ which is well matched to DHW and space heating needs.

The principle function of a solar thermal system is to convert incident solar radiation into thermal energy that can than be used for a specific application [10]. Solar thermal systems may be broadly divided into two categories: active and passive. All solar thermal systems possess a form of "collector" to gather incident solar radiation and a method to transport collected thermal energy to end-loads or processes. These collectors may be thought of as a special type of heat exchanger that converts solar radiation into thermal energy [11]. Systems classified as active or forced circulation require additional energy input and controller intervention for operation. For example, a pump is required in an active system to pass a working fluid through a collector to be charged and transported to an end-load. In passive systems, solar collection and transportation/storage is achieved without the intervention of external mechanisms such as pumps or controllers. In warm climates, passive hot water systems are sometimes used with a collector placed below a storage tank. As water temperature in the collector increases, the fluid's buoyancy increases and flows up into the storage tank. Colder water at the bottom of tank is then able to flow into the collector. This is an example of a "thermosyphon" system. Active and passive solar water heating systems are shown conceptually in Figure 1.3. 


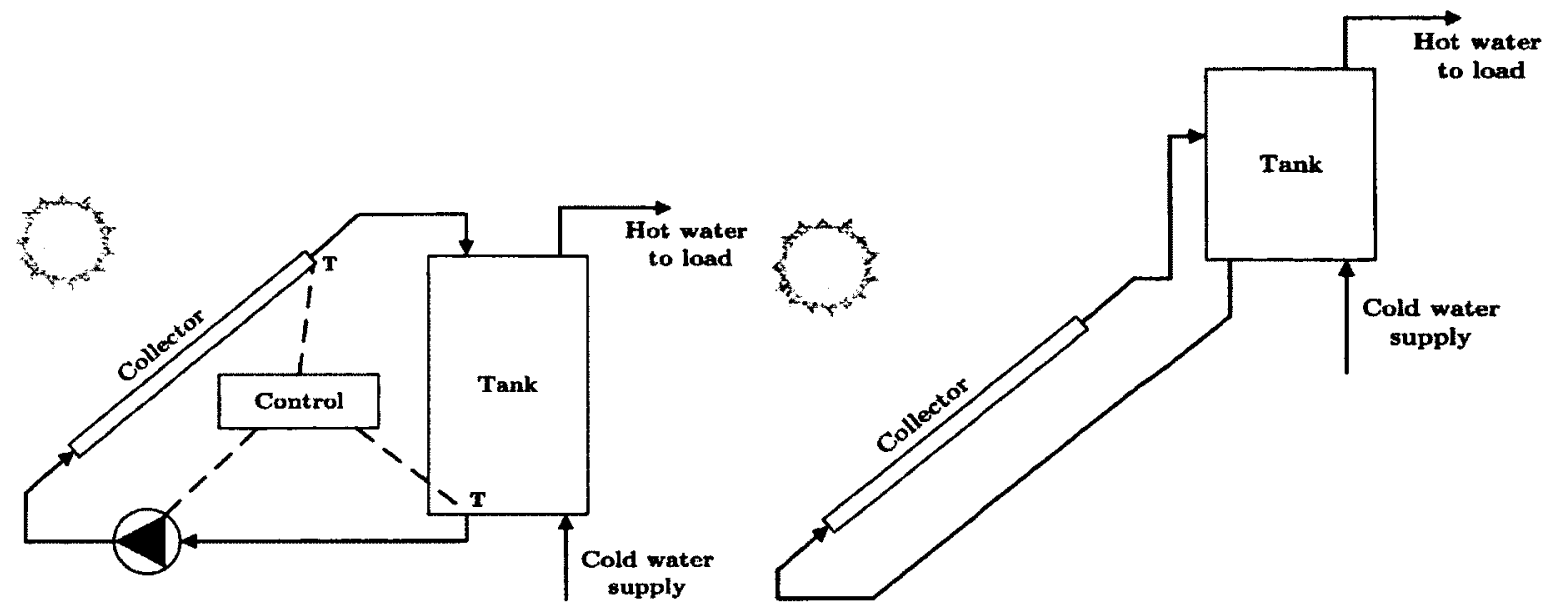

(a) Simple active solar thermal system

(b) Simple passive solar thermal system

Figure 1.3: Examples of active and passive solar thermal systems, adapted from [11]

Both active and passive solar thermal systems may be further sub-categorized as "direct" or "indirect" [10]. In direct systems, the fluid held in the tank is also circulated through the collector. The systems shown in Figure 1.3 may both be considered "direct". If a heat exchanger was placed between the collector and the storage tank, the systems would become indirect. An intermediate fluid transports thermal energy from the collectors to the tank [10]. The benefit of this arrangement is that an anti-freeze solution may be used in the collector loop in colder climates. The majority of systems found in North America and Europe are indirect, active systems [10]. Passive systems like the one shown above would not be suitable for climates with potential for freezing temperatures. Such systems would also be subject to considerable standby tank losses to the environment and require large amounts of insulation.

Solar thermal technologies have been deployed on a global scale. In 2004, the total global capacity for solar hot water and space heating was $77 \mathrm{GW}$ [12]. By 2006 the capacity had increased to $105 \mathrm{GW}$ [12]. European Union (EU) countries and China have seen a relatively large adoption of solar thermal technologies in recent years. By the end of 2011, the EU 27 and Switzerland had a total installed glazed collector area of 37 million $\mathrm{m}^{2}$ with a capacity of $26 \mathrm{GW}_{t h}{ }^{2}$ [13]. China reportedly installed 57 million $\mathrm{m}^{2}$ of collector area in 2011 , representing a growth rate of $16 \%$ compared to

\footnotetext{
${ }^{2}$ Thermal power
} 
2010 [13]. As of 2007 Canada there was 544 thousand $\mathrm{m}^{2}$ of installed solar thermal collectors. The majority $(71 \%)$ of these collectors were unglazed plastic collectors used for pool heating [14].

There is a large potential in Canada for solar thermal systems that provide space heating and DHW preparation (commonly referred to as solar "combisystems"). The latitude of major Canadian cities compares favourably to European cities where solar combisystems are more common. Space heating demands in Canada are also generally higher than in Europe.

\subsection{Solar Availability}

There are inherent complications with using solar energy to meet end loads. Solar energy is a "cyclic and time-dependent energy source" [15] that is not always well matched with energy needs. Becker and Stogsdill [16] surveyed published domestic hot water use data for different locations in North America. They reported typical peaks in DHW demand during the morning and evening, however solar availability is maximum at noon (for clear, sunny days), representing a diurnal mismatch. Intermittence due to cloud cover can also be problematic. These issues are illustrated in Figure 1.4. In the short term, solar availability and demand-side offsets can be addressed with the use of thermal energy storage (TES). Solar energy is collected and stored during periods of high solar availability and then recovered from storage during periods of demand. This bridges the gap between source and load.

At the annual scale, maximum solar production occurs during the summer months. Domestic thermal energy requirements, however, are highest during the winter months. This seasonal mismatch is illustrated in Figure 1.5.

Pinel et al. [9] described different methods that could be used to compensate for the seasonal offset in solar thermal systems. One strategy was to orient solar collectors at a higher tilt angle to promote higher collection during the winter months at the expense of summer production. Another strategy was to design a combisystem for winter operation and use the excess summer production to drive sorption chillers or desiccant systems to cool or dehumidify dwellings [17]. A final strategy was to use a large seasonal TES to store the high summer production and carry it over to the winter months when it is needed. This concept of seasonal storage has potential for 


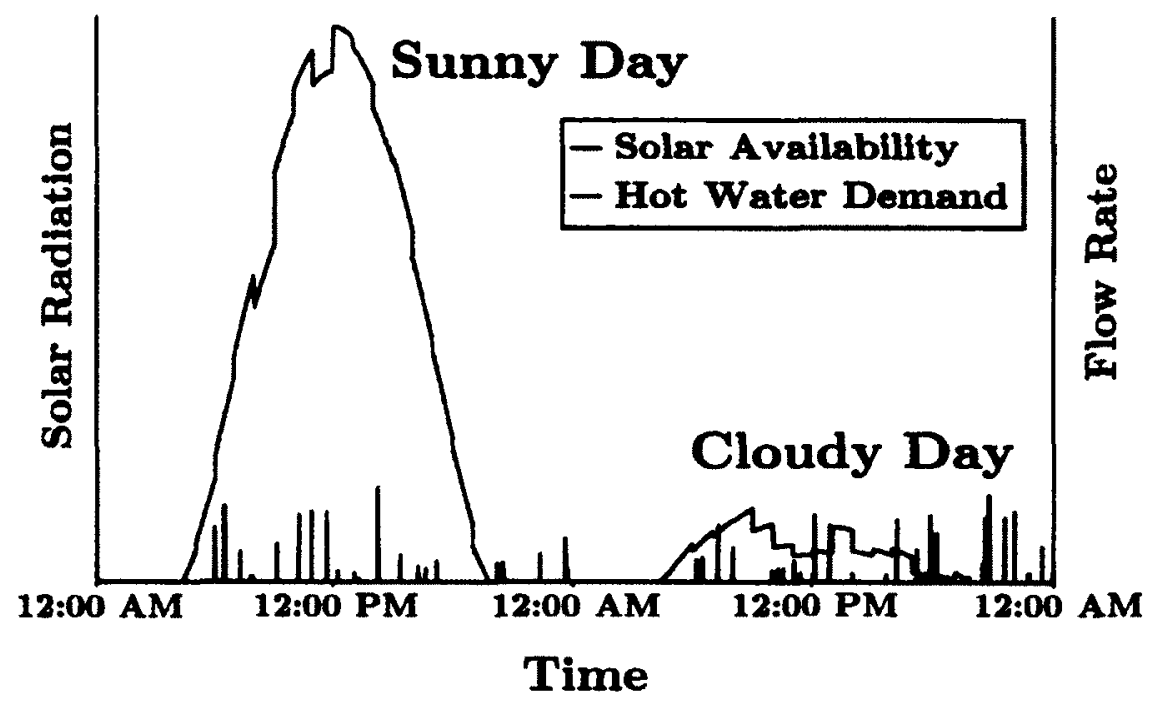

Figure 1.4: Cycle and intermittence of solar energy availability

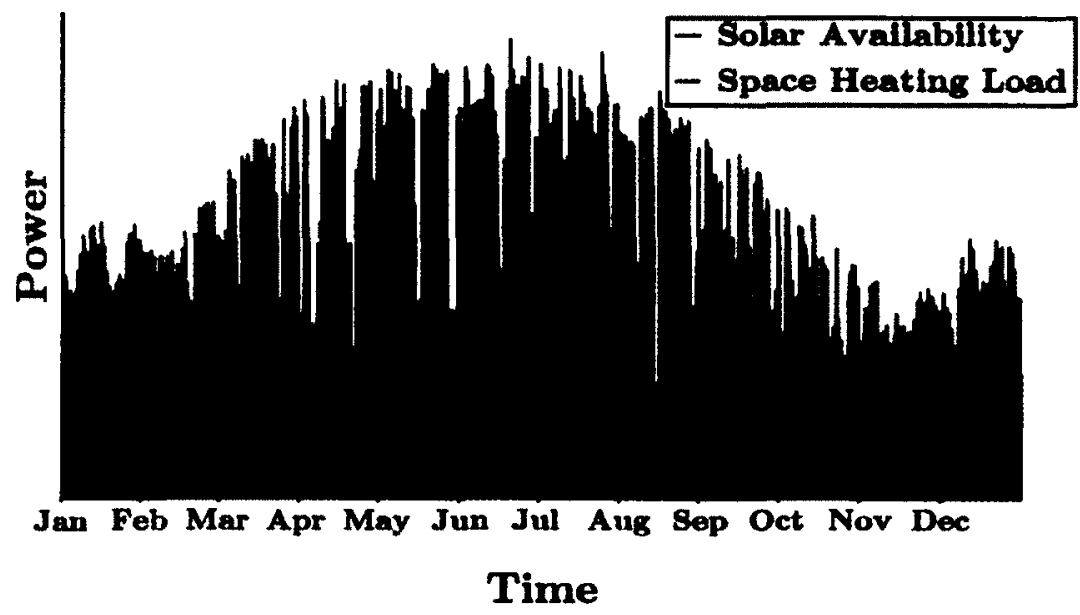

Figure 1.5: Seasonal offset of solar availability and space heating in Northern climates

Canadian climates, and was the focus of this study.

Braun et al. [18] considered space heating with seasonal solar thermal systems (SSTS) in northern latitudes using TRNSYS [19]. They found that in these climates significant reductions in collector area can be achieved if DHW loads are a small fraction compared to space heating. Hooper [20] stated that for Canadian homes with a SSTS capable of supplying $100 \%$ of the thermal demands would require $25 \%$ of the collector area compared to a system with short-term storage. Pinel et al. [9] noted that solar collectors tend to be expensive and that there is potential in developing 
economical SSTS systems that have high contributions to domestic thermal demands. Seasonal TES is discussed further in Chapter 2.

The use of TES in solar thermal systems represents the strength of the technology compared to photovoltaic (PV) systems. Potentially, a PV system may be used to power a reversible heat pump to provide both heating and cooling to a dwelling. Similar to solar thermal systems however, the intermittence and mismatch of solar availability and end-load demands present a challenge for PV system design and control. The electrical energy from a PV system during periods of solar collection would require storage or export to the grid if there is not a sufficient demand on-site. Electrical storage can be complex compared to TES, and electrical grid systems may not always be capable of carrying excess PV production.

\subsection{C-RISE Project}

The Carleton Research and Innovation in Sustainable Energy (C--RISE) house project is a new facility that will be constructed on Carleton University campus in Ottawa, Ontario. This facility is meant to function as a test- bed for innovative technologies in Canadian residential homes. In order to be representative of the residential building stock in Canada, the layout of the C-RISE house was designed as a single-family detached house (SFDH) using contruction material and techniques from a local contractor [21]. As of $2010,54.6 \%$ and $56.0 \%$ of dwellings were classified as SFDH in Ontario and Canada respectively [6].

The C-RISE building envelope was also to be designed to meet the $2012 \mathrm{R}-2000$ Standard [22]. This is a voluntary Canadian standard that applies to residential buildings with a focus on the "efficient use of energy, improved indoor air quality and better environmental responsibility in the construction and operation of a house" [22]. From a space heating perspective, $\mathrm{R}-2000$ sets building envelope requirements and annual space heating targets based on climate and heated interior volume.

\subsection{Research Objectives}

One of the objectives of the C-RISE project was to investigate the potential for a SSTS in a Canadian SFDH. The purpose of this study was to support the design of an 
SSTS for an Ottawa, Ontario climate. Key system parameters that were to be determined were appropriate seasonal storage volume, storage insulation levels, collector array area, and collector orientation. The solar thermal system was to be designed using "best-practices" determined from a literature review, shown in Chapter 2. This research was also intended to guide designers on system performance sensitivity to these key parameters. Often there are economic, aesthetic or architectural barriers that prevent designers from using desired system specifications. It is important to understand performance impacts when design compromises need to be made.

To accomplish these research objectives, the detailed simulation tools ESP-r [23] and TRNSYS [19] were used. The ESP $\mathrm{r}$ tool, described in Chapter 3, possessed strengths in modelling building envelopes. TRNSYS, described in Chapter 4, contained a large library of solar and heating, ventilation and air-conditioning (HVAC) equipment models and was well suited to representing the solar thermal system to be studied. A new co-simulation software, introduced in Chapter 4, was used for runtime coupling to take advantage of both simulation tools.

\subsection{Thesis Outline}

The thesis is organized in the following manner:

- Chapter 2 discusses literature that is relevant to the research topic and forms the basis of the work.

- Chapter 3 describes the building and energy systems modelling software ESP-r used to represent the $\mathrm{C}$-RISE house.

- Chapter 4 introduces the TRNSYS software used to represent the seasonal solar thermal system and method for co-simulation between TRNSYS and ESP-r.

- Chapter 5 outlines the development of the C-RISE house model in ESP-r

- Chapter 6 described the layout of the seasonal solar thermal system for the C-RISE house and its thermal management strategy. The development of the solar thermal plant system in TRNSYS is discussed as well as the strategy used for co-simulation between ESP $\cdots$ and TRNSYS. 
- Chapter 7 presents the results of the sensitivity analysis of the key parameters.

- Chapter 8 provides the conclusions of the research and recommendations. 


\section{Chapter 2}

\section{Literature Review}

\section{$2.1 \quad$ Introduction}

The basic principles of solar thermal systems were introduced in Chapter 1. To form the foundation for the current research, a literature review was conducted and presented below. This review begins with the analysis of different thermal energy storage options and their applicability to seasonal storage for residential buildings. Different case studies and analysis of seasonal solar thermal systems is then reviewed to examine the design, operation and performance of seasonal solar thermal systems in practice. Finally, different performance metrics for seasonal storage and solar thermal systems are identified and described.

\subsection{Thermal Energy Storage}

Seasonal storage of thermal energy for space heating and DHW preparation has been researched since the 1940's [9]. In 1979, more extensive work on seasonal TES began with the advent of the International Energy Agency Solar Heating and Cooling Programme's (IEA-SHC) Task 7 [24]. The focus of this Task was to study central solar heating plants using seasonal storage. Several authors noted the economic benefits of using seasonal storage in the context of a district heating system. Sillman [25] stated that large central systems benefit from economies of scale. Kozlowski [26] also noted increasing economic benefit with increasing storage size as well as reductions in heat loss as the surface to volume ratio decreased. Fisch et al. [27] pointed out that the investment cost per collector area for a large system was 20 to $30 \%$ the cost of a single house scale system. 
While large central systems offer several benefits, the Canadian residential building stock is largely composed of single family detached houses, illustrated in Chapter 1. This represents a challenge to the application of central seasonal thermal energy storage (TES) in Canada, especially for retrofit projects. Smaller scale TES systems have been extensively examined under IEA-SHC Tasks 32 [28] and 42 [29]. The following subsections provide an introduction to thermal energy storage, the different concepts and mechanisms of TES, and the applicability of these different concepts for seasonal storage.

\subsubsection{Thermal Energy Storage Mechanisms and Concepts}

Pilkington Solar International $\mathrm{GmbH}^{1}$ [30] stated that a thermal energy storage may be classified by its mechanism and concept. Pinel et al. [9] described two different TES concepts: active and passive. These concepts are not to be confused with active and passive solar thermal systems described in Chapter 1. Under an active storage arrangement, forced convection is permitted within the storage. The storage medium may flow into and out of the storage and pass through either a solar collector (direct solar thermal system) or heat exchanger (indirect solar thermal system) to be charged. Passive storage systems are charged and discharged via a thermal energy transport medium that passes through the storage medium. The storage medium of a passive TES system may be a liquid, solid, phase change material (PCM) or other storage mechanisms. Pinel et al. [9] noted that there were a few disadvantages to passive TES arrangements. Temperature differentials that drive heat transfer between the transport fluid and storage medium decrease in sensible TES systems as the storage becomes charged or discharged. Low conductivity of the storage medium itself may also limit passive systems.

The mechanism of thermal energy storage is "how" thermal energy is stored within a medium. IEA-SHC Tasks 32 [28] and 42 [29] identified four different TES mechanisms: sensible, latent, chemical reaction and thermo chemical (sorption). Hadorn [31] approximated the storage volumes required to store $6.7 \mathrm{MJ}$ of thermal energy using different TES mechanisms, illustrated in Figure 2.1. It can be seen from this figure that there may be potential for the relatively new chemical TES technologies for compact systems.

\footnotetext{
1 "Gesellschaft mit beschränkter Haftung" or limited liability company
} 


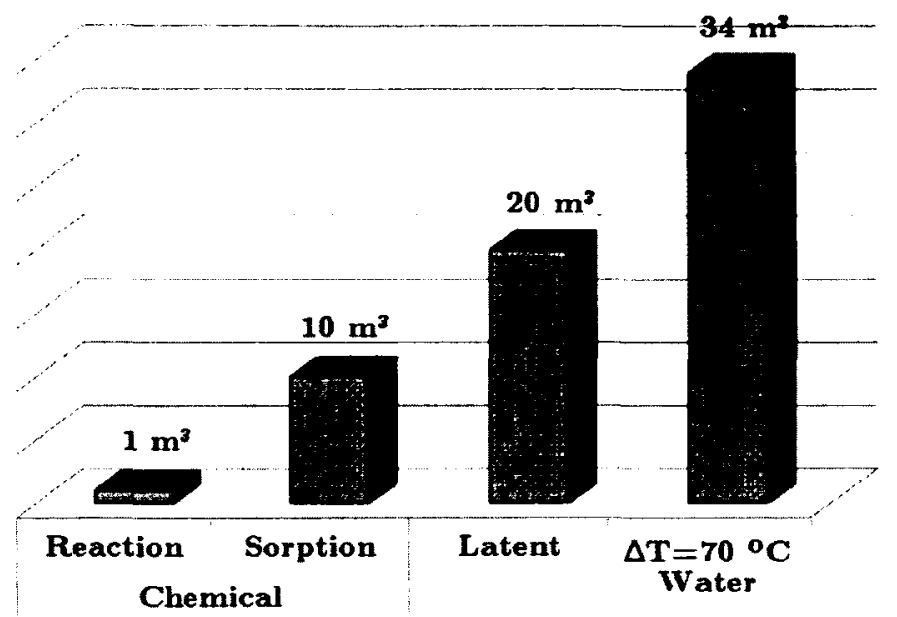

Figure 2.1: Volumes required to store 6.7 MJ, adapted from Hadorn [31]

Pinel et al. [9] performed an extensive review of these different mechanisms for use in residential seasonal storage applications. They concluded that chemical and latent storage mechanisms had desirable characteristics for seasonal storage, such as high energy density and reduced long-term thermal losses. However, Pinel et al. [9] stated that these innovative technologies required further research, particularly the identification of storage medium materials which exhibit good stability for charge and discharge cycling, and reduced costs. Sensible TES has typically been used in past and present seasonal solar thermal systems since theses systems tended to be large and reduced costs were of high importance [9]. Consequently, readily available storage media such as rocks, soil, and water have been used in practice [9]. These storage materials are typically inexpensive and readily available. For these reasons, sensible TES was selected for the C-RISE facility introduced previously. Two independent seasonal storage systems were to be constructed on site. One system was to use a soilbased solid sensible storage with embedded heat transfer pipes. The second system was a fluid-based sensible storage (water tank) and was the focus of this research. For further information on chemical and latent TES, the interested reader is directed to the review conducted by Pinel et al. [9].

Sensible TES systems are the simplest and best understood forms of thermal storage. The mechanism for charging a sensible TES is to raise the temperature of the storage medium. The thermal energy is recovered by reducing the storage temperature. Sensible storage can be done with materials in the solid, liquid, or gas phase. This leads to a broad selection of storage materials. To help limit the potential 
candidates for sensible storage, Hariri and Ward [32] identified several characteristic that a sensible TES should possess. These characteristic include:

- Thermal capacity per unit mass or volume;

- Operational temperature range;

- Energy transport medium's properties (toxicity, corrosiveness, heat capacitance);

- Stratification;

- Ease of energy extraction/injection;

- Containment of the storage medium;

- Control of thermal losses; and

- Cost.

These storage traits do not, however, consider storage size which is important for residential applications. Under these size constraints, specific heat and density of the material become important design considerations [15]. For residential applications this would limit the selection of storage media to solids and liquids [9].

The rate at which energy can be extracted or injected into the TES is another important design aspect. The rate of heat transfer should be well matched to the load requirements of the system. Liquid-based systems have the ability to be pumped from the storage to a load or collector and have relatively high heat transfer rates due to convection $[9,15]$. The issue with liquid systems is that it is difficult to maintain temperature stratification, discussed in Section 2.2.2.1. Solid-based storage systems can achieve much higher levels of temperature stratification, but have much lower heat transfer rates compared to liquid systems.

\subsubsection{Water Based Sensible Storage}

Hadorn [31] noted that sensible storage with water between temperatures of 20 and $80^{\circ} \mathrm{C}$ has been done for centuries and will remain the storage medium of choice in solar combisystems for years to come. This temperature operating range is well-suited to residential space heating and hot water loads. Water presents a favourable choice for sensible TES due to its relatively high specific heat and high rates for charge and discharge $[33,34]$. For these reasons, the remainder of this TES review focused on 
water-based sensible storage. Pinel et al. [9] identified three potential candidates for seasonal water-based storage: water tanks, aquifers and solar ponds.

Solar ponds were not considered practical for a Canadian residential application. Dinçer and Rosen [15] stated that this type of system is applicable to regions with little snow and large land availability. Aquifer TES systems inject and extract thermal energy into underground aquifers via installed wells. While this was an interesting concept, performance of these systems are dependent on the aquifer physical, chemical, and biological process [15] which vary from site to site. For the C-RISE project, water tanks were selected as a viable option for water-based storage and is discussed below.

Water tanks can be either an artificial structure of concrete or steel or a cavity within the ground or a geological feature [9]. Thermal energy can be injected or extracted into the water tank by either directly circulating the storage fluid or by passing a working fluid through a heat exchanger. Figure 2.2 illustrates a simple water storage tank that uses direct circulation of the storage medium for heat transfer. In Chapter 1, direct and indirect solar thermal systems were introduced. The inlets and outlets of the tank in Figure 2.2 could be connected directly to the solar collectors or an indirect arrangement could be used where an external heat exchanger is placed between the tank and collectors.

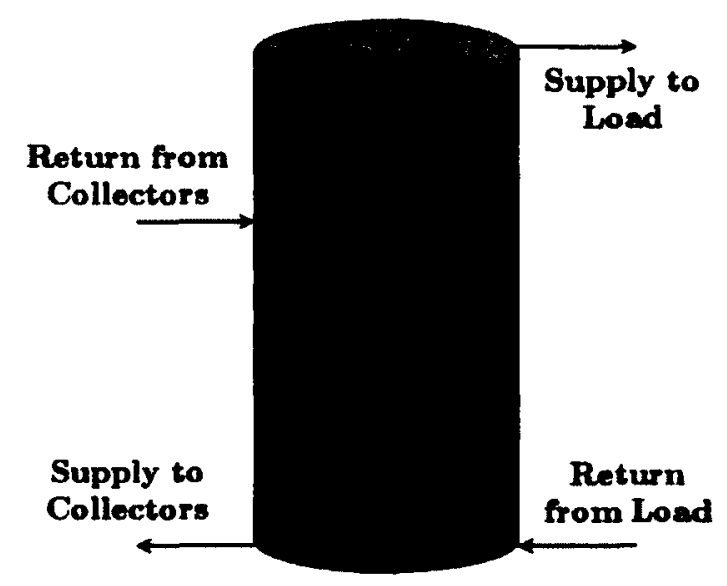

Figure 2.2: Simple solar hot water tank

Other indirect methods for charging/discharging water tanks is to use an immersed heat exchanger within the tank or a mantle heat exchanger wrapped around the periphery of the tank. These arrangements are illustrated in Figure 2.3. 


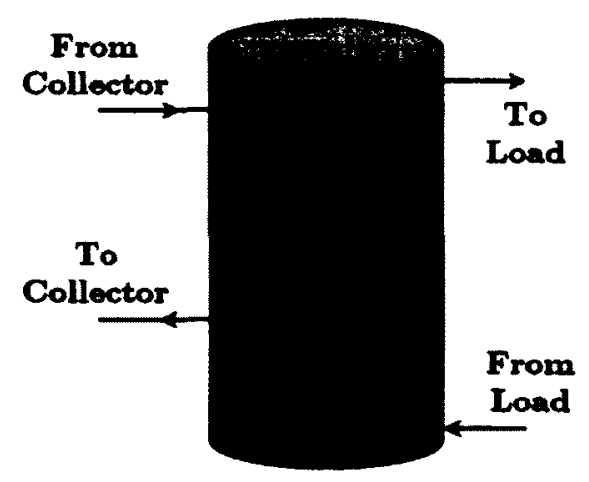

(a) Immersed heat exchanger

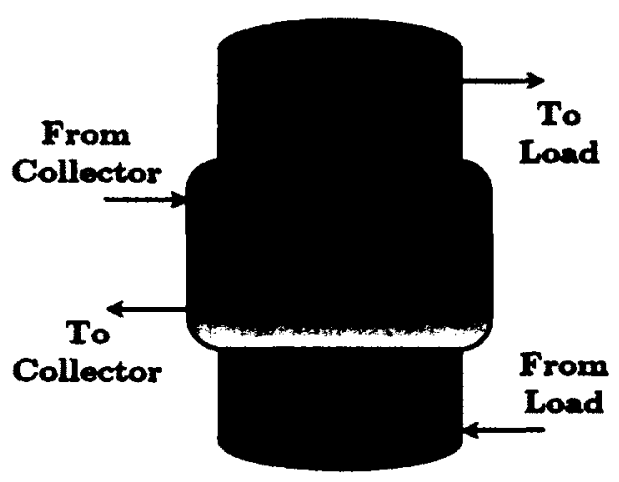

(b) Mantle heat exchanger

Figure 2.3: Indirect charging of sensible TES, adapted from Han et al. [35]

According to Dinçer and Rosen [15], an effective TES water tank must meet three general requirements:

- The tank is properly designed for stratification;

- The "dead" volume in the tank should be minimized; and

- Heat losses should be minimized.

Sections 2.2.2.1 and 2.2.2.2 describe tank stratification and tank self discharge (heat losses) respectively. A "dead" volume in a storage is a region or regions within the storage volume that is not bracketed by storage inlets and outlets and is therefore not active in the charge and discharge cycles. An example of effective and dead zones in water tanks is given in Figure 2.4.

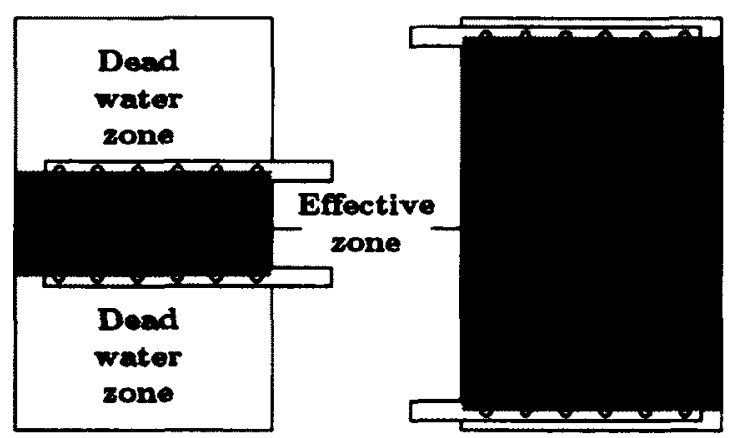

Figure 2.4: Effective volume of water in tank, adapted from Shimizu and Fujita (1985) 


\subsubsection{Stratification}

The challenge of using sensible TES is the potentially large operating temperature range to achieve a satisfactory energy density. Near full charge, the storage temperature is relatively high creating difficulty for injection of additional thermal energy. Near full discharge, the low quality thermal energy cannot be put to much use. Thermal stratification has been studied extensively since the 1960's [36] as a means to improve the usability of sensible TES systems. Thermal stratification is the existence of a temperature gradient within a storage that separates volumes at different temperatures. In fluid-based systems, stratification can occur naturally. Relatively cold fluid has a higher density and settles at the bottom of the tank while the warmer, less dense fluid rises to the top. Figure 2.5 illustrates three vertical water tanks, each holding equal amounts of thermal energy but with varying levels of stratification.
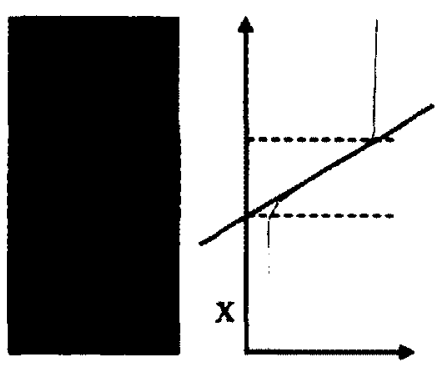

$\mathbf{T}$

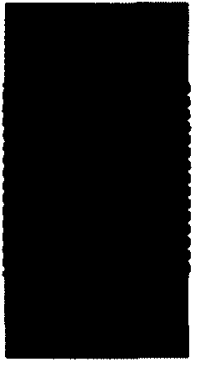

(b)

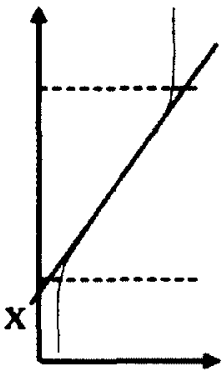

T

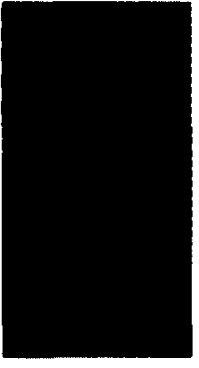

(c)

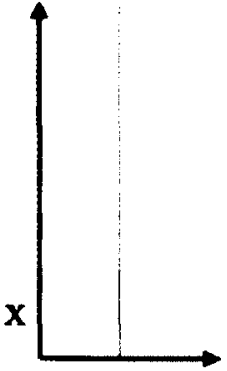

T

(a)

Figure 2.5: Different levels of thermal stratification, reproduced with permission from Cruickshank [10]

The benefit of a highly stratified storage system is that near full discharge, there is still a hot region at the top of the tank to meet thermal demands. As the storage reaches full charge, there is still a cold region to add thermal energy. For solar thermal systems, Duffie and Beckman [11] indicated that lower temperature fluid returning from a stratified storage into a collector improves the collector's efficiency by reducing heat losses to ambient. Cruickshank [10] also noted that a stratified storage can deliver hot water early in the morning, reducing auxiliary energy consumption.

There have been several studies that investigated the performance impact of thermal stratification in solar thermal systems. Hollands and Lightstone [37] calculated a $38 \%$ increase in the performance of solar hot water systems using low collector 
flow rates and high thermal stratification. Cristofari et al. [38] simulated a domestic solar hot water system in a Mediterranean climate. Modelling highly stratified storage tanks was found to increase energy savings by $5.25 \%$ compared to a fully mixed tank. Jesch and Braun [39] used the simulation software TRNSYS to model a simple solar hot water system and also stated performance improvement over conventional systems. Lund [40] used analytical and numerical methods to simulate central solar heating plants with seasonal storage (CSHPSS) of practical design using large water tanks. Solar fractions for the CSHPSS systems were found to increase by 35 to $60 \%$ when stratified storage was modelled compared to fully mixed tanks. Han et al. [35] also stated that seasonal storage systems can improve by $60 \%$ using stratified storage. Braun et al. [18], however, considered the effect of stratification in seasonal storage for a single-home using a one-dimensional plug flow tank model in TRNSYS and found the effect of stratification to be negligible.

Some researchers considered the impact of storage geometry on stratification. Eames and Norton [41] considered relatively small circular and square cross-sectional tanks with volumes between 10 and 24 litres. They found that differences in crosssectional geometry had little impact on thermocline ${ }^{2}$ development when low inlet velocities were used. Hahne and Chen [42], Hollands and Lightstone [37], and Lavan and Thompson [43] determined that the desirable height-to-diameter (H/D) ratios for smaller tanks was between 3 and 4 . Lundh et al. [44] stated that most commercial tanks have a H/D ratio of 2 to 2.5. They simulated a solar combisystem in TRNSYS using medium sized storage volumes between 2 and $10 \mathrm{~m}^{3}$. They found that the maximum performance occurred between H/D ratios of 2 to 4 for all studied storage volumes. Nelson et al. [45] considered stratification in chilled water tanks and found little benefit in H/D ratios beyond 3. Abdoly and Rapp [46], however, found that a properly designed water tank should have a H/D ratio greater than 10 . In the review done by Ochs [47], smaller storage tanks were found to have recommended H/D ratios between 1 and 10, but values between 3 and 4 were the most practical [48].

Depending on the thermal energy storage operation mode, internal or external losses are more significant [47]. Internal losses relate to exergetic losses such as destratification, while external losses deal with heat losses through the envelope of the TES. For a small tank system, the storage is likely charged and depleted daily (diurnal storage). Under these operating conditions, external losses have a smaller

\footnotetext{
${ }^{2}$ The thermocline is the intermediate region within a stratified storage between the hot and cold volumes
} 
performance impact compared to maintaining high levels for stratification. For seasonal storage. the system charges and stores energy over a period of several months. External losses are more significant and can be reduced by reducing the area-tovolume (A/V) ratio. Abdoly and Rapp [46] stated that a tall, slender water storage tank promotes good stratification, but the increased $\mathrm{A} / \mathrm{V}$ ratio would increase losses to the environment. For larger seasonal storage systems, Ochs [47] stated that H/D ratios of 1 were most promising.

Some researchers such as Prapas et al. [49], Mather [50], Cruickshank [10] and Dickinson [51] have investigated the use of multiple interconnected water tanks to promote stratification. Sillman [25] simulated a solar combisystem that was equipped with both a seasonal and diurnal tank. He stated that the use of two tanks provided additional benefits because the diurnal tank allows for the collection and use of lowtemperature energy in the fall and the collection of high temperature energy for hot water use in the spring. An example of a multi-tank setup is illustrated in Figure 2.6 .

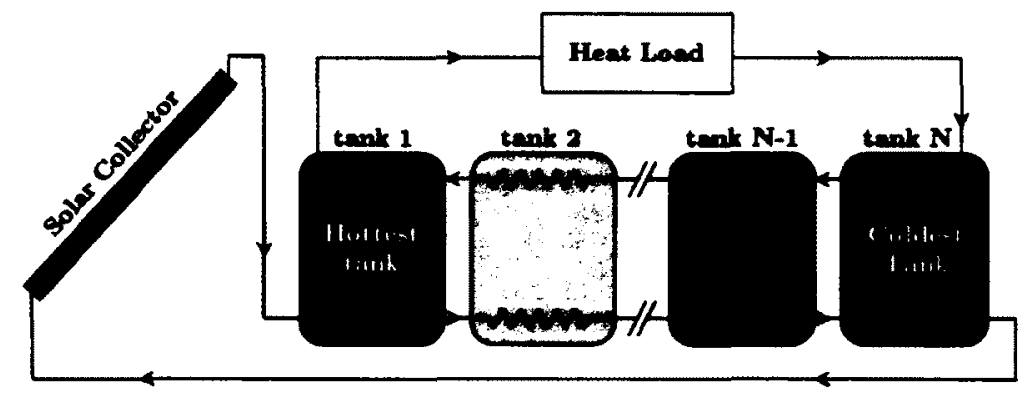

Figure 2.6: Multi-tank thermal storage system, adapted from Mather et al. [50]

Some aspects of stratification have been presented here. A solar thermal system's ability to promote and maintain stratification has been shown to significantly increase performance. For additional reviews on stratification in thermal energy storage, the interested reader is directed to Cruickshank [10], Han et al. [35] and Dickinson [51].

\subsubsection{Self Discharge}

As large sensible TES systems are charged, the higher storage temperatures result in an increase of thermal losses to the environment. Increased heat losses through the tank envelope also has the negative effect of inducing natural convection within the storage and destroying stratification, shown experimentally by Hess and Miller [52]. 
Typically sensible TES systems are insulated and sometimes buried to reduce this self discharge [9]. There are several benefits that buried (pit) systems can provide to help reduce losses. Pinel et al. [9] pointed out that the soil surrounding a buried TES will eventually warm and dry, reducing the soil conductivity and providing improved insulation. Givoni [53] noted several advantages to buried insulated water tanks:

- Higher thermal capacity per volume compared to rocks;

- Simple transport of thermal energy into and out of the storage;

- Relatively easy to insulate;

- Insensitive to ground moisture and water flow; and

- Accessibility to perform repairs from inside the tank.

Givoni [53] also noted several limitations to the buried system:

- With heavy insulation the ground does not contribute to thermal storage;

- Local leakages in the tank can lead to differential pressure and movements causing more leakage; and

- High costs associated with ensuring water tightness of tank envelopes.

To gain some of the benefits of buried systems and reduce excavation costs, some systems are partially buried and bermed. Rosen [54] pointed out that partially buried systems have lower hydraulic lift $^{3}$ requirements compared to fully buried systems. Rosen [54] also stated that in addition to providing insulation, the berm adds structural support to the tank walls and creates a mechanism for water drainage. Buried and bermed systems are illustrated in Figure 2.7. For residential applications, buried or bermed systems would not occupy a significant amount of usable space on the property in contrast to tanks situated on the surface or in the basement.

\footnotetext{
${ }^{3} \mathrm{Hydraulic}$ lift is associated with the power to pump a fluid to a higher elevation
} 


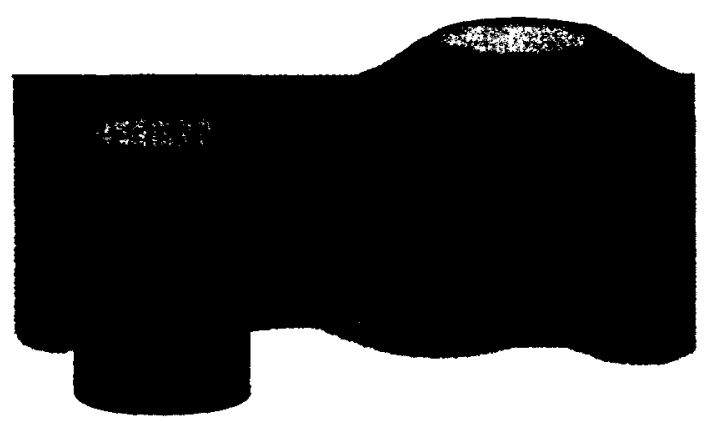

Figure 2.7: Buried and bermed storage tanks, adapted from Pinel et al. [9]

Despite measures to reduce losses to ambient, internal losses (destratification) can still occur in water tanks. Chung et al. [55] identified the four main factors for loss of stratification:

- Heat losses to the surrounding environment;

- Heat conduction between the warm and cool regions in the storage;

- Vertical conduction along the tank wall; and

- Mixing during charge or discharge.

Murthy et al. [56] conducted experimental analyses on scaled storage tanks constructed of mild steel and aluminum. They found that the aluminum tank destratified faster than the mild steel tank due to higher conductivity of the wall. They also stated that the degradation of stratification was caused by losses to ambient and conduction and thermal diffusion between hot and cold layers.

Ochs [47] pointed out that the mode of operation of the storage tank determined the self discharge mechanism which is dominant. For example, a seasonal storage has a relatively long storage period and charge-discharge cycle. Since thermal energy is stored for an extended period, the tank losses to ambient become significant. For diurnal tanks, the charge-discharge cycles are shorted and thermal energy is not stored as long. The losses to ambient become less significant compared to maintaining high levels of stratification.

\subsubsection{Modelling}

Modelling techniques of thermal energy storage have been described by Kozlowski [26], Duffie and Beckmen [11], Dinçer and Rosen [15], Newton [57] and Ochs [47]. 
Past models were developed to be computationally efficient and simplified to enable practical and cost-effective simulation on older machines. Ochs [47] defined two types of TES models; detailed (CFD) and coarse models. Generally, coarse TES models are considered one-dimensional and simplifying assumptions are applied to geometry, material properties and boundary conditions [47]. Ochs also stated that the decision to use either detailed or coarse models is dependent on the objectives of the simulation. For system scale annual simulations, a simple TES model that satisfies the energy balance may be sufficient. If the focus of the study is to examine the performance of new tank envelope materials or how ground temperatures for buried systems evolve over time, a more detailed model would be appropriate.

Duffie and Beckman [11] divided coarse stratified tank models into two categories; multinode and plug flow. Multinode models divide stratified tanks into $N$ nodes (sections) and energy balances are developed for each node. The set of energy balance differential equations can then be used to solve for node temperatures as a function of time. Plug flow models use a variable number of liquid segments at different temperatures. The location and temperatures of the segments are tracked over the duration of the simulation. Inlet flows are represented as the addition of new segments into the tank and their size are a function of flow rate and flow duration. Figure 2.8 illustrates multinode and plug flow models. For plug flow models, the uniform temperature volumes, $V$, can vary in size as time progresses. 


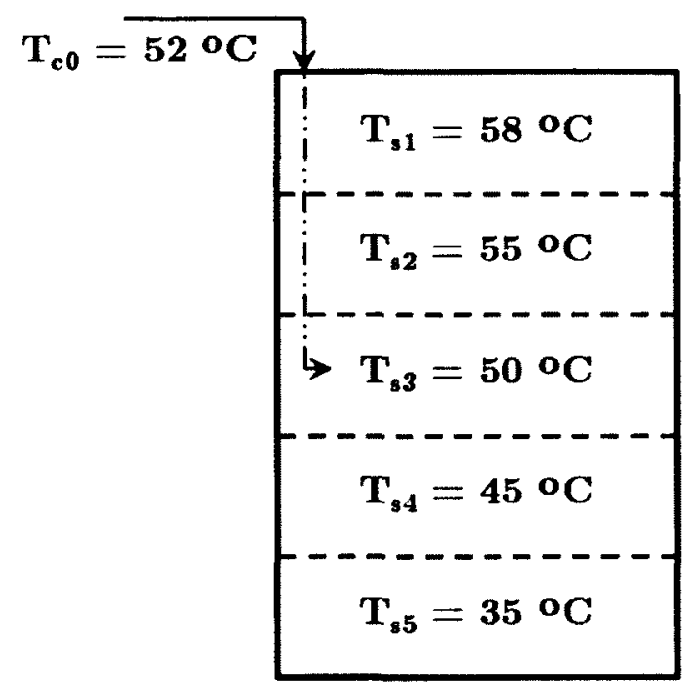

(a) Multinode

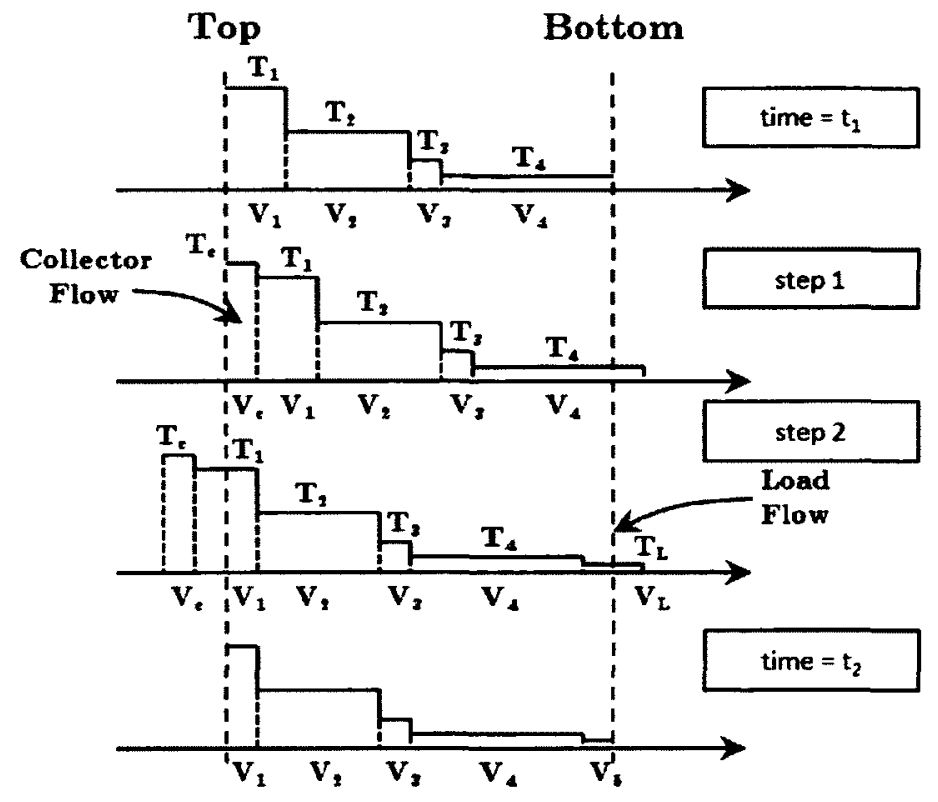

(b) Plug flow

Figure 2.8: One-dimensional water tank models, adapted from Duffie and Beckman [11]

The simulation software TRNSYS contains a library of coarse models for water tanks using either plug flow or multinode methods. Kleinbach et al. [58] compared the performance of multinode and plug flow models in a solar domestic hot water system using TRNSYS and compared results to experimental data. They found plug flow models to be computationally efficient, but tended to overpredict energy quantities compared to multinode systems. Zurigat et al. [59] also reviewed six different 1-D stratified tank models and compared them to experimental data. They noted that the computational overhead of more complex tank models were prohibitive for seasonal or annual system simulations.

Some researchers have modified coarse 1-D models to try and capture additional phenomenon in the storage tank. Eames and Norton [41] used experimental data to validate a 3-D numerical model of circular and square cross section tanks. When they compared results with a $1-\mathrm{D}$ tank model they found that the $1-\mathrm{D}$ model simulated a slower degradation of the stratification in the tank. They suggested increasing the effective thermal conductivity between the isothermal layers in the 1-D model to better match modelled and experimental results. Jordan and Furbo [60] performed experiments to characterize mixing due to inlet jets for two commercial water tanks 
using different diffuser designs. They then developed correlations based on inlet flow rate and density difference between the inlet and storage fluid to adjust inlet height within the tank to account for mixing. Zurigat et al. [61] implemented a mixing index into a 1-D stratified tank model based on empirical correlations for improved agreement with experimental data.

The XST model by Marazella [62] is a 1-D multinode model of a buried cylindrical tank available in the extended TRNSYS component libraries. The model used a 2-D finite difference conduction model to simulate the soil surrounding the storage to calculate tank losses. Validation of the XST model for simulating large storage tanks has been carried out in the literature. Dalenbäck [63] used monitored data from the Särö project south of Götenborg, Sweden. This was a central solar heating plant with seasonal storage that provided space heating and domestic hot water to 48 apartments. The TES was a cylindrical steel tank, $7 \mathrm{~m}$ high with a storage volume of $640 \mathrm{~m}^{3}$. The tank was placed in a rock excavation and insulated with loose mineral wool. Dalenbäck [63] concluded that the XST model was able to simulate actual system performance in a realistic way. The temperatures of the rock surrounding the water tank was not considered in this validation, only the storage temperatures. Raab et al. [64] validated the XST model using data from the CSHPSS in Hannover, Germany. They found storage temperature deviations of $\pm 3 \%$ between measured and simulated values.

Further details on tanks models that were of interest to this work may be found in Chapter 4. For this research, 1-D models were determined to be the most applicable. The annual simulations required to investigate the performance of a seasonal solar thermal system (SSTS) at a single house scale limited TES model choices to computationally efficient options. Additionally, the validation studies for 1-D models discussed above provided confidence in results of $1-\mathrm{D}$ modelling techniques.

\subsection{Past Projects and Studies}

There are numerous reviews and studies of solar heating systems with seasonal storage in practice. The majority of these systems are central heating systems supplying thermal energy to entire residential developments. Here, a few CSHPSS systems are discussed and for more comprehensive reviews the interested reader is directed to Bankston [65], Dalenbäck [66], Lottner and Mangold [67], Schmidt et al. [34], 
Ochs [47], Bauer et al. [68] and Novo et al. [33]. Particular interest for this review was SSTS applied at a single-house-scale, especially their sizing, design, operation regime and performance.

\subsubsection{Experimental Facilities}

This section reviews some of the experimental facilities which used seasonal solar thermal systems to supply thermal energy to domestic end-loads. The majority of systems found in the literature were at a community scale, supplying thermal energy to several homes through a district heating system. There have been however, a few single house scale facilities such as the Riverdale House and Passive House in Ireland which are discussed below.

\subsubsection{Hannover CSHPSS}

The CSHPSS plant in Hannover, Germany has been studied and reviewed by researchers such as Raab et al. [64], Schmidt et al. [34], Novo and Bayon [33] and Ochs [47] since it began operation in 2000. Under the German R\&D programme Solarthermie2000plus, the Institute of Building and Solar Technology at the Technical University of Braunschweig carried out data acquisition on the Hannover plant. The district heating system used a $2,795 \mathrm{~m}^{3}$ seasonal hot water storage to supply space heating and domestic hot water to 106 multi-family units [64]. The system was charged with flat-plate solar collectors with a total aperture area of $1473 \mathrm{~m}^{2}$. This resulted in a storage volume to collector area ratio of approximately $1.9 \mathrm{~m}^{3} / \mathrm{m}^{2}$. The hot water storage was equipped with three levels of charging and discharging and had a cylindrical shape with a frustum top, illustrated in Figure 2.9. Depending on the temperature of the return fluid from solar collector loop entering the tank, the fluid could be injected at one of the two levels [64].

The tank itself was made of reinforced pre stressed concrete, $30 \mathrm{~cm}$ thick on the sides, $20 \mathrm{~cm}$ on the bottom and $25 \mathrm{~cm}$ on top [64]. The sides and top were insulated with expanded glass granules, $30 \mathrm{~cm}$ thick on the bottom and increasing linearly to $70 \mathrm{~cm}$ on the top [47]. The H/D ratio of the storage was approximately 0.7 and the area-to-volume ratio was approximately $0.41 \mathrm{~m}^{2} / \mathrm{m}^{3}$ [47]. The annual thermal losses of the storage are between 324 and $360 \mathrm{GJ}, 30$ to $40 \%$ higher than design losses [47]. 


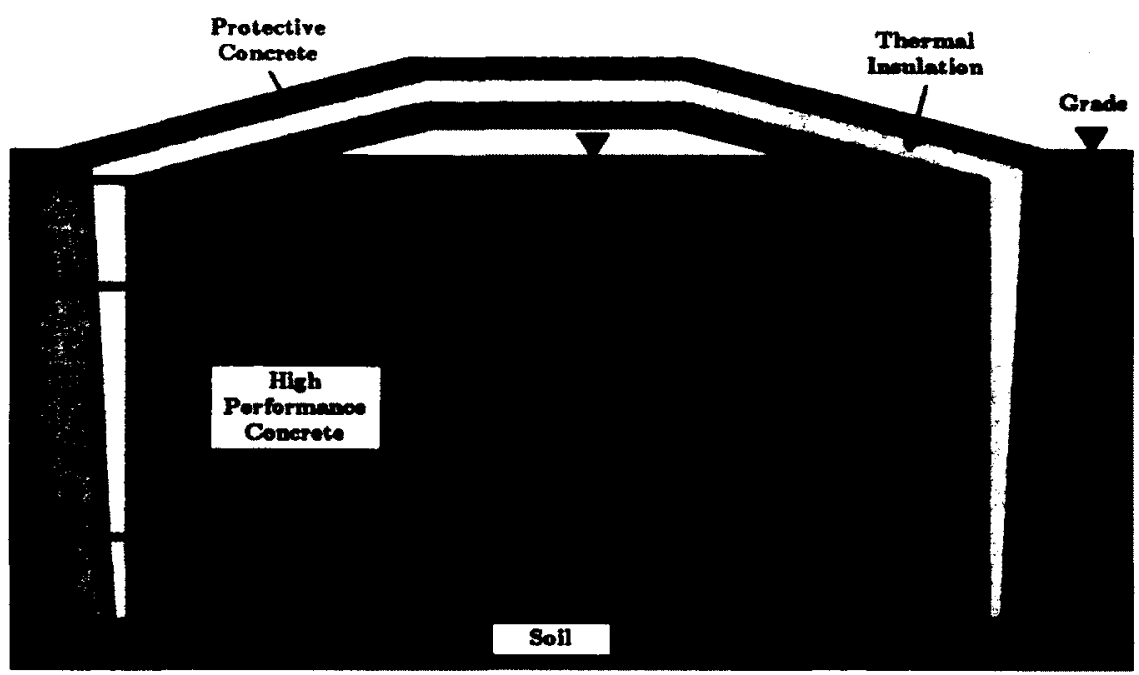

Figure 2.9: Seasonal hot water storage in Hannover, adapted from Ochs [47]

The system was monitored with 13 temperature sensors within the tank, several heat flux sensors on the top, bottom, and sides of the tank and temperature sensors within the soil [47]. In 2002, the tank had a storage efficiency (defined in Section 2.4) of $71.2 \%$ and the system was able to supply $28 \%$ of the demands of the district heating system [64]. The calculated long-term annual solar fraction was $39 \%$ for an annual thermal demand of $2.5 \mathrm{TJ}$ [34].

\subsubsection{Drake Landing Solar Community}

The Drake Landing Solar Community (DLSC) in Okotoks, Alberta is a CSHPSS supplying space heating and domestic hot water to 52 single-detached homes [69]. This system was conceived by Natural Resources Canada and was the first central solar heating plant in North America. It also had the highest solar fraction goals of any solar thermal plant put into operation; $90 \%$ of space heating and $50 \%$ of hot water loads met by the system after 5 years of operation [69-71]. A borehole thermal energy storage (BTES) system was used for seasonal energy storage. The BTES consisted of 144 vertical boreholes in the ground, each $37 \mathrm{~m}$ deep [71]. Polyethylene tubes were extended to the bottom of the borehole where a $U$-shaped bend was made and the line returned to the surface [71]. The borehole field had an area with a rough diameter of $35 \mathrm{~m}$ and was covered with insulating materials then graded [71] and representing approximately $50,000 \mathrm{~m}^{3}$ of storage in the ground [72]. A short-term buffer storage was included in the system to act as a central hub between the solar collectors, district 
heating loop and BTES [70]. The buffer consisted of two interconnected horizontal cylindrical tanks, each holding $130 \mathrm{~m}^{3}$ of water [73].

Solar collection was accomplished with 798 flat-plate collectors, representing a collector area of $2293 \mathrm{~m}^{2}$ [71]. To reduce heating demands, the houses in community were designed to Canadian R-2000 standards resulting in annual space heating loads below $70 \mathrm{GJ}$ [69]. A simplified system schematic of the Drake Landing Solar Community is shown in Figure 2.10.

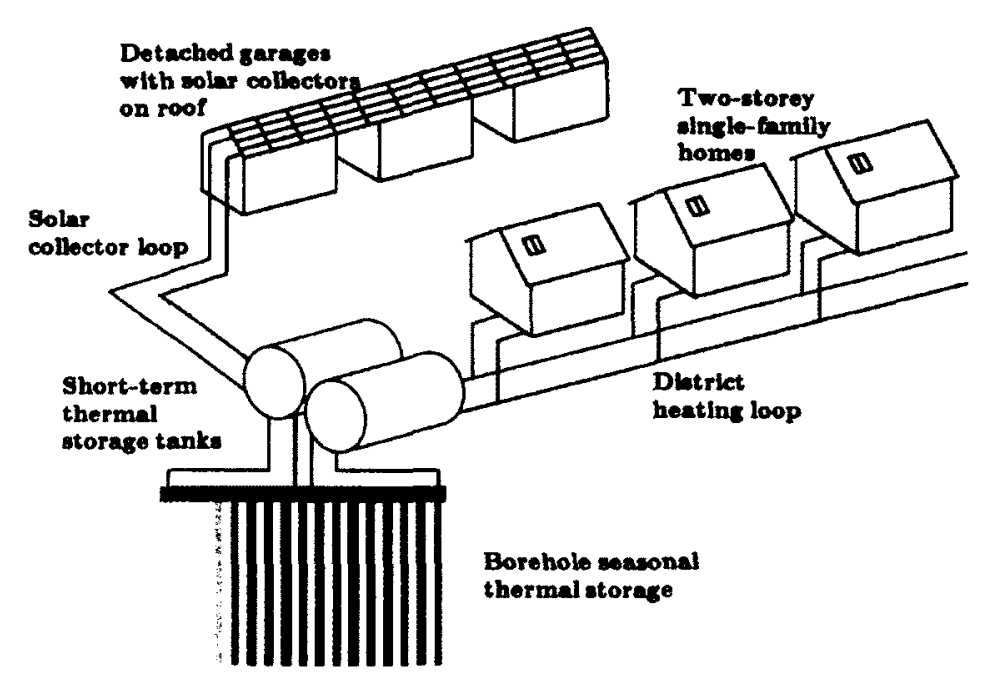

Figure 2.10: System schematic of the Drake Landing Solar Community, adapted from McDowell and Thorton [70]

For further information and research on the DLSC, the interested reader is directed to McDowell and Thorton [70], Wamboldt [71], Rysanek [73], Wong et al. [72] or the Drake Landing Solar Community website [69].

\subsubsection{Riverdale House}

The Riverdale house is a semi-detached duplex built as part of the Canada Mortgage and Housing Corporation's EQuilibrium ${ }^{\mathrm{TM}}$ Housing Project. The house was designed and built by Habitat Studio \& Workshop Ltd. in Edmonton, Alberta. The annual energy consumption was predicted to be less than the on-site production, intending to function as a net-zero energy home [74]. The active solar heating system of the house contained $21 \mathrm{~m}^{2}$ of vertically mounted flat-plate solar collectors, a $300 \mathrm{~L} \mathrm{DHW}$ tank, a $7 \mathrm{~kW}$ water-to-water heat pump and a $17 \mathrm{~m}^{3}$ seasonal storage water tank [75]. 
The space heating system was a forced air system using fan-coil heat exchanger. The hot water circulated in the fan-coil could be sourced from the seasonal storage, the seasonal storage via the heat pump or from the DHW tank depending on source temperatures and demand [75]. It was estimated that the active solar heating system could provide $6.9 \mathrm{GJ} / \mathrm{yr}$ and $8.1 \mathrm{GJ} / \mathrm{yr}$ of $\mathrm{DHW}$ and space heating respectively [75]. This would result in the active solar thermal system meeting $83 \%$ and $21 \%$ of total annual DHW and space heating requirements of the house.

\subsubsection{Passive House with Solar Energy Storage in Ireland}

In 2006, Scandinavian Homes Ltd. built a $215 \mathrm{~m}^{2}$ Passive House in Galway, Ireland. The design space heating load of this single family home was $6.6 \mathrm{GJ} / \mathrm{yr}$ [76]. In 2009, a $23 \mathrm{~m}^{3}$ seasonal storage water tank was added to the site to provide space heating. The tank was a pre-cast concrete tank with an elliptical cross-section and approximate exterior dimensions of $3 \mathrm{~m}$ by $4.5 \mathrm{~m}$ by $2.5 \mathrm{~m}$ [77]. The tank was completely buried with $20 \mathrm{~cm}$ of polyurethane spray and $40 \mathrm{~cm}$ of expanded polystyrene (EPS) on the vertical walls. The top was insulated with $40 \mathrm{~cm}$ of EPS and $8 \mathrm{~cm}$ of polyurethane spray and the bottom was insulated with $60 \mathrm{~cm}$ of EPS [77].

An evacuated tube solar collector (ETC) array was installed on the house with a total aperture area of $10.6 \mathrm{~m}^{2}$ with a tilt angle of $35^{\circ}$ from the horizontal ${ }^{4}$ and surface azimuth of $15^{\circ}$ west of south [77]. The seasonal storage volume to collector area ratio was approximately $2.2 \mathrm{~m}^{3} / \mathrm{m}^{2}$. During solar collection, a solar loop controller was used to first circulate the outlet fluid of the collector array through an immersed heat exchanger in a $300 \mathrm{~L} \mathrm{DHW} \mathrm{tank.} \mathrm{Once} \mathrm{the} \mathrm{tank} \mathrm{reached} \mathrm{a} \mathrm{setpoint} \mathrm{temperature} \mathrm{of}$ $65^{\circ} \mathrm{C}$, the controller then diverted solar collector outlet flow to an immersed coil in the seasonal tank [78].

Domestic hot water was drawn directly from the DHW tank. Incoming mains water was pre-heated by an immersed heat exchanger in the seasonal tank [78]. Space heating of the house was accomplished with the use of a hydronic floor heating system and a solar heat exchanger in the heat recovery ventilator (HRV). A water/ethylene glycol mixture was used as an energy transport medium between the seasonal storage and the hydronic floor/HRV, where thermal energy was drawn out of the seasonal tank with the use of immersed heat exchangers [77].

\footnotetext{
$53^{\circ}$

${ }^{4} \mathrm{~A}$ typical slope of solar collectors is the latitude of the site. The latitude of Galway, Ireland is
} 
For 2010 , the total space heating demand was 4.3 GJ, $65 \%$ of the predicted value [76]. The domestic hot water load for 2010 was 3.1 GJ [76]. The active solar thermal system was able to provide a $93 \%$ DHW solar fraction and $56 \%$ space heating solar fraction. Colclough et al. [78] performed a cool down test of the tank to determine the effective heat loss coefficient of the entire storage, found to be $10 \mathrm{~W} / \mathrm{K}$. This value was more than double the expected tank loss coefficient of approximately $4 \mathrm{~W} / \mathrm{K}[79]$. No significant stratification was observed in the seasonal tank in the first year of operation. Colclough et al. [76] stated that the temperature difference between the bottom and top rarely exceeded $2^{\circ} \mathrm{C}$ and attributed this to the design of the tank.

Clarke et al. [77] used experimental data to calibrate a TRNSYS model of the system. They studied the influence of increasing the collector area from 10.6 to $20 \mathrm{~m}^{2}$. They found that total solar fraction (DHW and space heating) could increase from 47 to $67 \%$. The seasonal storage volume to collector area ratio of the new arrangement was approximately $1.1 \mathrm{~m}^{3} / \mathrm{m}^{2}$.

\subsubsection{Simulation Studies}

There have been several simulation studies that have examined seasonal solar thermal storage for residential applications. Sillman $[25,80]$ used simplified models to compare diurnal and SSTS. The study considered district systems that supplied only space heating or domestic hot water, or both to 50 residential units. The TES for the systems was assumed to be water tanks with a constant heat loss coefficient of 0.11 $\mathrm{W} / \mathrm{m}^{2} \mathrm{~K}$. They were also assumed to be buried with the surround soil modelled at a constant temperature equal to the average ambient temperature of the climate. Under this assumption, the ground would be unable to heat up as the TES lost thermal energy. This would likely lead to an over-prediction of storage losses since the ground would remain at a relatively low temperature.

For SSTS, it was found that performance increased linearly with increasing storage volume until the storage reached sufficient size to hold all summer thermal energy collection. Sillman $[25,80]$ called this the point of "unconstrained operation" and hypothesized that this was the economic optimum. It was also observed that SSTS which supplied predominately hot water performed poorly. To address this, Sillman $[25,80]$ found that the use of both a diurnal and seasonal tank improved performance for systems supplying both space and hot water heating. He noted that a two tank 
arrangement permitted the collection of low temperature heat during the winter and high temperature heat during the spring when the seasonal tank would be nearly fully discharged.

Sillman $[25,80]$ also considered a SSTS for a single-family home. He noted that smaller systems suffer from higher storage losses. When comparing the 50-house district system to the single-house system, annual performance was found to decrease by 20 to $30 \%$. Storage heat loss coefficients were identical for both systems, however the method on scaling down the district system to a single house system was unclear.

Hugo $[81,82]$ used a more sophisticated model to study seasonal solar thermal combisystem for a single-house located in Montréal, Québec. TRNSYS was used to simulate a one-storey detached house with a total heated floor area of $186 \mathrm{~m}^{2}$. The modelled house was based on an existing building constructed in the 1990's. In contrast to the work performed by Sillman $[25,80]$, the system examined by Hugo $[81,82]$ featured a single storage tank which supplied both the space heating and DHW. The storage was a vertical cylindrical water tank with an inlet stratification devices for the solar collector return inlet and space heating loop return inlet. This tank was modelled in TRNSYS using a multinode stratified tank model Type 534 discretized into ten nodes. The tank was assumed to have no thermal losses to the environment since there was assumed to be an extreme level of thermal insulation.

Space heating was supplied to the occupied zones via hydronic floors that circulated the TES fluid directly. Domestic hot water was supplied to end-loads at a setpoint temperature of $45^{\circ} \mathrm{C}$ by heating incoming mains water with a heat exchanger connected to the seasonal storage tank. Auxiliary energy was supplied to space heating and DHW loops with tankless water heaters.

Hugo [81] considered both ETC and flat-plate solar collectors. Based on sensitivity analyses, high solar fractions above $90 \%$ were achievable with a storage volume of $34.7 \mathrm{~m}^{3}$ and ETC area of $47.1 \mathrm{~m}^{2}$. This represented a storage to collector area ratio of approximately $0.7 \mathrm{~m}^{3} / \mathrm{m}^{2}$ for a solar fraction of $96.6 \%$. When flat-plate collectors were used, a $93.6 \%$ solar fraction was achieved with a storage volume of $38.6 \mathrm{~m}^{3}$ and collector area of $53.0 \mathrm{~m}^{2}$. These results indicated potential for using relatively lower cost flat-plate collectors with a comparable annual performance to a system with a similar array of ETCs. 


\subsection{Performance Indices}

In order to analyse the solar thermal system in this research, performance indices needed to be defined. This section reviews some performance metrics defined in the literature. The indices are divided into overall system performance and performance of the TES under simulated operating conditions.

\subsubsection{System Performance}

Annual solar fraction, $\Im$, is the most widely used metric in solar thermal system research and has been introduced previously in this chapter. Duffie and Beckman [11] define annual solar fraction as

$$
\Im=\frac{Q_{t o t}-Q_{a u x, p u r c h a s e d}}{Q_{t o t}}=\frac{Q_{s}}{Q_{t o t}}
$$

Solar fraction represents the ratio of solar energy contribution to a total load, $Q_{\text {tot }}$. For a combisystem, $Q_{t o t}$ represents the total purchased energy ${ }^{5}$ of a zero collector area system required for annual space heating and DHW preparation. The useful energy that is contributed to the system by solar energy is $Q_{s}$, which may also be expressed as the difference between total purchased energy of a zero collector area system and auxiliary purchased energy contributed to meet the end loads in the solar thermal system, $Q_{a u x, p u r c h a s e d}$.

Solar fraction is a relatively simple metric for assessing performance. For active solar thermal systems, pumps, control valves, and controllers are typically used. These components require additional energy, commonly termed "parasitic loads" which are not accounted for in solar fractions. To illustrate the consequence of parasitic loads, consider the increase of a solar collector array area. The solar fraction may increase, but additional pump power will likely be required to circulate the working fluid through more collectors.

To address the deficiencies of the solar fraction metric, the IEA-SHC Task 26 [83] defined the "extended fractional thermal energy savings", $f_{\text {sav,therm. This metric }}$ represents the combined total energy consumption (parasitic and auxiliary) of a solar combisystem compared to the total consumption of a reference case [8]. The extended

\footnotetext{
${ }^{5}$ Purchased energy can be considered as the primary energy delivered to the site. Some researchers define a $Q_{l o a d}$, which is the energy contributed to the end load not considering thermal conversion efficiencies.
} 
fractional thermal energy savings was expressed in this research as

$$
f_{\text {sav }, \text { therm }}=1-\frac{Q_{t o t, p a r}}{Q_{t o t, r e f}}
$$

where

$$
\begin{gathered}
Q_{t o t, p a r}=Q_{a u x}+Q_{p a r} \\
Q_{t o t, r e f}=Q_{t o t}+Q_{p a r, r e f}
\end{gathered}
$$

The total energy to operate the combisystem, $Q_{t o t, p a r}$, is the sum of the auxiliary energy supplied to the end-load, $Q_{a u x}$, and the parastic electrical energy consumed by pumps, actuated valves, controllers, etc, $Q_{p a r}$. The total energy of the reference case, $Q_{\text {tot,ref }}$, is the sum of the total purchased energy delivered to the space heating and DHW loads, $Q_{\text {load }}$, and the parastic energy to run that system, $Q_{\text {par,ref }}$.

\subsubsection{Storage Performance}

There are numerous metrics used for the performance of TES systems. Researchers such as Haller et al. [84] and Castell et al. [48] have studied characterization metrics for stratification in tanks. Dinçer and Rosen [15] presented the relevant theory and methods for exergetic analysis of TES. Dinçer and Rosen [15] define exergy as the "maximum amount of work that can be produced by a stream of matter or energy as it comes into equilibrium with a reference environment." For this research, the energy balance of the TES was of particular interest.

Dinçer and Rosen [15] defined four overall energy efficiencies for TES

$$
\begin{gathered}
\eta_{s}^{A}=\frac{Q_{s, \text { out }}}{Q_{s, \text { in }}} \\
\eta_{s}^{B}=1-\frac{Q_{s, \text { loss }}}{Q_{s, \text { in }}} \\
\eta_{s}^{C}=\frac{Q_{s, \text { out }}}{Q_{s, \text { in }}+Q_{s, i}} \\
\eta_{s}^{D}=1-\frac{Q_{s, \text { loss }}}{Q_{s, \text { in }}+Q_{s, i}}
\end{gathered}
$$

where $Q_{s, \text { out }}$ is the energy recovered from the TES over a specified period, $Q_{s, \text { in }}$ is the energy injected into the TES over the period, $Q_{s, l o s s}$ is the energy losses from the 
storage over the period and $Q_{s, i}$ is the energy in the TES at the beginning of the specified period. Ochs [47] referred to $\eta_{s}^{A}$ as the "storage utilization factor."

\subsection{Conclusions}

Several different methods for thermal energy storage were reviewed. There has been interesting work conducted on advanced systems and new storage materials. However, at the current state of the research, sensible TES systems were determined to be the most practical for residential applications from an economic and material availability perspective. In particular, water tanks were found to be the most appropriate due to its high heat capacity and high rates of heat transfer.

Moving forward with layout design of the C-RISE SSTS, a two-tank system studied by Sillman $[25,80]$ and used by the Passive House in Ireland [76-78] showed potential. Sillman $[25,80]$ pointed out that a two-tank system permitted the collection of low temperature heat during the winter and high temperature heat during the spring when the seasonal tank would be nearly fully discharged.

The system layout used in the Passive house in Ireland [76--78] was also interesting, where each tank was designed to meet a specific thermal load. The smaller diurnal tank supplied the house with DHW while the seasonal storage provided space heating. This reduced complexity in the system and would decrease the cycling of the seasonal storage. This type of system layout was determined to have potential for the C-RISE application and a similar system was applied to this research. 


\section{Chapter 3}

\section{Whole-Building Energy Simulation using ESP-r}

\subsection{Introduction}

In order to meet the research objectives described in Chapter 1 , a method for determining thermal demands of a residential building in Ontario was required. Simulation tools that incorporate the numerous heat and mass transfer mechanisms occurring within a building could be used to fulfill this requirement. Clarke [85] stated that there are many different energy flowpaths that exist in building envelopes, such as transient conduction through walls, longwave radiation exchange between surfaces and air flow through cracks and openings. The flowpaths interact dynamically and determine the comfort level within a building and the energy required to maintain desired comfort levels [85]. Building performance simulation (BPS) tools capable of modelling many or most of these energy flow paths already exist. Examples of these include TRNSYS [19] or EnergyPlus [86]. For this work, the Environmental Systems Performance: Research version $(\mathrm{ESP}-\mathrm{r}$ ) [23] energy simulation tool was selected due to its extensive validation [87], its treatment of coupled building processes (described below) and the ability to modify software source code to meet research needs.

Since its inception in the 1970's [88], ESP-r has experienced ongoing active development by a worldwide community of code developers. Capabilities of ESP-r have expanded to include additional solvers such as acoustics, moisture and air flow, indoor air quality and electrical networks [23]. ESP-r uses a partitioned solution technique, where specialized solvers handle different building domains (such as thermal, air flow, or electrical) [89]. The interdependancies of the domains, for example air 
flow due to a temperature difference, is handled by data exchange between domains or "handshaking" at a time step basis [89]. This handshaking procedure is illustrated in Figure 3.1.

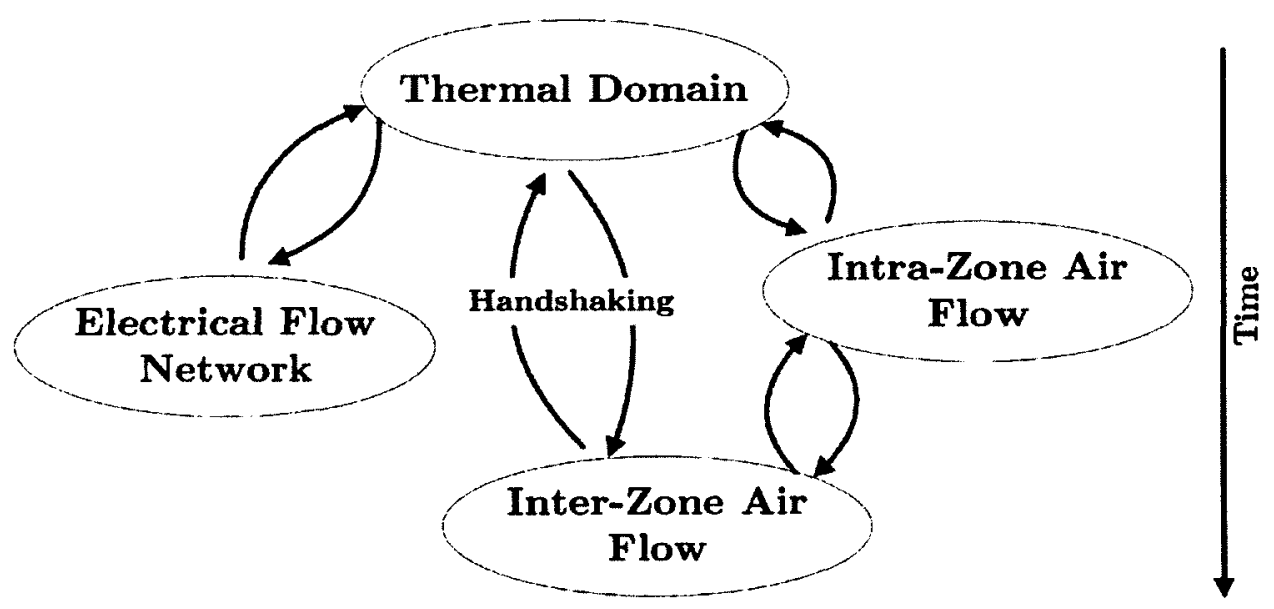

Figure 3.1: Handshaking of solver domains in ESP-r, adapted from BeausoleilMorrison [89]

The following sections provide an overview of the methods used by ESP-r's thermal, air flow and plant domains.

\subsection{Building Thermal Domain}

ESP-r uses a numerical method based on a finite-difference control-volume scheme to determine the energy balance for a building system. Clarke [85] defined three steps involved in constructing a numerical building model. First, the system being considered is discretized into nodes representing finite control-volumes (CV). The manner in which ESP $-\mathrm{r}$ discretizes buildings is described in Section 3.2.1. Once nodes have been established, a nodal set of equations is developed. Section 3.2 .2 presents simple cases for node heat-balance equation development in ESP-r. Lastly, the system of nodal equations is collected and state variables are solved simultaneously. An overview of ESP r's implementation of the simultaneous solution method is provided in Section 3.2.3. For an indepth discussion on the numerical method used in ESP-r's thermal domain, the interested reader is directed to Clarke [85] or Beausoleil--Morrison [89]. 


\subsubsection{Discretization of System}

The discretiztion of a building system in ESP-r is largely controlled by the user. Depending of the goals of the simulation, a building model can range from highly detailed to simplified. ESP-r constructs models of buildings by representing internal spaces as "zones" containing a single air node. Rooms in a building may be lumped together as one zone for simplicity if they are assumed to be at similar thermal conditions. Dividing a building model into several zones may also be done, but typically requires additional inputs that may be non-trivial to define. For example, characterizing air flow between rooms influenced by the opening and closing of doors.

Once the building has been modelled as a system of zones, the zones are discretized into several nodes. Figure 3.2 represents a simple case for a discretized building zone in ESP-r. The air node is bounded by several building multi-layer constructions (MLC) such as walls, windows, floors, ceilings. The building constructions are divided into several nodes to represent the many layers that they are composed of. Figure 3.3 shows a cross-section of a discretized simple external wall in ESP-r, where each constituent layer is divided into one internal node and nodes at each interface between adjacent layers or air volume. Clarke [88] conducted a parametric study to determine the sensitivity of spatial discretization of building fabrics. He concluded that for most practical cases, three nodes or more per homogeneous building layer provided sufficient accuracy.

\subsubsection{Formation of Finite Volume Equations}

Once the building system has been discretized, energy conservation equations are developed for each node in the system. Sections 3.2.2.1 describes the method used by ESP-r to construct energy balance expressions through opaque constructions. The energy balances for air nodes, solid-fluid interfaces, and transparent constructions is omitted for clarity and the interested reader is directed to Clarke [85], Lomanowski [91] or Beausoleil-Morrison [89] for further details. 


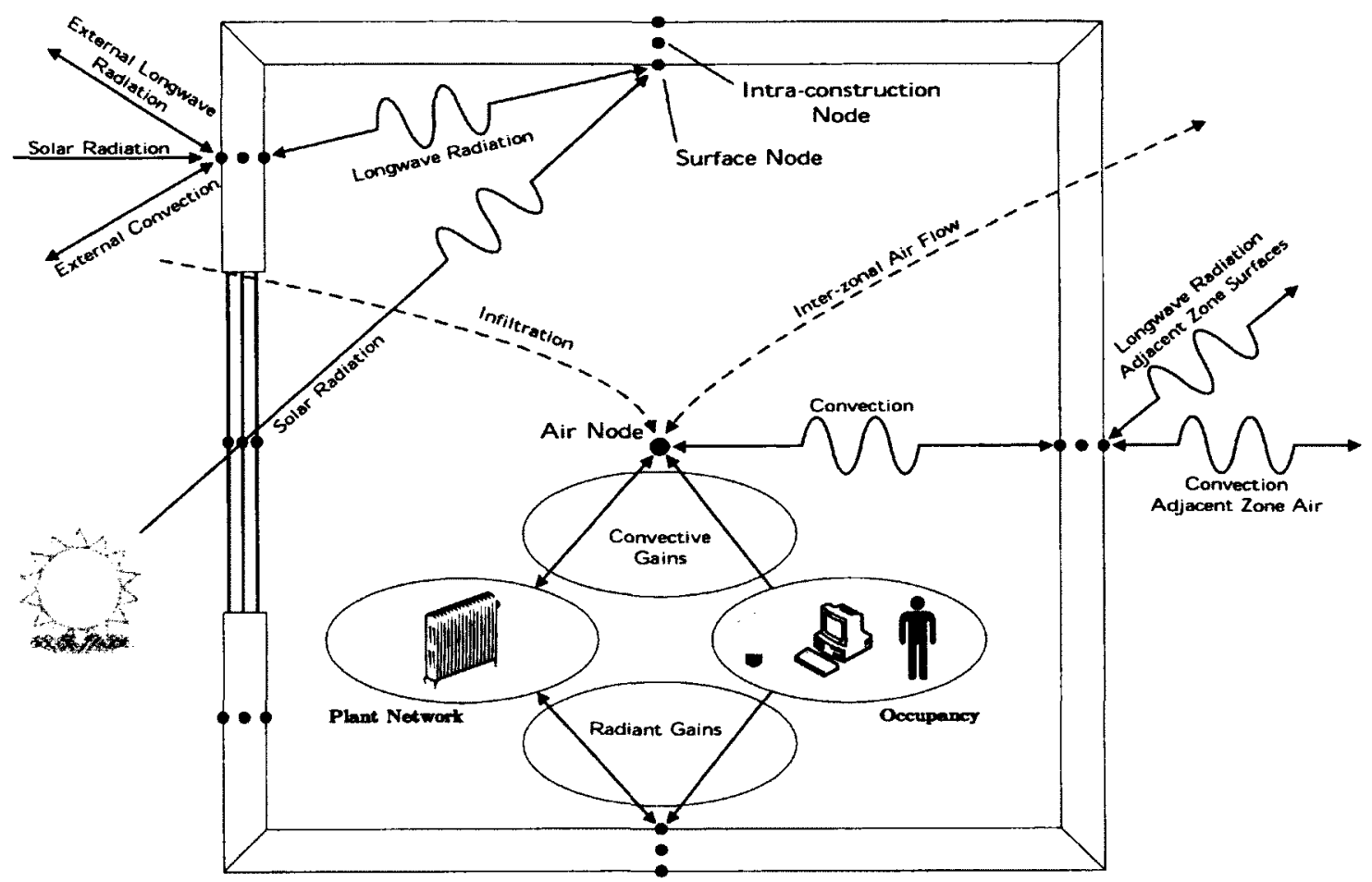

Figure 3.2: ESP-r discretization and energy flowpaths in a modelled building zone, adapted from Kopf [90]

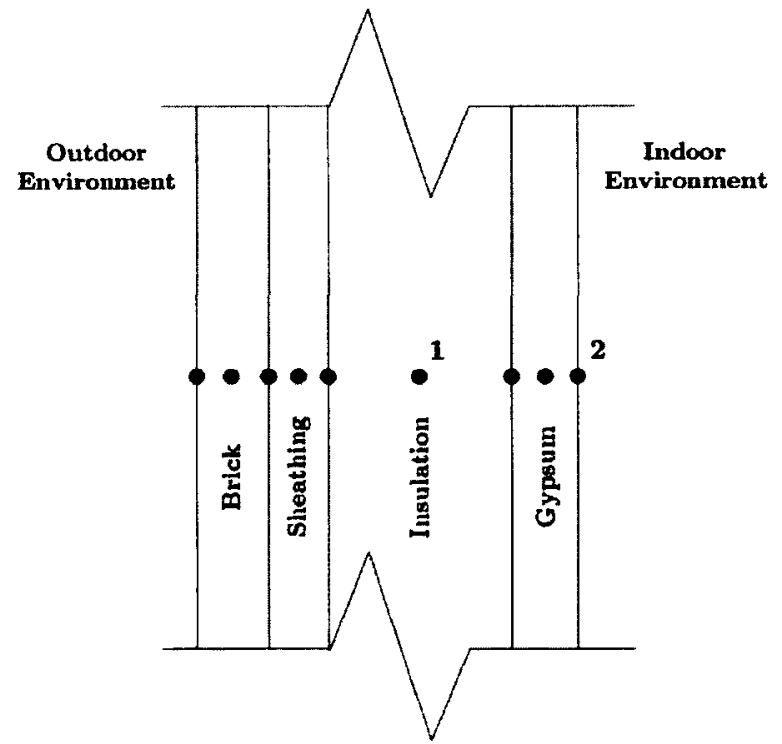

Figure 3.3: ESP $-\mathrm{r}$ discretization of an external opaque wall, adapted from Beausoleil--Morrison [89] 


\subsubsection{Energy Balance Through Opaque Constructions}

Heat transfer through opaque building constructions is treated as a one-dimensional heat conduction problem with constant thermophysical properties. Beausoleil-Morrison [89] stated that this approach is common in the building simulation field since building materials are typically characterized by effective conductivity encompassing other modes of heat transfer that may be occurring within a construction. Figure 3.4 illustrates the homogeneous control volume (CV) of Node 1 in Figure 3.3. The thickness of the CV is $\Delta x[\mathrm{~m}]$ and the user-defined length and width of the surface is $\Delta y$ and $\Delta z$ repectively. The heat conduction into and out of the CV from adjacent nodes is given as $\dot{Q}[\mathrm{~W}]$.

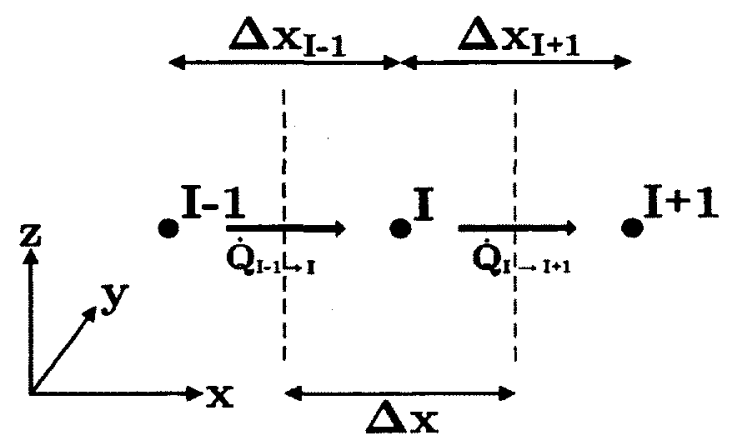

Figure 3.4: Control-volume heat balance at homogeneous layer in construction, adapted from [89]

The energy balance for the CV is composed of three terms shown in Equation 3.1.

$$
\left\{\begin{array}{c}
\text { Energy Stored } \\
\text { in } C V
\end{array}\right\}=\left\{\begin{array}{c}
\text { Net Conducted } \\
\text { into } C V
\end{array}\right\}+\left\{\begin{array}{c}
\text { Energy Generated } \\
\text { in } C V
\end{array}\right\}
$$

Expressed mathematically, the energy balance is,

$$
\rho c_{p} \frac{\partial T}{\partial t}=-\frac{\partial \dot{Q}_{x}^{\prime \prime}}{\partial x}+\dot{Q}_{p l a n t}^{\prime \prime \prime}
$$

where $\rho$ is the density of the homogeneous layer $\left[\mathrm{kg} / \mathrm{m}^{3}\right], c_{p}$ is the specific heat of the layer $[\mathrm{J} / \mathrm{kg} \mathrm{K}], T$ is temperature $[\mathrm{K}], t$ is time $[\mathrm{s}], \dot{Q}_{x}^{\prime \prime}$ is the conducted heat flux 
in the $\mathrm{x}$ direction $\left[\mathrm{W} / \mathrm{m}^{2}\right]$, and $\dot{Q}_{\text {plant }}^{\prime \prime \prime}$ is plant flux injection into a construction node $\left[\mathrm{W} / \mathrm{m}^{3}\right]$. Integrating Equation 3.2 over the control volume yields,

$$
\left(\rho c_{p} \Delta x \Delta y \Delta z\right)_{I} \frac{\partial T}{\partial t}=\dot{Q}_{I-1 \rightarrow I}-\dot{Q}_{I \rightarrow I+1}+\dot{Q}_{p l a n t}
$$

Using the backwards Euler method to approximate the first order derivative in the left-hand expression in Equation 3.3 yields,

$$
\left(\rho c_{p} \Delta x \Delta y \Delta z\right)_{I} \frac{T_{I}^{t+\Delta t}-T_{I}^{t}}{\Delta t}=\dot{Q}_{I-1 \rightarrow I}-\dot{Q}_{I \rightarrow I+1}+\dot{Q}_{p l a n t}
$$

where $t$ is the "present time" and $t+\Delta t$ is the "future time". The conduction terms $\dot{Q}_{I-1 \rightarrow I}$ and $\dot{Q}_{I \rightarrow I+1}$ can be approximated using an explicit form of the one dimensional Fourier's law of heat conduction,

$$
\begin{aligned}
& \dot{Q}_{I-1 \rightarrow I} \approx k_{I-1} \frac{\Delta y \Delta z}{\Delta x_{I-1}}\left(T_{I-1}^{t}-T_{I}^{t}\right) \\
& \dot{Q}_{I \rightarrow I+1} \approx k_{I+1} \frac{\Delta y \Delta z}{\Delta x_{I+1}}\left(T_{I}^{t}-T_{I+1}^{t}\right)
\end{aligned}
$$

Substituting Equations 3.5 and 3.6 into 3.4 and setting the plant flux equal to the present time value gives rise to the explicit form of the discretized energy balance of the node.

$$
\begin{aligned}
& \left(\rho c_{p} \Delta x \Delta y \Delta z\right)_{I} \frac{T_{I}^{t+\Delta t}-T_{I}^{t}}{\Delta t} \\
& =k_{I-1} \frac{\Delta y \Delta z}{\Delta x_{I-1}}\left(T_{I-1}^{t}-T_{I}^{t}\right)-k_{I+1} \frac{\Delta y \Delta z}{\Delta x_{I+1}}\left(T_{I}^{t}-T_{I+1}^{t}\right)+\dot{Q}_{p l a n t}^{t}
\end{aligned}
$$

An implicit form of the energy balance equation may be formulated if the future temperatures and future plant flux injection are used.

$$
\begin{aligned}
& \left(\rho c_{p} \Delta x \Delta y \Delta z\right)_{I} \frac{T_{I}^{t+\Delta t}-T_{I}^{t}}{\Delta t} \\
& =k_{I-1} \frac{\Delta y \Delta z}{\Delta x_{I-1}}\left(T_{I-1}^{t+\Delta t}-T_{I}^{t+\Delta t}\right)-k_{I+1} \frac{\Delta y \Delta z}{\Delta x_{I+1}}\left(T_{I}^{t+\Delta t}-T_{I+1}^{t+\Delta t}\right)+\dot{Q}_{p l a n t}^{t+\Delta t}
\end{aligned}
$$


While the explicit form is computationally simple, it has the disadvantage of being constrained by stability limits for temporal or spacial discretizations [92]. The implicit form of the energy balance maintains stability over much larger temporal discretizations, however the larger timesteps may lead to higher truncation error [92]. By default, ESP-r uses a weighted average of the implicit and explicit formulations, commonly referred to as the Crank-Nicolson method [93]. This semi-implicit method has the advantage of unconditional stability combined with accuracy [85]. Equation 3.9 gives the fundamental discretized energy balance in ESP-r for a homogeneous opaque $\mathrm{CV}$, which is derived from the addition of Equations 3.7 and 3.8, dividing through by volume $(\Delta x \Delta y \Delta z)$ and collecting future and present time values.

$$
\begin{aligned}
& {\left[\frac{2 \cdot\left(\rho c_{p}\right)_{I}}{\Delta t}+\frac{k_{I-1}}{\Delta x \Delta x_{I-1}}+\frac{k_{I+1}}{\Delta x \Delta x_{I+11}}\right] T_{I}^{t+\Delta t}-\left[\frac{k_{I-1}}{\Delta x \Delta x_{I-1}}\right] T_{I-1}^{t+\Delta t}} \\
& -\left[\frac{k_{I+1}}{\Delta x \Delta x_{I+1}}\right] T_{I+1}^{t+\Delta t}-\frac{\dot{Q}_{\text {plant }}^{t+\Delta t}}{\Delta x \Delta y \Delta z}=\left[\frac{2 \cdot\left(\rho c_{p}\right)_{I}}{\Delta t}+\frac{k_{I-1}}{\Delta x \Delta x_{I-1}}+\frac{k_{I+1}}{\Delta x \Delta x_{I+11}}\right] T_{I}^{t} \\
& -\left[\frac{k_{I-1}}{\Delta x \Delta x_{I-1}}\right] T_{I-1}^{t}-\left[\frac{k_{I+1}}{\Delta x \Delta x_{I+1}}\right] T_{I+1}^{t}-\frac{\dot{Q}_{\text {plant }}^{t}}{\Delta x \Delta y \Delta z}
\end{aligned}
$$

\subsubsection{Simultaneous Solution Method}

Once the energy balance expressions have been derived for all nodes, the system of equations can be cast in the matrix format,

$$
\mathbf{A} \boldsymbol{\theta}^{t+\Delta t}=\mathbf{B} \boldsymbol{\theta}^{t}+\mathbf{C}
$$

$\mathbf{A}$ and $\mathbf{B}$ are two-dimensional matrices containing coefficients for the future and present time row variables respectively. $\boldsymbol{\theta}^{t+\Delta t}$ and $\boldsymbol{\theta}^{t}$ are column vectors containing nodal temperature, $T_{I}$, and plant flux, $q_{I, p l a n t}$, at future and present time rows respectively. The column vector $\mathbf{C}$ contains known boundary conditions such as imposed flux or known temperatures. Since the right side of Equation 3.10 contains knowns, the terms can be collected into one matrix $\mathbf{Z}$ such that,

$$
\mathbf{A} \boldsymbol{\theta}^{t+\Delta t}=\mathbf{Z}
$$

The solution of $\theta^{t+\Delta t}$ may be obtained by multiplying both sides of Equation 3.11 
by the inverse matrix of $\mathbf{A}$.

$$
\boldsymbol{\theta}^{t+\Delta t}=\mathbf{A}^{-1} \mathbf{Z}
$$

In ESP-r, matrix $\mathbf{A}$ is sparse with values primarily along the diagonal. To conserve computing memory and increase simulation speed, matrix $\mathbf{A}$ is partitioned and processed independently. A Gaussian elimination technique is then used to solve for the unknown variables in vector $\theta^{t+\Delta t}$. For further details on the method used to construct and solve the matrices in ESP $-\mathrm{r}$, the interested reader is directed to Clarke [85] or Beausoleil-Morrison [89].

\subsection{Building Air Flow}

There are several types of air flow that can occur in building envelopes. Air exchange between indoor and outdoor spaces can be divided into two general categories, ventilation and infiltration [94]. Ventilation is the intentional addition of fresh outdoor air into a building by means of a mechanical system or by envelope design promoting natural flow such as operable windows. Infiltration is the unintentional flow into a building through cracks and leaks in the façade. The primary drivers of infiltration and natural ventilation are temperature differences between ambient and internal spaces (stack effect) and wind pressure [94]. Air in an internal space can also be exchanged with other building spaces due to openings, such as doors, and mechanical systems. Several methods are available to model building air flows, ranging from the simplified to the very detailed, depending on simulation goals.

Following the partitioned solution scheme described in Section 3.1, ESP $\mathrm{r}$ uses customized solvers to determine air mass flow rates through a building. Handshaking between the thermal domain and the air flow solvers is achieved by using flow rate solutions, $\dot{m}$, to calculate heat advection in the thermal zone. Thermal domain air node temperatures may also be communicated to air flow solvers to determine buoyancy-driven flows. Air flow techniques used in the research are discussed next. For additional information on ESP-r's air flow modelling, the interested reader is directed to Clarke [85] or Hensen [95]. 


\subsubsection{Scheduled Flow}

Scheduled flow is the simplest treatment of zone infiltration and ventilation in ESP-r requiring minimal user input. The user specifies an hourly schedule for air flow, with constant values over the period. Infiltration air is typically assigned a "rule of thumb" value (ASHRAE Fundamentals [94] provides a list of studies and infiltration rates for North American residential buildings). For ventilation air, the source is specified as either a constant temperature source, another modelled zone or outdoor air. Scheduled air flow has an application at early design stage when there is little information available or in zones/models where detailed air flow modelling is not necessary.

\subsubsection{Air Flow Networks}

Air flow networks provide a more detailed approach to building air flow modelling. This technique operates on a steady-state, incompressible flow assumption. The zones in a building model are represented as unknown pressure points (nodes). The network is constructed by defining flow connections between zones, such as through cracks, intentional openings, or fans. Nodal heights are defined relative to a datum to account for buoyancy effects. Boundary nodes represent the pressure at the building external surface. These values are considered to be known pressures corresponding to a wind velocity and direction. The mass flow between linked nodes is modelled using "component flow models" which set the mass flow rate as a function of pressure difference between the nodes. For a complete description for component flow models in ESP $-\mathrm{r}$, the interested reader is directed to Hensen [95].

Figure 3.5 illustrates a simple air flow network in a three zone building. The nodes East and West are known boundary conditions at the building façade. Internal nodes are connected to the boundaries by component flow models representing cracks in the façade and open windows. Connections between internal nodes are also defined to characterize air flow through interior doorways and stairwells.

Once the network nodes and connections have been established, an iterative Newton Raphson method is used to establish the unknown pressures. All nonboundary nodes are assigned an arbitrary pressure and mass flow through nodal connections are determined based on their component flow model. Since the model uses a steady-state assumption, the sum of flows entering an exiting the node is zero. 


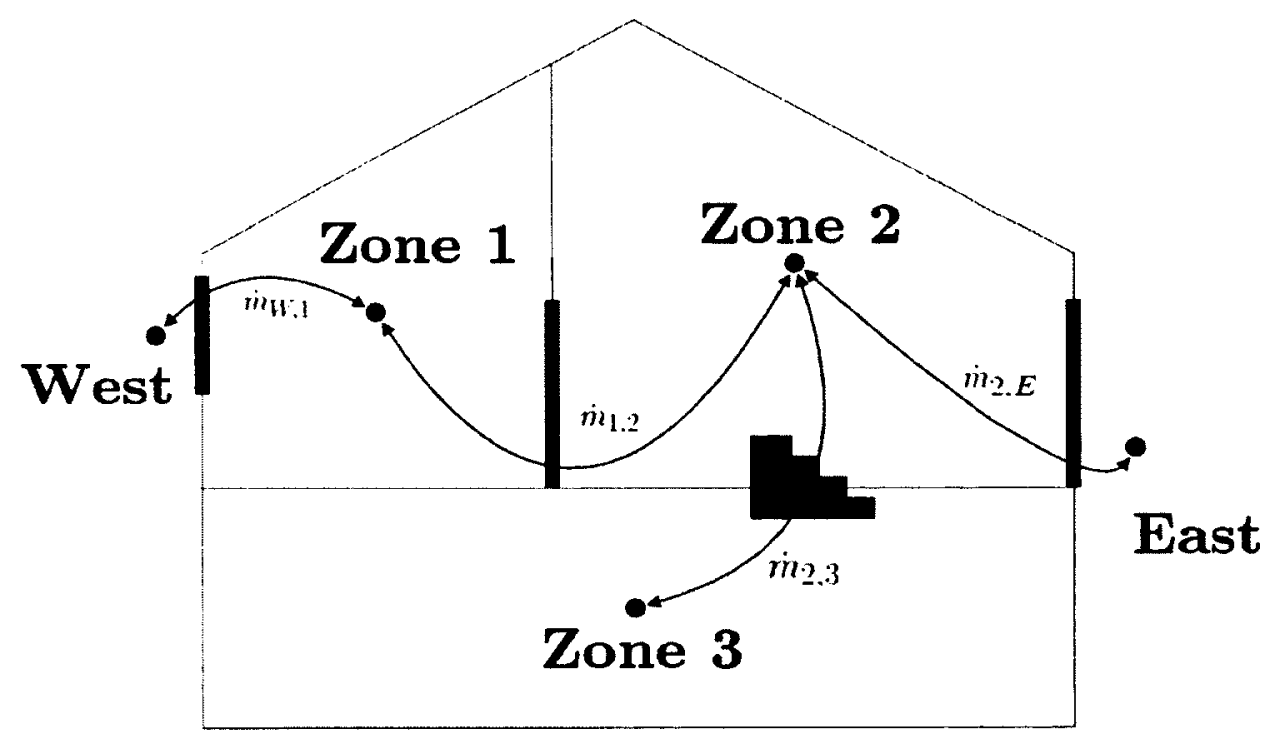

Figure 3.5: Simple illustration of a building air flow network

The unknown pressures are corrected and iteration continues until error reaches a user defined tolerance. For further details on the air flow network method, the interested reader is directed to Clarke [85] or Hensen [95].

\subsubsection{AIM-2 Model}

The Alberta Infiltration Model (AIM-2) [96] is single-zone air infiltration model developed for low-rise buildings. At each time step, the AIM-2 model recalculates the building infiltration, taking into account both stack and wind effects. The model is based on a power law relating flow to the pressure difference between the interior and ambient, shown in Equation 3.13.

$$
\dot{V}=C \Delta P^{n}
$$

$\dot{V}$ is the total infiltration $\left[\mathrm{m}^{3} / \mathrm{s}\right]$ and $\Delta P$ is the pressure difference $[\mathrm{Pa}]$. The flow coefficient $C\left[\mathrm{~m}^{3} / \mathrm{s} \mathrm{Pa}^{n}\right]$ and flow exponent $n$ can be determined empirically using a blower door test [97]. This test uses a powerful fan to depressurize a residential home [98]. The pressure difference and fan flow rate are recorded at different states to determine how leaky a house is. Wang et al. [99] conducted a validation study of the AIM-2 model using tracer gas measurements of 16 test houses in Ottawa, Canada. The AIM-2 model was found to underestimate air infiltration by approximately $5 \%$ 
compared to other models tested which demonstrated overestimation by 7 to $15 \%$.

Since ESP-r has the capability to model multiple zones for a low-rise building, the implementation of the single zone AIM-2 model requires the user to specify what zones receive infiltration and which zone to use as a reference indoor state. For further details on the AIM-2 model, the interested reader is directed to Wang et al. [99].

\subsection{Plant Network Domain}

Clarke [85] identified two methods that can be used to model building plant systems: sequential and simultaneous. The sequential method is used in software such as TRNSYS and is described in further detail in Chapter 4. A simultaneous solution is used in ESP-r, similar to the simulation technique of the building domain. In his thesis, Hensen [95] stated that simultaneous solution of both thermal and plant domains are simplified if they both employ a similar numerical technique. Like the thermal domain, building plant systems are discretized into a set of finite-volumes. Each component of a plant system may be represented by one or more finite-volumes, or nodes, like the system shown in Figure 3.6. All nodes have associated conservation equations that can relate to mass flow, energy or electrical current depending on the component and a capacitance to model transient effects. These conservation expressions are constructed using the Crank-Nicolson scheme similar to the thermal domain nodes and each system of conservation equations takes on a form similar to Equation 3.10. 


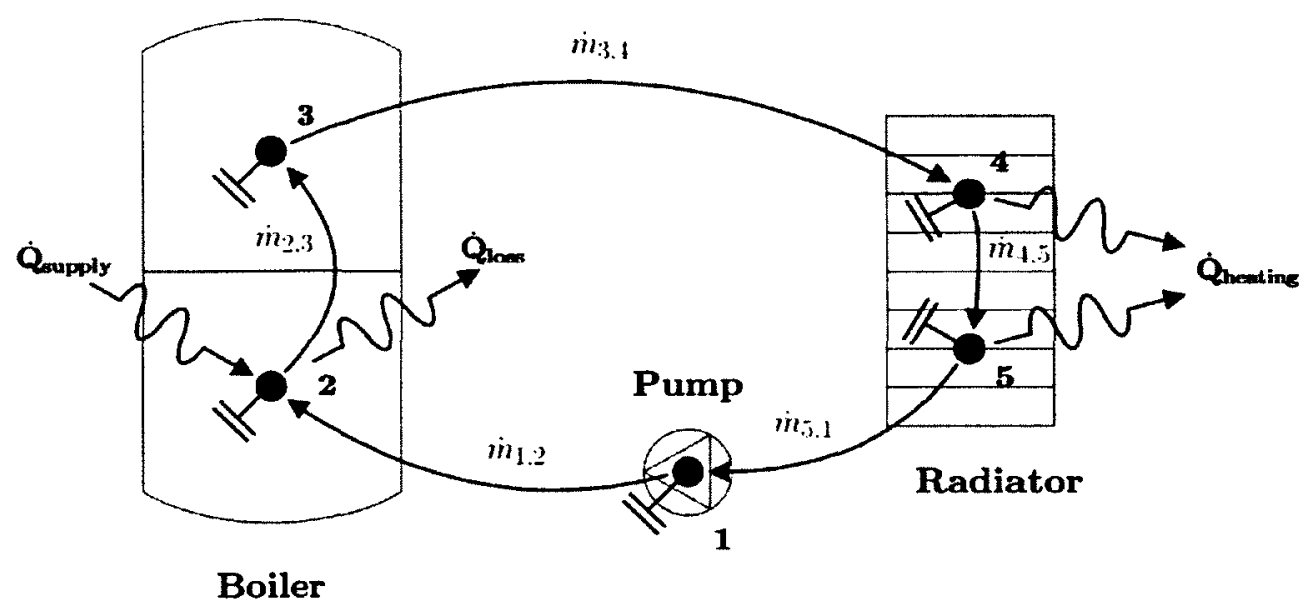

Figure 3.6: Simple illustration of an ESP $-\mathbf{r}$ plant network

ESP-r contains a suite of plant components such as pumps and boilers, some of which are detailed by Hensen [95]. Issues arise with ESP-r when new and innovative systems are being considered with no representative components currently in the software. Those attempting to add new components into ESP r require extensive knowledge of the source code and the way in which ESP-r places coefficients into system matrices for simultaneous solution. This can be prohibitive for rapid development and simulation of innovative systems. To overcome this difficulty, software has been developed [100] to exploit the robust building domain solver of ESP-r and couple it with TRNSYS, a software design to model new, renewable systems. The techniques utilized by this coupling software are discussed in Chapter 4. For further information on ESP-r's plant domain, the interested reader is directed to Clarke [85] or Henson [95]. 


\section{Chapter 4}

\section{Solar Thermal System Simulation using TRNSYS}

\subsection{Introduction}

In the previous chapter, the simulation tool ESP $r$ was introduced. ESP-r was determined to be suitable for modelling the dynamic response of building envelopes under climatic and occupant loads, however Section 3.4 highlighted weaknesses in ESP-r's representation of building plant and HVAC systems. Specifically, the modelling of new and innovative components was non-trivial in ESP-r and required extensive knowledge of the software's thermal domain and plant domain source code. In order to meet the research objectives mentioned in Chapter 1, another simulation tool was considered for representation of the seasonal solar thermal system (SSTS).

TRNSYS [19] is a commercially available simulation tool used in research to model "the dynamic thermal response of transient systems" [101]. In addition to extensive libraries of different solar and HVAC components, called "Types", the graphical user interface (GUI) in TRNSYS allowed the user to easily visualize and create mass or energy flow connections between plant components. The GUI in ESP-r currently had no facilities for visualization of plant systems or connections, only text-based reporting. TRNSYS was also a modular program and permitted easy implementation of new components and control algorithms. For these reasons, the TRNSYS simulation tool was selected to represent the solar thermal system in this work.

The TRNSYS software tool did contain a detailed building model, Type 56, which had been validated by Bradley et al. [102,103]. Past researchers, such as Hugo [81], 
had represented both solar thermal plant systems and building envelopes in TRNSYS in order to capture the integrated behaviour of plant and building. However, Beausoleil-Morrison et al. [100] argued that TRNSYS was originally designed for modelling renewable energy systems and was less precise in treating building physics compared to ESP-r. For example, heat conduction through walls was treated differently in ESP-r and TRNSYS. ESP-r used a numerical method based on finitedifference control-volumes, described in Chapter 3. TRNSYS, however, employed a conduction transfer function (CTF) method. Delcroix et al. [104] assessed the CTF method implementation in TRNSYS using different test cases at the minimum timebase $^{1}$. They found that for very thick or highly insulated walls, especially when using short simulation timesteps, would result in a "stair-step" effect. This effect is illustrated in Figure 4.1, comparing a finite-difference calculation and and CTF calculation for a wall surface temperature ${ }^{2}$.

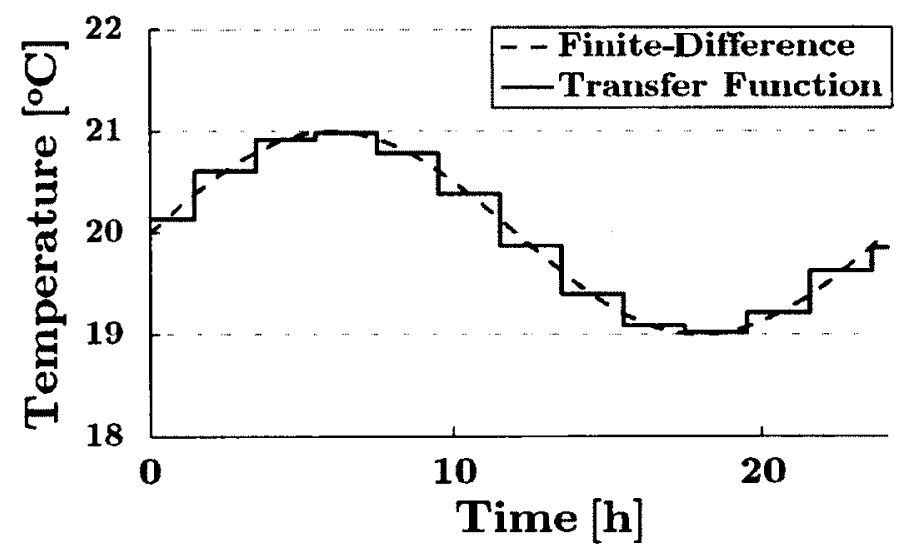

Figure 4.1: Illustration of stair-step effect

Delcroix et al. [104] pointed out that this effect could have implications on control studies where short timesteps were required. Since the C-RISE house was to be modelled with heavy insulation to meet the $\mathrm{R}-2000$ standard and short timesteps were to be used for system controls, this "stair-step" effect was assumed to have an impact on simulation results. It is important to note that Delcroix et al. [104] provided workarounds and improvement suggestions for the CTF implementation in

\footnotetext{
${ }^{1}$ The CTF represents a discrete time series. The timestep of this series is referred to in TRNSYS as the "timebase".

${ }^{2}$ This figure is for demonstration purposes only and does not represent actual data. For further details on the "stair-step" effect, the interested reader is directed to Delcroix et al. [104]
} 


\section{TRNSYS.}

Additionally, ESP-r and TRNSYS use different methods for treatment of convective heat transfer coefficients. ESP-r contains a library of several convective heat transfer correlations from the literature which are used to update heat transfer coefficients at each timestep based on building conditions for all surfaces [89]. A simplified approach is taken in TRNSYS, where the Type 80 component may be used to calculate the heat transfer coefficients based on the temperature difference between a fluid and surface for use in Type 56 [105]. Type 80 is limited to 10 surfaces and the heat transfer correlations must take the form of a Power Law [106]. All other surfaces in a building model uses fixed heat transfer correlations. Peeters et al. [107] reviewed internal convection heat transfer modelling and determined that careful selection of convection correlations was important for accurate modelling of building energy simulation.

The challenge with using separate simulation tools to model the building envelope and solar thermal system was that both systems were expected to dynamically interact with each other. For example, a failure of the modelled solar thermal system to meet space heating loads would have an effect on building envelope thermal conditions. This would then influence the thermal system as it tries to catch up to meet the heating load. These types of integrated interactions between systems did not permit separate analysis, but rather an integrated simulation approach was required.

Trčka et al. [108] noted that current building performance simulation tools were not comprehensive enough to represent modern integrated buildings and mechanical systems. They also noted that extending functionality in current tools would be costly and non-trivial. Trčka et al. [108] recommended the coupling of complimentary tools by linking them at run -time to take advantage of the existing software. They identify this strategy as "co-simulation", where a minimum of two different software tools solve coupled differential-algebraic sets of equations and exchange data during time integration [108]. This strategy was applied to this research to take advantage of the complimentary strengths of ESP $-r$ and TRNSYS.

The objective of this chapter is to briefly introduce the solution methods of TRNSYS. The mathematical methods of two key TRNSYS models used in the research, the flat-plate collector and stratified tank, is also presented here. Section 4.4 then describes the method that was used to perform a co-simulation between ESP-r and TRNSYS. 


\subsection{TRNSYS Solution Methodology}

Klein et al. [101] described TRNSYS as a modular program that consisted of several component models and an executive routine. System hardware such as pumps, valves, or tanks were represented in self-contained subroutines called "types". These types accepted inputs, such as mass flow and temperature, and produced outputs representative of the modelled hardware. The user could specify the design parameters of each component, for example maximum flow rate of a pump, which remained constant for the duration of the simulation. The inputs and outputs of types were able to change with time or could have been set as constants. A variety of different mechanical systems could be represented by mapping outputs of one type to the inputs of others. TRNSYS types and system networking are illustrated in Figure 4.2
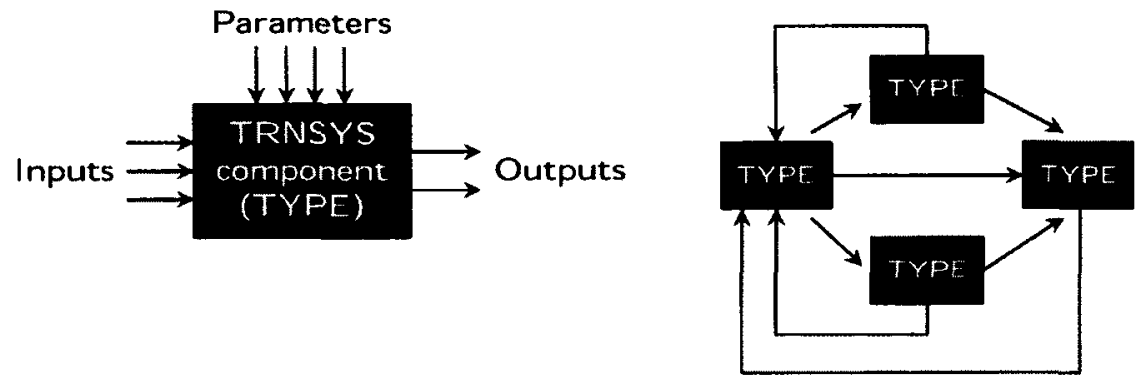

Figure 4.2: TRNSYS type and networking, adapted from Beausoleil-Morrison et al. $[100]$

All the inputs and outputs of types in a TRNSYS network were managed by the executive routine, or kernel. At each timestep, the system response to an external forcing function, such as incident solar radiation and ambient temperature, was calculated iteratively. The TRNSYS kernel considered the types as black boxes, calling type subroutines and mapping outputs of connected types to the current type's inputs. At each iteration, types whose inputs had changed were called again until convergence was reached. Beausoleil-Morrison et al. [100] stated that the convergence criteria in TRNSYS may be based on a relative or absolute difference, but is the same for all inputs whether the units are temperature, humidity, etc. Figure 4.3 illustrates the interaction between the kernel and types, and the iteration process.

For additional information on the TRNSYS simulation tool, the interested reader is directed to TRNSYS [19], Klein et al. [101] or Beausoleil-Morrison et al. [100]. 


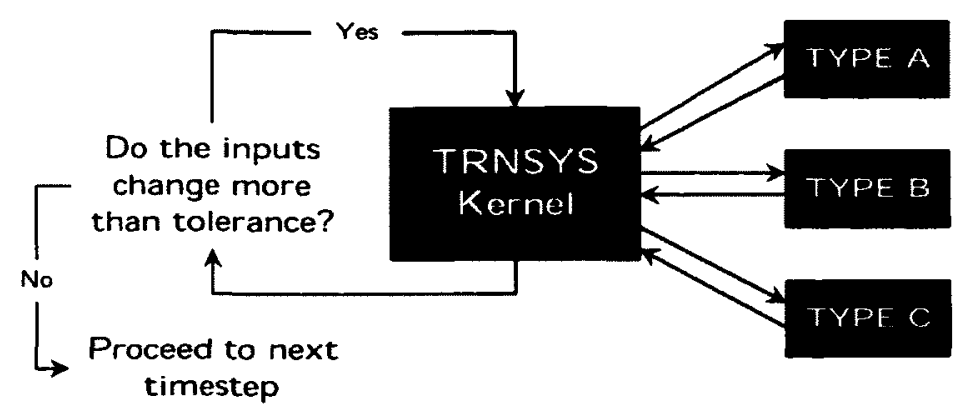

Figure 4.3: TRNSYS solution method, adapted from Beausoleil-Morrison et al. [100]

\subsection{Models in TRNSYS}

\subsubsection{Flat-plate Solar Collector}

Mentioned in Chapter 1, all solar thermal systems possess some form of solar collector to convert incident solar radiation into thermal energy. There are several different types of solar thermal collectors, such as evacuated tube or concentrating collectors. According to Duffie and Beckman [11], flat-plate collectors may be designed to operate up to approximately $100^{\circ} \mathrm{C}$ above ambient. This temperature range is well suited for domestic hot water and space heating loads. Duffie and Beckman [11] also noted that flat-plate collectors use both beam and diffuse solar radiation, do not require solar tracking, need little maintenance and are mechanically simpler compared to concentrating collectors. Most importantly, flat-plate collectors are generally inexpensive compared to other types of collector. For these reasons, flat-plate collectors were considered in this research. Figure 4.4 illustrates the basic components of a flat-plate solar thermal collector.

Modelling of flat-plate solar thermal collectors in TR.NSYS was accomplished using Type 539 in the extended component libraries from Thermal Energy System Specialists (TESS) [109]. This was a transient model that considered the thermal capacitance of the collector. Typically, steady-state models are used to simulate solar thermal collectors. Thermal mass was included in this work to promote model stability. Beausoleil-Morrison et al. [100] stated that network loops in TRNSYS which contain no mass or time delays may experience non-convergence. These "algebraic loops" represent a system of equations where the output is plus or minus the input and during iterations can cause the outputs to oscillate. 


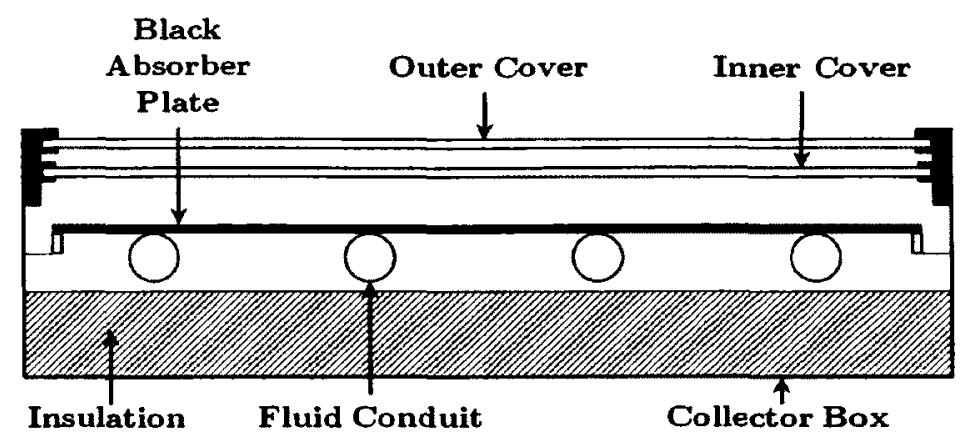

Figure 4.4: Cross-section of simple flat-plate collector, adapted from Duffie and Beckman [11]

To understand the solution methodology of Type 539, a differential length $d x$ of fluid conduit along the direction of flow in a flat-plate collector was first considered. Duffie and Beckman [11] give the useful gain of the collector fluid per length, $\dot{Q}_{u}^{\prime}$, along $d x[\mathrm{~W} / \mathrm{m}]$ as

$$
\dot{Q}_{u}^{\prime}=W F^{\prime}\left[S-U_{L}\left(T_{f}-T_{a}\right)\right]
$$

where $W$ is the centre-to-centre spacing of fluid conduits in the collector $[\mathrm{m}], S$ is the solar radiation absorbed by a collector per unit area of absorber $\left[\mathrm{W} / \mathrm{m}^{2}\right], U_{L}$ is the first order overall heat loss coefficient for the collector $\left[\mathrm{W} / \mathrm{m}^{2} \mathrm{~K}\right], T_{f}$ is the local fluid temperature $\left[{ }^{\circ} \mathrm{C}\right]$, and $T_{a}$ is the ambient temperature $\left[{ }^{\circ} \mathrm{C}\right]$. The collector efficiency factor, $F^{\prime}$, is a unitless property of the solar thermal collector and varies with fluid flow rate in the collector. Duffie and Beckman [11] described $F^{\prime}$ as the ratio of actual useful gain of the collector to the useful gain if the absorber plate were at the local fluid temperature in the fluid conduit.

Cooper and Dunkle (1981) (qtd. in Duffie and Beckman [11], page 296) suggested a linear dependence of the overall loss coefficient $U_{L}$ with respect to the temperature difference. TESS [109] also assumed a linear dependence of the overall heat loss coefficient and recast Equation 4.1 in the form

$$
\dot{Q}_{u}^{\prime}=W F^{\prime}\left[S-U_{L}\left(T_{f}-T_{a}\right)-U_{L / T}\left(T_{f}-T_{a}\right)\left|\left(T_{f}-T_{a}\right)\right|\right]
$$

where $U_{L / T}$ is the quadratic loss coefficient $\left[\mathrm{W} / \mathrm{m}^{2} \mathrm{~K}^{2}\right]$ for the second order term.

Multiplying Equation 4.2 by differential length $d x$ gives the useful gain over length $d x, \dot{Q}_{u}[\mathrm{~W}]$. Defining the differential collector area $A^{\prime}\left[\mathrm{m}^{2}\right]$ as $W$ multiplied by $d x, q_{u}$ 
can be expressed as

$$
\dot{Q}_{u}=A^{\prime} F^{\prime}\left[S-U_{L}\left(T_{f}-T_{a}\right)-U_{L / T}\left(T_{f}-T_{a}\right)\left|\left(T_{f}-T_{a}\right)\right|\right]
$$

The useful gain over length $d x$ could also be determined by performing an energy balance between the inlet and outlet to the section

$$
\dot{Q}_{u}=\dot{m} c_{p, f l u i d}\left(T_{f}-T_{i n, x}\right)
$$

where $\dot{m}$ is the mass flow rate of the fluid in the conduit $[\mathrm{kg} / \mathrm{s}], c_{p, f l u i d}$ is the specific heat of the fluid $[\mathrm{J} / \mathrm{kg} \mathrm{K}]$, and $T_{i n, x}$ is the inlet fluid temperature into the differential length of fluid conduit $\left[{ }^{\circ} \mathrm{C}\right]$. Substituting Equation 4.4 into Equation 4.2 yields

$$
\dot{m} c_{p, f l u i d}\left(T_{f}-T_{i n, x}\right)=A^{\prime} F^{\prime}\left[S-U_{L}\left(T_{f}-T_{a}\right)-U_{L / T}\left(T_{f}-T_{a}\right)\left|\left(T_{f}-T_{a}\right)\right|\right]
$$

Equation 4.5 is a steady-state expression. To account for transience, a thermal capacitance term can be added to the left-hand side of Equation 4.5.

$$
\begin{aligned}
& C_{c o l l, d x} \frac{d T_{f}}{d t}+\dot{m} c_{p, f l u i d}\left(T_{f}-T_{i n, x}\right)= \\
& A^{\prime} F^{\prime}\left[S-U_{L}\left(T_{f}-T_{a}\right)-U_{L / T}\left(T_{f}-T_{a}\right)\left|\left(T_{f}-T_{a}\right)\right|\right]
\end{aligned}
$$

where $C_{\text {coll }, x}$ is the combined thermal capacitance of the fluid and collector for differential area $A^{\prime}[\mathrm{J} / \mathrm{K}]$.

Type 539 used a one-dimensional model, considering the collector as a series of isothermal nodes [109]. This discretization scheme is illustrated in Figure 4.5. The governing differential equation for node $j$ may be cast using Equation 4.6 as [109]

$$
\begin{aligned}
& C_{\text {coll }, j} \frac{d T_{j}}{d t}+\dot{m} c_{p, \text { fluid }}\left(T_{j}-T_{j-1}\right)= \\
& A_{j} F^{\prime}\left[S-U_{L}\left(T_{j}-T_{a}\right)-U_{L / T}\left(T_{j}-T_{a}\right)\left|\left(T_{j}-T_{a}\right)\right|\right]
\end{aligned}
$$

$T_{j-1}$ is the inlet fluid temperature to node $j$ which was sent from adjacent node $j-1$. This differential equation was then solved analytically to determine $T_{j}$ for the current timestep. For details on this solution, the interested reader is directed to TESS [109]. 


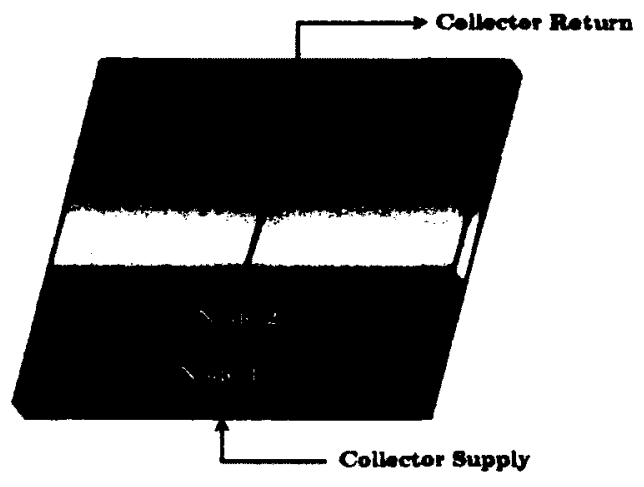

Figure 4.5: One-dimensional discretization of a solar thermal collector

In addition to providing the thermal capacitance of the collector, Type 539 required standard thermal performance input to determine collector characteristics such as $F^{\prime}$ and $U_{L}$. Commonly available test data for solar thermal collectors are the thermal efficiency curves. Duffie and Beckman [11] give the instantaneous thermal efficiency as

$$
\eta_{i}=F_{R}(\tau \alpha)_{n}-a \frac{\left(T_{i n}-T_{a}\right)}{G_{T}}-b \frac{\left(T_{i n}-T_{a}\right)^{2}}{G_{T}}
$$

where $G_{T}$ is the total solar radiation incident on the collector $\left[\mathrm{W} / \mathrm{m}^{2}\right]$ and $F_{R}$ is the unitless heat removal factor. Duffie and Beckman [11] describe this factor as being equivalent to the effectiveness of a heat exchanger, representing the ratio of actual heat transfer to the maximum possible transfer. The transmittance-absorptance product for normal incident radiation, $(\tau \alpha)_{n}$, is also a unitless property of the collector related to how normal incident solar radiation in transmitted and absorbed by the collector absorber plate. For further details on these factors, the interested reader is directed to Duffie and Beckman [11].

The coefficents $a$ and $b$ are experimentally determined and have the units of $\left[\mathrm{W} / \mathrm{m}^{2} \mathrm{~K}\right]$ and $\left[\mathrm{W} / \mathrm{m}^{2} \mathrm{~K}^{2}\right]$ respectively. Equation 4.8 is defined in terms of the difference between the collector inlet temperature, $T_{i n}$, and the ambient temperature, $T_{a}$. Duffie and Beckman [11] noted that the form of Equation 4.8 is typical for North America. In Europe, Equation 4.8 is usually in terms of the difference between the average collector temperature and ambient, resulting in different $a$ and $b$ coefficients.

The user was required to input $F_{R}(\tau \alpha)_{n}, a$, and $b$ for the collector being considered into Type 539 as well as the incidence angle modifiers (IAMs). The IAMs are unitless correction factors for $(\tau \alpha)_{n}$ for off-normal incident solar radiation on the collector [11]. 
Relationships between test and operating conditions were used to determine the $F^{\prime}$, $U_{L}$ and $U_{L / T}$ parameters in Equation 4.7. The transformation between test and collector operating conditions is not described here for clarity, and the interested reader is directed to Duffie and Beckman [11] and TESS [109] for further details.

\subsubsection{Stratified Storage Tank}

There are several storage tank models available in the TRNSYS standard and extended libraries. Allard et al. [110] performed experimental validation on five different TRNSYS storage tank models: Types 4, 38, 60, 340, and 534. Data from an experimental setup using a $270 \mathrm{~L}$ commercially available hot water tank equipped with two electric heating elements was used for the validation. Allard et al. [110] performed two experiments, a water draw test from the tank and tank charging with the electric heating elements. It was found that when these experiments were replicated in TRNSYS, tank models Type 534 and Type 340 gave results with the highest accuracy. Both of these were multinode models. Type 38 was a plug-flow model and it was found that the variable number of volume segments represented in the tank was never sufficient to capture the stratification [110]. Type 4 was a multinode model, but did not have the capability to consider de-stratification. For Type 60, Allard et al. [110] stated that results were significantly effected my numerical errors.

For this research, the stratified tank model Type 534 from TESS was used. This is a one-dimensional multinode model that assumed a vertical, cylindrical tank divided into a user defined $N$ number of equal sized nodes. The nodal discretization scheme for this model is shown in Figure 4.6.

Each node represented an isothermal control volume within the tank. During each simulation timestep, an energy balance was performed formed for each node in the tank. Mass could transfer into and out of adjacent nodes, or through tank inlet or outlet ports. Heat could transfer between adjacent nodes by conduction or could be lost to the environment. These losses were determined by a user-specified U-value that was defined for each node. The energy balance for arbitrary tank node $i$ is illustrated in Figure 4.7.

Since this was a 1-D model, an approximation was used to represent vertical heat conduction along the tank wall. Newton [57] defined an additional conductivity, $\Delta k$, 


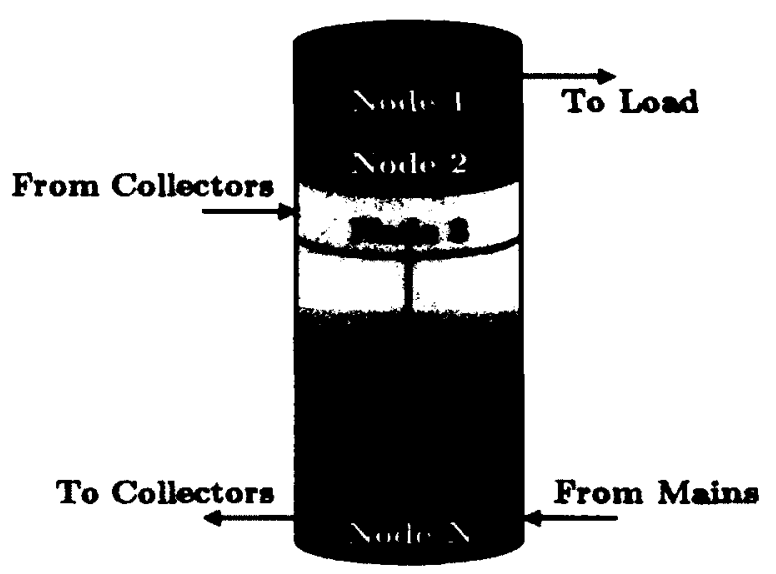

Figure 4.6: 1-D discretization of a stratified tank

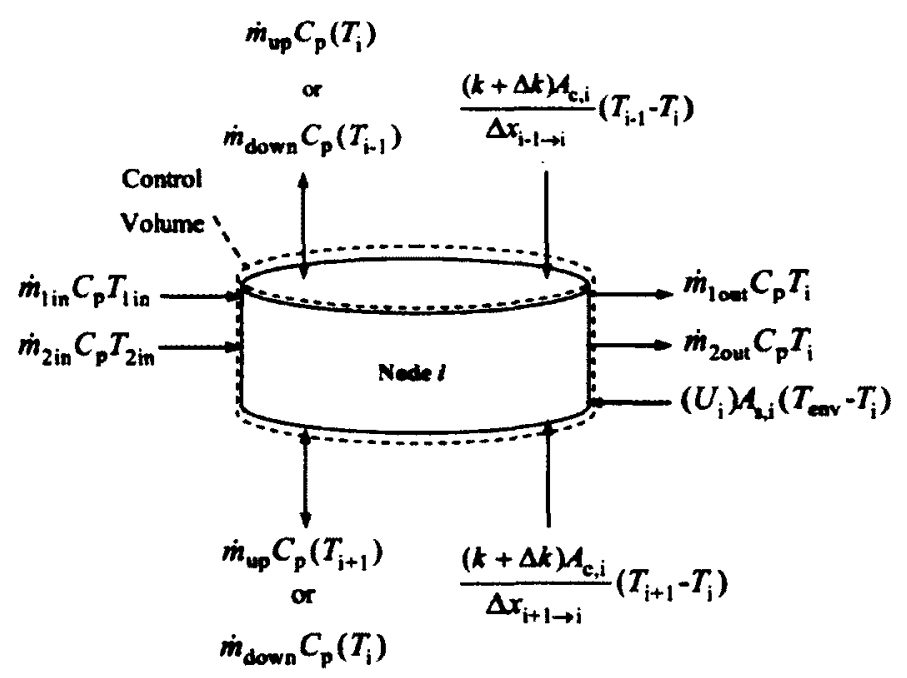

Figure 4.7: Control volume for tank node $i$, reproduced with permission from Cruickshank [10]

shown in Figure 4.7. It was recommended that $\Delta k$ be determined experimentally. If no data was available, an approximation of $\Delta k$ was suggested by Newton [57] using the tank wall conductivity, $k_{\text {wall }}$, multiplied by the ratio of the cross-sectional area of the tank wall, $A_{c, w a l l}$, to the cross-sectional area of the tank fluid, $A_{c}$. This can be expressed mathematically as

$$
\Delta k=k_{w a l l} \frac{A_{c, \text { wall }}}{A_{c}}
$$

Cruickshank [10] tested this approximation with commercial domestic hot water tanks 
and found it to be suitable. She also noted that Equation 4.9 relied on a few assumptions:

- the wall and fluid of each node is at the same temperature;

- the conductivity of the wall is uniform and constant for each node over the timestep; and

- the radius of the tank is much greater than the thickness of the wall.

Detailed discussion of the multinode stratified tank model was omitted for clarity. The solution methods used for TRNSYS tank models are well documented and the interested reader is directed to Newton [57], Cruickshank [10] and TESS [111] for additional information.

\subsection{Linking ESP-r and TRNSYS}

Section 4.1 introduced the concept of co simulation to link two or more complimentary simulation tools at run time. This section introduces the Harmonizer, the middleware tool used to perform co-simulations between ESP $-\mathrm{r}$ and TRNSYS. This software acted as a mediator between the two simulation tools, controlling the passing of data between them. Beausoleil-Morrison et al. [100] noted that the advantage of an additional mediator software was the localization of the co-simulation behaviour. The algorithms for passing data and checking for solution convergence between $\mathrm{ESP}-\mathrm{r}$ and TRNSYS did not have to be written into the existing software, but was contained in the Harmonizer.

While ESP-r could be compiled to run on a variety of operating systems (OS), TRNSYS was only available for the Windows OS. Thus, the Harmonizer was developed to run in the Windows environment. Both TRNSYS, ESP-r, and the Harmonizer were compiled as shared libraries, known as dynamic-link libraries (DLL) in Windows [100]. At the beginning of a co-simulation, the Harmonizer executable was invoked which loaded the DLLs. Each DLL then had access to subroutines contained in the other libraries.

New components needed to be introduced in both ESP $-\mathrm{r}$ and TRNSYS to facilitate the transfer of data between ESP $-\mathrm{r}$ and TRNYS. In ESP $r$, four new components were added to the plant database: hydronic sending and receiving coupling components (HCC), and air sending and receiving components (ACC) [100]. The coupling 
components were specified in an ESP-r explicit plant network and linked to other components to be represented in ESP-r. The user selected which components were represented in ESP $-\mathbf{r}$ and which were represented in TRNSYS. Figure 4.8 illustrates two different ways a simple plant system could be represented in a co-simulation project.

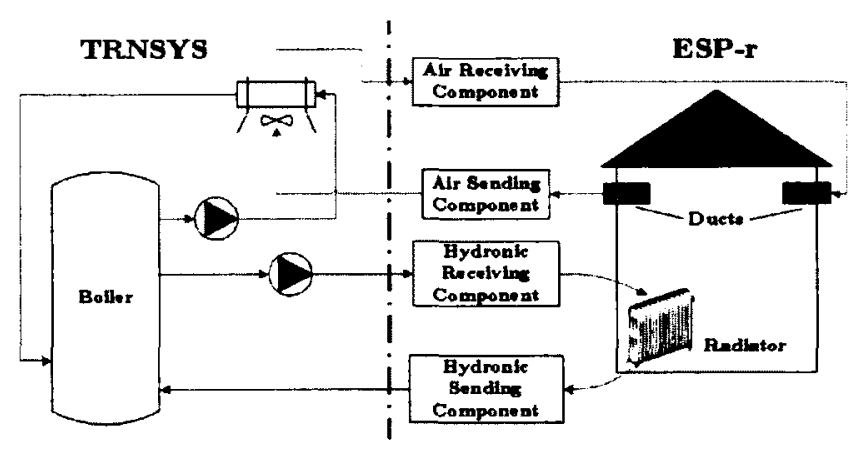

(a) Majority of plant in TRNSYS

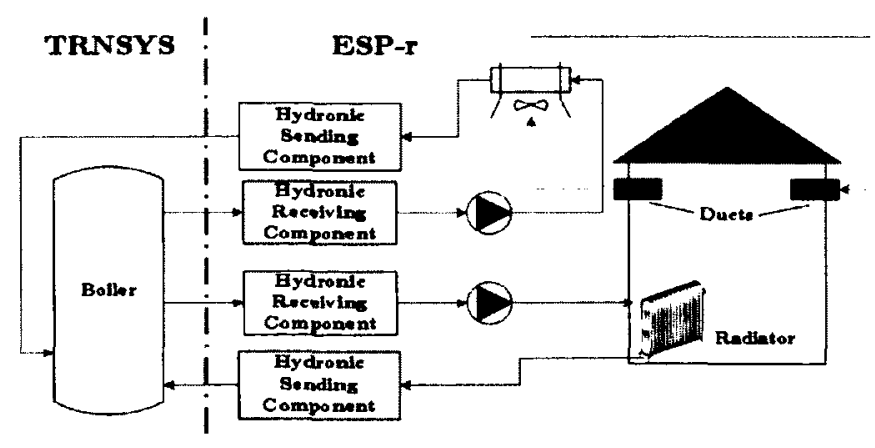

(b) Majority of plant in ESP-r

Figure 4.8: Illustration of different co-simulation techniques for modelling of a simple plant

A new component called Type 130 was created to manage the sending and receiving of data in TRNSYS. Only one instance of Type 130 was required for a TRNSYS co-simulation project. In Type 130's parameters, the user specified the number of HCCs and ACCs that were defined in the corresponding ESP-r plant network. The outputs of TRNSYS components to be sent to ESP $-\mathrm{r}$ were linked to the appropriate Type 130 inputs. Data sent from ESP $-r$ to TRNSYS were set as Type 130 outputs and connected to the appropriate TRNSYS component inputs.

Additionally, Beausoleil-Morrison et al. [100] described a new subroutine that was written into ESP-r to send the air point temperatures of all defined thermal zones to Type 130 in TRNSYS. This allowed for control of plant components in TRNSYS based on a sensed zone temperature. The subroutine also allowed for ESP-r thermal zones to receive heat gains from TRNSYS. This allowed, for example, the passing of heat losses of a tank modelled in TRNSYS to the air of a basement zone in ESP $r$.

In order to perform a co-simulation, the user needed to define an input file which provided paths to the Harmonizer, ESP-r, and TRNSYS DLLs. The locations of the ESP-r configuration file and the TRNSYS deck file also needed to be specified. An example of a harmonizer input file used in the research is provided in Appendix $D$. 
Both the ESP $-\mathrm{r}$ and TRNSYS projects to be co-simulated required an equal number of timesteps per hour as well as identical simulation start and stop days. Once a co-simulation was invoked, the Harmonizer took overall control of the simulation. ESP $\mathrm{r}$ is permitted to solve its plant network and then pass data to the Harmonizer. The Harmonizer then passes the data to Type 130 in TRNSYS, where the methods described in Section 4.2 were used to solve the system. Prior to marching forward in time, the Harmonizer interrogates the data that had been exchanged between ESP $\mathbf{r}$ and TRNSYS and determines if convergence has been met. If the convergence criteria had not been satisfied, the Harmonizer invokes the simulators again at the same timestep with the latest data. Once the Harmonizer has determined that convergence had been reached, both ESP-r and TRNSYS were permitted to march forward in time. For further information on the Harmonizer, the interested reader is directed to Beausoleil-Morrison et al. [100]

Wills et al. [112] compared simulation results of a simplified hydronic floor heating system modelled in ESP - $r$ and with the Harmonizer. For co-simulation, the hydronic floor was represented in the ESP-r plant network and supplied with a hot water stream from TRNSYS. The controls for the heating system were contained entirely within TRNSYS. It was found that there was no significant differences between the ESP-r only and co-simulation results, demonstrating the functionality of the Harmonizer. Beausoleil-Morrison et al. [100] also demonstrated the use of co-simulation with the Harmonizer by successfully modelling a complex solar thermal and photovoltaic system that supplied hot water, space heating, and electricity to a detached residential building.

\subsection{Closing Remarks}

The current and previous chapters introduced the simulation tools ESP-r and TRNSYS. ESP-r was identified as a robust tool for building physics modelling which employed a finite-difference control volume method to treat heat and mass transfer. The facilities for modelling plant and HVAC systems were also briefly discussed. The modelling of plant systems in ESP-r was non-trivial and the addition of new and innovative components required extensive knowledge of the software source code. TRNSYS was identified as a flexible tool for the representation of plant and HVAC systems which complimented the weaknesses of ESP-r's plant modelling. TRNSYS 
was orginally designed for the analysis of solar thermal systems and had expanded to include several component models for HVAC components. The structure of the software also allowed for new components to be integrated into the software with relative ease. With the use of the Harmonizer co-simulation tool, the strengths of both tools could be exploited to model the coupled interactions of a building envelope and plant system.

In the following chapters, the building envelope and SSTS models are introduced. The C-RISE house was developed in ESP-r and is described in Chapter 5 . Chapter 6 then provides a description of the seasonal solar thermal system layout considered in the research and its implementation into TRNSYS. Chapter 6 then concludes with a description of the strategy used to perform co-simulation with both the ESP $-\mathrm{r}$ and TRNSYS simulation tools. 


\section{Chapter 5}

\section{Modelling of Building Physics and Hydronic Floor Heating for the C-RISE House}

The C-RISE house project at Carleton University was introduced in Chapter 1. This building was intended to be a test facility for new and innovative technologies in the residential building sector. A single family detached house (SFDH) dwelling type design was used to be representative of the majority of residential building stock. Initially, the C-RISE house was based on architectural plans from a local contractor [21]. These plans formed the basis of the building model that was created in ESP $\mathrm{r}$ for this research. Recently however, the C-RISE layout had been redesigned based on consultation with project members. Nonetheless, both designs were to adhere to the $2012 \mathrm{R}-2000$ building standard [22] and were anticipated to have comparable size and heating loads.

One aspect of the C-RISE house project mentioned in Chapter 1 was the investigation of a SSTS for use at a single house scale. The goal of this research was to analyse the solar thermal system using the detailed simulation software described in Chapters 3 and 4 . In this chapter, the C-RISE building envelope model created in ESP- $r$ for use in this research is described. This model was created to simulate the dynamic, coupled interaction of the building with the solar thermal system modelled in TRNSYS. Thermal energy was transferred to the building envelope by a radiant hydronic floor system, modelled in the ESP-r explicit plant facility discussed in Section 5.4. The strategy used to link the ESP-r plant to TRNSYS is then described in Chapter 6. 


\subsection{Building Geometry}

Figure 5.1 shows the ESP $-\mathrm{r}$ wireframe and Google Sketchup [113] surface rendered representations of the C-RISE house. The Google Sketchup model was created for illustration purposes only. The house was two storeys with a basement, attached garage and an attic. The rear of the house was positioned to face due south to take advantage of the large glazing distribution on that façade. The south façade had a window-to-wall ratio of $35 \%$ compared to the $28 \%$ distribution on the north façade. There was no glazing on the east and west façades. The large window distribution on the south façade was meant to promote increased solar gains or insolation, to reduce heating loads during the winter.
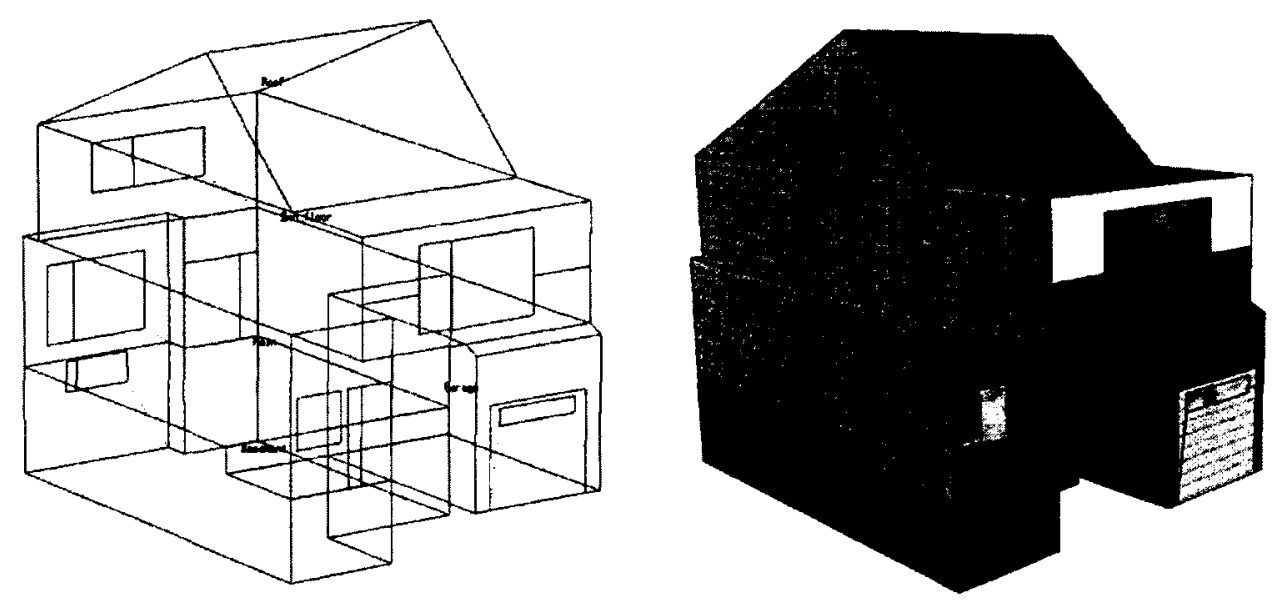

Figure 5.1: Wireframe and rendered C-RISE building model

Space heating in the C-RISE house was supplied to both the first (main) and second floors, representing a heated floor area and heated volume of $125.7 \mathrm{~m}^{2}$ and $330 \mathrm{~m}^{3}$ respectively. This heated floor area could be considered typical for a residential dwelling. The 2007 Survey of Household Energy Use [114] indicated that the majority of residential dwellings in Ontario had a heated floor area between 93 and $139 \mathrm{~m}^{2}$.

For modelling in ESP-r, the C-RISE house needed to be discretized into thermal zones (introduced in Chapter 3). For this research, the primary goal of the ESP-r model was to simulate accurate overall building heating loads. Variation of temperatures between individual rooms or distribution of daylighting within the envelope was less critical and allowed for lumping of rooms into single thermal zones. In the final C-RISE house model, 5 zones were defined: main floor, second floor, basement, garage 
and attic. Typically, the occupied spaces of a SFDH are considered to be thermally similar and are modelled as a single zone, for example the work of Pietila [115] or Kopf [90]. In the C-RISE house however, heating was to be supplied to the occupied spaces via a hydronic in-floor heating system. This required explicit representation of the floor surfaces in ESP-r. To address this deviation from standard practice, a sufficiently high air exchange between the main and second floors was specified so that the zone air nodes were essentially well mixed.

Exterior windows (or glazing) was modelled using a technique introduced by Swan [116]. This modelling technique involved lumping glazing into one surface on each building face and to represent the framing material as an adjacent surface. This transformation is illustrated in Figure 5.2. Purdy and Beausoleil-Morrison [117] performed a sensitivity analysis between explicit and simplified geometric representation of façade glazing on a SFDH. They found that when the glazing in the model was altered from an accurate geometric representation to a lumped surface of equal area on each façade, there was little sensitivity to annual heating loads.

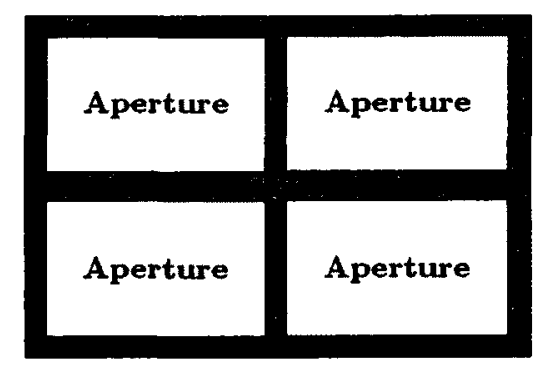

(a) Realisitic

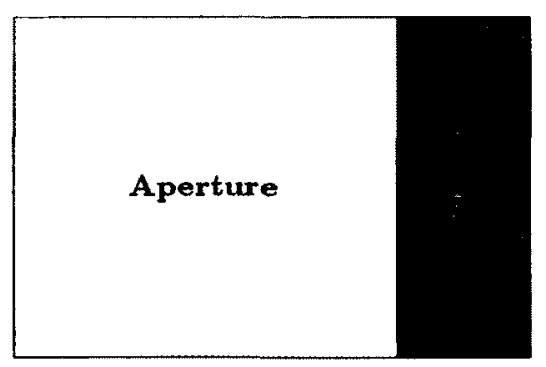

(b) Simplified

Figure 5.2: Different representations of glazing and framing, adapted from Swan $[116]$

\subsection{Building Materials and Constructions}

Wall construction specifications were provided by the contractor [118]. The construction configurations and levels of insulation were selected by the contractor as part of the company's strategy to comply with the $2012 \mathrm{R}-2000$ standard [22]. The north and south façades (front and back) were modelled with brick cladding, and the east and west façades with aluminium siding. These wall assemblies had total RSI-values of 4.7 and $4.9 \mathrm{~m}^{2} \mathrm{~K} / \mathrm{W}$ respectively. This cladding distribution may be seen in the 
rendered model in Figure 5.1. The cross-sections of the external walls are illustrated in Figure 5.3. Each exterior wall had R6 expanded polystyrene (EPS) outboard of the sheathing and R22 fibreglass batting inboard.

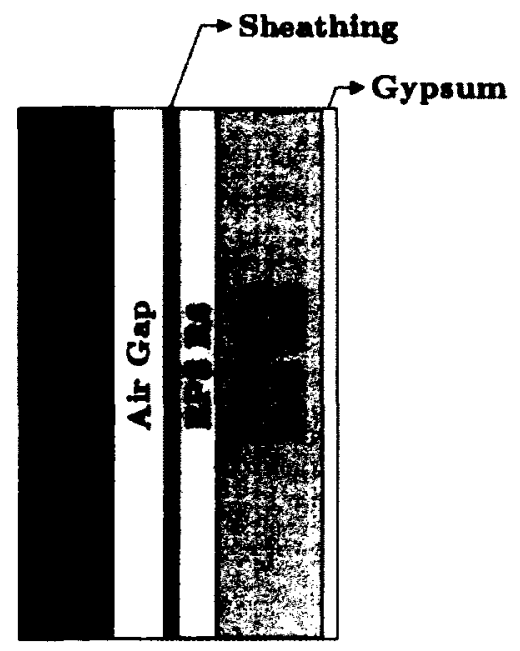

(a) Brick

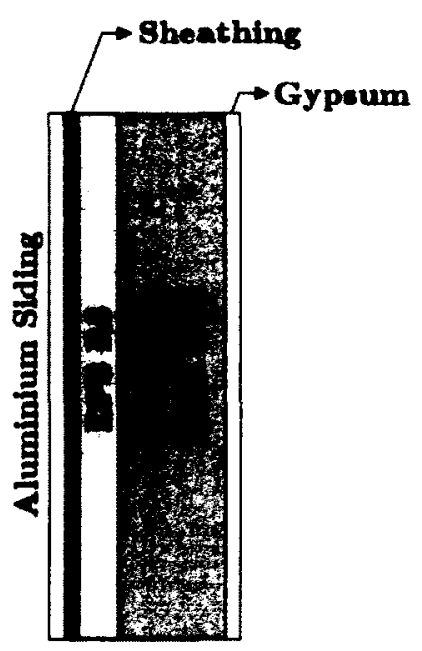

(b) Aluminium Siding

Figure 5.3: C-RISE exterior wall cross-sections

Not represented in Figure 5.3 is the 2 by 6 wood framing in the fibreglass layer. In the contractor's specifications the wood studs were spaced 24 inches on-centre (O.C.). The presence of these studs in the insulation layer were expected to create "thermal bridging" through the wall due to the stud's relatively high conductivity compared to the fibreglass insulation. Explicit treatment of thermal bridging in ESP- $r$ is non-trivial due to the software's one-dimensional treatment of heat transfer through surfaces. To account for the presence of framing, the parallel path method for heat conduction was used. This method is suitable for building enclosures that use framing with relatively low conductivity like wood [94, 119]. The percentage of total wall area to framing was assumed to be $22 \%$, based on values given in ASHRAE standard 90.1-2010 [120] for 24 inch O.C. framing. An "effective" wall assembly thermal resistance was determined for each exterior wall and the thickness of insulation layers in ESP-r were adjusted to satisfy the new thermal resistance value. For more information on the parallel path method, the interested reader is directed to ASHRAE Fundamentals [94] or Straube and Burnett [119]. 
Windows for the C-RISE house were modelled as generic triple glazed doublelow $\mathrm{e}^{1}$ argon fill. This glazing system was selected due to uncertainty in the contrctor's final choice for glazing. The ENERGY STAR ${ }^{\circledR}$ requirements for glazing in Ottawa (Climate Zone B) is a maximum $U$ value of $1.60 \mathrm{~W} / \mathrm{m}^{2} \mathrm{~K}$ [121]. R-2000 minimum requirements for glazing are double glazed with low $\mathrm{e}$ coating and inert gas fill [22]. The triple-glaze system was modelled with a centre-of-glass U-value of $0.87 \mathrm{~W} / \mathrm{m}^{2} \mathrm{~K}$ to exceed minimum requirements and a solar heat gain coefficient (SHGC) of $0.56^{2}$. The rear façade contained a sliding patio door which was modelled as a double-glazed single-low-e argon fill window with a centre-of-glass U-value of $1.61 \mathrm{~W} / \mathrm{m}^{2} \mathrm{~K}$ and SHGC of 0.65 . All glazing surfaces, except those in the garage, were modelled using ESP-r's complex fenestration construction (CFC) facility. The garage glazing used the ESP-r standard transparent materials construction (TMC) facility. Discussion of CFCs is beyond the scope of this work and the interested reader is directed to Lomanowski [91] for further details.

There were several other surfaces modelled in the C-RISE house with different construction layers and properties. These surfaces were not discussed here for clarity, however detailed information on the constructions used may be found in Appendix C.

\subsection{Building Air Flow}

In Section 3.3, different pathways for air flow in building envelopes was briefly discussed. This section presents the specific treatment and assumptions of air flow in the C-RISE model. Swan [116] noted that while building zone envelopes have a primary influence on space heating and cooling, heat transport by air flow can also have a significant impact. In the study by Purdy and Beausoleil-Morrison [123], they found that when the airtightness rating of a single-family home was increased from 1.5 to 3.0 air changes per hour (ACH), the heating load increased by $27 \%$. This sensitivity to house thermal loads warranted careful consideration of building air flow.

Figure 5.4 provides an illustration of the different flow paths that were considered in the C-RISE model. Occupied thermal zones were significant in determining space heating loads and detailed models were used to determine their air flow. The garage

\footnotetext{
${ }^{1}$ low-emissivity

${ }^{2}$ SHGC determined from the WINDOW 6.3 tool from the Lawrence Berkeley National Laboratory [122]
} 
and attic zones were considered to be buffer zones between ambient and conditioned spaces. They were assumed to have minor influence on heating loads and infiltration into these zones was modelled using simplified methods.

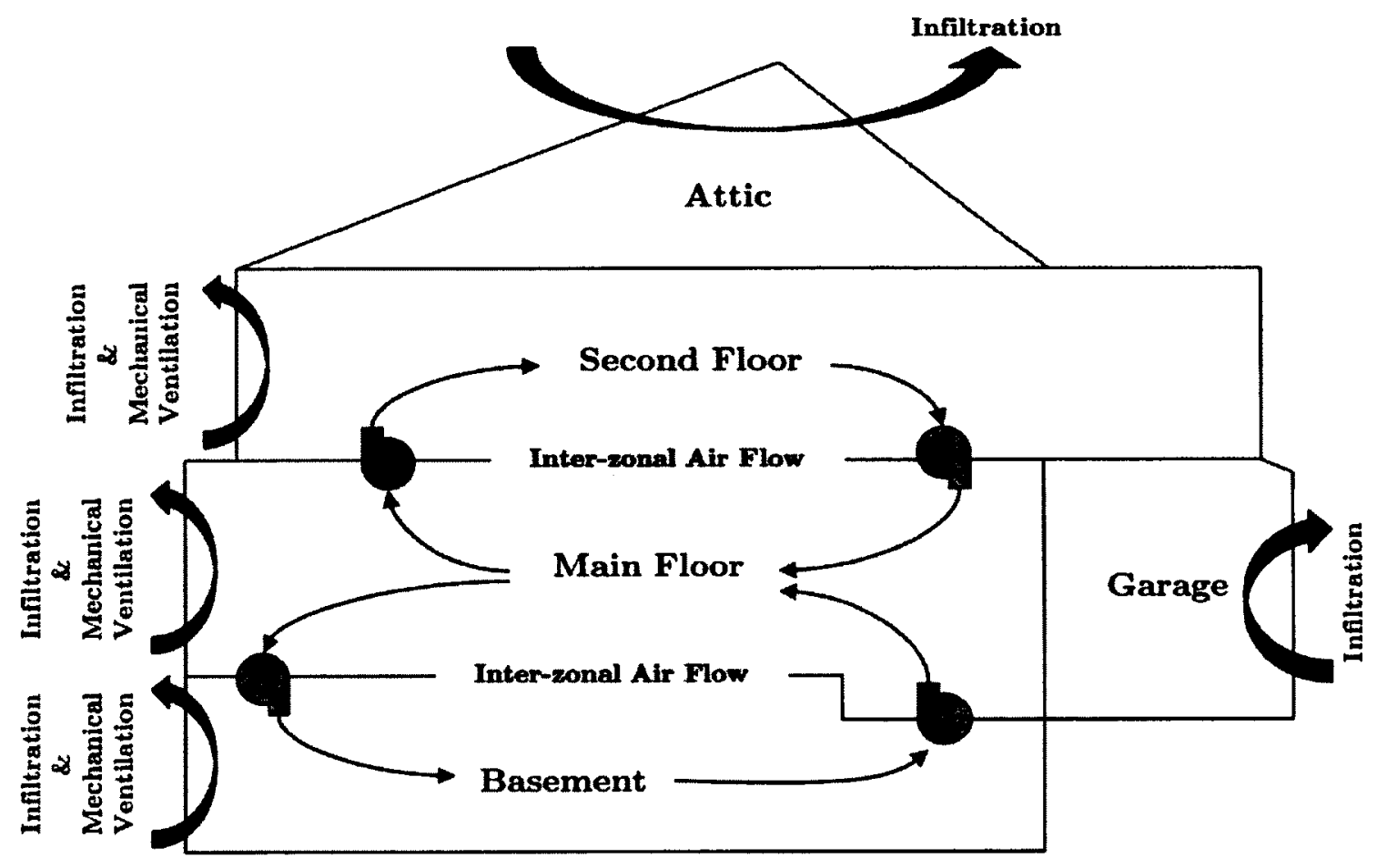

Figure 5.4: Air flowpaths in the C-RISE building model

\subsubsection{Infiltration}

Infiltration into the C-RISE house was modelled using the AIM-2 model introduced in Section 3.3.3. This model was selected due to its accurate treatment of infiltration compared to other methods [99]. Since the C-RISE house did not yet exist, there were no existing empirical data to input into the model. For this work, the AIM-2 default setting of "energy tight rating" was used which corresponded to $1.5 \mathrm{ACH}$ at $50 \mathrm{~Pa}$ depressurization. The AIM-2 input file into ESP-r may be found in Appendix D.

The AIM-2 model was intended only for modelling infiltration in occupied spaces. For the C-RISE house, the basement was assumed to be semi-occupied and received 
infiltration from the AIM-2 model. The ESP-r implementation of AIM-2 also controlled infiltration to the attic space, specifying a constant infiltration of $0.5 \mathrm{ACH}$. The garage zone fell outside of the modelling capabilites of AIM-2 and was specified a constant infiltration of $0.5 \mathrm{ACH}$. Modelled infiltrations are summarized in Table 5.1.

Table 5.1: C-RISE air infiltration

\begin{tabular}{|l|c|c|}
\hline Zone & Model & Air Leakage \\
\hline \hline Main floor & AIM-2 & "Energy tight" \\
\hline Second floor & AIM-2 & "Energy tight" \\
\hline Basement & AIM-2 & "Energy tight" \\
\hline Attic & AIM-2 & $0.5 \mathrm{ACH}$ \\
\hline Garage & Constant & $0.5 \mathrm{ACH}$ \\
\hline
\end{tabular}

\subsubsection{Ventilation}

Ventilation air was passed to both occupied zones as well as the basement. Based on calculations from the 2010 Ontario Building Code [124], the minimum capacity of the entire ventilation system needed to be $55 \mathrm{~L} / \mathrm{s}$.

A heat recovery ventilator (HRV) was modelled in ESP $-\mathrm{r}$ to provide building ventilation to the C-RISE house. An HRV is a type of heat exchanger device that pre-conditions incoming fresh air using building exhaust air. The high efficiency Lifebreath ${ }^{\circledR} 195$ DCS [125] HRV was selected for the C-RISE model. This unit had an effectiveness of $92 \%$ at $0^{\circ} \mathrm{C}$ and a rated flow rate of $55 \mathrm{~L} / \mathrm{s}$.

\subsubsection{Inter-zonal Air Exchange}

Swan [116] accounted for inter-zonal air exchange in occupied spaces by constructing an air flow network which set fixed mass flow rates between zones. Since there was no information on internal partitions for the C-RISE house, this method was used as an approximation. In Section 5.1 it was pointed out that typically the occupied space of a SFDH model is represented as a single zone. The minimum flow rate to achieve well-mixed zones was $0.55 \mathrm{~kg} / \mathrm{s}$, determined from performing a sensitivity analysis 
shown in Appendix A. The same sensitivity technique was repeated for the exchange between the basement and main floor and a final mass flow rate of $0.35 \mathrm{~kg} / \mathrm{s}$ was used.

\subsection{Hydronic Heating Floor}

Mentioned previously, a hydronic radiant floor system was used to supply space heating to the C-RISE house on the main and second floors. This heating system used embedded pipes to circulate a heat-transfer fluid within a hydronic radiant floor to deliver heating to building occupants. The use of a fluid-based system allowed for direct circulation of the thermal energy storage medium which would reduce heat transfer losses between the storage and the load. Compared to a convection based system, such as a fan-coil heat exchanger, Watson and Chapman [126] stated that a radiant system is expected to use 12 to $18 \%$ less energy while providing equivalent comfort. Additionally, the low supply temperatures required by a hydronic system were well matched to the typical operating temperature range of solar flat-plate collectors which were to be used by the C-RISE seasonal solar thermal system.

Modelling of the hydronic floor was carried out in the ESP-r plant domain using a plant component developed by Laouadi [127]. This component used a semi-analytical approach to model the heat transfer from serpentine piping embedded in a floor. Originally, the model was only capable of representing slab-on-grade systems. For this study, a model source code modification proposed by Manzan [128] was implemented to enable representation of hydronic thin-slab systems on subfloors. Details of this modification as well as information on the component solution method may be found in Appendix E.

The hydronic floors on the first and sccond floors in the C-RISE house were the only plant elements that were represented in ESP-r. Both floors were supplied with hot water streams from TRNSYS via the Harmonizer. The return fluids from the floors were then sent back to TRNSYS. All control systems for the hydronic floors were also modelled in TRNSYS. Details of the space heating loop and controls are presented in Section 6.2. 


\subsubsection{Hydronic Floor Design}

Design of the hydronic floor system was accomplished using manufacturer literature [129-131] and ASHRAE's 2008 HVAC Systems and Equipment Handbook [132]. Figure 5.5 illustrates the poured gypsum thin slab system that was selected and modelled for the C-RISE house.

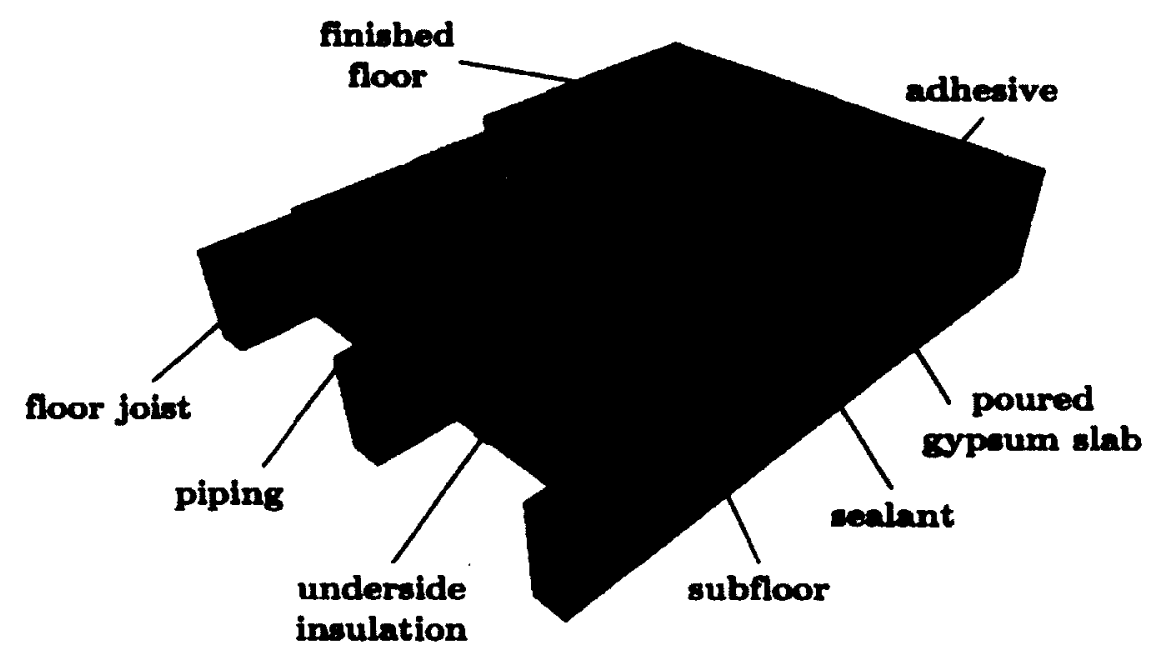

Figure 5.5: Poured gypsum thin slab system, adapted from [129]

A typical slab thickness of $31.75 \mathrm{~mm}$ was used [129] with an $8 \mathrm{~mm}$ concrete tile floor covering. From manufacturer recommendations [131], underside insulation for the main floor was R19, since the basement space beneath was considered unheated, even though the space received heat indirectly from air exchange with the main floor zone. Underside insulation for the second floor was set to R11 [131]. Fluid was circulated in the floor using cross-linked polyethylene (PEX) tubing with a nominal tube diameter of $12 \mathrm{~mm}$. For this work, the thermal bridging of the the floor joists was neglected.

An annual simulation was run using ideal zone heating controls to establish the maximum heating power required by the main and second floor zones. A basic OnOff controller was used with a setpoint of $22^{\circ} \mathrm{C}$ and an infinite heating capacity. Maximum heating power required for the main and second floors was 3.7 and $2.9 \mathrm{~kW}$ respectively. The floor areas in the C-RISE model to function as the active hydronic floors were 46 and $50 \mathrm{~m}^{2}$ on the main and second floors, thus the maximum heating flux of the floor, $\dot{Q}_{f l o o r}^{\prime \prime}$ needed to be approximately 80 and $56 \mathrm{~W} / \mathrm{m}^{2}$ respectively. 
Once the maximum heating flux was determined, the pipe spacing, $M$ (shown in Figure 5.6), was determined using the panel design graph in ASHRAE's 2008 HVAC Systems and Equipment Handbook Chapter 6 [132]. The design temperature drop across the radiant floor was $10^{\circ} \mathrm{C}$ based on recommendation from ASHRAE [132] and Olesen [133].

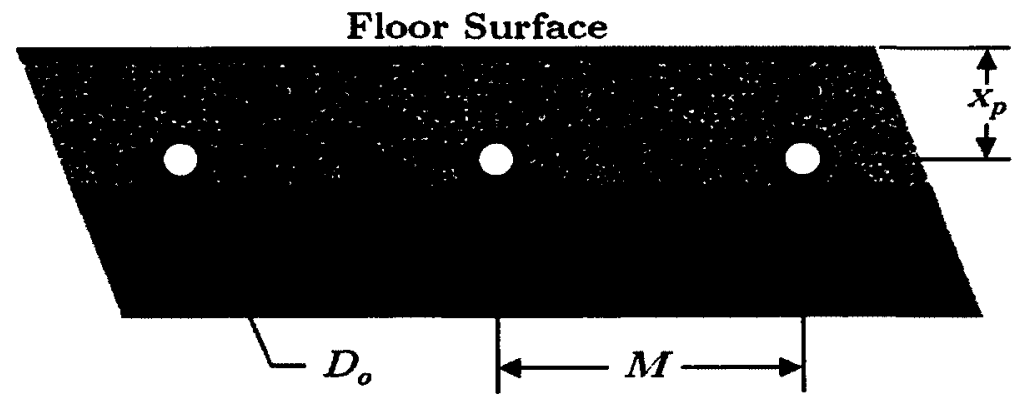

Figure 5.6: Hydronic floor cross-section

The design parameters determined from ASHRAE [132] formed a starting point of the hydronic floor design. Simulation in ESP-r was then used to make coarse adjustment to the floor configuration. The focus of this research was not to optimize hydronic floor operation. The final hydronic floor component parameters used in the C-RISE model is summarized in Table 5.2. The final design iteration divided each floor into four circuits. The model from Laouadi [127] allowed for representation of a hydronic floor system with inlet headers that divided flow evenly into equal length piping circuits. Figure 5.7 illustrates a single hydronic floor component that is divided into to circuits.

Table 5.2: Radiant floor parameters

\begin{tabular}{|l|c|c|}
\hline Radiant Floor Parameters & Main Floor & Second Floor \\
\hline \hline Number of Circuits & 4 & 4 \\
Length per Circuit [m] & 57.5 & 39.4 \\
Radiant Floor Area $\left[\mathrm{m}^{2}\right]$ & 46 & 31.5 \\
Pipe Spacing [m] & 0.2 & 0.2 \\
Nominal PEX Diameter [mm] & 12 & 12 \\
\hline
\end{tabular}




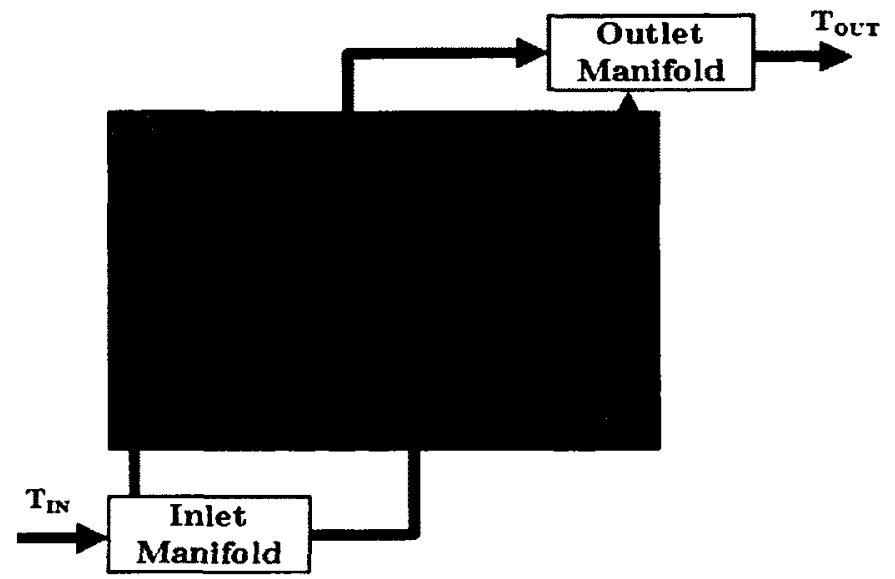

Figure 5.7: Single hydronic floor with two circuits

Information on the thermophysical properties of the floor materials and construction layout may be found in Appendix C.

\subsection{Boundary Conditions and Internal Gains}

Building site climate data are the primary boundary conditions of both the ESP $-\mathrm{r}$ and TRNSYS systems. For this work, the Canadian Weather year for Energy Calculation (CWEC) data for Ottawa, Ontario was used [134]. This is an hourly climate file that has been constructed by joining twelve typical meteorological months based on a minimum of 30 years of historical data. Ambient temperatures, relative humidity, wind speed and direction and solar radiation data were read into both ESP-r and TRNSYS at each timestep. When simulation timesteps were less than one hour, the climate data was linearly interpolated.

The other major load condition imposed on the C-RISE model was internal gains due to the presence of occupants. Running appliances, lights and other electronics and equipment within the building envelope eventually appear as a thermal gain within the space. Purdy and Beausoleil-Morrison [135] investigated the sensitivity of residential heating loads to internal gains. They found that when the internal gains were doubled, the annual heating load decreased by $9 \%$ and was considered to have a significant influence on simulation results.

Saldanha and Beausoleil-Morrison [136] measured the electricity draws of 12 Ottawa, Ontario homes at one minute intervals over a one year period. End-use specific 
data was also measured to determine what portion of each house's total consumption was due to specific appliances and HVAC equipment. The total non-HVAC energy consumption for the measured homes ranged between 9.5 and 39.5 GJ per year. For this research, a mid-level energy consumer of $19.6 \mathrm{GJ}$ per year was selected. This data was taken from a townhouse with 2 occupants and $120 \mathrm{~m}^{2}$ of floor area. The energy consumed by these appliances were ultimately rejected to the building zones as thermal gains. For C-RISE model, the non-HVAC internal gains were distributed between the main, second, and basement zones by a weighting of $60 \%, 20 \%$, and $15 \%$. The remaining $5 \%$ of the load was assumed to have been lost to ambient.

For the C-RISE house, 2 occupants were assumed. The latent and sensible load per person and occupancy schedule were based on the single zone model values provided in the "Building America House Simulation Protocols" [137]. The gains from the occupants was divided evenly between the main and second floors.

\subsubsection{BASESIMP}

Modelling of heat transfer between the basement of the C-RISE house and the ground was accomplished using the BASESIMP [138] algorithm. This is a regression-based algorithm developed from over 100,000 finite-element simulations using BASECALC under different foundation configurations $[138,139]$. The algorithm computes a heat loss for the foundation at each timestep and apportions those losses to foundation surfaces in the ESP-r model. The weighting of each flux apportioning is user-defined. For more details on BASESIMP, the interested reader is directed to BeausoleilMorrison and Mitalas [138].

The C-RISE foundation layout is shown in Figure 5.8. BASESIMP assumes a rectangular layout and requires the length and width as inputs. The C-RISE house basement had an irregular shape, and equations for equivalent length and width proposed by Beausoleil-Morrison (1998) were used (qtd. in Pietila [115], page 32). The equivalent dimensions are expressed as

$$
L=\frac{P_{b}}{4}+\frac{\sqrt{P^{2}-16 \cdot A}}{4} W=\frac{P_{b}}{4}-\frac{\sqrt{P^{2}-16 \cdot A}}{4}
$$

where $L$ is the basement length $[\mathrm{m}], W$ is the basement width $[\mathrm{m}], P_{b}$ is the basement perimeter $[\mathrm{m}]$ and $A$ is the floor area $\left[\mathrm{m}^{2}\right]$. The poured concrete of the foundation was assumed to be $20 \mathrm{~cm}$ with a thermal conductivity of $1.73 \mathrm{~W} / \mathrm{m} \mathrm{K}$. 


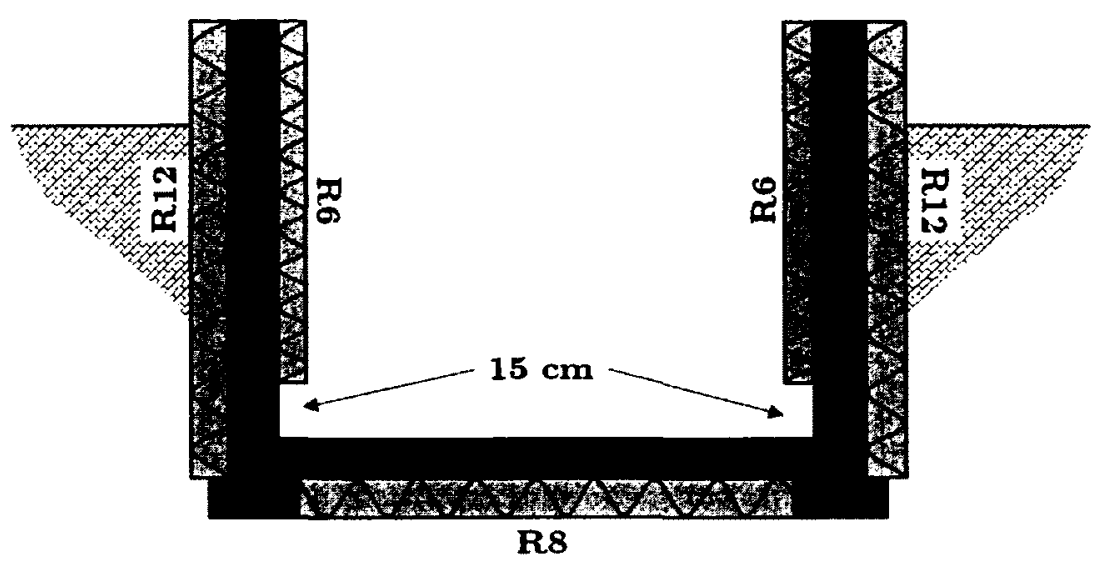

Figure 5.8: C-RISE Foundation Layout

The concrete slab of the garage floor was also modelled using BASESIMP. Both ESP-r BASESIMP input files for the basement and the garage may be found in Appendix D.

\subsection{Closing Remarks}

This chapter described the representation of the C-RISE house in the ESP $-\mathrm{r}$ simulation tool. A discussion was provided on the geometry defined in ESP-r and the composition of external wall constructions and glazing used in the building envelope. The treatment of infiltration and ventilation air was also established, as well as the internal gains of the building due to the assumed occupancy of two people. With the C-RISE house defined in ESP-r, preliminary simulation of the C-RISE allowed for insight into the building's space heating demands. In the next chapter, the seasonal solar thermal system developed in TRNSYS is discussed. The layout of the system is described as well as the assumptions and parameters used to model the individual plant components. Also introduced in the next chapter is the strategy that was used to facilitate co-simulation between the ESP-r and TRNSYS models. 


\section{Chapter 6}

\section{Modelling and Co-simulation of the Seasonal Solar Thermal System}

Once the C-RISE building envelope model was established in ESP-r, a seasonal solar thermal system (SSTS) model needed to be implemented in TRNSYS. This system was meant to operate as a solar combisystem, supplying both space heating and DHW to the building occupants. Weiss [8] stated that combisystems are inherently complex compared to solar DHW systems. The addition of space heating loads causes considerable variation for system thermal demands throughout the year [8], creating challenges for system design. While existing solar combisystems described in the literature were useful guides to design, different solar thermal applications typically contain unique thermal loads and local climate conditions. In general, system designs that perform well in one application or climate is not universally applicable to other applications.

Mentioned in Chapter 1, the objectives of this research was to design a solar thermal system for the C-RISE house based on "best practices" from the literature. Once a basic concept for the system was established, detailed simulation was used to analyse the sensitivity of key system parameters on annual performance. The parameters focused on in this study were seasonal storage volume and geometry, seasonal storage insulation levels, collector area, and collector orientation. Often in practice the "optimum" design parameters cannot be achieved due to physical or economic constraints and there was value in understanding the sensitivity of system performance to these design compromises.

Section 6.1 introduces the layout of the SSTS used in the study. The parameter and modelling assumptions for plant components in TRNSYS are described, as well 
as the parameter constraints which were imposed on the system. Finally, Section 6.2 discusses the control of the C-RISE hydronic slabs and the strategy for co-simulation between ESP-r and TRNSYS.

\subsection{Seasonal Solar Thermal System}

Figure 6.1 illustrates the layout of the seasonal solar thermal combisystem used for this research. Based on the recommendations from Sillman $[25,80]$, a dual-storage system that included both a diurnal and seasonal tank was selected. This was similar to the Irish Passive House system studied by Clarke et al. [77]. The diurnal tank only supplied DHW for the C-RISE house, while the seasonal storage tank connected directly to the hydronic floor heating systems located on the main and second floors of C-RISE. Each hydronic floor had its own independent space heating loop attached to individual inlet and outlet ports on the seasonal tank. This is represented in Figure 6.1 by the " $x 2$ " on the space heating loop.

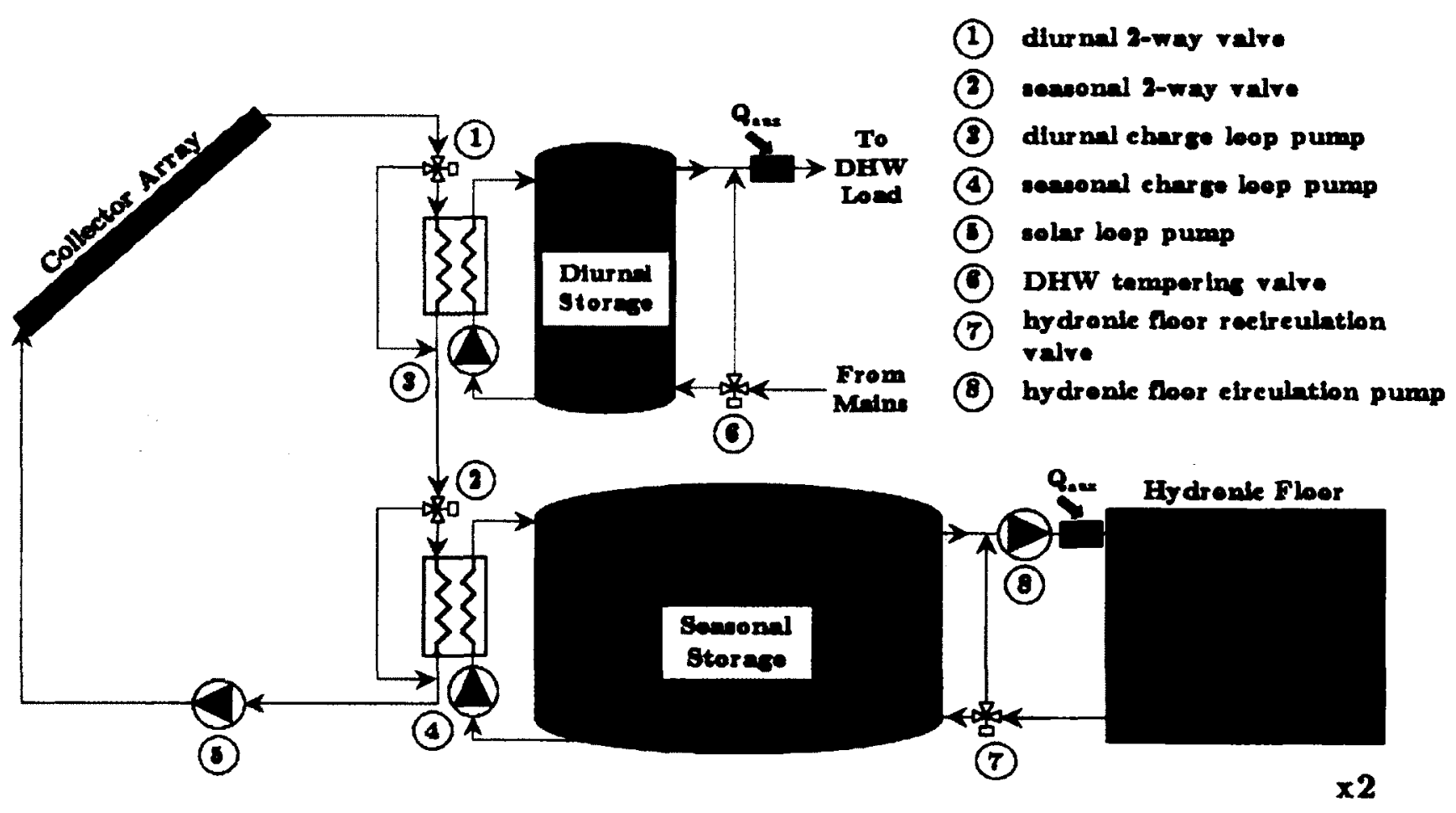

Figure 6.1: Seasonal solar thermal system considered in the research 
In Chapter 1, it was noted that the majority of North American solar thermal systems were indirect systems. This type of system was adopted for the C-RISE system in order to provide freeze protection for the collectors in Ottawa's cold climate. An anti-freeze fluid composed of a 50/50 percent propylene glycol-water mixture by volume was used as the heat transfer fluid in the collector loop. The modelled thermal properties of the anti freeze mixture were taken from a propylene glycol supplier [140]. For this work, the 50/50 propylene glycol-water mixture specific heat and density was taken at $60^{\circ} \mathrm{C}$ and were equal to $3.70 \mathrm{~kJ} / \mathrm{kg} \mathrm{K}$ and $1.02 \mathrm{~kg} / \mathrm{m}^{3}$ respectively. This assumption was required since several of the TRNSYS components used could only accept static thermophysical properties.

\subsubsection{Thermal Management Strategy}

The thermal management of the SSTS is shown in Figure 6.1. The design was based on a "temperature level" concept, similar to the approach used in the Irish passive house project described in Clarke et al. [77]. For the C-RISE solar thermal system, two temperature levels were specified, referred to as Level 1 and Level 2 . Level 1 was "high" temperature and priority, and was associated with the diurnal tank. The relatively small size of the diurnal tank lead to a greater amount of charge-discharge cycling compared to the seasonal tank. Also, the diurnal tanks needed to be heated to $65^{\circ} \mathrm{C}$ as frequently as possible to prevent legionella growth, discussed below. Level 2 corresponded to the seasonal tank. This storage was given second priority since it had a large thermal mass and was less sensitive to extended periods of low solar radiation. Also, the seasonal tank supplied thermal energy to hydronic slabs which were designed to operate at relatively low temperatures.

\subsubsection{Solar Loop Controller}

A central solar loop controller (SLC) was used to manage useful collector gains. The basic principle of the SLC was to determine if fluid at the bottom of the storage tanks were colder than the outlet fluid temperature of the collector. If one of them was, then useful gain may be achieved from the solar collector. This is a simple approach to solar thermal system control that is often used [11]. Additional control complexity was added to this concept to manage the two thermal storages in the C-RISE solar thermal system, described below. 
Figure 6.2 illustrates the control logic of the SLC used for the C-RISE solar thermal system. At each timestep, a sensor compared the outlet temperature of the solar collector array, $T_{\text {coll,out }}$, and the bottom of the diurnal tank, $T_{D H W, b o t}$. If the collector outlet was determined to be higher than $T_{D H W, b o t}$ within a certain deadband, the SLC would turn on the solar loop pump, diurnal charge loop pump, and set the diurnal 2-way valve to direct flow to the diurnal tank heat exchanger, shown in Figure 6.1. Another sensor then compared the temperature entering the seasonal 2-way valve, $T_{\text {Seas,val }}$, and the bottom of the seasonal tank, $T_{\text {Seas,bot }}$. If $T_{\text {Seas,val }}$ was greater than $T_{\text {Seas,bot }}$, the seasonal 2-way valve directed flow to the seasonal tank heat exchanger and the seasonal charge loop pump was switched on. A final sensor was used to compare $T_{\text {coll,out }}$ and $T_{\text {Seas,bot }}$. This sensor was used for cases where $T_{\text {coll,out }}$ was not sufficient to charge the diurnal tank. The diurnal 2-way valve would be set to bypass the diurnal heat exchanger and the seasonal 2-way valve would direct flow to the seasonal heat exchanger.

The Type 2 component referred to in Figure 6.2 was a TRNSYS standard library type used to model a differential controller. This controller took the difference between a high temperature, $T_{H}$, and low temperature, $T_{L}$. This temperature difference was then compared to an upper $\left(\Delta T_{H}\right)$ or lower $\left(\Delta T_{L}\right)$ deadband temperature difference. The controller could also sense a monitoring temperature, $T_{m o n}$. The controller would turn off if $T_{\text {mon }}$ exceeded a user-defined limit temperature $T_{\text {lim }}$. A flow chart of the Type 2 control logic is provided in Figure 6.3.

The SLC took advantage of this limit temperature to specify a maximum temperature of $65^{\circ} \mathrm{C}$ at the top of the diurnal tank. Once this temperature was achieved, the diurnal 2-way valve would bypass the diurnal heat exchanger to send solar useful gain to the seasonal storage. According to ASHRAE Guideline 12-2000 [141], legionella bacteria grows in the temperature range 25 to $42^{\circ} \mathrm{C}$. ASHRAE [141] recommends potable hot water be stored above $60^{\circ} \mathrm{C}$ or at the very least periodically heated to $66^{\circ} \mathrm{C}$. In future work, it is recommended to base the upper temperature limit on the rated maximum temperature of the storage tank. 


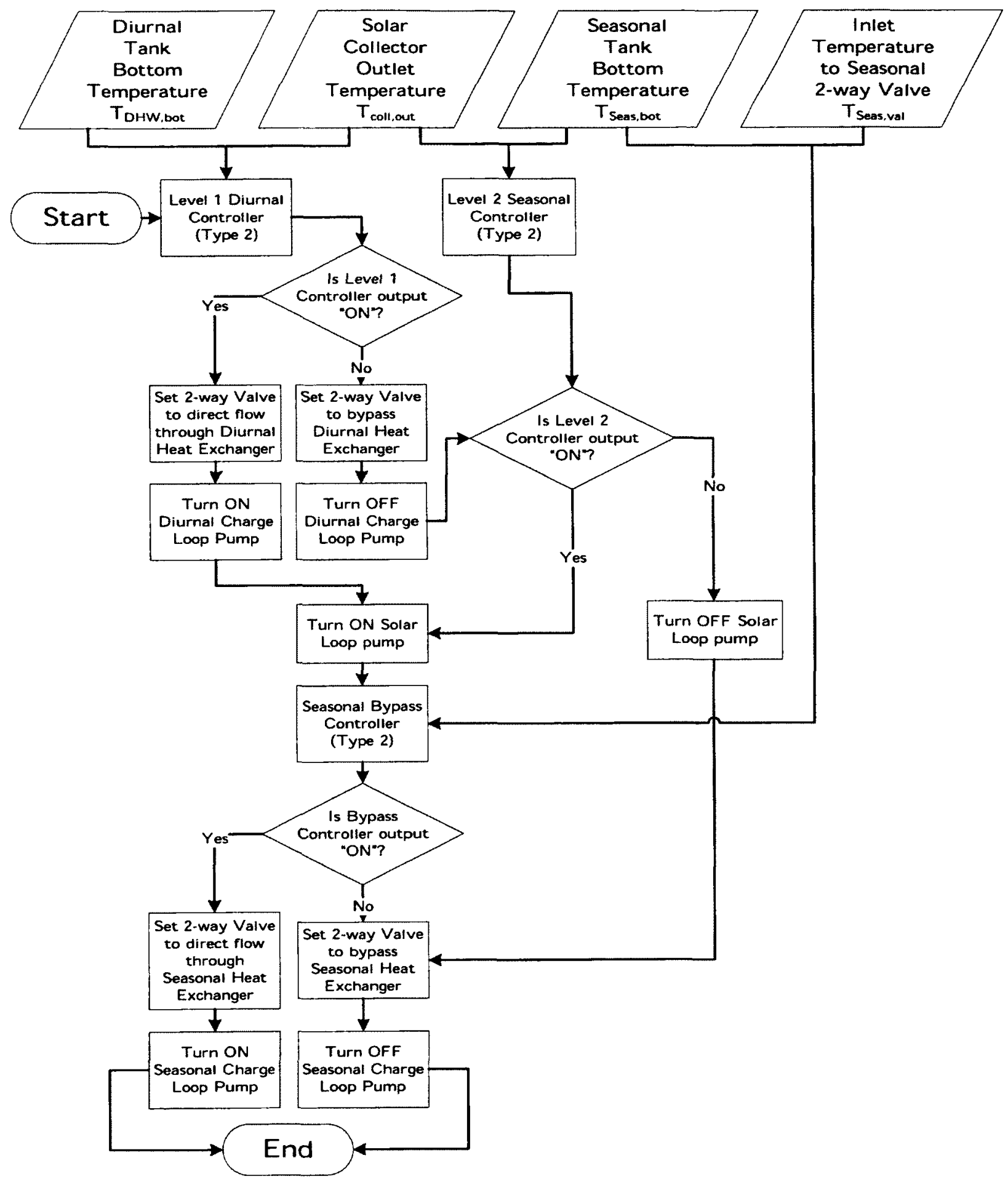

Figure 6.2: Solar loop control logic 


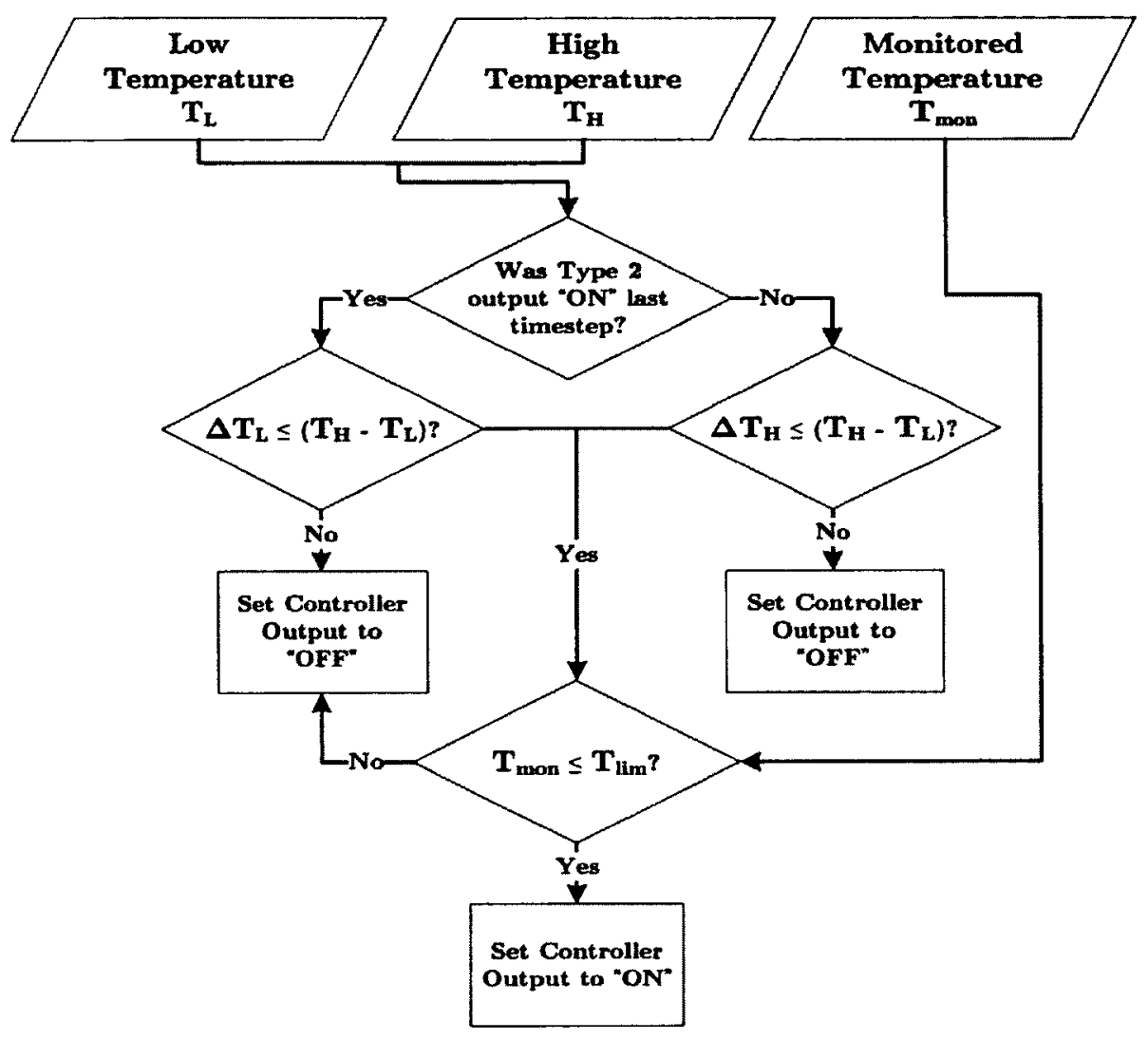

Figure 6.3: TRNSYS Type 2 control logic

\subsubsection{Diurnal Tank}

The diurnal tank size and configuration was held constant to limit the number of system variants studied. To determine an appropriate diurnal tank volume, a daily DHW consumption for the C-RISE house was assumed. Evarts and Swan [142] provided a rule- of-thumb value of $60 \mathrm{~L} /$ day/occupant for DHW consumption. They found this value to be a good estimate for households with four or more occupants, but under predicted consumption with households of one to three people. In Section 5.5, two occupants were assumed for the C-RISE house. For a conservative estimate, an average DHW draw of $200 \mathrm{~L} /$ day was assumed. This value was also the average total water consumption rate per capita found from the Halifax Regional Municipality Solar City pilot program reported by Evarts and Swan [142].

Heimrath [143] stated that for $200 \mathrm{~L} /$ day DHW loads, the DHW tank should be no smaller than $250 \mathrm{~L}$ for solar applications. The volume of the diurnal tank was $300 \mathrm{~L}$. The geometry of the diurnal tank was determined from a H/D ratio of 3.5 
based on recommended ratios given in Chapter 2. Using the $300 \mathrm{~L}$ storage volume, this ratio lead to a storage height of $1.67 \mathrm{~m}$ and diameter of $48 \mathrm{~cm}^{1}$. Based on the recommendations of Streicher et al. [144], a uniform insulation thickness of $15 \mathrm{~cm}$ was specified for the side, top, and bottom of the diurnal tank. The thermal conductivity of the tank insulation, $k_{i n s}$, was assumed to be $0.04[\mathrm{~W} / \mathrm{m} \mathrm{K}]$ based on the tank insulation values used in IEA-SHC Task 26 [8].

Figure 6.4 illustrates the inlet and outlet port locations on the diurnal tank. Mains water entered the bottom of the diurnal tank to replace hot water drawn from the top to meet DHW end-loads. During the tank charging cycle, water was extracted from the bottom of the diurnal tank and was circulated through the diurnal heat exchanger. The return fluid from the heat exchanger was then re-injected back into the diurnal tank at some height $c$. For this research, $c$ was assumed to be $65 \%$ of the total storage height. Lundh et al. [44] examined the sensitivity of $c$ to system performance. They found little sensitivity as long as $c$ was greater than $50 \%$ of the tank height.

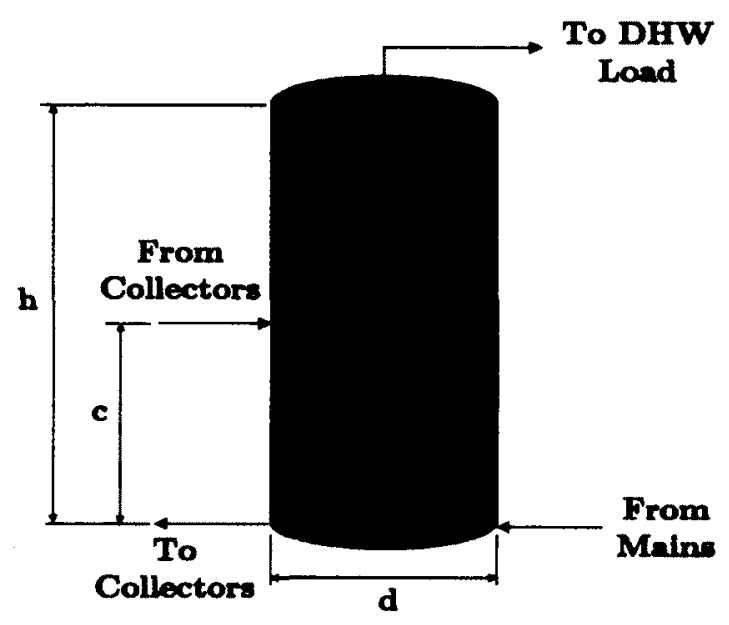

Figure 6.4: Inlet and Outlet Port Locations for the DHW Tank

\subsubsection{Modelling the Diurnal Tank in TRNSYS}

The diurnal tank was modelled in TRNSYS using Type 534, which was introduced in Chapter 4. Thermophysical fluid properties for water at atmospheric pressure

\footnotetext{
${ }^{1}$ These dimensions only consider the volume of fluid held within the tank and not the tank envelope
} 
and $35^{\circ} \mathrm{C}$ were assumed since the Type 534 required static fluid parameters. The $15 \mathrm{~cm}$ of insulation mentioned previously was represented as an effective U-value of $0.34 \mathrm{~W} / \mathrm{m}^{2} \mathrm{~K}$ along the side of the tank, calculated using Equation 6.1 [145].

$$
U_{D H W, s i d e}=\left[\frac{r_{i}}{k_{i n s}} \ln \frac{r_{o}}{r_{i}}\right]^{-1}
$$

where $r_{i}$ is the inside radius of the tank fluid [m] and $r_{o}$ is the outside radius of the tank and insulation [m]. Equation 6.1 was derived in terms of the surface area on the inside of the tank. The top and bottom surfaces of the diurnal tank were assumed flat resulting in a $U$-value of $0.27 \mathrm{~W} / \mathrm{m}^{2} \mathrm{~K}$.

The external environment of the diurnal tank was set to the basement of the C-RISE model. At each timestep, the Harmonizer passed the basement zone temperature from ESP-r to TRNSYS to compute heat losses from the diurnal tank. Any heat losses experienced by the tank were subsequently passed back through the Harmonizer to the basement zone in ESP $-\mathrm{r}$ as a heat gain.

Destratification due to conductivity along the tank walls was modelled with the effective conductivity method shown in Section 4.3.2. Using data from the residential tanks studied by Cruickshank [10], the diurnal tank wall was assumed to be steel with a conductivity of $50 \mathrm{~W} / \mathrm{m} \mathrm{K}$ and a thickness of $4 \mathrm{~mm}$. This equated to an effective conductivity of the diurnal tank, $\Delta k_{D H W}$, was calculated to be $1.69 \mathrm{~W} / \mathrm{m} \mathrm{K}$.

Type 534 employed a one-dimensional multinode approach to model tank stratification. A large number of nodes is required to accurately model highly stratified storage tanks [10]. The user was required to specifiy the number of nodes to use in the tank model. For this research, the number of nodes modelled in the diurnal tank, $N_{D H W}$, was left as a variable to examine the sensitivity of the considered solar thermal system to stratification.

\subsubsection{Domestic Hot Water Loads}

Mentioned previously, an average DHW draw of $200 \mathrm{~L} /$ day was assumed for the C RISE house. This value meant that on average $200 \mathrm{~L}$ of DHW was delivered to the end-load each day. For this research, the $200 \mathrm{~L} /$ day annual DHW profile at a 6 -minute timestep developed by Jordan and Vajen $[146,147]$ were used. These draw profiles were developed as part of the IEA-SHC Task 26 [83] to represent "realistic" profiles. Jordan and Vajen $[146,147]$ developed several profiles using a base case 
of a single-family home with an average $200 \mathrm{~L} /$ day draw and a $45^{\circ} \mathrm{C}$ setpoint at the end-load. Statistical means were used to develop a years worth of data where the occurrence, duration, and magnitude of DHW draws varied from day-to-day about an average daily DHW draw volume. Details of the DHW profile development was omitted here for clarity. The interested reader is directed to Jordan and Vajen $[146,147]$ for additional information.

The profile was read into TRNSYS at each co-simulation timestep using the Type 9 data reader. The DHW flow rate was set as an input to the DHW tempering valve shown in Figure 6.1. The temperature of the incoming mains water was determined from the TRNSYS Type 15 weather reader which used an algorithm developed by Burch and Christensen [148].

To remain consistent with the DHW draw profile data, the setpoint temperature of the DHW delivered to the occupants was $45^{\circ} \mathrm{C}$. This temperature was compliant with the Ontario Building Code [124], which stated that DHW should not be delivered to occupants higher than $49^{\circ} \mathrm{C}$ to prevent scalding. Control of the delivered DHW temperature was accomplished using a tempering valve, modelled in TRNSYS using Type 11 which mixed incoming cool mains water with hot water from the diurnal tank to achieve the $45^{\circ} \mathrm{C}$. The layout of the DHW loop is shown in Figure 6.1.

\subsubsection{Seasonal Storage Tank}

Chapter 2 highlighted the applicability of water tanks for residential seasonal storage due to the desirable thermophysical characteristics of water, relatively low cost, and availability. The seasonal storage considered in this research was a buried concrete tank with a square cross section. Figure 6.5 illustrates an elevation view of the buried tank configuration. According to a geological survey conducted near the proposed C-RISE house site by Golder Associates [149] in 2010, the ground water (GW) was approximately $5 \mathrm{~m}$ from the soil surface. To avoid moisture issues with the tank insulation and excessive heat losses, the tank geometry was constrained to be $0.5 \mathrm{~m}$ above the ground water. This constrained the height of the buried tank to $4.5 \mathrm{~m}$, but the internal tank fluid height, $h_{\text {Seas }}$, was able to vary with varying insulation thickness.

The top surface of the tank was modelled as being flush with the ground surface with an insulation cover. The proximity to the soil surface was assumed to 


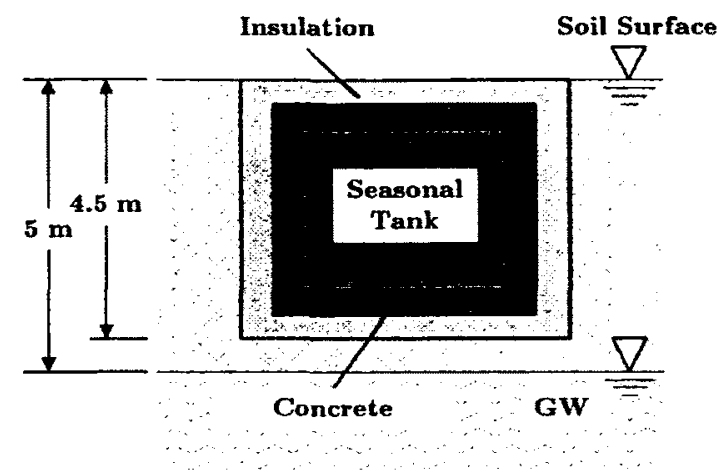

Figure 6.5: Seasonal tank elevation section

permit accessibility for maintenance as well as reduced excavation costs. The envelope of the tank was assumed to be $20 \mathrm{~cm}$ thick concrete based on other reported storage tank constructions found in the literature, such as Lottner and Mangold [67] or Raab et al. [64]. Conductivity of concrete can vary over a large range of values and is dependent on several factors, such as moisture content or concrete composition. For this research, it was assumed that the concrete conductivity was $1.72 \mathrm{~W} / \mathrm{m} \mathrm{K}$ based on the standard value used for basement foundations in the BASECALC simulation tool. The insulation on the buried seasonal tank was assumed to be extruded polystyrene (XPS) with an effective conductivity, $k_{\text {Seas,ins }}$, of $0.04 \mathrm{~W} / \mathrm{m} \mathrm{K}$. This conductivity value was consistent with the tank insulation conductivity used in the IEA-SHC Task 26 studies [8] and fell within the range of XPS conductivities ( 0.034 to $0.050 \mathrm{~W} / \mathrm{m} \mathrm{K}$ ) reported by Hadorn [150].

The treatment of the seasonal tank envelope was simplified, only considering the concrete walls and XPS insulation as an effective U-value. In practice, buried TES envelopes tend to be much more complex with additional layers for moisture management. In addition to reducing heat loss from the storage, Ochs et al. [151] stated that buried TES envelopes had to protect the insulation from moisture penetration and be able to allow for drying for cases when the insulation gets wet. For the purposes of this work, moisture penetration of the TES envelope was neglected and the thermal resistivity of the moisture and drainage layers was not considered. Past researchers such as Raab et al. [64] represented buried seasonal TES envelopes using U-values with reasonable agreement with experimental data. For future work, a more robust modelling approach is recommended for the seasonal tank envelope.

The inlet and outlet ports of the seasonal storage were modelled as fixed at either the top or bottom of the tank. During a space heating demand, hot water was drawn 
from the top of the tank to supply the hydronic slab and return fluid was injected at the tank bottom. During tank charging, water was drawn from the bottom of the tank and passed through the seasonal tank heat exchanger and returned to the tank at the top. These charging and discharging loops are illustrated in Figure 6.1.

\subsubsection{Modelling the Seasonal Tank in TRNSYS}

Modelling of the seasonal tank in TRNSYS was accomplished using Type 531. This was a 1-D multinode stratified tank model which used the same solution method as Type 534 discussed previously. This type however, was not constrained to representing only circular cross-sections. The surface area of the side of the tank control volumes were determined from a user specified cross-sectional perimeter. For this work, the perimeter was determined from the square cross-section of the tank.

Both the geometry and number of nodes modelled for the seasonal tank were allowed to vary as part of this study. The water properties assumed for the diurnal tank were assumed for the seasonal tank for consistency. Destratification due to wall conduction was also modelled in the same manner as Type 534. This method had been tested for smaller tanks, but no literature could be located to demonstrate its applicability for large storages. Cruickshank [10] however, noted that this approximation was valid for tanks where the cross-sectional area of the fluid was much greater than cross sectional area of the wall. Large seasonal storage tanks would typically satisfy this condition and the effective conductivity method was used. The additional conductivity of the seasonal tank, $\Delta k_{\text {Seas }}$, was recalculated as the tank geometry was varied in this research.

\subsubsection{Ground Conduction Model}

To model the heat losses of the buried seasonal tank, a three-dimensional finitedifference conduction model was used to represent the surrounding ground. This was a custom component created by Pinel [152] for use in this work and was based upon the conduction method described in the text by Patankar [153]. This ground modelling approach had been applied by researchers such as Dalenbäck [63], Kozlowski [26], and Raab et al. [64] for buried seasonal storage with good agreement with experimental data.

The ground conduction model was capable of representing the ground surrounding a rectangular cross-section tank. Since a rectangular cross-section has two planes of 
symmetry, only a quarter of the model domain needed to be simulated. This is illustrated in Figure 6.6. Adiabatic boundary conditions were imposed along the planes of symmetry as well as at the outer boundaries far from the edge of the tank. The bottom plane in the ground model represented the ground water boundary and was assigned a constant temperature boundary condition. For the Ottawa climate considered in this research, a constant deep earth temperature of $8^{\circ} \mathrm{C}$ was assumed. The current version of the ground conduction model did not permit thermal coupling of the buried tank and the basement of the C-RISE model. It is recommended that future work considers this interaction and the impact of building space heating loads and tank losses.

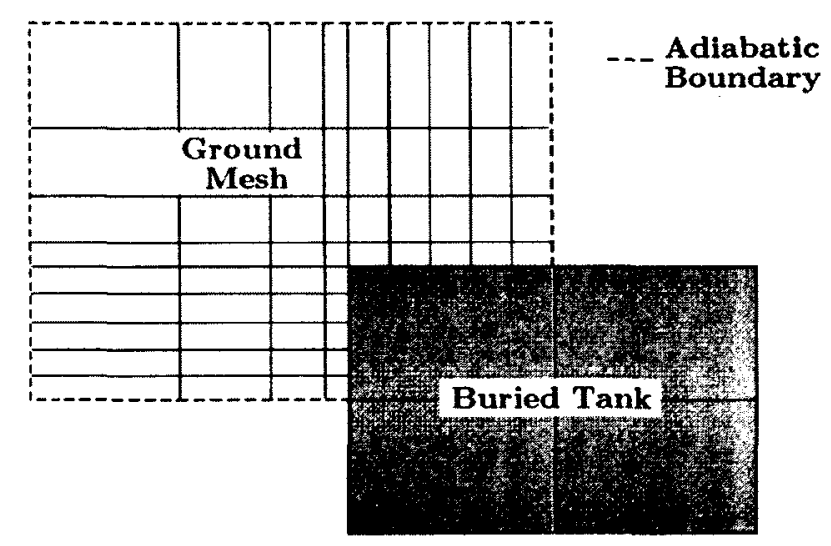

Figure 6.6: Cross sectional plan view of the ground conduction model

At the ground surface, the model performed an energy balance. The surface radiation absorptivity and combined convective and radiative heat transfer coefficient was supplied to the model as an input. The surface albedo (radiation reflectivity) was provided as an output of the TRNSYS Type 15 weather reader. For periods of snow cover, the surface albedo was set to 0.5 and for other periods it was 0.2 . The surface absorptivity used by the ground model was calculated as one minus the albedo at each timestep. The assumed heat transfer coefficient at the ground surface was a constant $7 \mathrm{~W} / \mathrm{m}^{2} \mathrm{~K}$ for all cases considered in the study. This was a coarse approximation based on the recommended values for combined convective and radiative heat transfer for interior surfaces from ASHRAE [94]. It is recommended for future work that a surface heat transfer coefficient is considered which is dependent on local wind speed and sky temperature and is updated at each timestep.

The estimation of the C-RISE site soil properties were taken from Pinel [152] and 
Golder Associates [149]. Pinel [152] used the methods of Côté and Konrad [154,155] to determine the composite soil-water properties at various temperatures and levels of saturation. A basic soil description from Pinel [152] was used and is given in Table 6.1. The current state of the ground conduction model however, could only accept constant thermophysical properties. Due to this restriction, soil at $10^{\circ} \mathrm{C}$ and a $30 \%$ saturation was assumed. The soil conductivity and capacity $\left(\rho c_{p}\right)$ was calculated at these conditions to be approximately $0.85 \mathrm{~W} / \mathrm{m} \mathrm{K}$ and $1780 \mathrm{~kJ} / \mathrm{m}^{3} \mathrm{~K}$ respectively. The parameter $\kappa$ is an empirical soil parameter used to account for different soils at frozen or unfrozen states [154].

Table 6.1: Basic soil properties assumed for the research

\begin{tabular}{|l|c|}
\hline \multicolumn{2}{|c|}{ Soil Description } \\
\hline \hline Porosity $\mathrm{m}_{\text {void }}^{3} / \mathrm{m}^{3}$ & 0.376 \\
\hline Clay content [-] & 0.01 \\
\hline$\kappa[-]$ & 1.9 \\
\hline \hline \multicolumn{2}{|c|}{ Soil Particle Properties } \\
\hline \hline Thermal Conductivity [W/m K] & 2 \\
\hline Density $\left[\mathrm{kg} / \mathrm{m}^{3}\right]$ & 2800 \\
\hline Specific Heat $[\mathrm{J} / \mathrm{kg} \mathrm{K}]$ & 750 \\
\hline
\end{tabular}

Since the ground conduction model was computationally expensive, a capability was included in the model to allow for larger simulation timesteps compared to the global co-simulation timestep for ESP-r and TRNSYS. For this research, the ground conduction model was calculated hourly. This was assumed to have a minor influence on seasonal tank heat losses since the ground was considered to be thermally massive with temperatures evolving slowly over time.

\subsubsection{Solar Thermal Collectors}

For reasons stated in Section 4.3.1, flat-plate collectors were chosen for C-RISE due to their low cost. For this work, the flat-plate collector model COL-4x8-TL-SGI-SD10 US from Ontario manufacturer Enerworks Solar Heating and Cooling was used. This was a relatively high efficiency flat-plate collector from a local manufacturer. Testing 
on this collector was conducted by Bodycote Materials Testing Canada Inc. [156] in accordance to SRCC OG-100 Standard "Test Methods and Minimum Standards for Certifying Solar Collectors".

The reported gross and aperture areas of the collector were 2.874 an $2.712 \mathrm{~m}^{2}$ respectively [156]. In Section 4.3.1, an expression was shown for the second order instantaneous efficiency of solar thermal collectors. Based on the test data from Bodycote [156], the efficiency curve for the Enerworks collector was

$$
\eta_{i}=0.717-4.033 \frac{\left(T_{i n}-T_{a}\right)}{G_{T}}-0.0184 \frac{\left(T_{i n}-T_{a}\right)^{2}}{G_{T}}
$$

The capacitance of the collector was not determined directly in the tests, however Bodycote [156] determined a collector time constant, $\tau$, of 100 seconds. Duffie and Beckman [11] define $\tau$ as "the time required for a fluid leaving a collector to change through $(1-1 / e)=(0.632)^{2}$ of the total change from its initial to its ultimate steady state value after a step change in incident radiation or inlet fluid temperature."

Insufficient experimental data was available to calculate the capacitance of the collector directly from $\tau$. To determine the capacitance, TRNSYS simulation was performed to model the Enerworks collector under the same time constant testing conditions reported by Bodycote [156]. Type 539, introduced in Section 4.3.1, was used to model the collector and the collector capacitance in the model parameters was adjusted until a time constant of approximately 100 seconds was achieved. The final capacitance used in the research was $41.2 \mathrm{~kJ} / \mathrm{K}$ per collector.

\subsubsection{Array Configuration}

Figure 6.7 illustrates the layout of the collector array for the C-RISE solar thermal system. There were two flat-plate collectors connected in series per branch and a variable number of parallel branches. Inlet flow into the collector array was evenly distributed to each branch. Connecting collectors in series allows for a greater temperature rise across the collectors at the expense of collector efficiency. The reduced efficiency is a result of the increased inlet temperature to the second collector in the series.

\footnotetext{
2 " $\mathrm{e}$ " is Euler's number
} 


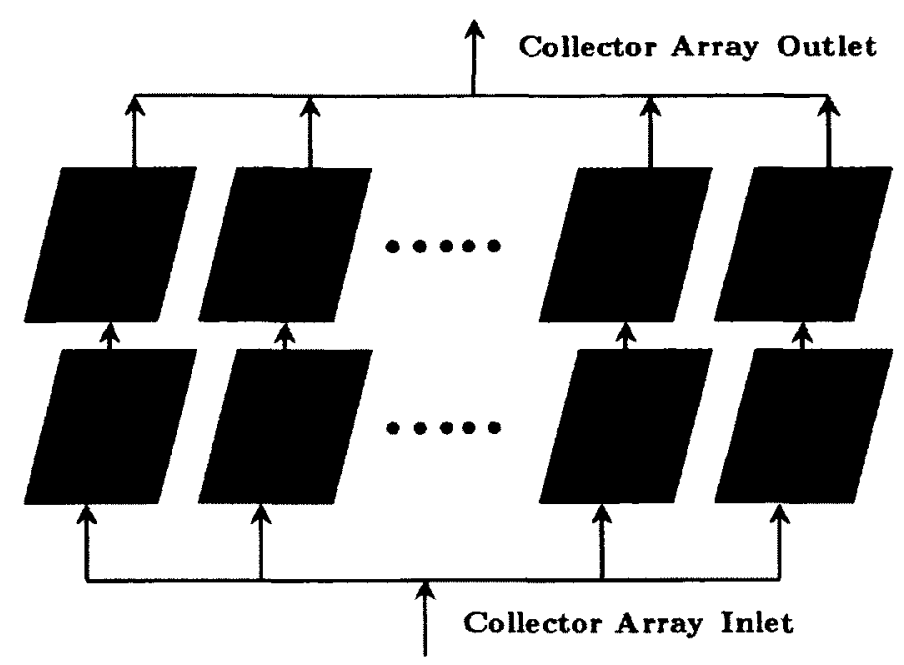

Figure 6.7: Collector array layout

\subsubsection{Specific Collector Flow Rates}

Traditionally, collector flow rates were designed to maximize the collector heat removal factor $F_{R}[37,157]$. Duffie and Beckman [11] stated that the maximum collector useful gain occurs when the entire absorber plate is at the inlet temperature. As the flow rate through a collector increases, the temperature difference across the collector is reduced and the average temperature of the absorber will approach the inlet temperature and increase $F_{R}$. Consequently, past methods of system design for maximized $F_{R}$ has lead to relatively high flow rates of approximately $54 \mathrm{~kg} / \mathrm{hr} \mathrm{m} \mathrm{m}^{2}$ of collector area [37].

Andersen [158] stated that specific collector flow rates, $\dot{m}_{c o l l}^{\prime}$, for solar thermal systems may vary between 9 and $72 \mathrm{~kg} / \mathrm{hr} \mathrm{m}^{2}$. For central solar heating plants with seasonal storage, Kozlowski [26] stated that the system performance was highly influenced by how the collector operated. With high collector flow rates $\left(54 \mathrm{~kg} / \mathrm{hr} \mathrm{m}^{2}\right)$, mixing was encouraged within the storage tank and promoted destratification [26]. Low flow systems $\left(18 \mathrm{~kg} / \mathrm{hr} \mathrm{m}^{2}\right)$ however, produced a larger temperature rise across the collectors and helped to maintain stratification [26].

For this research, a low collector flow rate was selected to take advantage of the higher temperature rise across the collector and the improvement to stratification in the storage tank. The specific collector flow rate that was used was $12 \mathrm{~kg} / \mathrm{hr} \mathrm{m} \mathrm{m}^{2}$, taken from the 10 to $15 \mathrm{~kg} / \mathrm{hr} \mathrm{m}^{2}$ typical collector low flow rates stated by Streicher et. al [144]. As the array area varied in the parametric study, the flow rate into the 
collector array was determined by multiplying the $12 \mathrm{~kg} / \mathrm{hr} \mathrm{m}^{2}$ specific flow rate by the array gross area.

\subsubsection{Secondary Components of the Solar Thermal System}

The key components of the C-RISE solar thermal system have been described above. This section discusses the pumps, heat exchangers and auxiliary heaters used in the SSTS and the assumptions that were made in their modelling.

\subsubsection{Pumps}

The C-RISE SSTS contained five pumps that were explicitly represented in the TRNSYS model: the solar loop pump, the diurnal and seasonal tank charge pumps, and the hydronic slab circulation pumps. These pumps are shown in Figure 6.1. These pumps were single-speed On-Off types for simplicity and relatively low cost compared to variable-speed pumps. The flow rate of the solar loop pump was adjusted according to the collector array gross area, $A_{c}$, described in Section 6.1.5. The power consumption of the solar loop pump, $\dot{Q}_{e l, p u m p, s o l a r}[\mathrm{~W}]$, was approximated using Equation 6.3 from the reference conditions of IEA-SHC Task 26 [8].

$$
\dot{Q}_{e l, p u m p, s o l a r}=\left[44.6 \cdot \exp \left(0.0181 \cdot A_{c}\right)\right]
$$

The flow rates for the diurnal and seasonal charge loop pumps shown in Figure 6.1 were matched to the flow rate of the solar loop pump. Fanney and Klein [157] carried out experiments and simulations on two solar DHW systems, one which circulated potable water directly from the storage tank through the collector, and one which had an external heat exchanger between the collector and storage tank. For the external heat exchanger system, Fanney and Klein [157] found that reducing the flow rate on the tank-side did not improve system performance. Any performance gains expected by lower tank flows and improved stratification was negated by the penalty incurred by reduced heat exchanger heat transfer coefficient. The power consumption of each charge loop pump, $\dot{Q}_{e l, p u m p, c h a r g e}[\mathrm{~W}]$, was calculated with Equation 6.4, derived from the reference conditions of IEA-SHC Task 26 [8].

$$
\dot{Q}_{e l, p u m p, \text { charge }}=\left[78.3 \cdot \exp \left(0.0156 \cdot A_{c}\right)\right]-\dot{Q}_{e l, p u m p, s o l a r}
$$

The hydronic floor circulation pumps were specified a constant maximum flow rate 
of $72 \mathrm{~kg} / \mathrm{hr}$ based on the design and coarse adjustment of the hydronic slab system discussed in Section 5.4.1. The power consumption of the hydronic floor circulation pumps were assumed to be $93 \mathrm{~W}$, based on the reference conditions of IEA-SHC Task 26 [8] for space heating circulation pumps for a system with a nominal burner power of $15 \mathrm{~kW}$.

\subsubsection{Heat Exchangers}

Two external heat exchangers were modelled in the C-RISE SSTS; the diurnal and the seasonal storage heat exchangers in the solar loop shown in Figure 6.1. These components were modelled in TRNSYS using the counterflow heat exchanger Type 5b. To calculate the heat transfer, Type $5 \mathrm{~b}$ accepted an overall heat transfer coefficient, $U A_{H X}[\mathrm{~W} / \mathrm{K}]$, as an input at each timestep. For this research, the $U A_{H X}$ for both heat exchangers was set to a constant value of $30 \mathrm{~W} / \mathrm{K}$ per $\mathrm{m}^{2}$ of gross collector area. This was the recommended value found from the sensitivity analysis conducted by Streicher et al. [144]. They found that beyond this specific $U A$ value there was little benefit to system performance.

\subsubsection{Auxiliary Heaters}

Three in-line auxiliary heaters were included in the C-RISE solar thermal system, i.e. one placed in the DHW loop with a setpoint of $45^{\circ} \mathrm{C}$ to ensure the minimum temperature of the DHW was met, and one in each space heating loop to ensure that the supply temperature required by the hydronic floor was met. The placement of these auxiliary heaters may be seen in Figure 6.1. Type 6 was used in TRNSYS to represent these auxiliary heaters. This component was a very simple in-line heater that performed a steady-state energy balance at each timestep. The component would add energy to the incoming fluid stream over the timestep up to a maximum power output specified by the user.

For the current work, the auxiliary heaters were assumed to be perfectly insulated from the environment and had a maximum output of $15 \mathrm{~kW}$ each, based on the reference output of a single family home boiler used in IEA-SHC Task 26 [8]. The power conversion efficiency of the auxiliary heater was specified to $90 \%$ based on the mean annual efficiency of a gas boiler relative to the lower heating value [8]. The setpoint of the space heating auxiliary heaters was taken as an input at each timestep from the hydronic slab controller described in Section 6.2. 


\subsection{Hydronic Slab Control and Operation}

Control of the hydronic slabs located on the main and second floors in the C-RISE house were modelled in TRNSYS. The hydronic slabs themselves were modelled in the ESP-r plant network and received a hot water supply from TRNSYS via the Harmonizer software. The return fluid from the hydronic slab was then sent back from ESP-r to TRNSYS. Figure 6.8 illustrates the structure used for co-simulation between the two tools. Mentioned previously, each hydronic slab in ESP-r had its own independent space heating loop with independent controls and ports on the seasonal storage.

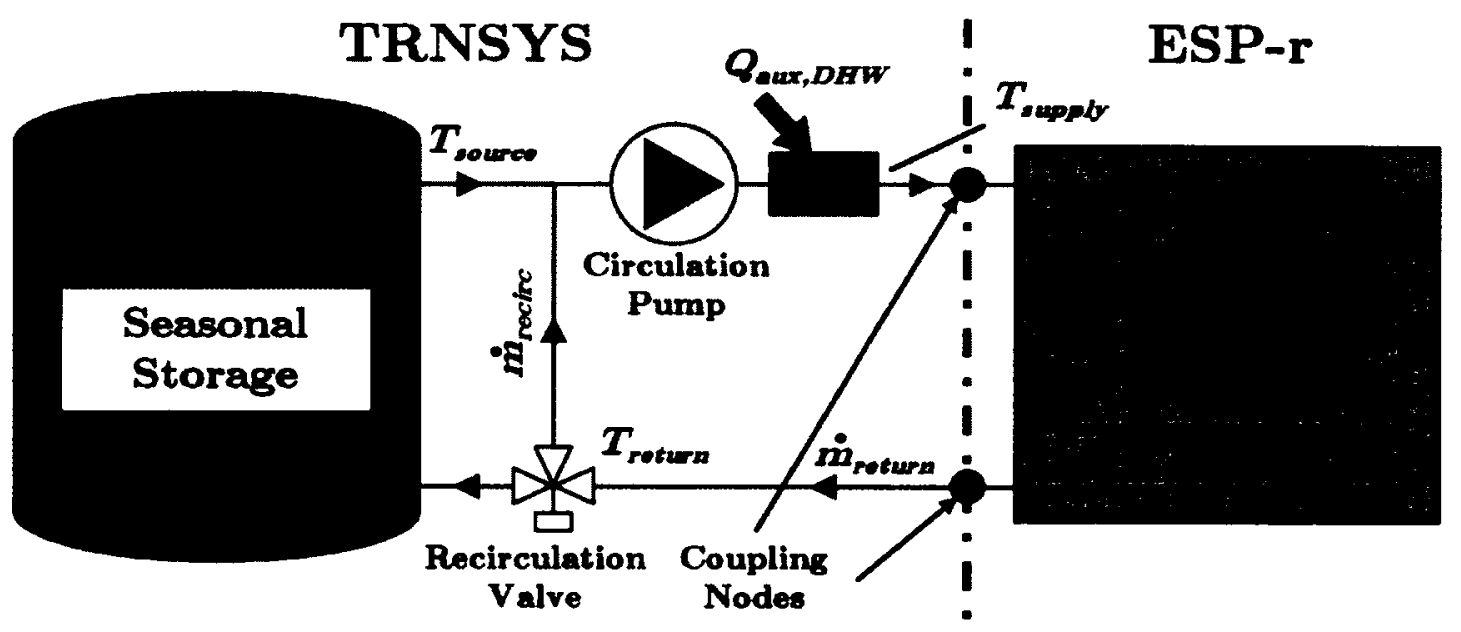

Figure 6.8: TRNSYS / ESP-r co-simulation of the space heating loop

Leigh and MacCluer [159] stated that the general belief for radiant floor control strategies was that they differed from conventional hot water heating systems due to lower operating temperatures, maximum temperature limits imposed on the floor surface, and the thermal inertia characteristics of the floor slab. Several different control strategies have been proposed in the literature. Leigh and MacCluer [159] cited two major radiant slab control schemes, proportional flux-modulation or temperature modulation. Proportional flux-modulation control operates by controlling the heat per unit time delivered by the boiler to the floor slab at a constant flow rate based on thermostat error from the setpoint temperature [159]. A more typical control [129] was the outdoor reset control (ORC) method, which was selected for this study.

The ORC method used slab supply temperature modulation to control heat output from the system. The supply setpoint temperature was modified based on sensed 
outdoor temperatures. The concept of this control scheme was to match the rate of heat loss from the building envelope to heat supply by the plant system [159]. A "reset curve" was used to establish the relationship between ambient and supply temperatures. It was a linear relationship defined by two points: maximum supply temperature at minimum ambient, and minimum supply temperature at maximum ambient. The reset curve used in the study is shown in Figure 6.9.

This type of control configuration was open loop and unconditionally stable [160]. Without feedback from indoor conditions however, the controller was unable to react to temperature rises in the conditions space due to occupant activity or solar gains. MacCluer proposed improvement on ORC by incorporating an indoor feedback loop [161]. He found that offset-modulation can improve performance without the risk of instability by using careful design. Offset-modulation is achieved by vertical translation of the reset curve up or down in response to a thermostat deviation ${ }^{3}$. Figure 6.9 illustrates this translation, where the reset curve was able to move between the dashed lines.

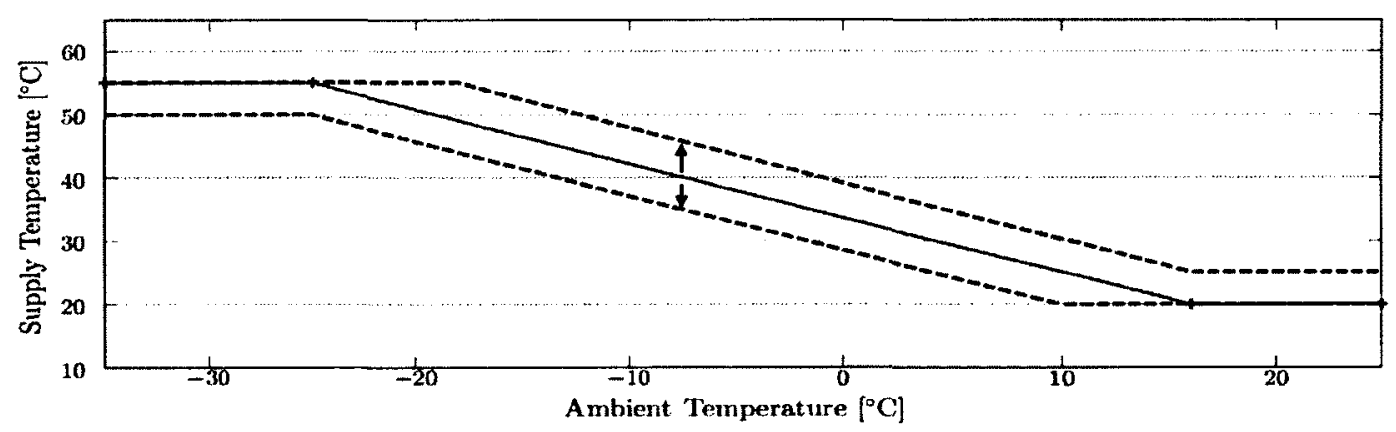

Figure 6.9: Outdoor reset curve and offset-modulation

The ORC with offset-modulation functioned by first determining the supply setpoint temperature for the hydronic slab, $T_{\text {set,sup }}$, based on the user defined reset curve. The current timestep zone temperature, $T_{z o n e}$, and user defined zone setpoint temperature, $T_{\text {set, } z o n e}$ was then used to determine the thermostat deviation $\Delta T_{\text {dev }}$, calculated using Equation 6.5.

$$
\Delta T_{\text {dev }}=T_{\text {set }, z o n e}-T_{z o n e}
$$

\footnotetext{
${ }^{3}$ Thermostat deviation is the difference between the setpoint temperature and the sensed drybulb temperature.
} 
A new setpoint temperature, $T_{\text {set, mod }}$, was then determined based on

$$
T_{\text {set }, \text { mod }}=T_{\text {set,sup }}+\Delta T_{\text {dev }} \cdot G
$$

where $G$ is the unitless user defined gain.

Modelling of the ORC with offset-modulation was accomplished in TRNSYS by creating a new component called Type 211. The source code for this component may be found in Appendix F. The final control parameters for the ORC were based coarse adjustments from simulation and are summarized in Table 6.2.

Table 6.2: Outdoor reset control parameters

\begin{tabular}{|l|c|}
\hline Maximum Supply Temperature $\left[{ }^{\circ} \mathrm{C}\right]$ & 55 \\
\hline Ambient Temperature at Max. Supply $\left[{ }^{\circ} \mathrm{C}\right]$ & -25 \\
\hline Minimum Supply Temperature $\left[{ }^{\circ} \mathrm{C}\right]$ & 20 \\
\hline Ambient Temperature at Min. Supply $\left[{ }^{\circ} \mathrm{C}\right]$ & 16 \\
\hline Setpoint Temperature $\left[{ }^{\circ} \mathrm{C}\right]$ & 20 \\
\hline Gain $[-]$ & 10 \\
\hline
\end{tabular}

To control the actual $T_{\text {supply }}$ entering the hydronic slab, a recirculation valve (shown in Figure 6.8) was used. In TRNSYS, this component was modelled using the Type 11 tempering valve. At each timestep, the recirculation valve received $T_{\text {set,mod }}$ from the ORC, the hot water source temperature from the top of the seasonal tank, $T_{\text {source }}$, and the hydronic floor return temperature, $T_{\text {return }}$, shown in Figure 6.8. The recirculation valve would send a portion of $T_{\text {return }}$ to temper $T_{\text {source }}$ to the setpoint temperature specified by the ORC. The other portion of $T_{\text {return }}$ was sent to the bottom of the seasonal tank to replace the hot water leaving the top. In cases where $T_{\text {source }}$ was too low, the recirculation valve diverted all flow to the seasonal tank and the auxiliary heater described in Section 6.1.5.3 was used to raise the slab supply temperature to $T_{\text {set,mod }}$. The tempering valve control scheme is illustrated in Figure 6.10.

The variable $\gamma$ was the unitless fraction of the return floor mass flow rate, $\dot{m}_{\text {return }}$ $[\mathrm{kg} / \mathrm{hr}]$, that was sent to the seasonal storage tank and varies between 0 and 1 . The recirculated mass flow rate, $\dot{m}_{\text {recirc }}[\mathrm{kg} / \mathrm{hr}]$, was then determined from 


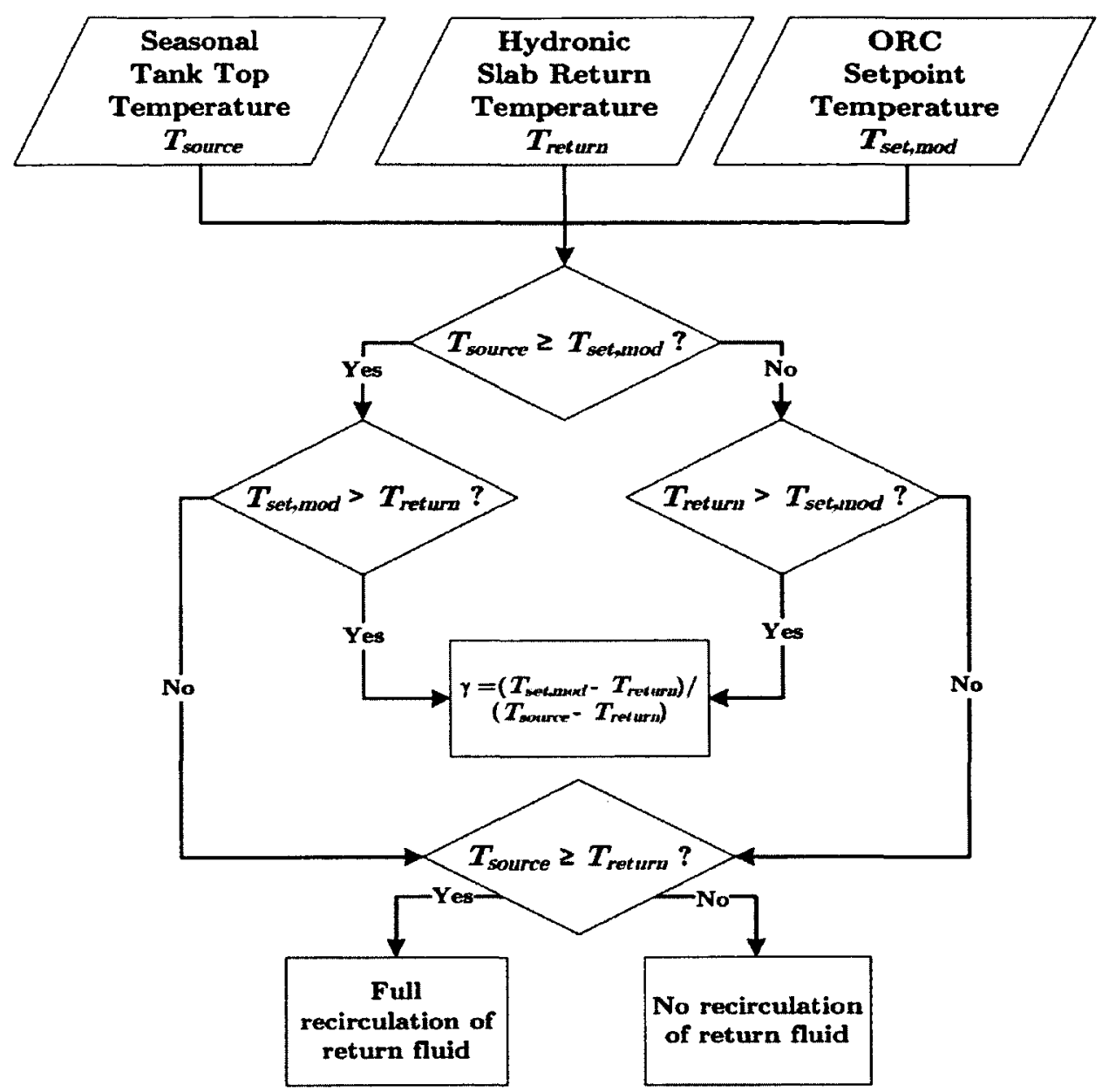

Figure 6.10: Hydronic floor recirculation valve control logic

$$
\dot{m}_{\text {recirc }}=\dot{m}_{\text {return }} \cdot(1-\gamma)
$$

While the setpoint floor supply temperatures were controlled by the ORC, a separate independent controller controlled the hydronic floor circulation pumps. A simple heating controller with a temperature deadband was used for each occupied zone. The circulation pumps were turned on when the occupied space dropped below $19^{\circ} \mathrm{C}$. The floor pump continued to run until an upper temperature limit of $21^{\circ} \mathrm{C}$ was reached. The space temperature was then allowed to float back down to $19^{\circ} \mathrm{C}$. 


\subsection{Closing Remarks}

This Chapter reviewed the development and model creation of the C-RISE SSTS. Once the building and plant models were established in ESP-r and TRNSYS, cosimulation was used to examine the sensitivity of the annual system performance to key parameters. Specifically, the sensitivity study focused on seasonal tank volume, geometry, and insulation and collector array area and slope. The individual sensitivity studies conducted in this work and their results are presented in the next chapter. 


\section{Chapter 7}

\section{Results and Discussion}

Several aspects of the seasonal solar thermal energy system was designed using "best practices" and recommendations from the literature, described in Chapter 6. There was still however, several key parameters that needed to be determined for the SSTS. These key parameters included the volume and geometry of the seasonal storage buried water tank, insulation levels of the seasonal storage, collector array area, and tilt of the array. To determine the appropriate parameters for the C-RISE application, detailed models of the test facility building and SSTS were developed in ESP-r and TRNSYS, described previously in Chapters 5 and 6 respectively. A co-simulation tool, referred to as the "Harmonizer", was then used to facilitate communication between the two simulation tools at runtime. This chapter describes the parametric and sensitivity analyses conducted using co-simulation of the detailed models as well as the results and discussion.

Section 7.1 provides the baseline annual space heating and DHW loads of the C RISE house and the method of their calculation. Section 7.2 then reviews and discusses the results of the numerical sensitivity study performed for selected discretized models in TRNSYS. Section 7.3 provides the results for the coarse parametric study performed using the co-simulation models. The purpose of that study was to investigate different combinations of solar collector area, seasonal storage volume, and seasonal storage insulation to determine their corresponding annual performances. Section 7.4 reviews the annual performance of a "selected case" system selected from the previous parametric study. Both the performance of the system as a whole and the individual components were considered to determine if the simulation models were functioning as expected and to demonstrate performance of the two-tank concept. Also in Section 7.4, additional sensitivity analyses were undertaken to examine 
the sensitivity of annual system performance to seasonal tank geometry and collector array tilt.

A 6-minute timestep was used for all co-simulations conducted in this research, with the exception of the temporal sensitivity test cases discussed in Section 7.2. This timestep was chosen to match the time interval of the DHW demand profiles mentioned in Section 6.1.2.2. Barnaby and Crawley [162] stated that past and present building performance simulations typically used 1- hour as the natural timestep. This convention was derived from the time interval of historical climate data. When considering a detailed plant network model however, a relatively long timestep becomes less practical. Over 1-hour control outputs in the plant system were expected to vary. This variation would not be captured with a 1-hour timestep. A 6-minute timestep was assumed to better represent plant controls and system response.

Annual simulations were performed from March $1^{\text {st }}$ to February $28^{\text {th }}$. According to Duffie and Beckman [11], March was a convenient choice for defining the beginning of the year. Seasonal storage for solar thermal systems were assumed to be at their lowest temperatures by this month, allowing for easier estimation of initial conditions. For this work, an initial uniform seasonal storage at $20^{\circ} \mathrm{C}$ was arbitrarily selected. To reduce the influence of initial condition estimates, a two year simulation period was used for each co-simulation performed. The first year was meant to reducc the influence of initial temperature assumptions for the seasonal tank and ground conduction model. The second year was then used for the analysis presented below and was assumed to represent annual steady-state operation. The suitability of this assumption is explored in Section 7.3.

\subsection{Space Heating and DHW Loads}

The C-RISE building model in ESP-r was not modified for all simulations conducted in this study. As the SSTS parameters were varied in TRNSYS, the annual space heating supplied to the occupied zones of the C RISE house was found to vary slightly. This variation was assumed to be the result of the coupled treatment of the building and plant domains in the co-simulation. For example, the inability of the SSTS to meet hydronic floor supply setpoint temperatures would have an influence on the thermal state of the zone at both the current and future timesteps. Nontheless, this variation was found to be negligible. For all system configurations considered in the 
parametric study described in Section 7.3, the annual space heating load, $Q_{\text {space }}$, had a mean value of $21.77 \mathrm{GJ}$ with a population standard deviation of $0.02 \mathrm{GJ}$. It should be noted that this variation was unrelated to the space heating loop auxiliary heaters, which were found to have sufficient heating capacity for all cases.

Calculation of the annual space heating supplied to the C-RISE house was accomplished by performing an energy balance across the hydronic floors on the main and second floors. The annual energy supplied by hydronic floor $i, Q_{s p a c e, i}[\mathrm{GJ}]$, was calculated using Equation 7.1.

$$
Q_{\text {space }, i}=\int_{\text {year }} \dot{m}_{i}(t) c_{p}\left[T_{\text {supply }, i}(t)-T_{\text {return }, i}(t)\right] d t
$$

where $\dot{m}_{i}(t)$ was the mass flow rate into hydronic floor $i$ at time $t[\mathrm{~kg} / \mathrm{s}], T_{\text {supply,i }}(t)$ was the inlet temperature to hydronic floor $i$ at time $t\left[{ }^{\circ} \mathrm{C}\right]$, and $T_{\text {return, } i}(t)$ was the outlet temperature of the hydronic floor $i$ at time $t\left[{ }^{\circ} \mathrm{C}\right]$.

The annual DHW heating load, $Q_{D H W}[\mathrm{GJ}]$, was determined using Equation 7.2.

$$
Q_{D H W}=\int_{\text {year }} \dot{m}_{D H W}(t) c_{p}\left[T_{\text {set,DHW }}-T_{\text {mains }}(t)\right] d t
$$

where $\dot{m}_{D H W}(t)$ was the DHW draw flow rate at time $t[\mathrm{~kg} / \mathrm{s}], T_{s e t, D H W}$ was the setpoint temperature of the DHW at the end $-\operatorname{load}^{1}\left[{ }^{\circ} \mathrm{C}\right]$, and $T_{\text {mains }}(t)$ was the mains water temperature $\left[{ }^{\circ} \mathrm{C}\right]$ at time $t$. For each co-simulation run, the DHW draw profiles and climate data used to calculate $T_{\text {mains }}(t)$ did not change. Consequently, $Q_{D H W}$ did not vary throughout the study and was found to be $11.1 \mathrm{GJ}$.

\subsection{Numerical Sensitivity Analysis}

Prior to the parametric study of the detailed SSTS model, a numerical sensitivity analysis was conducted to examine grid dependence of the discretized TRNSYS components. The key components considered in this study were the TRNSYS Type 539 flat-plate collector, Type 534 diurnal tank, Type 531 seasonal tank, and the custom ground conduction model. Temporal sensitivity tests were also conducted to assess the simulation results sensitivity to time discretization. The sensitivity analyses for the diurnal and seasonal tanks are discussed below. The remaining results of the sensitivity analysis may be found in Appendix A.

\footnotetext{
${ }^{1}$ For this work, the DHW setpoint was a constant $45^{\circ} \mathrm{C}$
} 
All numerical sensitivity co-simulations were carried out using the system parameters shown in Table 7.1 , where $t_{\text {Seas,ins }}$ was the thickness of the seasonal tank insulation, and $\dot{m}_{\text {coll }}^{\prime}$ was the specific collector flow rate.

Table 7.1: System parameters used for the numerical sensitivity study

\begin{tabular}{lr}
\hline \multicolumn{2}{c}{ Seasonal Storage } \\
\hline Storage volume, $V_{\text {Seas }}\left[\mathrm{m}^{3}\right]$ & 250 \\
Storage height, $h_{\text {Seas }}[\mathrm{m}]$ & 3.5 \\
Insulation thickness, $t_{\text {Seas,ins }}[\mathrm{cm}]$ & 60 \\
\hline \multicolumn{2}{c}{ Solar Collectors } \\
\hline Gross collector area, $A_{c}\left[\mathrm{~m}^{2}\right]$ & 34.49 \\
Collector Tilt, $\beta\left[^{\circ}\right]$ & 45 \\
Specific collcctor flow rate, $\dot{m}_{\text {coll }}^{\prime}\left[\mathrm{kg} / \mathrm{hr} \mathrm{m}{ }^{2}\right]$ & 15 \\
\hline
\end{tabular}

For the discretization of the storage tanks, the TRNSYS software is limited to representing a combined 100 nodes for all tanks within the simulation model. Also, as the number of nodes in the 1-D tank models increase, the differential volume of each node decreases. The volume of the node receiving inlet flow must be able to hold the total volume gained over the timestep or the tank will not reach convergence. These factors limited the range of nodes that could be specified for the tanks considered in this study.

\subsubsection{Diurnal Tank Discretization}

The number of discrete nodes modelled in the diurnal tank, $N_{D H W}$, were varied between 1 and 50. This sensitivity study not only examined grid dependence for the diurnal tank model, but also provided insight into the significance of stratification. A single node tank model represented a fully mixed storage. As additional nodes were added, the model was able to represent greater degrees of stratification. This was a modelling artefact, where increasing the number of nodes decreased inlet jet mixing modelled in the tank. To capture the behaviour of a real stratified tank, it is recommended that in future work the $1 \mathrm{D}$ model is experimentally calibrated. Based on the literature review conducted in Chapter 2. stratification was expected to develop within the diurnal tank. 
The annual auxiliary energy supplied to the DHW load and the annual diurnal tank losses to the basement zone are shown in Figure 7.1 for each discretization case.

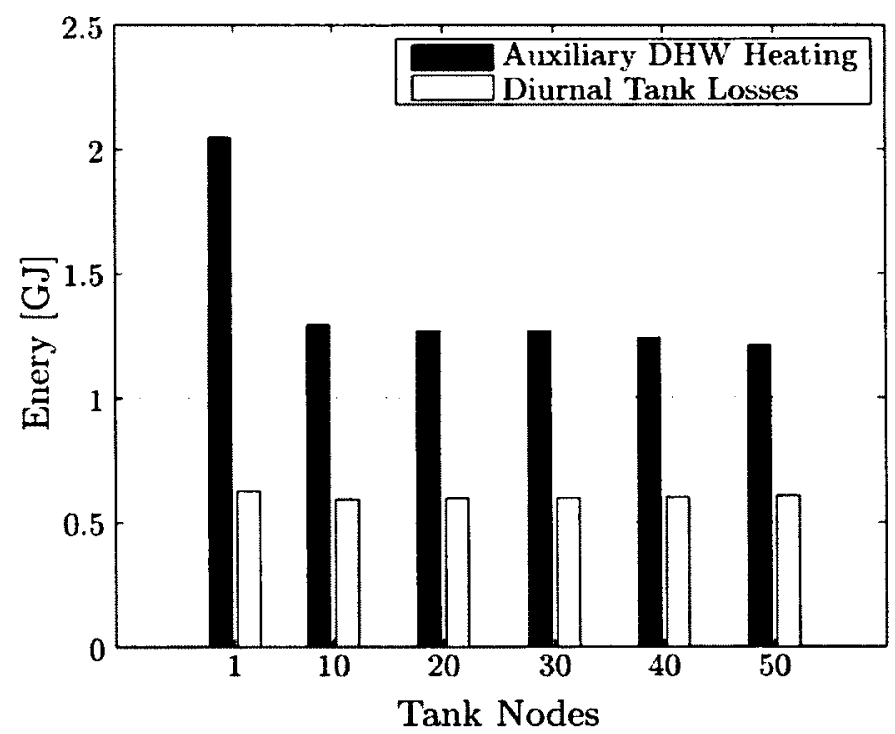

Figure 7.1: Annual results of the diurnal tank discretization study

In this study, the $15 \mathrm{~kW} \mathrm{DHW}$ auxiliary heater was at maximum output for no more than $0.14 \%$ of the year. The single node (fully-mixed) case required $2.0 \mathrm{GJ}$ of auxiliary energy per year. This corresponded to an annual DHW solar fraction of 81.5\%, calculated from Equation 7.3.

$$
\Im_{D H W}=\frac{Q_{D H W}-Q_{a u x, D H W}}{Q_{D H W}}
$$

where $Q_{a u x, D H W}$ was the annual encrgy supplied directly to the DHW fluid stream [GJ].

When the number of nodes in the diurnal tank was increased to $10, Q_{a u x, D H W}$ decreased by $42.5 \%$ and $\Im_{D H W}$ was increased to a value of $88.3 \%$. A performance increase was anticipated since the tank was capable of representing stratification. The annual average temperature difference between the top and bottom node of the tank was $20.6^{\circ} \mathrm{C}$.

Further increases in the number of nodes in the diurnal tank did not significantly influence the annual performance of the tank, shown in Figure 7.1. Increasing the number of nodes from 10 to 50 decreased $Q_{a u x, D H W}$ by $6.6 \%$. The annual average temperature difference between the top and bottom nodes for the 50 node case was 
$21.2^{\circ} \mathrm{C}$. The diurnal tank losses to the basement thermal zone were found to be largely insensitive to $N_{D H W}$. This was expected since the level of tank insulation specified for the model was relatively thick.

Based on these findings, a 10 node diurnal tank representation was assumed to be sufficient for modelling the diurnal tank. Flow rates into the tank however, were varied in the parametric study discussed in Section 7.3. Previously in Section 6.1.4, a relationship was defined between collector area and solar loop flow rates. In order to capture the potential increase in stratification due to lower tank flow rates, the number of diurnal tank nodes used for the parametric study was set to 50 .

\subsubsection{Seasonal Tank Discretization}

A discretization sensitivity study was also conducted for the seasonal tank model. Similar to the previous discretization study, increasing the nodes in the seasonal tank allowed for modelling of greater stratification. This study allowed for investigation of the significance of seasonal storage stratification to annual performance. Figure 7.2 presents the results for the different seasonal tank discetization cases. The number of nodes modelled for the seasonal tank, $N_{\text {Seas }}$, was varied from 1 to 20 nodes.

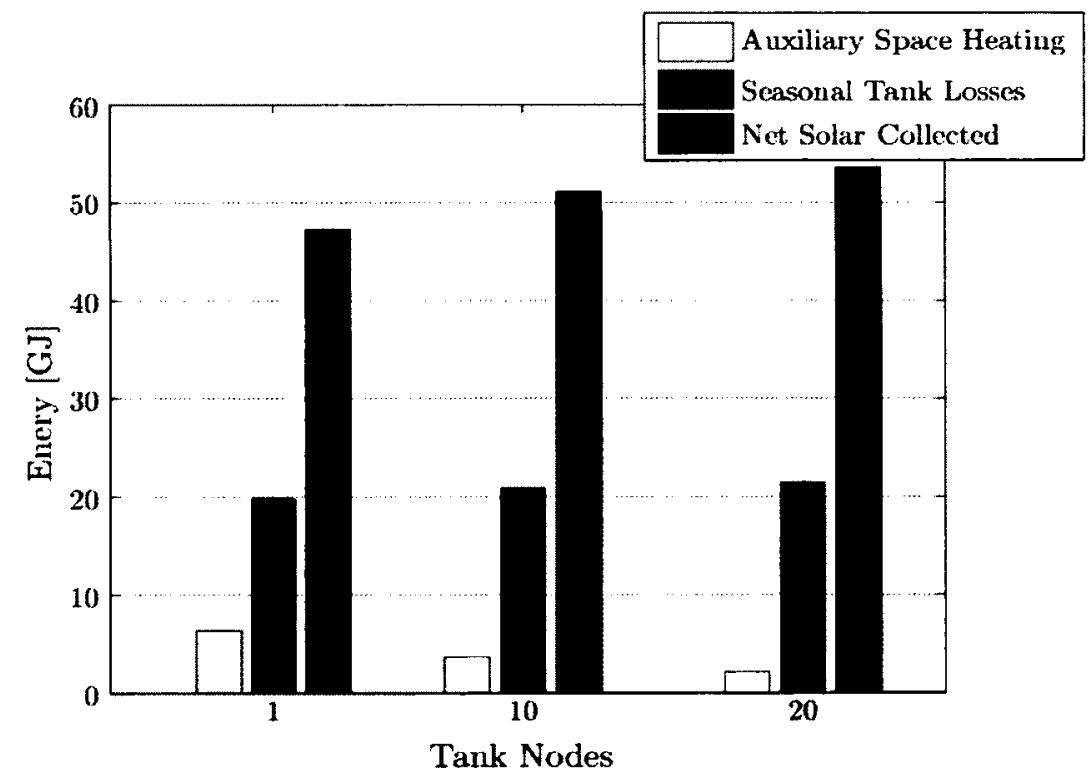

Figure 7.2: Annual results of the seasonal tank discretization study 
For the single node (fully mixed) case, the annual auxiliary energy supplied to the space heating loops, $Q_{a u x, s p a c e}$, was found to be $6.4 \mathrm{GJ}$. The corresponding space heating solar fraction, $\Im_{\text {space }}$, was $70.8 \%$. $\Im_{\text {space }}$ was calculated using Equation 7.4.

$$
\Im_{\text {space }}=\frac{Q_{\text {space }}-Q_{\text {aux }, \text { space }}}{Q_{\text {space }}}
$$

where $Q_{\text {space }}$ was recalculated for each system configuration co-simulated, described previously in Section 7.1.

When $N_{\text {Seas }}$ was increased to $10, Q_{a u x, \text { space }}$ reduced by $42 \%$ compared to the fullymixed case. The annual space heating solar fraction for the 10 node tank increased to a value of $83.2 \%$. Similar to the diurnal tank, these increases were related to the increased stratification in the seasonal tank. The annual average temperature difference between the top and bottom of the scasonal storage was $8.3^{\circ} \mathrm{C}$ for the 10 node tank. In the stratified case, higher temperature regions could be maintained at the top of the tank to meet space heating loads. For the fully-mixed case, the maximum temperature reached for the seasonal tank was $57.4^{\circ} \mathrm{C}$. By permitting stratification, the top of the tank was able to reach $63.9^{\circ} \mathrm{C}$.

Shown in Figure 7.2, further increasing $N_{\text {Seas }}$ from 10 to 20 nodes continued to decrease the auxiliary energy required for space heating by $41.1 \%$. This increased $\Im_{\text {space }}$ by another $8.3 \%$ and the annual average temperature difference between the top and bottom increased to $11.3^{\circ} \mathrm{C}$. $N_{\text {Seas }}$ was found to have little impact on the seasonal tank losses to ambient, increasing from $19.8 \mathrm{GJ}$ at 1 node to $21.4 \mathrm{GJ}$ at 20 nodes.

The net ${ }^{2}$ annual solar energy collected, $Q_{\text {coll }}[\mathrm{GJ}]$, was also analyzed in this study. In Chapter 2, stratification of a TES was said to improve solar thermal system performance by segregating hot and cold regions. The cold region at the bottom of a water tank allowed for lower temperatures to be sent to the solar collector, improving collector efficiency. When the seasonal tank was modelled as fully-mixed, the average annual inlet temperature of the collector array was $51.7^{\circ} \mathrm{C}$ and annual useful gain of the collector was 47.3 GJ. For the stratified tank with 20 nodes, the average annual inlet temperature decreased by $4.3^{\circ} \mathrm{C}$ and annual solar collection increased by $13.3 \%$.

\footnotetext{
2 "net" is used here since there were timesteps in the simulation where the solar loop pump turned on and the collector rejected thermal energy to ambient. The annual amount of energy was found to be negligible and is discussed further in Appendix B
} 
For the parametric study discussed in Section $7.3, N_{\text {Seas }}$ was fixed to 20 . Mentioned previously, the increases in stratification with increasing nodes is a modelling. artefact. Some stratification in the current system was assumed to occur based on experimental data from district scale seasonal solar thermal systems such as the buried tank system in Hannover, Germany [64]. It was assumed that 20 nodes was sufficient to represent stratification for the current system. It is recommended that future work uses experimental data to calibrate the 1 . D storage model to represent inlet jet mixing and stratiication.

\subsubsection{Summary of Findings}

This section focused on the numerical sensitivity of annual performance of the solar thermal system to discretizations of the diurnal and seasonal tanks. Numerical sensitivities were also investigated for the solar collectors, ground conduction model, and simulation timestep. The results of theses studies may be found in Appendix A.

Not only did the numerical sensitivity allow for investigation of grid dependence, but for the diurnal and seasonal tanks, it allowed for exploration of system performance dependence on stratification. The solar thermal system was found to be sensitive to the level of stratification in both the diurnal and scasonal tanks. When the diurnal tank was increased from 1 to 10 nodes, the annual DHW solar fraction increased from $81.5 \%$ to $88.3 \%$. The seasonal tank exhibited a higher sensitivity. An increase from 1 to 10 nodes increased the annual space heating solar fraction from $70.8 \%$ to $83.2 \%$. The tank losses to the environment however, were found to be largely insensitive to stratification. This was likely due the the relatively high level of insulation for both storage tanks.

\subsection{Parametric Study}

The majority of the C RISE SSTS was designed based on literature review and "best practices", described in Chapter 6. Mentioned previously, key parameters for the SSTS still required determination. The seasonal storage volume, $V_{\text {Seas }}$, gross solar collector area, $A_{c}$, and insulation thickness for the seasonal storage, $t_{\text {Seas }, \text { ins }}$, were major system parameters chosen for analysis. Using co simulation of the detailed ESP $r$ and TRNSYS models, a coarse parametric analysis of the SSTS was undertaken. A 
Table 7.2: System parameters used for the parametric study

\begin{tabular}{l|r}
\hline \multicolumn{2}{c}{ Seasonal Storage } \\
\hline Storage volume, $V_{\text {Seas }}\left[\mathrm{m}^{3}\right]$ & $80,120,180,240,300$ \\
Wall thickness, $t_{\text {Seas, wall }}[\mathrm{cm}]$ & 20 \\
Insulation thickness, $t_{\text {Seas }, \text { ins }}[\mathrm{cm}]$ & $30,45,60,80$ \\
\hline \multicolumn{2}{c}{ Solar Collectors } \\
\hline Gross collector area, $A_{c}\left[\mathrm{~m}^{2}\right](\#$ of collectors) & $17.24(6), 22.99(8), 28.74(10), 34.49(12)$ \\
Collector tilt, $\beta\left[^{\circ}\right]$ & 50 \\
Specific collector flow rate, $\dot{m}_{\text {coll }}^{\prime}\left[\mathrm{kg} / \mathrm{hr} \mathrm{\textrm {m } ^ { 2 } ]}\right.$ & 12 \\
\hline
\end{tabular}

summary of the parameters used in this study is provided in Table 7.2.

The upper limit of the collector area was based upon early estimates of the C-RISE roof space available. For $V_{\text {Seas }}$, a relatively large range of parameters was selected to explore. A relatively wide range of insulation levels was also selected since this parameter was found to vary significantly in practice. According to Hadorn [150], seasonal storages should have a minimum of $50 \mathrm{~cm}$ of insulation, and may be as high as 80 or $100 \mathrm{~cm}$. At the beginning of this research it was unclear what storage volume was required to carry summer solar gains to winter loads. Preliminary estimates based on simplified calculations indicated a volume of $300 \mathrm{~m}^{3}$ was required to accomplish high solar fractions for the C RISE house. Detailed simulation was used to better estimate seasonal storage volume with a goal of reducing the volume to better suit residential applications.

To constrain the variables in the system, the height of the seasonal tank fluid, $h_{\text {Seas }}$, was fixed for each value of $t_{\text {Seas,ins. }}$. In Section 6.1.3, it was stated that the total height of the tank was constrained to $4.5 \mathrm{~m}$ based on site geometric limits. The $20 \mathrm{~cm}$ concrete layers on the top and bottom further reduced the available height of the tank fluid to $4.1 \mathrm{~m}$. As the insulation of the seasonal tank increased, the available height of the seasonal storage fluid decreased proportionally. The $h_{\text {Seas }}$ and corresponding $t_{\text {Seas,ins }}$ values considered in this study are provided in Table 7.3. 
Table 7.3: Variation of seasonal tank fluid height in relation to insulation thickness

\begin{tabular}{c|c}
$t_{\text {Seas,ins }}[\mathrm{cm}]$ & $h_{\text {Seas }}[\mathrm{m}]$ \\
\hline \hline 30 & 3.5 \\
45 & 3.2 \\
60 & 2.9 \\
80 & 2.5
\end{tabular}

To compare the systems considered, a single performance metric was used for simplicity. The annual space heating and DHW solar fraction, $\Im_{\text {total }}$, was selected and is defined in Equation 7.5.

$$
\Im_{\text {total }}=\frac{\left(Q_{\text {space }}+Q_{D H W}\right)-\left(Q_{a u x, \text { space }}+Q_{a u x, D H W}\right)}{\left(Q_{\text {space }}+Q_{D H W}\right)}
$$

Figures 7.3, 7.4, 7.5, and 7.6 present the results of parametric study. Additional results of the parametric study may be found in Appendix B. Similar to the numerical study discussed previously, $Q_{\text {space }}$ was recalculated at each data point. 


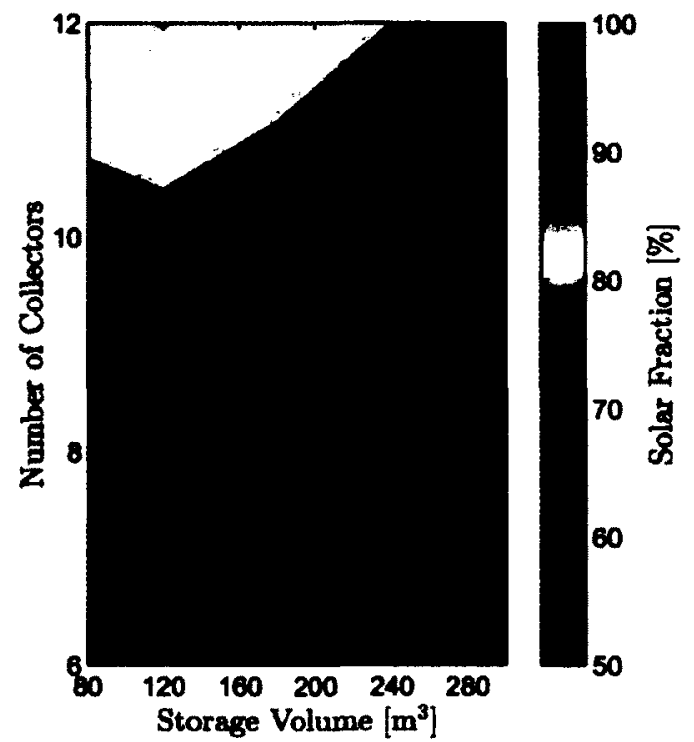

Figure 7.3: $30 \mathrm{~cm}$ insulation on the seasonal tank

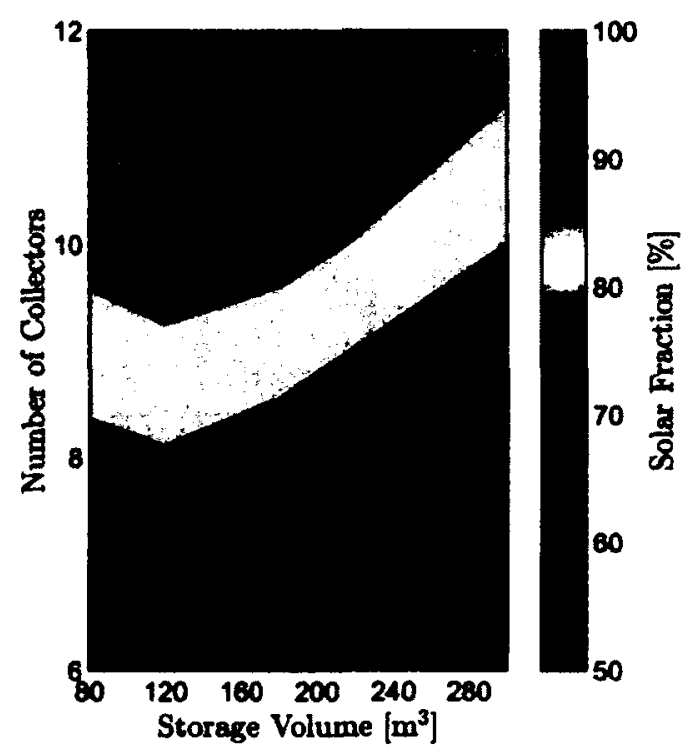

Figure 7.5: $60 \mathrm{~cm}$ insulation on the seasonal tank

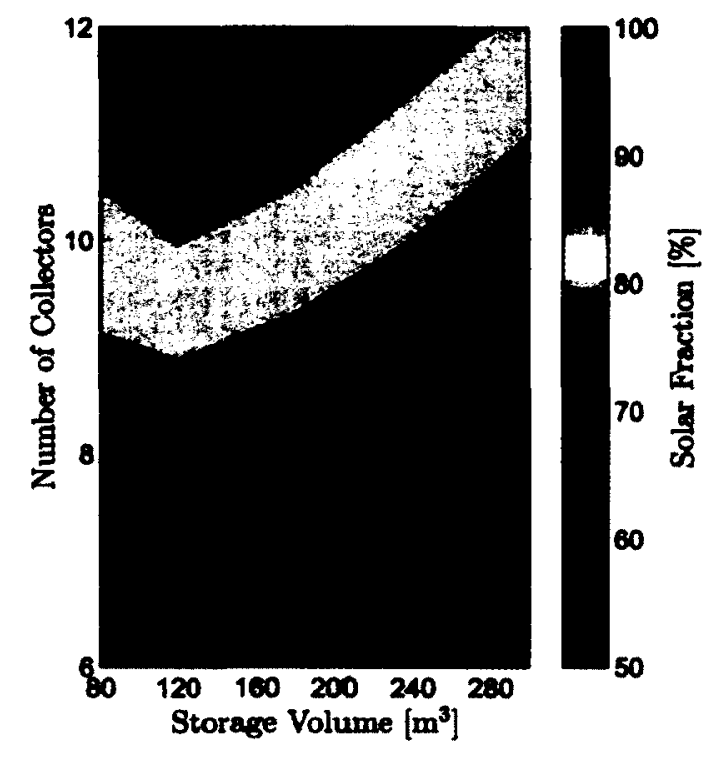

Figure 7.4: $45 \mathrm{~cm}$ insulation on the seasonal tank

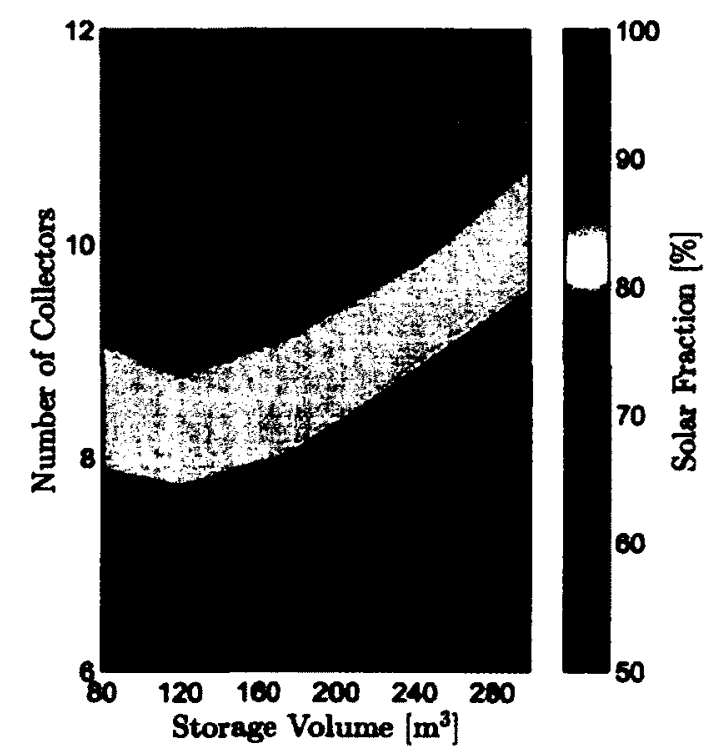

Figure 7.6: $80 \mathrm{~cm}$ insulation on the seasonal tank

Mentioned previously, co-simulations were run over a two year period to allow the SSTS to reach steady-state operation. To check the validity of this assumption, the difference between the initial and final average seasonal storage temperatures 
were determined for each system configuration considered. They were found to vary between 0.05 and $2.20^{\circ} \mathrm{C}$, where the larger temperature differences were observed for the larger storage volumes. This was not considered to be a large deviation. Therefore all data points taken in this study were assumed to be at steady-state. The auxiliary heaters described in Section 6.1.5.3 were also examined to ensure that they had sufficient capacity. The $15 \mathrm{~kW}$ heaters used in the space heating loops were found to be oversized. For all configurations considered, the highest heater output was $2.1 \mathrm{~kW}$. The $15 \mathrm{~kW} \mathrm{DHW}$ auxiliary heater however, reached maximum output between 0.08 and $0.12 \%$ of the time during the year. This was considered an insignificant length of time and was assumed to have negligible impact on the calculation of $\Im_{\text {total }}$.

For all data points considered, $\Im_{\text {total }}$ varied between $45.4 \%$ and $94.7 \%$. The highest $\Im_{\text {total }}$ occurred for the case with 12 collectors, a storage volume or $120 \mathrm{~m}^{3}$, and $80 \mathrm{~cm}$ of insulation on the seasonal tank. In fact, it was found that when $t_{\text {Seas,ins }}$ was varied the SSTS configuration with the highest $\Im_{\text {total }}$ occurred for 12 collectors and $120 \mathrm{~m}^{3}$.

Table 7.4 provides $\Im_{\text {total }}$ for all the $45 \mathrm{~cm}$ seasonal storage insulation cases considered.

Table 7.4: $\Im_{\text {total }}$ results for the $45 \mathrm{~cm}$ insulation case

\begin{tabular}{c|cccc}
\hline \multirow{2}{*}{$\begin{array}{c}\text { Storage } \\
\text { Vol. }\left[\mathbf{m}^{3}\right]\end{array}$} & \multicolumn{4}{|c}{ Number of Collectors } \\
$\mathbf{8 0}$ & $\mathbf{6}$ & $\mathbf{8}$ & $\mathbf{1 0}$ & $\mathbf{1 2}$ \\
\cline { 2 - 5 } $\mathbf{1 2 0}$ & $63.5 \%$ & $75.2 \%$ & $83.7 \%$ & $89.2 \%$ \\
$\mathbf{1 8 0}$ & $63.1 \%$ & $76.0 \%$ & $85.1 \%$ & $90.8 \%$ \\
$\mathbf{2 4 0}$ & $55.9 \%$ & $73.6 \%$ & $83.4 \%$ & $89.9 \%$ \\
$\mathbf{3 0 0}$ & $51.4 \%$ & $65.6 \%$ & $80.0 \%$ & $87.3 \%$ \\
\hline
\end{tabular}

It can be seen in Table 7.4 that generally when seasonal storage volume increased with fixed collector area, the $\Im_{\text {total }}$ tended to decrease. This was also apparent in the contour plots shown previously. For SSTS configurations with more than 6 collectors, $\Im_{\text {total }}$ initially increased as $V_{\text {Seas }}$ increased from 80 to $120 \mathrm{~m}^{3}$. Further increasing $V_{\text {Seas }}$ was then found to reduce $\Im_{\text {total }}$. This finding was contrary to previous results obtained by Braun et al. [18] or Sillman [25]. Both researchers used simplified simulation models 
and demonstrated increases in $\Im_{\text {total }}$ for a SSTS with increasing storage volume and fixed collector arca.

For SSTS configurations with 6 collectors, the annual useful gain of the collectors varied between $28.2 \mathrm{GJ}$ and $35.1 \mathrm{GJ}$. Shown in Section 7.1, the annual energy required for the DHW and space heating end loads was $33 \mathrm{GJ}$. This suggested that the 6 collector array had insufficicnt area for meeting close to $100 \%$ of the domestic loads. At greater collector areas, $\Im_{\text {total }}$ would initially improve when $V_{\text {Seas }}$ was increased from 80 to $120 \mathrm{~m}^{3}$. Around $120 \mathrm{~m}^{3}$ there appeared to be a critical point, then $\Im_{\text {total }}$ began to decline with increasing $V_{\text {Seas }}$.

To explain this behaviour, the annual useful gain of the solar collectors, $Q_{\text {coll }}$, was considered. The trend observed for all cases was that increasing $V_{\text {Seas }}$ lead to an increase of $Q_{\text {coll }}$. At the same time, the annual efficiency of the seasonal storage, $\eta_{s, \text { Seas }}$, was observed to decline with increasing $V_{\text {Seas }}$. The calculation of $\eta_{s, \text { Seas }}$ is shown in Equation 7.6:

$$
\eta_{s, \text { Seas }}=\frac{Q_{\text {Seas }, \text { out }}}{Q_{\text {Seas }, \text { in }}}
$$

where $Q_{\text {Seas,out }}$ is the annual energy discharged from the seasonal tank to the space heating load [GJ], and $Q_{\text {Seas,in }}$ is the annual energy charged into the seasonal tank [GJ]. It was determined that at the critical point, the losses from the seasonal storage became more significant than the increase in $Q_{\text {coll }}$.

Since the height of the seasonal storage was fixed for a constant $t_{\text {Seas,ins }}$, the aspect ratio of the seasonal tank varied with volume. Specifically, the surface-tovolume ratio of the seasonal storage decreased with increasing volume while overall surface area of the tanks increased at a larger rate. For example, when the storage volume for the $45 \mathrm{~cm}$ insulation case increased from 80 to $300 \mathrm{~m}^{3}$, the surface to volume ratio decreased by $13.8 \%$. Conversely, the surface area of the seasonal storage increases by $223 \%$ leading to elevated tank losses.

Examination of the sensitivity of the solar thermal system to $t_{\text {Seas,ins }}$ was not clear using the contour plots shown previously. Figure 7.7 plots $\Im_{\text {total }}$ versus $t_{\text {Seas,ins }}$ for the system configuration with 12 collectors and a seasonal storage volume of $120 \mathrm{~m}^{3}$. As expected, the annual performance was seen to increase with increasing insulation of the storage. There was however, diminishing returns with increasing insulation thickness. Between 60 and $80 \mathrm{~cm} \Im_{\text {total }}$ increased from 93.3 to $94.7 \%$, whereas over the shorter interval of 45 to $60 \mathrm{~cm} \Im_{\text {total }}$ increased from 90.8 to $93.3 \%$. Again, it is 
important to point out that the height of the seasonal tank varied with insulation thickness and the surface to volume ratio varied between 1.25 and $1.38 \mathrm{~m}^{2} / \mathrm{m}^{3}$.

An additional sensitivity analysis was conducted based on the findings from the coarse parametric study. Here the SSTS was fixed at 12 collectors and a scasonal tank insulation thickness of $45 \mathrm{~cm}$. The seasonal storage volume was varied between 80 and $150 \mathrm{~m}^{3}$ to examine the sensitivity of $\Im_{\text {total }}$ near the critical point discussed previously. The results of this study are shown in Figure 7.8. Over the range of $V_{\text {Seas }}$ 
considered here, the annual performance $\Im_{\text {total }}$ was found to vary between $89.2 \%$ and $90.8 \%$.

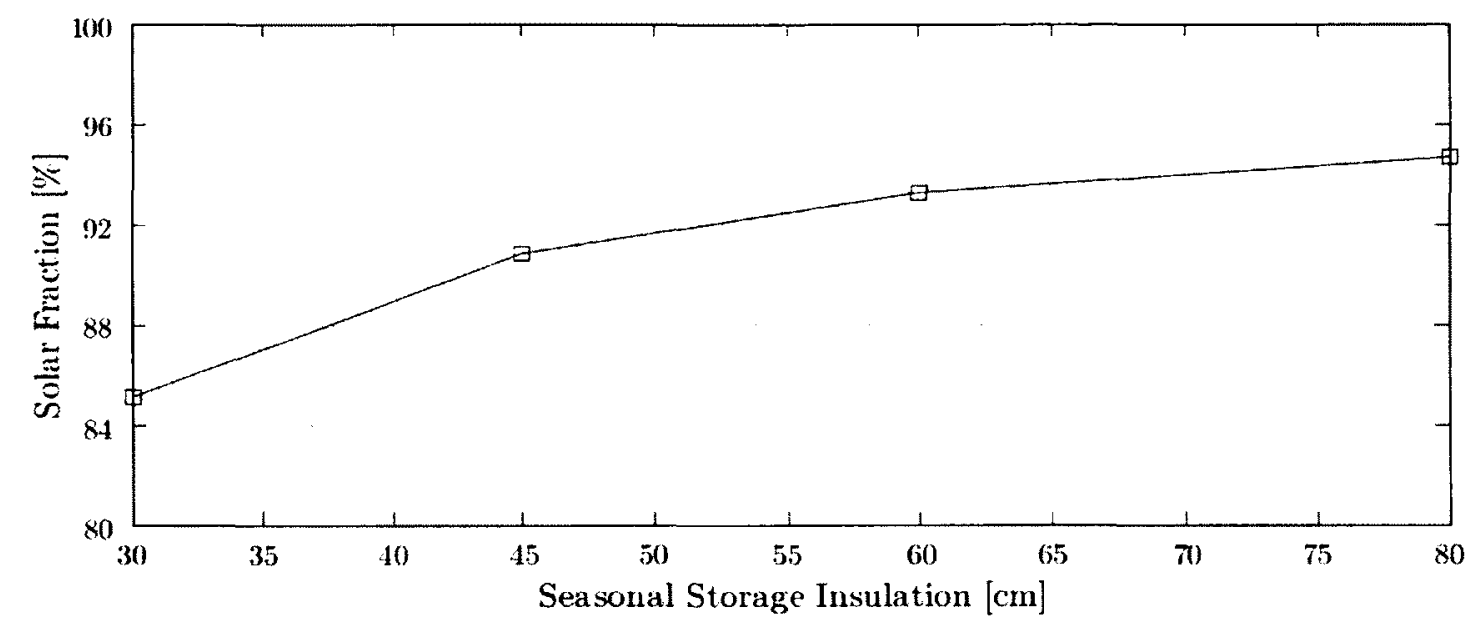

Figure 7.7: Sensitivity of $\Im_{\text {total }}$ to $t_{\text {Seas,ins }}$ for the 12 collector and $120 \mathrm{~m}^{3}$ system

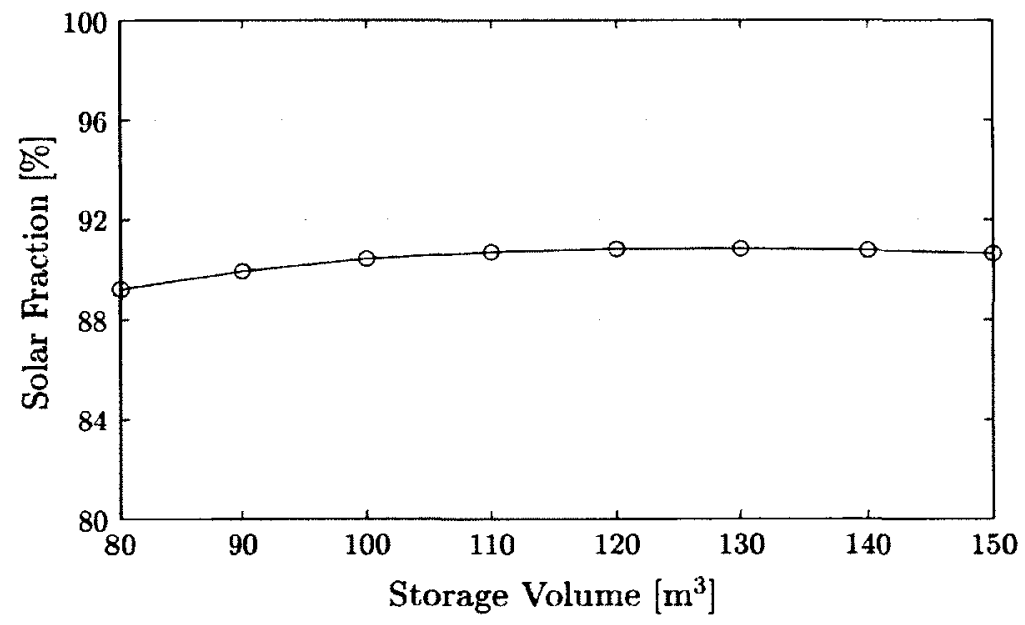

Figure 7.8: Sensitivity analysis for $45 \mathrm{~cm}$ seasonal tank insulation and 12 collector case

In Section 7.4, a detailed analysis of SSTS with 12 collectors, $80 \mathrm{~m}^{3}$, and $45 \mathrm{~cm}$ thick tank insulation is discussed. The purpose of this analysis was to evaluate the performance of the two tank SSTS system developed for this study. This also allowed for indepth examination of the model implementation of the C-RISE building and solar thermal system to ensure that they were behaving as expected. The term 
"selected case" was used to refer to this system configuration. It should be noted that the "selected case" does not pertain to an "optimum" case. The selected case was found to achieve a $\Im_{\text {total }}$ of $89.2 \%$ with the smallest $V_{\text {Seas }}$ considered in this study. Relatively small storage volumes were desirable for the residential application where cost and availability of space is a major concern.

\subsubsection{Summary of Findings}

The general findings of the parametric study are as follows:

- The seasonal solar thermal systems considered with 6 collector panels were found to have insufficient annual collection to meet the majority of the DHW and space heating loads of the C-RISE house.

- For cases with 8 or more solar collectors, $\Im_{t o t a l}$ was found to initially increase with increasing $V_{\text {Seas }}$ up to a critical point. Once that point was reached, $\Im_{\text {total }}$ would then begin to decrease with increasing $V_{\text {Seas }}$.

- For all levels of seasonal tank insulation considered, the system configurations with 12 collectors and $120 \mathrm{~m}^{3}$ seasonal storage volume were found to have the highest $\Im_{\text {total }}$. The seasonal storage volume to gross collector area ratio for this configuration was $3.48 \mathrm{~m}^{3} / \mathrm{m}^{2}$.

- For the $120 \mathrm{~m}^{3}$ seasonal storage and 12 collector case, there was diminishing returns with increasing seasonal tank insulation thickness. From 60 to $80 \mathrm{~cm}$ $\Im_{\text {total }}$ increased by $1.4 \%$.

- $\Im_{\text {total }}$ was found to be relatively insensitive to $V_{\text {Seas }}$ between 80 and $150 \mathrm{~m}^{3}$.

\subsection{Analysis of "Selected Case"}

The previous section used a single metric to compare the performance of several parameters of the C RISE seasonal solar thermal system. In this section a single configuration of the SSTS is examined, referred to as the "selected case". The purpose of this study was to evaluate the performance of the two tank SSTS concept. This study also allowed for examination of the behaviour of the model and whether it was behaving as expected. 
The overall performance and operation of the system is first discussed below. The discussion is then shifted to key components of the system, namely the solar collectors and storage tanks. This was necessary to examine how these components were functioning in the simulation and evaluate their annual performance. Information on the "selected case" parameters and annual performance is provided in Table 7.5.

Table 7.5: System parameters of the "selected case"

\begin{tabular}{lr}
\hline \multicolumn{2}{c}{ Seasonal Storage } \\
\hline Storage volume, $V_{\text {Seas }}\left[\mathrm{m}^{3}\right]$ & 80 \\
Storage height, $h_{\text {Seas }}[\mathrm{m}]$ & 3.2 \\
Insulation thickness, $t_{\text {Seas, } i n s}[\mathrm{~cm}]$ & 45 \\
Storage efficiency, $\eta_{s, \text { Seas }}[\%]$ & 59.1 \\
\hline \multicolumn{1}{c}{ Solar Collectors } \\
\hline Number of Collectors & 12 \\
Gross collector area, $A_{c}\left[\mathrm{~m}^{2}\right]$ & 34.49 \\
Collector tilt, $\beta\left[{ }^{\circ}\right]$ & 50 \\
Specific collector flow rate, $\dot{m}_{\text {coll }}^{\prime}\left[\mathrm{kg} / \mathrm{hr} \mathrm{m}^{2}\right]$ & 12 \\
\hline \multicolumn{1}{c}{ Annual System Performance } \\
\hline Annual solar energy collected, $Q_{\text {coll }}[\mathrm{GJ}]$ \\
Annual space heating solar fraction, $\Im_{\text {space }}[\%]$ & 43.0 \\
Annual DHW solar fraction, $\Im_{D H W}[\%]$ & 89.1 \\
\hline
\end{tabular}

Figure 7.9 shows the monthly values of energy collected from the solar resource, energy discharged from the diurnal and seasonal storage tanks, and auxiliary energy supplied to the DHW and space heating loads. This figure demonstrates the seasonal operation of the solar thermal system, where summer collection of solar energy is carried over for use in winter space heating demands.

As the summer season progressed, the monthly solar energy collected began to reduce. It will be shown in Section 7.4.2 that the average storage tank temperatures continued to rise to a maximum temperature by August. While the temperature increase was necessary for sensible thermal energy storage, the elevated temperatures had the adverse effect of increasing average inlet temperatures to the solar collectors. 


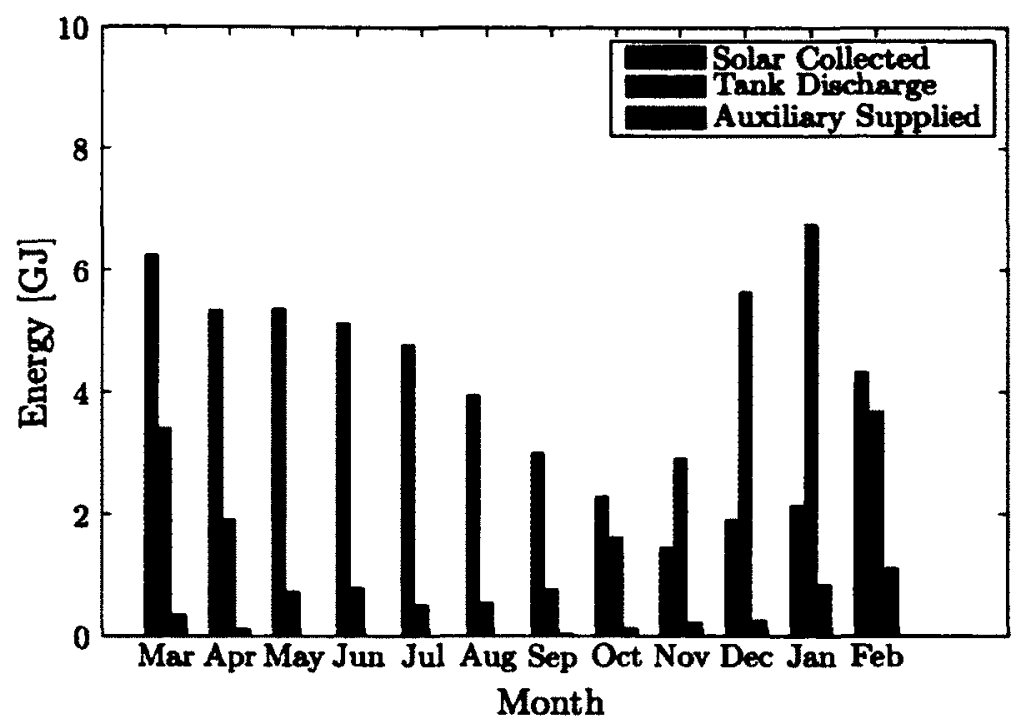

Figure 7.9: Energy supplied to and delivered by the "selected case" seasonal solar thermal system

This subsequently reduced the collector efficiencies, shown below, and lead to the reduction of monthly solar collected as the summer progressed.

\subsubsection{Solar Collectors}

Figure 7.10 provides monthly box plots for the collector instantaneous efficiencies, defined in Section 4.3.1. The upper and lower bounds of the boxes represent the 75 th and 25 th percentiles of the monthly data sets respectively. The line within the box represents the median of each data set and the whiskers extend to the outermost points not considered outliers ${ }^{3}$. The points shown beyond whiskers represented outlier values. A general periodic trend may be seen, where the efficiency reached its lowest levels in October and November.

It should be noted that the instantaneous efficiency expression was defined for steady-state operation. The application of this metric to the transient system lead to efficiencies in excess of $100 \%$, which have been clipped from Figure 7.10 for clarity. The thermal capacity of the collectors were able to store heat in its thermal mass. After the sun had set, the collector may still have a temperature above ambient. If there was a large demand for DHW, the makeup water in the diurnal tank would be

\footnotetext{
${ }^{3}$ For this study, outliers were defined as data which did not fall within $99.3 \%$ of the distribution.
} 
relatively low and may be used to extract useful gain from the warmed collector even though there was no solar radiation.

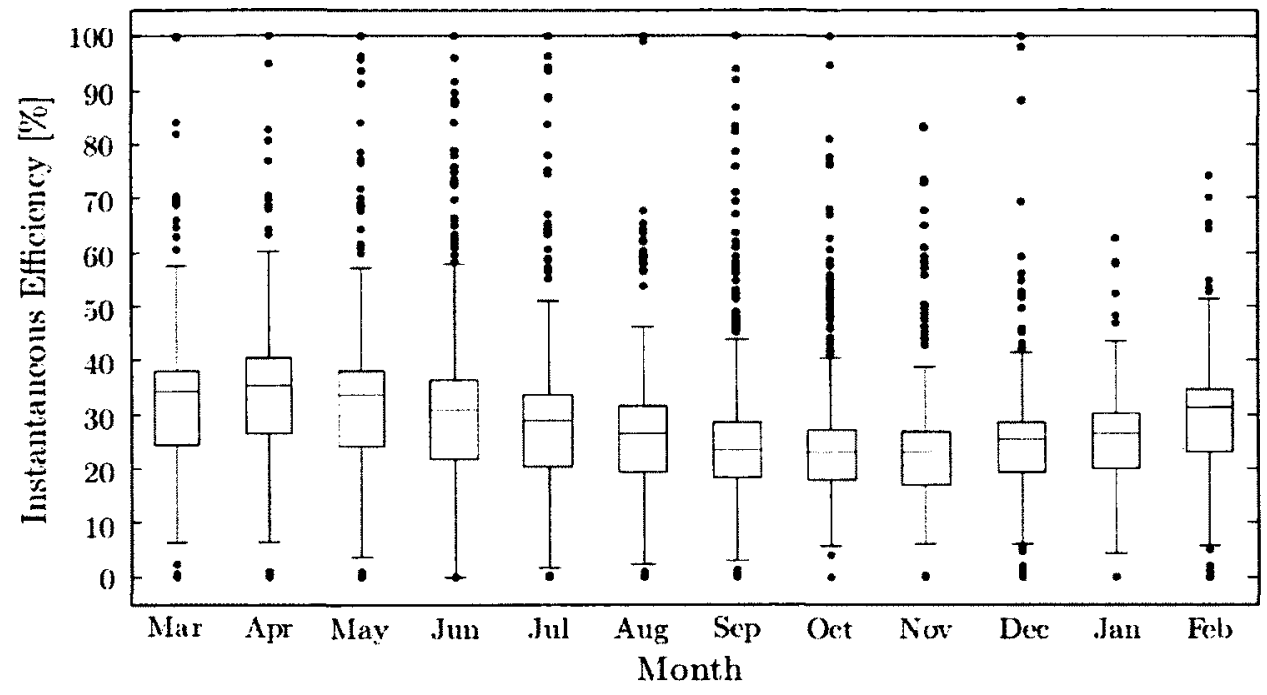

Figure 7.10: Instantaneous efficiencies of the solar collectors

The median values of the solar collectors never exceeded a relatively low $40 \%$. This was a consequence of the low flow design described in Section 6.1.4. As the seasonal storage tank temperature increased during charging during the summer, so too did the inlet temperatures to the collector array. This is illustrated in the box plots given in Figure 7.11 . 


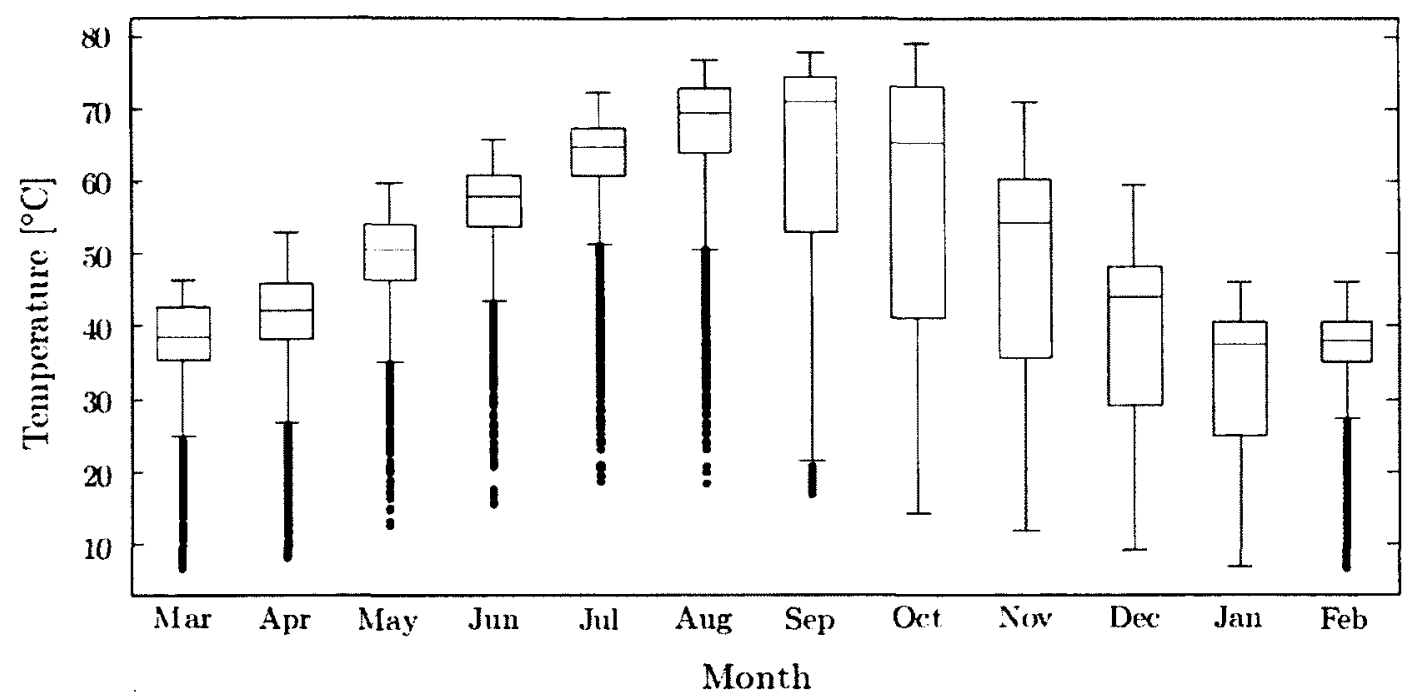

Figure 7.11: Inlet temperatures of the solar collectors

By September and October, the supply temperatures to the array were reaching their highest values. These elevated temperatures meant there were fewer periods during the month where useful solar collection could be achieved. This period however, coincided with relatively low average solar radiation levels.

\subsubsection{Seasonal Tank}

The top, bottom, and average temperatures for the seasonal storage are provided in Figure 7.12. The maximum annual temperature reached at the top of the seasonal storage was $81.5^{\circ} \mathrm{C}$ in September. By February, the seasonal storage was nearly fully discharged. The minimum temperature at the top of the tank was $43.0^{\circ} \mathrm{C}$, occurring during the month of March.

Over the course of the year, the seasonal storage lost 15.5 GJ through the tank envelope, $50.8 \%$ of which was lost from the sides of the tank and $25.4 \%$ through the top. The resulting annual storage efficiency was 55.6\%, calculated using Equation 7.6. This value meant that little over half of the energy injected into the seasonal tank was later recovered for meeting space heating loads. This low efficiency was expected since the seasonal tank reached relatively high temperatures near full charge and stored the high temperature thermal energy for relatively long periods.

The rise and fall of the seasonal tank temperatures appeared to correlate well 


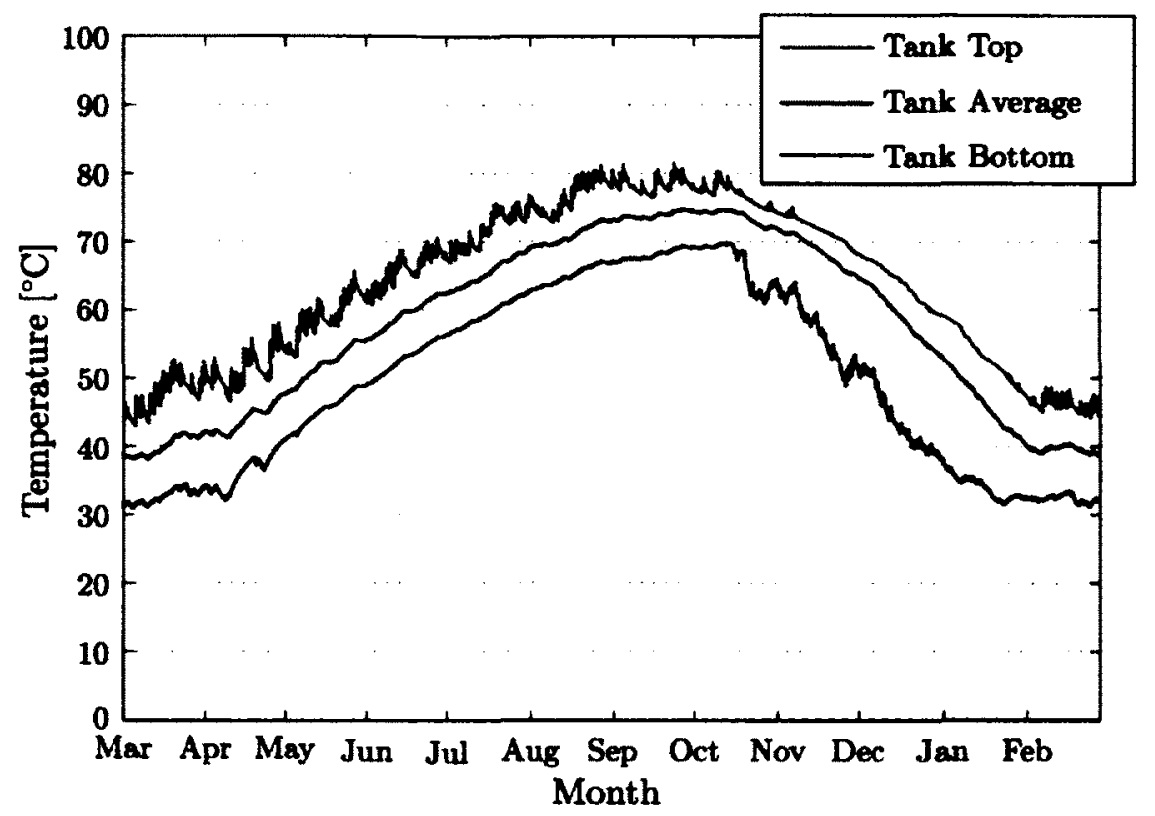

Figure 7.12: "Selected case" annual seasonal tank temperatures

with the inlet temperatures to the collector array shown in Figure 7.12. This type of interaction was expected based on the layout of the solar collector loop shown in Section 6.1. The seasonal storage charge loop was upstream of the solar collector array inlet and the seasonal storage was anticipated to have a large influence on inlet temperatures to the collectors.

\subsubsection{Diurnal Tank}

Figure 7.13 illustrates the temperatures at the top of the diurnal tank. The frequent temperature oscillations in the diurnal tank top temperature illustrates the high cycling of the storage. This relatively small tank was also much more sensitive to solar intermittence. There are several periods where the top volume of fluid was unable to reach the $65^{\circ} \mathrm{C}$ setpoint. This is most obvious in January, when there were several days of low solar insolation.

Throughout the year, the diurnal tank spent $44.2 \%$ of the time below $60^{\circ} \mathrm{C}$. Figure 7.13 however, shows that the tank frequent reaching the $65^{\circ} \mathrm{C}$ setpoint. It was mentioned in Section 6.1.1.1 that for potable water tanks the temperature should be held at $60^{\circ} \mathrm{C}$ or at least periodically cycled up to $66^{\circ} \mathrm{C}$. For future work, it is 


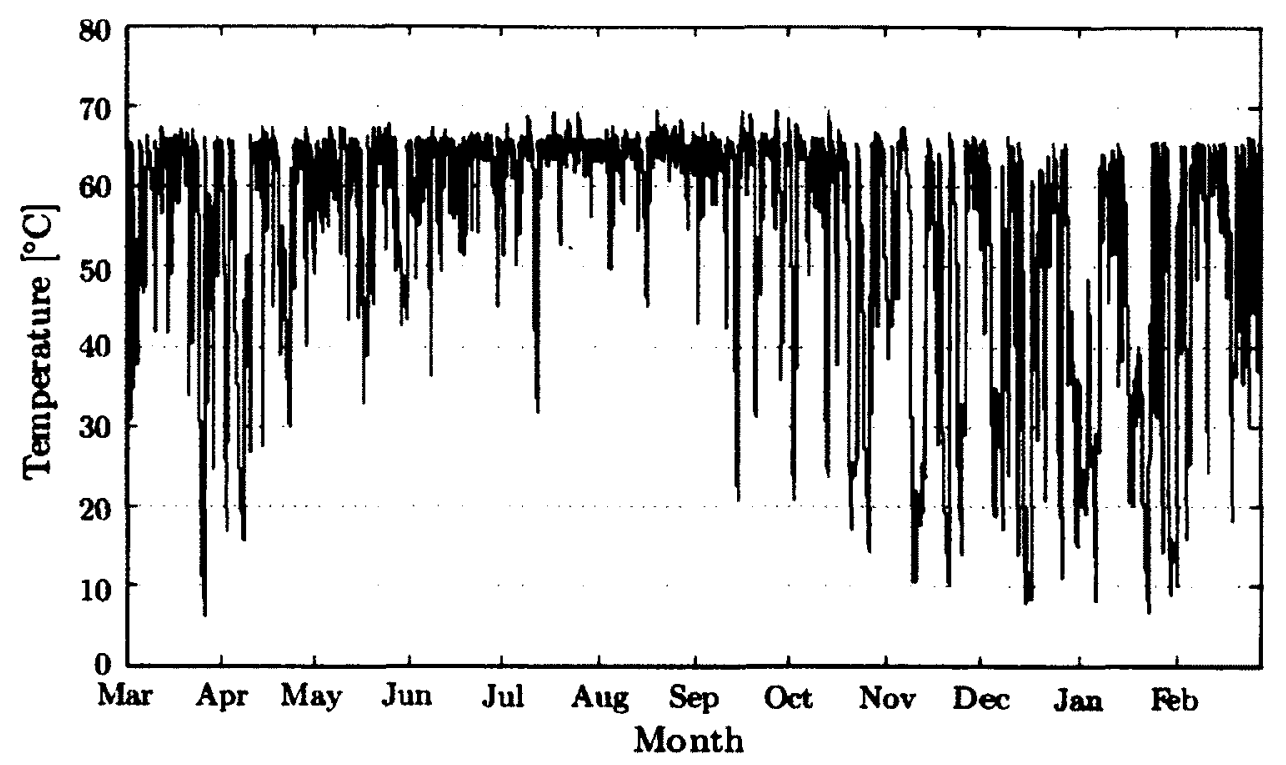

Figure 7.13: "Selected case" annual diurnal tank top temperatures

recommended that an auxiliary heat source be included within the diurnal tank to ensure minimum temperature requirements.

The storage efficiency of the diurnal tank for the year was $92.6 \%$. A relatively high storage efficiency was expected since the charge-discharge cycle of the diurnal tank was relatively short. Energy supplied to the diurnal tank was almost immediately withdrawn to meet $\mathrm{DHW}$ loads, creating a relatively short period of time for that energy to be lost to ambient. For the "selected case" diurnal tank, the annual energy lost to the basement zone of the C-RISE house was $0.76 \mathrm{GJ}$.

\subsubsection{Hydronic Slab Operation}

While design and investigation of occupant comfort was not the focus of the current research, it was still beneficial to examine simulated conditions in the occupied spaces of C-RISE. There was little value in analyzing a SSTS which was unable to provide sufficient heating to occupants. In Section 6.2, the heating setpoint of the occupied spaces was specified as $20 \pm 1^{\circ} \mathrm{C}$. In this section, the ability of the SSTS to meet the heating setpoint is examined.

Figure 7.14 illustrates the zone temperatures and casual gains for the main zone in the C-RISE house. The second floor zone was found to follow similar trends and was omitted here for clarity. During the heating season, the zone air temperature can 
be seen oscillating about the $20^{\circ} \mathrm{C}$ setpoint temperature. The lower band for space heating of both occupied zones was $19^{\circ} \mathrm{C}$. During the year the main and second floor air temperature was below $19^{\circ} \mathrm{C} 10.7 \%$ and $9.1 \%$ of the time respectively. In a previous study conducted by Edwards [163], an acceptable limit for time spent not meeting the setpoint of $5 \%$ was adopted. Based on this criteria, the space heating system modelled for this work required refinement to meet acceptable levels of occupant comfort.

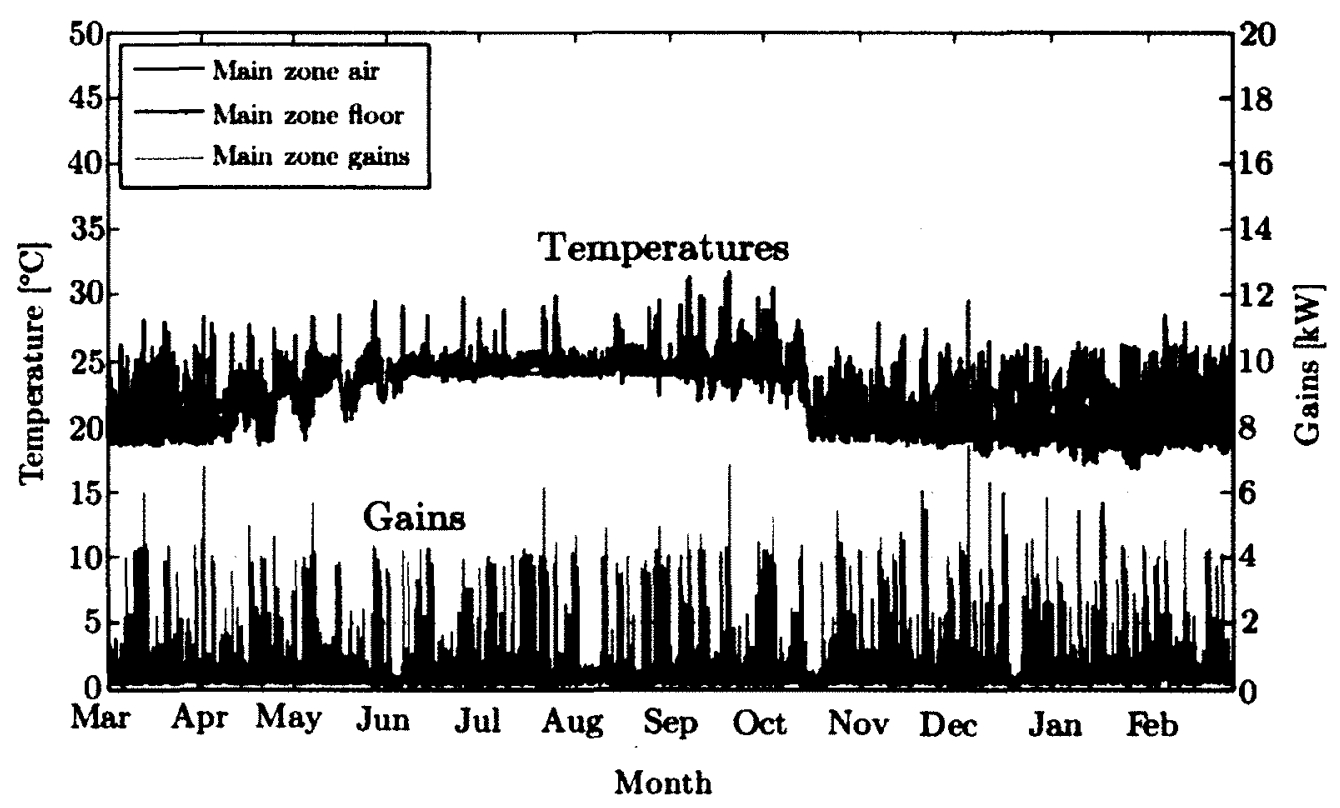

Figure 7.14: Temperatures and internal gains of the main floor zone

To investigate the severity of the unmet setpoint temperature, the time spent below $18^{\circ} \mathrm{C}$ was considered. This temperature was typical of a nighttime setback temperature. The main and second zones were found to have spent $1.3 \%$ and $0.8 \%$ of the year below $18^{\circ} \mathrm{C}$ respectively. This suggested that while the system was unable to meet the space heating load for the occupied spaces it did not deviate far from the lower heating temperature limit. The maximum average floor temperatures reached in the main and second floors were 28.1 and $27.2^{\circ} \mathrm{C}$ respectively. These values were below the $29^{\circ} \mathrm{C}$ temperature limit [132].

Figure 7.15 illustrates the main zone air and hydronic floor temperatures, and internal zone gains for the one week period between January $27^{\text {th }}$ and February $2^{\text {nd }}$. This period in the CWEC climate file was classified as a "winter extreme week" [164]. The minimum ambient drybulb temperature during this period was $-25^{\circ} \mathrm{C}$. 


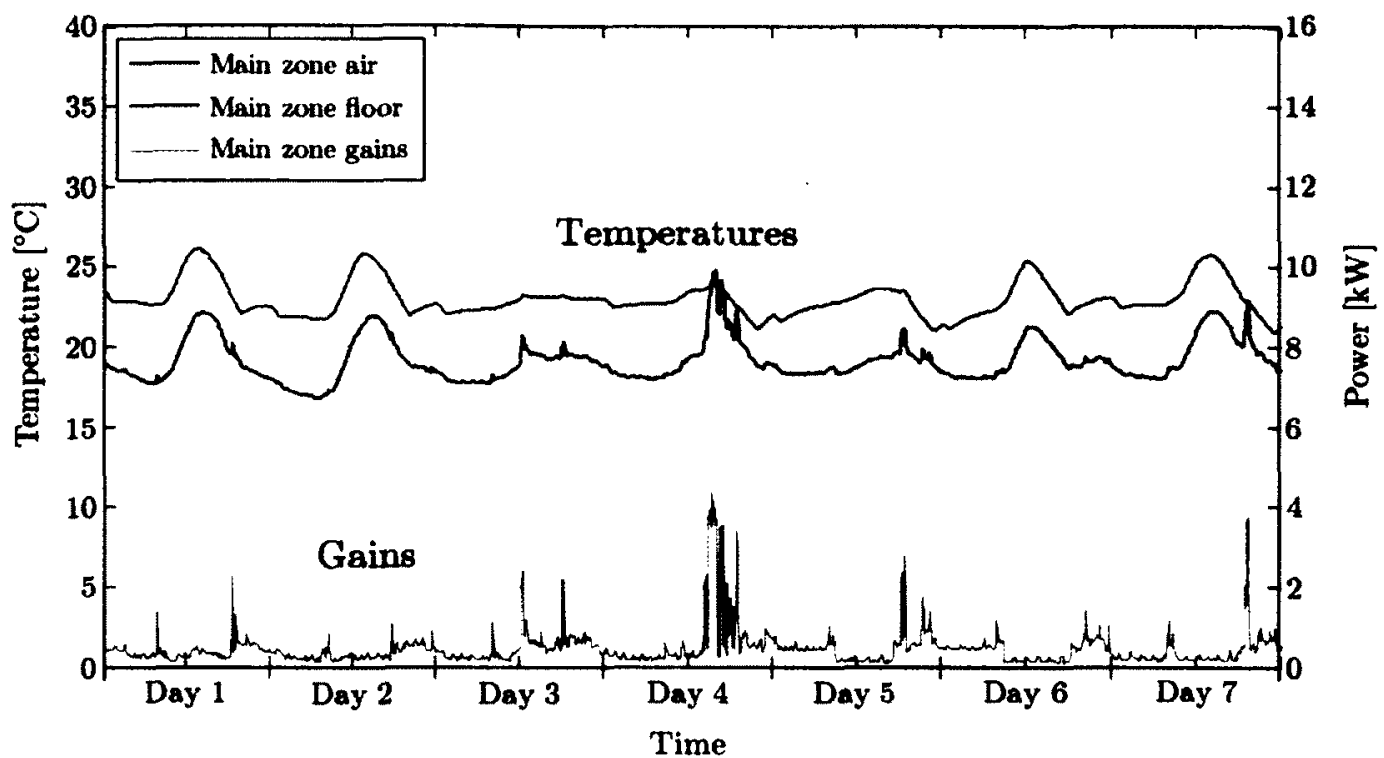

Figure 7.15: Temperatures and internal gains of the main floor zone for $\mathrm{Jan} 27^{\text {th }}$ to Feb $2^{\text {nd }}$

It was observed from the figure that the majority of time during this week was spent below the $20^{\circ} \mathrm{C}$. This is related to a control issue for the hydronic floor systems. It was shown previously that the auxiliary heaters had sufficient capacity for the space heating application. It is recommended for future work that the control and design of the hydronic floor be refined. For this research, the system was assumed to be sufficient for investigating and comparing annual SSTS performance. For both the main and second floors, the annual average drybulb temperature was $22.0^{\circ} \mathrm{C}$.

The air temperature of occupied zones was used to define and control acceptable thermal conditions for occupants. However, the space is conditioned using an infloor heating system where a large portion of the heat transfer is radiation. A much better metric for evaluating comfort in this type of system would be the operative temperature, which represents the combined influence of the air temperature and the mean radiant temperature ${ }^{4}$. An occupant may feel comfortable if there is sufficient radiant heat exchange between themself and the heat surface. Olesen [133] noted that a heated floor system can achieve an equivalent operative temperature with a reduced air temperature compared to a $100 \%$ convective heating system. Detailed analysis of thermal comfort however, was beyond the scope of this work. It is recommended that

\footnotetext{
${ }^{4}$ Mean radiant temperature is the surface temperature of an imaginary black enclosure that would have an equivalent exchange of radiant heat as the current enclosure the occupant is in [165]
} 
future work consider the thermal comfort definitions provided in ASHRAE Fundamentals [94] and comfort criteria in ASHRAE Standard 55 [165] to evaluate occupant comfort with the hydronic floor system.

\subsection{5 "Selected Case" Sensitivity Analysis}

Throughout the Parametric study discussed in Section 7.3, the seasonal tank crosssectional geometry was constrained to a square to reduce the surface to volume ratio. In practice however, such geometries may not be structurally or economically feasible. A coarse sensitivity analysis using the "best case" was conducted to examine the influence of varying tank geometries to system performance. There was also interest in examining the sensitivity of collector array slope to system performance. For the C-RISE house, the collectors were to be laid flat against the roof. The designers were interested in the relationship of the roof slope to solar thermal system performance.

\subsubsection{Seasonal Tank Height to Diameter Ratio}

The H/D ratio of the "selected case" was 0.64 . Ochs [47] had stated that a typical $H / D$ for seasonal storages was 1 . To examine the impact of H/D ratio of the C-RISE seasonal storage, a sensitivity analysis was conducted. Since the cross-section of the seasonal storage was square, the diameter in this study was defined using the hydraulic diameter. The length, width, and height of the seasonal storage is illustrated in Figure 7.16.

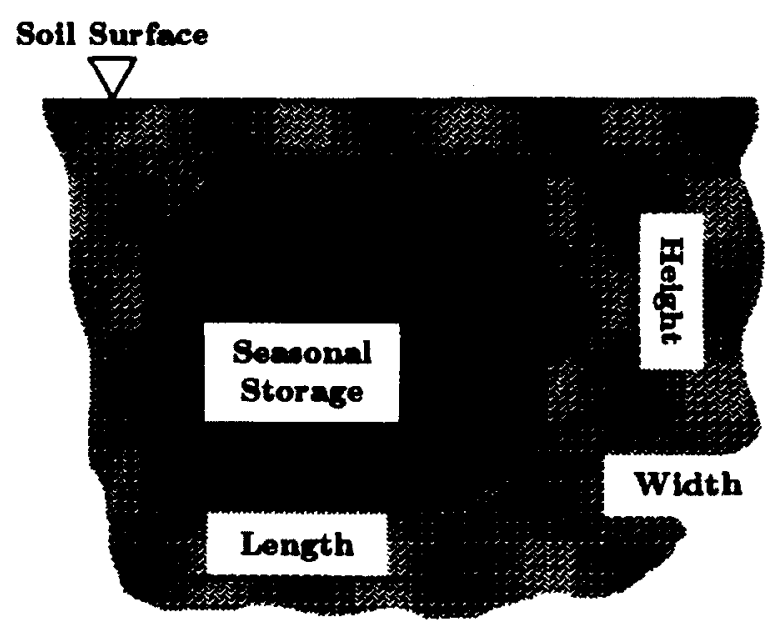

Figure 7.16: Seasonal storage length, width, and height definitions 
For a square cross section, the hydraulic diameter is simply the length of one side of the square. As the height of the seasonal storage varied, the distance between the bottom of the tank and the ground water remained fixed at $0.5 \mathrm{~m}$. Based on the geometry of the $\mathrm{C}$ - RISE site, by a $\mathrm{H} / \mathrm{D}$ ratio of 0.65 the top of the buried tank would rise above the soil surface. For all cases considered here the soil surface was translated up so as to be flush with the top of the tank. This was assumed to approximate berming of the storage. Due to these geometric constraints, the $\mathrm{H} / \mathrm{D}$ ratio was varied only from 0.5 to 1 . The results of this analysis are given in Figure 7.17.

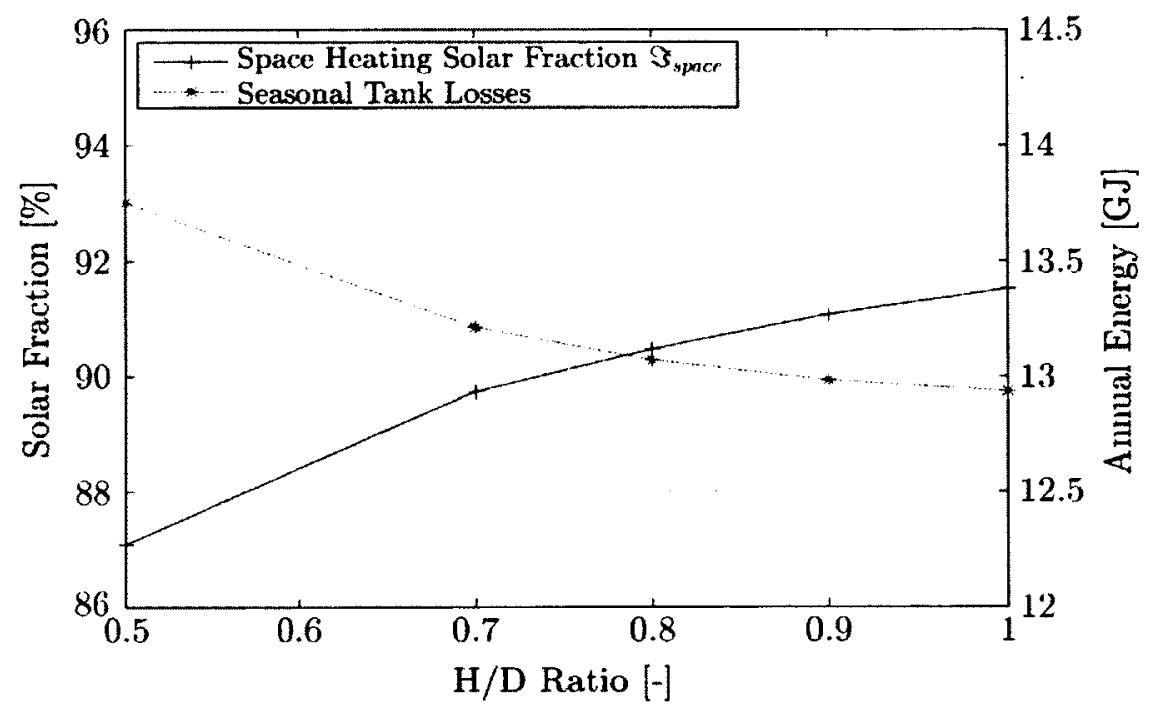

Figure 7.17: Seasonal storage H/D ratio sensitivity study

The $\Im_{\text {space }}$ was expected to improve as H/D increased. By increasing the height of the tank, greater stratification could be achicved. The annual average temperature difference between the top and the bottom of the seasonal storage increased by $1.9^{\circ} \mathrm{C}$ over the range of $\mathrm{H} / \mathrm{D}$ considered here. The seasonal storage losses were also found to reduce as the $\mathrm{H} / \mathrm{D}$ was increased. At $\mathrm{H} / \mathrm{D}$ of 1 , the seasonal storage would have a cube geometry and reach the minimum surface to volume ratio.

Increasing the $\mathrm{H} / \mathrm{D}$ from 0.5 to 1 increased $\Im_{\text {space }}$ by $5.1 \%$. The losses from the seasonal tank were found to decrease by $5.9 \%$ over the same range. These results were anticipated since the increase in height in the storage would allow for a greater degrees of stratification and improved surface to volume ratio over that range. 


\subsubsection{Seasonal Tank Length to Width Ratio}

For the length to width ratio $(\mathrm{L} / \mathrm{W})$ study, the height of the seasonal storage was fixed. The results of this study are shown in Figure 7.18. It was found that beyond a $\mathrm{L} / \mathrm{W}$ of 0.6 , the annual performance of the system was relatively insensitive to the ratio.

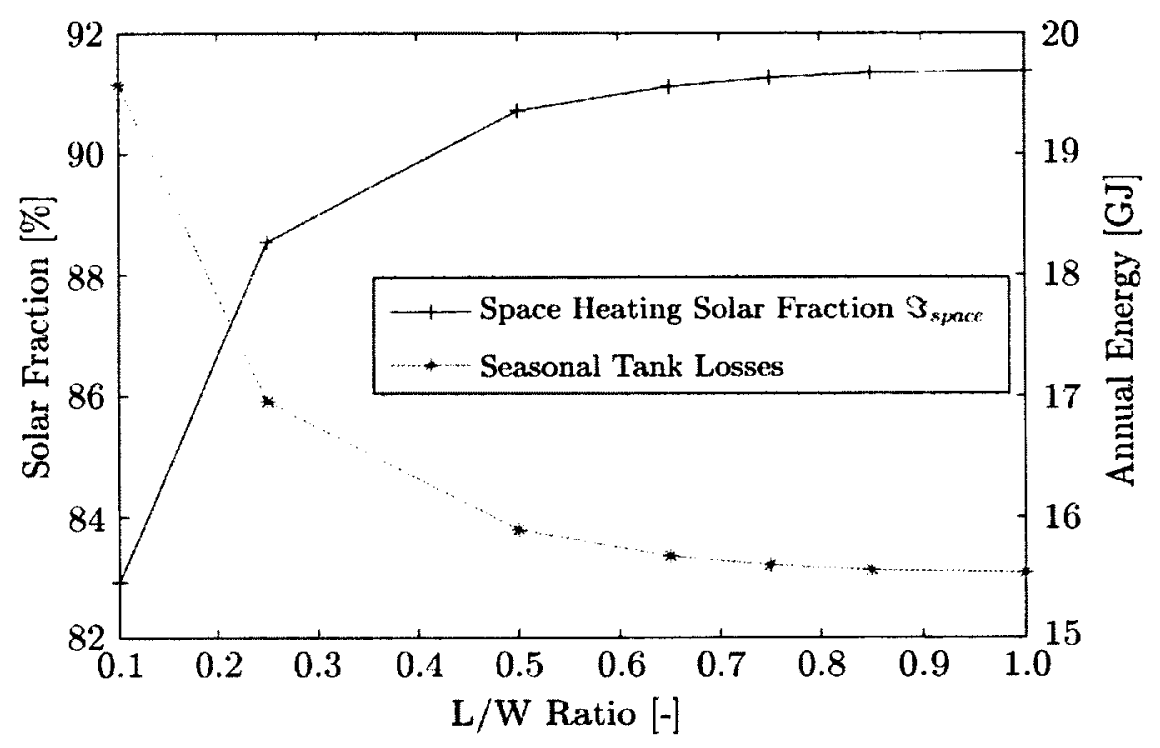

Figure 7.18: Seasonal storage L/W ratio sensitivity study 


\subsubsection{Collector Slope}

The solar thermal collectors for the C-RISE house were to be mounted flat against the roof of the house. The driving force behind this decision was aesthetics. There was also a secondary benefit of cost savings by removing the need for collector racking structures. Designers of the building envelope were considering roof slope angles between $50^{\circ}$ and $55^{\circ}$. A sensitivity analysis was conducted to examine the impact of collector slope. The collector slope was plotted against $\Im_{D H W}$ and $\Im_{\text {space }}$, shown in Figure 7.19 .

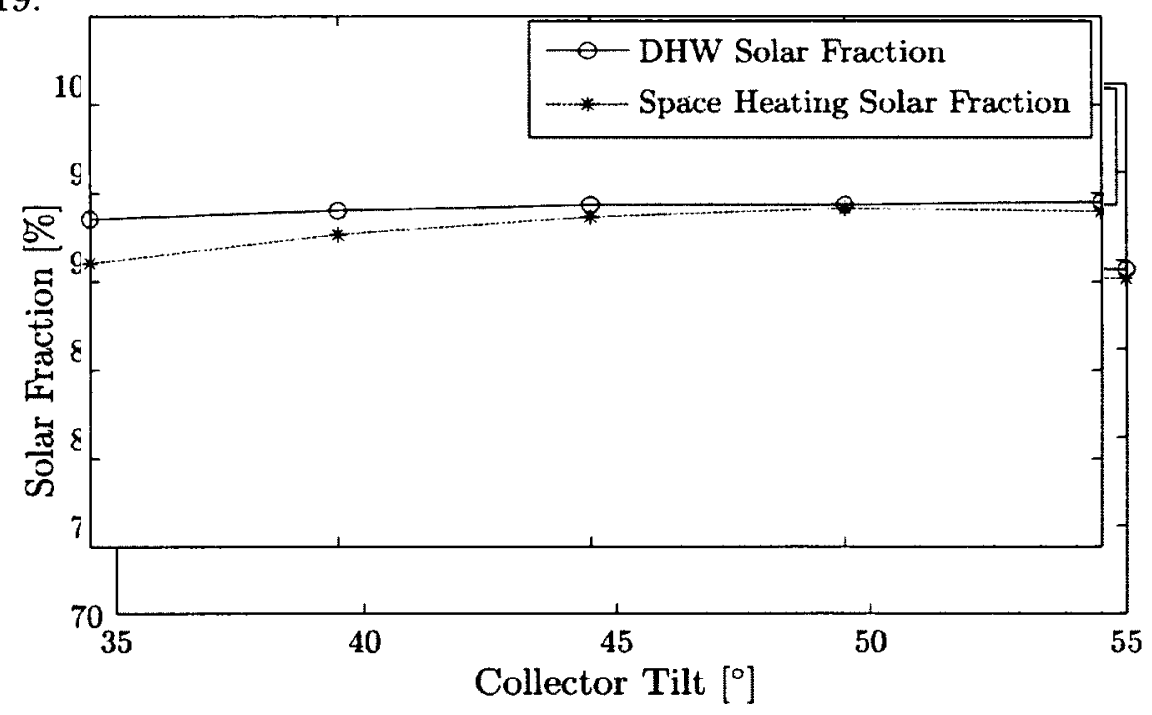

Figure 7.19: Collector slope sensitivity

At the beginning of this research it was unclear if the collector should be biased towards winter collection (collector slope greater than latitude) or summer collection (collector slope less than latitude). In Figure 7.19 it can be observed that a slope of $55^{\circ}$ provided good performance for both $\Im_{D H W}$ and $\Im_{s p a c e}$. The values of these were $89.5 \%$ and $89.0 \%$ respectively. The system performance was observed to be insensitive to collector slope between for values above $45^{\circ}$. Below $45^{\circ}$, the space heating solar fraction begins to reduce noticeably. For the Ottawa, Canada latitude, collector tilts below $45^{\circ}$ would represent a bias to summer collection with a reduction in winter useful gains.

The DHW solar fraction appeared to be less affected by the collector slope than $\Im_{\text {space }}$. It is important to note however, that the DHW auxiliary heater was shown to reach maximum output in Section 7.2.1. The auxiliary energy not being able to meet 
the load would influence the calculation of $\Im_{D H W}$, which can be seen in Equation 7.3.

\subsubsection{Parasitic Loads}

Up to this point, no consideration was given to the annual energy required to operate the pumps in the system, referred to as the parasitic load, $Q_{\text {par }}$. For the "selected case", the annual energy required to run the solar, diurnal and seasonal charge, and hydronic floor circulation pumps was $2.61 \mathrm{GJ}$. When this $Q_{p a r}$ was added to auxiliary energy terms in Equation 7.5, the annual space heating and DHW solar fraction for the "selected case" reduced from $89.2 \%$ to $81.3 \%$.

\subsubsection{Summary of Findings}

The general findings of the "selected case" analysis are as follows:

- The SSTS was found to follow a seasonal cycle, where useful solar gains from the summer were carried over to meet winter thermal demands.

- The solar thermal collectors had mean monthly efficiencies below 40\%. This was expected since the system was designed as "low flow" to encourage higher temperature rises across the collectors at the expense of efficiency.

- The inlet temperatures of the collectors were found to follow a similar trend of the seasonal storage temperatures. Elevated seasonal storage temperatures caused increases in the collector inlet temperatures and consequently reduced collector efficiency.

- The yearly storage efficiency of the diurnal tank was $92.6 \%$. This relatively high efficiency was expected since the diurnal tank was found to generally chargedischarge daily. This created a relatively short storage period where thermal energy could be lost to ambient.

- For the seasonal tank, the yearly storage efficiency was $55.6 \%$. The seasonal storage was required to hold relatively high temperatures for extended periods

- The occupied spaces of the C-RISE house were found to spend between $9.1 \%$ and $10.7 \%$ of the time below the $19^{\circ} \mathrm{C}$ heating setpoint. While this performance was not considered satisfactory, the annual average drybulb temperature of the occupied spaces was $22^{\circ} \mathrm{C}$ and the system operation was considered appropriate for the annual system performance analysis. 
- Varying the H/D ratio of the seasonal storage from 0.5 to 1 was found to improve the annual total solar fraction by $5.1 \%$ while reducing tank losses by $5.9 \%$.

- When the $\mathrm{L} / \mathrm{W}$ ratio of the seasonal storage was varied between 0.1 and 1 , the annual performance was found to be relatively insensitive to $\mathrm{L} / \mathrm{W}$ for values beyond 0.6 .

- Increasing the tilt angle of the collector array from $45^{\circ}$ to $55^{\circ}$ was found to have minimal impact on annual performance. Reducing the collector tilt from $45^{\circ}$ to $35^{\circ}$ however, was found to significantly impact the space heating solar fraction.

- When the annual parasitic loads were incorporated into $\Im_{t o t a l}$, the annual performance reduced from $89.2 \%$ to $81.3 \%$. 


\section{Chapter 8}

\section{Conclusions and Recommendation}

\subsection{Conclusions}

Introduced in Chapter 1, the C-RISE project at Carleton University was a new test facility created to study new and innovative technologies for the Canadian residential sector. One area of research to be considered at the facility was the use of solar thermal energy to supply domestic hot water (DHW) and space heating loads for a singlefamily home. The focus of this work was the development and sensitivity analysis of a seasonal solar thermal energy system which used a relatively large water tank to carry over useful summer solar gains for winter use. The majority of the seasonal solar thermal system (SSTS) was designed based on previous work in the literature and "best practices". There were still however, key parameters that needed to be sized for the specific residential application in order to achicve high solar fractions $(\geq 90 \%)$. These parameters included collector array area, collector orientation, seasonal storage volume, and seasonal storage insulation.

Also of interest in this work was the sensitivity of annual performance of the SSTS to several system parameters and operational charaterstics. These included the level of stratification in the diurnal and seasonal storage tanks, and the geometry of the seasonal storage tank.

The objectives of this research was achieved with the use of detailed models developed in the ESP $\mathrm{r}$ and TRNSYS simulation tools. The robust modelling capabilities of ESP-r were used to represent the building system and hydronic floors of the C-RISE house, while the flexibility and extensive libraries available in TRASYS were used to model the SSTS. Co simulation of these tools was then accomplished with a new tool called the "Harmonizer" which facilitated data exchange and simulation 
control between ESP $r$ and TRNSYS. The following sections describe work which was undertaken to meet the objectives of the research.

\section{Influence of Stratification on Annual System Performance}

The models used to represent the thermal storages used in the C-RISE SSTS were taken from the TESS extended libraries in TRNSYS. These were 1-D multinode models which were capable of representing varying degrees of stratification in the tank. The user had the option to specify one or numerous nodes inside the storage tanks. By varying the number of nodes represented in the tank models, greater levels of stratification within the tank model could be achieved.

When the diurnal tank was simulated with a single-node, no stratification could be represented in the model and the tank was considered as "fully-mixed" at each timestep throughout the simulation. When 10 nodes were specified in the tank, $\Im_{D H W}$ increased by $8.3 \%$. With 10 nodes, the annual average temperature difference between the tank top and bottom was $20.6^{\circ} \mathrm{C}$. Similar results were observed for the seasonal tank, where $\Im_{\text {space }}$ increased by $17.5 \%$ when tank nodes were increased from 1 to 10 . For this case the annual average temperature difference between the tank top and bottom was $8.3^{\circ} \mathrm{C}$.

These performance increases with stratification were anticipated since stratification had been shown in the literature to improve solar thermal system performance. Therefore, it was found that storage stratification had a significant impact on annual performance of the SSTS. This was especially true for the seasonal storage. When the seasonal tank was modelled with several nodes, higher temperatures were achieved in the storage. The single-node (fully-mixed) tank model diffused the inlet fluid of the tank over the entire storage volume. The multinode model enabled incoming charge fluid to diffuse over smaller, discrete volumes in the tank. This hot region at the top of the tank could be used to meet space heating loads while the cool region at the bottom allowed for lower return temperatures to the collector.

\section{Parametric Study of the Seasonal Solar Thermal Energy System}

To determine the feasible combination of collector array area, seasonal storage volume, and seasonal storage insulation, a coarse parametric study was conducted. 
Annual performance results were obtained from co simulation of the TRNSYS and ESP-r models. The parameter space was selected to be sufficiently broad since it was unknown what the appropriate parameter values would be for this specific residential applications.

When 6 collector panels were used, increasing the seasonal storage volume from $80 \mathrm{~m}^{3}$ only decreased the annual total solar fraction, $\Im_{\text {total }}$. For cases with 8 or more collector panels, increasing the volume from $80 \mathrm{~m}^{3}$ was found to initially increase $\Im_{\text {total }}$ up to a critical point. After the critical point, further increases in the seasonal storage volume lead to decreases in $\Im_{\text {total }}$. As the seasonal storage volume increased, the annual useful gains of the solar collector also increased. This was expected since the increased thermal capacity reduced the seasonal storage operating temperatures, allowing for lower temperatures to be sent to the collector. As the volume increased, so too did the tank losses to ambient. The critical point was assumed to occur where the tank losses became more significant than the increase in collector useful gain.

For every level of seasonal storage insulation considered, the highest performance found in the coarse parameter space was for the 12 collector and $120 \mathrm{~m}^{3}$ configuration. At $80 \mathrm{~cm}$ scasonal tank insulation, this configuration had a $\Im_{\text {total }}$ equal to $94.7 \%$. To test the sensitivity of annual performance to storage volumes within the critical range, a sensitivity analysis was conducted which varied the seasonal storage volume between 80 and $150 \mathrm{~m}^{3}$ with a fixed collector area and insulation level. It was found that with that range $\Im_{\text {total }}$ varied between $89.9 \%$ and $90.8 \%$, indicating low sensitivity within that region.

\section{Performance of the "Selected Case"}

A high performance case was selected from the parametric study discussed previously. The system consisted of a 12 solar collectors, $80 \mathrm{~m}^{3}$ of seasonal storage volume, and $45 \mathrm{~cm}$ of seasonal tank insulation. The purpose of this study was to demonstrate the operation of the SSTS layout used in the research and to demonstrate that the simulation models were behaving as expected. For this configuration, the $\Im_{\text {total }}$ was simulated to be $89.2 \%$. At this $\Im_{\text {total }}$, there was still room to improve the system.

Both the diurnal and seasonal tanks were observed to receive useful gains from the solar collectors. The annual storage efficiency of the diumal tank was calculated 
to be $92.6 \%$, which represented the ratio of energy discharged to energy charged over the year. This high efficiency was expected since the diurnal tank would charge and discharge typically on a daily basis. This created a relatively short period of time for tank losses to ambient. The seasonal tank however, was found to have an annual storage efficiency of $55.6 \%$. This was expected since the useful gains from the summer were held at relatively high temperature for storage periods much longer than the diurnal tank.

The annual temperatures of the occupied spaces were considered to examine the operation of the space heating control. It was found that between $28 \%$ and $29 \%$ of the time during the year, the main and second floors of the C-RISE house were below $20^{\circ} \mathrm{C}$. The response of the slab system was found to be relatively slow, with periods of undershoot and overshoot for the $20^{\circ} \mathrm{C}$ heating setpoint. While this research was not focused on control of the hydronic floors, the system was assumed to be acceptable for estimating annual energy required to the meet the C -RISE space heating demands.

\section{Influence of Seasonal Storage Geometry and Collector Orientation on Annual System Performance}

The final sensitivity analysis conducted in this research was for the sensitivity of annual performance of the "selected case" to the geometry of the seasonal storage and the tilt of the collector array. For the seasonal tank geometry, two non dimensional ratios were considered; the length to width ratio (L/W) of the seasonal tank cross-section and the height to hydraulic diameter ratio (H/D). For the L/W study, the height of the seasonal tank was fixed. Beyond a ratio of 0.6 the system $\Im_{\text {space }}$ was found to be insensitive to $\mathrm{L} / \mathrm{W}$. When the $\mathrm{H} / \mathrm{D}$ ratio was varied with a square cross section of the tank, $\Im_{\text {space }}$ was found to increase as H/D approached 1. $\Im_{\text {space }}$ was expected to improve with increasing H/D since the increased height would promote greater stratification with the storage.

\section{Closing Remarks}

This research examined several sensitivities and parameters of a SSTS for a single family home in Ottawa, Canada. This research was part of the larger C RISE project at Carleton University. In practice, using the optimum storage volumes 
or insulation levels may not always be economically feasible. There was value in understanding how a design compromise may impact system performance. This allowed designers with guidance for balancing costs to system performance. The use of detailed simulation models also allowed for estimation of appropriate collector areas, storage volumes, and tank insulation levels for the C RISE SSTS system.

While much of the results obtained here were unique to the specific application and SSTS configuration, an important contribution of this work was the demonstration of co simulation to represent complex systems. The complimentary strengths of two simulation tools were exploited to represent a relatively complex building and plant system. By using co simulation, new and innovative building technologies could be modelled and explored. The "Harmonizer" co-simulation tool used to facilitate data transfer between ESP $r$ and TRNSYS allowed for a "strong coupling" between the tools. Iterations between the tools was performed at each timestep to capture the coupled dynamic behaviour between plant and building systems. Following the co simulation work of Beausoleil Morrison et al. [100], this work demonstrated the use of co simulation for modelling of the complete energy system. While the focus of the work was primarily overall annual performance, all aspects such as ground coupling of the seasonal storage tank and transient behaviour of the hydronic floor system was considered through the use of complimentary detailed simulation tools.

It should be noted that the sensitivity and performance results obtained in this study should not be over-generalized to other applications. Many of the contraints, assumptions, and boundary conditions used within this research was specific to the C - RISE SSTS. This work did not attempt to encapsulate all possible designs and control of a residential single house scale SSTS.

\subsection{Recommendations and Future Work}

This work represented a step towards using detailed models to examine the complex building and solar thermal systems. While a high level of complexity was included in the models developed for this work, there was potential further refinement of models and assumptions. Demonstrating the use of co simulation created opportunities to answer interesting questions and explore other aspects of single house scale solar thermal systems. This section discusses the recommendations for moving forward and future work. 
In this study, the upper limit of the collector array area was constrained to $34.5 \mathrm{~m}^{2}$. Other rescarchers such as Hugo [81] considered flat-plate collector areas over $50 \mathrm{~m}^{2}$ for residential scale single family home SSTS. It would be interesting to examine if the SSTS configuration used in this research could achieve high solar fractions with larger collector areas and reduced storage volumes. The collector array was also constrained to face due south. While this was a desirable orientation for non-tracking collector arrays [15], aesthetic or site constraints may force other array orientations. It may be interesting to examine the sensitivity of the C-RISE SSTS to collector azimuth position.

Flat plate collectors were chosen for this study for their relatively low cost and simplistic operation. It would be interesting to follow up this thesis with an investigation of other solar collection technologies. Hugo [81] had compared the use of flat-plate collectors to evacuated tube collectors (ETC). He was able to reduce the collector area required by using ETCs. Recently, evacuated flat-plate collectors have become available on the market. These type of collectors use an evacuated space between the glazing and absorber to reduce heat losses and allow for higher collector efficiencies during periods of relatively cold ambient temperatures. It would be interesting to compare the costs and benefits of these collectors with ETCs and conventional flat-plate collectors.

Throughout this study, the inlet and outlet ports modelled on the diurnal and seasonal tanks were fixed. The TRNSYS models allow for representation of inlet stratifiers, where incoming charge fluid is injected at a region of the tank with a similar temperature. Lundh et al. [44] compared the fractional energy savings of a solar combisystem with fixed inlets and a combisystem where inlet fluids are injected at a level with a similar temperature mimicking a stratification device. Nominal improvement of fractional energy savings between 1 and $3 \%$ was found for most cases. When the storage tanks were large $\left(6\right.$ and $\left.10 \mathrm{~m}^{3}\right)$ and poorly insulated, the fixed inlet case reduced the fractional energy savings by $10 \%$. Future work will examine performance increases from using a stratification device in the seasonal storage tank.

At the outset of the research, there was interest in examining a seasonal storage system that contained several tanks. This would be a larger scale system similar to the multi tank concepts studied by Cruickshank [10] or Mather et al. [50]. Time did not permit the examination of this system configuration, however future work intends to study if there is any benefit to a multi-tank seasonal storage. 
The boundary conditions of the buried seasonal storage was modelled using a 3-D soil conduction model. The envelope of the tank was represented and an effective Uvalue with no thermal mass. Researchers such as Ochs et al. [166] point out that the effective conductivity typically decreases with increasing temperature and moisture content. Ochs [47] stated that in practice effective conductivity of buried thermal energy storage insulation is typically 4 to 10 times higher than test values. Pinel and Beausoleil Morrison [167] also reviewed improvements in soil heat and mass transfer modelling and its application in building foundation modelling. Future work for this research would focus on a more robust treatment of the seasonal storage envelope and physical process in the soil to better estimate tank heat losses to the surrounding soil.

The performance of the hydronic floor heating systems were discussed in Chapter 7. The results indicated that there was potential for improvement of the heating system and further research required to assess occupant comfort. Moving forward, it would be beneficial to investigate control schemes and parameters for hydronic floor systems used in solar combisystem applications. Future work focusing on improved controls, floor control influence on annual system performance, and a robust treatment of occupant comfort analysis is recommended.

Incorporation of heat pumps into the SSTS system was also an area of interest that was not addressed in this thesis. By February or March when the temperature levels in the seasonal tank have reduced, there may be potential in using heat pumps to extract additional thermal energy from the seasonal storage tank instead of directly supplying auxiliary energy to the fluid stream. Future work exploring the feasibility of this SSTS configuration is recommended.

Finally, all of the components modelled within this study were based on assumptions and recommendations from the literature. With the commissioning of the C-RISE research facility, there will be an oppourtunity to extract experimental data from the SSTS built on site to calibrate and validate the models used for the co simulations performed in this work. 


\section{List of References}

[1] Ontario Ministry of the Environment, "Annual report 2008-09: Climate change action plan," Tech. Rep. PIBS\# 7286e, Goverment of Ontario, Toronto, Canada, 2009.

[2] Ontario Ministry of the Environment, "Climate progress. Ontario's plan for a cleaner, more sustainable future: Annual report 2009 2010," Tech. Rep. PIBS\# 8290e, Goverment of Ontario, Toronto, Canada, 2011.

[3] Ontario Power Generation Inc., "Power generation," 2013. Accessible online at http://www.opg.com/power/.

[4] Ontario Power Generation Inc., "Annual report," tech. rep., 2010. Accessible online at http://www.opg.com/pdf/Annual\%20Reports/Annual\%20Report\% 202010.pdf.

[5] Ontario Ministry of the Environment, "Data downloads," 2013. Accessible online at http://www.ene.gov.on.ca/environment/en/resources/collection/ data_downloads/index.htm\#GHG.

[6] "National energy use database." Natural Resources Canada, Office of Energy Efficiency. Accessible online at http://www.oee.nrcan.gc.ca/corporate/ statistics/neud/dpa/data_e/databases.cfm?attr $=0$.

[7] "Solar heat worldwide: Markets and contribution to the energy supply 2010," tech. rep., International Energy Agency: Solar Heating \& Cooling Programme, 2012.

[8] W. Weiss, ed., Solar Heating Systems for Houses: A Design Handbook for Solar Combisystems. James \& James, 2003.

[9] P. Pinel, C. A. Cruickshank, I. Beausoleil-Morrison, and A. Wills, "A review of available methods for seasonal storage of solar thermal energy in residential applications," Renewable and Sustainable Energy Reviews, vol. 15, no. 7, pp. 3341 3359, 2011.

[10] C. A. Cruickshank, Evaluation of a stratified multi-tank thermal storage for solar heating applications. Ph.D., Queen's University, 2009.

[11] J. Duffie and W. Beckman, Solar Engineering of Thermal Processes. John Wiley \& Sons, third ed., 2006. 
[12] A. N. Celik, T. Muneer, and P. Clarke, "A review of installed solar photovoltaic and thermal collector capacities in relation to solar potential for the EU-15," Renewable Energy, vol. 34, no. 3, pp. 849 - 856, 2009.

[13] "Solar thermal markets in Europe: Trends and markets statistics 2011," tech. rep., European Solar Thermal Industry Federation, 2012.

[14] "Solar thermal." Natural Resources Canada, CanmetENERGY. Accessible online at http://canmetenergy.nrcan.gc.ca/renewables/solar-thermal/437.

[15] I. Dinçer and M. Rosen, Thermal Energy Storage: Systems and Applications. John Wiley \& Sons, second ed., 2011.

[16] B. R. Becker and K. E. Stogsdill, "A domestic hot water use database," ASHRAE Journal, pp. 21-25, 1990.

[17] International Energy Agency (IEA), "Shc: Task 38 - solar air-conditioning and refrigeration." Accessible online at http://iea-shc.org/task38/.

[18] J. Braun, S. Klein, and J. Mitchell, "Seasonal storage of energy in solar heating," Solar Energy, vol. 26, no. 5, pp. 403 411, 1981.

[19] Solar Energy Laboratory, University of Wisconsin Madison, "TRNSYS: A Transient Systems Simulation Tool," 2012. Accessible online at http://sel.me. wisc.edu/trnsys/.

[20] H. F. C, "The possibiltiy of complete solar heating of canadian buildings," in 60th Annual General and Professional Meeting of the Engineering Institute of Canada, 1955.

[21] M. Sachs, "C-RISE construction drawings." email correspondence, 2011. Urbandale Construction.

[22] Office of Energy Efficiency, "2012 R-2000 standard," tech. rep., Natural Resources Canada, 2012.

[23] Energy Systems Research Unit, University of Strathclyde, "ESP-r," 2012. Accessible online at http://www.esru.strath.ac.uk/Programs/ESP-r.htm.

[24] International Energy Agency (IEA), "SHC: Task 7 - Central Solar Heating Plants With Seasonal Storage." Accessible online at http://archive.iea-shc. org $/ \operatorname{task07/.~}$

[25] S. Sillman, "Performance and economics of annual storage solar heating systems," Solar Energy, vol. 27, no. 6, pp. 513 528, 1981.

[26] D. Kozlowski, Modelling of seasonal thermal energy storage systems. Ph.D., University of Wisconsin-Madison, 1989.

[27] M. Fisch, M. Guigas, and J. Dalenbäck, "A review of large-scale solar heating systems in Europe," Solar energy, vol. 63, no. 6, pp. 355 366, 1998. 
[28] International Energy Agency (IEA), "SHC: Task 32 Advanced Storage Concepts for Solar and Low Energy Buildings." Accessible online at http://archive. iea-shc.org/task32/.

[29] International Energy Agency (IEA), "SHC: Task 42 Compact Thermal Energy Storage." Accessible online at http://task42.iea-shc.org/.

[30] Pilkington Solar International GmbH, "Survey of thermal storage for parabolic trough power plants," tech. rep., National Renewable Energy Laboratory, 2000.

[31] J. C. Hadorn, "Advanced storage concepts for active solar energy - IEA SHC task 32 2003-2007," 2008.

[32] A. Hariri and I. Ward, "A review of thermal storage systems used in building applications," Building and Environment, vol. 23, no. 1, pp. 1 10, 1988.

[33] A. Novo and J. Bayon, "Review of seasonal heat storage in large basins: Water tanks and gravelwater pits," Applied Energy, vol. 87, no. 2, pp. 390-397, 2010.

[34] T. Schmidt, D. Mangold, and H. Müller-Steinhagen, "Central solar heating plants with seasonal storage in Germany," Solar Energy, vol. 76, no. 1-3, pp. 165-174, 2004.

[35] Y. Han, R. Wang, and Y. Dai, "Thermal stratification within the water tank," Renewable and Sustainable Energy Reviews, vol. 13, no. 5, pp. 1014-1026, 2009.

[36] E. Andersen, S. Furbo, M. Hampel, W. Heidemann, and H. Müller-Steinhagen, "Investigations on stratification devices for hot water heat stores," International Journal of Energy Research, vol. 32, no. May 2007, pp. 255-263, 2008.

[37] K. Hollands and M. Lightstone, "A review of low-flow, stratified-tank solar water heating systems," Solar Energy, vol. 43, no. 2, pp. 97 105, 1989.

[38] C. Cristofari, G. Notton, P. Poggi, and A. Louche, "Influence of the flow rate and the tank stratification degree ontheperformances of a solar flat-plate collector," International Journal of Thermal Sciences, vol. 42, no. 5, pp. 455- 469, 2003.

[39] L. F. Jesch and J. E. Braun, "Variable volume storage and stratified storage for improved water heater performance," Solar Energy, vol. 33, no. 1, pp. 83 87, 1984.

[40] P. Lund, "Effect of storage thermal behavior in seasonal storage solar heating systems," Solar Energy, vol. 40, no. 3, pp. 249-258, 1988.

[41] P. Eames and B. Norton, "The effect of tank geometry on thermally stratified sensible heat storage subject to low Reynolds number flows," International Journal of Heat and Mass Transfer, vol. 41, no. 14, pp. 2131 2142, 1998.

[42] E. Hahne and Y. Chen, "Numerical study of flow and heat transfer characteristics in hot water stores," Solar energy, vol. 64, no. 1-3, pp. 9 18, 1998.

[43] Z. Lavan and J. Thompson, "Experimental study of thermally stratified hot water storage tanks," Solar Energy, vol. 19, pp. 519 524, 1977. 
[44] M. Lundh, K. Zass, C. Wilhelms, K. Vajen, and U. Jordan, "Influence of store dimensions and auxiliary volume configuration on the performance of mediumsized solar combisystems," Solar Energy, vol. 84, no. 7, pp. 1095 1102, 2010.

[45] J. Nelson, A. Balakrishnan, and S. S. Murthy, "Experiments on stratified chilled-water tanks," International Journal of Refrigeration, vol. 22, no. 3, pp. 216 -234, 1999.

[46] M. Abdoly and D. Rapp, "Theoretical and experimental studies of stratified thermocline storage of hot water," Energy Conversion and Management, vol. 22, no. 3, pp. 275-285, 1982.

[47] F. Ochs, Modelling large scale thermal energy stores. Ph.D., University of Stuttgart, 2009.

[48] A. Castell, M. Medrano, C. Solé, and L. Cabeza, "Dimensionless numbers used to characterize stratification in water tanks for discharging at low flow rates," Renewable Energy, vol. 35, no. 10, pp. 2192 2199, 2010.

[49] D. Prapas, S. Tsiamouris, V. Giannaros, and B. Sotiropoulos, "Storage tanks interconnection and operation modes in large DHW solar systems," Solar Energy, vol. 51, no. 2, pp. 83 91, 1993.

[50] D. Mather, K. G. T. Hollands, and J. L. Wright, "Single- and multi-tank energy storage for solar heating systems: fundamentals," Solar Energy, vol. 73, no. 1, pp. 3-13, 2002.

[51] R. M. Dickinson, Analysis and Development of Draw Strategies for a Multi-Tank Thermal Storage System for Solar Heating Applications. M.A.Sc., Carleton University, 2012.

[52] C. Hess and C. Miller, "An experimental and numerical study on the effect of the wall in a thermocline-type cylindrical enclosure-I experments," Solar Energy, vol. 28, no. 2, pp. 145 - 152, 1982.

[53] B. Givoni, "Underground longterm storage of solar energy - An overview," Solar energy, vol. 19, pp. 617 623, 1977.

[54] M. Rosen, "A semi-empirical model for assessing the effects of berms on the heat loss from partially buried heat storage tanks," International Journal of Solar Energy, vol. 20, no. 1, pp. 57 77, 1998.

[55] J. D. Chung, S. H. Cho, C. S. Tae, and H. Yoo, "The effect of diffuser configuration on thermal stratification in a rectangular storage tank," Renewable Energy, vol. 33, no. 10, pp. 2236 2245, 2008.

[56] S. Murthy, J. Nelson, and T. Rao, "Effect of wall conductivity on thermal stratification," Solar Energy, vol. 49, no. 4, pp. 273-277, 1992.

[57] B. J. Newton, Modeling of Solar Storage Tanks. M.A.Sc., University of Wisconsin Madison, 1995. 
[58] E. Kleinbach, W. Beckman, and S. Klein, "Performance study of onedimensional models for stratified thermal storage tanks," Solar Energy, vol. 50, no. 2, pp. 155 166, 1993.

[59] Y. Zurigat, K. Maloney, and A. Ghajar, "A comparison study of onedimensional models for stratified thermal storage tanks," Journal of Solar Energy Engineering, vol. 111, no. 3, pp. 204-210, 1989.

[60] U. Jordan and S. Furbo, "Thermal stratification in small solar domestic storage tanks caused by draw-offs," Solar Energy, vol. 78, no. 2, pp. 291-300, 2005.

[61] Y. Zurigat, P. Liche, and a. Ghajar, "Influence of inlet geometry on mixing in thermocline thermal energy storage," International Journal of Heat and Mass Transfer, vol. 34, no. 1, pp. 115-125, 1991.

[62] L. Marazella, "Multi-flow stratified thermal storage model with full-mixed layers PdM - XST," tech. rep., Institut für Thermodynamik und Wärmetechnik Universität Stuttgart FRG and Dipartimento di Energetica Politecnico di Milano, 1992.

[63] J.-O. Dalenbäck, Solar heating with seasonal storage. Some aspects of the design and evaluation of systems with water storage. Ph.D., Chalmers University of Technology, 1993.

[64] S. Raab, D. Mangold, and H. Müller-Steinhagen, "Validation of a computer model for solar assisted district heating systems with seasonal hot water heat store," Solar Energy, vol. 79, no. 5, pp. 531-543, 2005.

[65] C. Bankston, "The status and potential of central solar heating plants with seasonal storage," in ASES '86: Proceedings of the 1986 Annual Meeting of the American Solar Energy Society Inc, pp. 79 91, 1986.

[66] J.-O. Dalenbäck, "Central solar heating plants with seasonal storage status report," tech. rep., Chalmers University of Technology, Göteborg, Sweden, 1990.

[67] V. Lottner and D. Mangold, "Status of seasonal thermal energy storage in Germany," in Proc. of Terrastock, pp. 1-8, 2000.

[68] D. Bauer, R. Marx, J. NuB bicker Lux, F. Ochs, W. Heidemann, and H. MüllerSteinhagen, "German central solar heating plants with seasonal heat storage," Solar Energy, vol. 84, no. 4, pp. 612-623, 2010.

[69] Drake Landing Solar Community, "About DLSC," 2013. Accessible online at http://www.dlsc.ca/about.htm.

[70] T. P. McDowell and J. W. Thorton, "Simulation and model calibration of a large-scale solar seasonal storage system," in Third National Conference of IBPSA-USA, pp. 174-181, IBPSA USA, July 2008.

[71] J. Wamboldt, Central solar heating plants with seasonal storage for residential applications in Canada: A case study of the Drake Landing Solar Community. M.Es., Queen's University, 2009. 
[72] B. Wong, A. Snijders, and L. McClung, "Recent Inter-seasonal Underground Thermal Energy Storage Applications in Canada," in 2006 IEEE EIC Climate Change Conference, pp. 1-7, IEEE, May 2006.

[73] A. Rysanek, Second law performance analysis of a large thermal energy storage vessel using CFD. M.Sc, Queen's University, 2009.

[74] Canada Mortgage and Housing Corporation, "Project profile: Riverdale NetZero project - Edmonton, Alberta," tech. rep., 2008. Accessible online at http://www.cmhc-schl.gc.ca/odpub/pdf/65521.pdf.

[75] Canada Mortgage and Housing Corporation, "Riverdale NetZero active solar thermal system," tech. rep., 2009. Accessible online at http://www.cmhc-schl. gc.ca/odpub/pdf/66741.pdf?fr=1337021684560.

[76] S. Colclough, P. Griffiths, and N. Hewitt, "A year in the life of a passive house with solar energy store," in Energy Storage Conference, (Belfast, Ireland), IC SES, 2011.

[77] J. Clarke, S. Colclough, P. Griffiths, and J. T. McLeskey, "A passive house with seasonal solar energy store: In situ data and numerical modeling," International Journal of Ambient Energy, vol. 0, no. ja, pp. 1 35, 0.

[78] S. Colclough, P. Griffiths, and M. Smyth, "Solar energy storage - critical success factors for passive houses in Ireland," in World Renewable Energy Congress XI, (Abu Dhabi, UAE), pp. 1-6, WREC/WREN, Sept. 2010.

[79] S. Colclough. personal communication, 2013.

[80] S. Sillman, "The trade-off between collector area, storage volume, and building conservation in annual storage solar heating systems," tech. rep., Solar Energy Research Institute, Golden, Colorado, 1981.

[81] A. Hugo, Computer simulation and life cycle analysis of a seasonal thermal storage system in a residential building. M.A.Sc, Concordia University, 2008.

[82] A. Hugo, R. Zmeureanu, and H. Rivard, "Solar combisystem with seasonal thermal storage," Journal of Building Performance Simulation, vol. 3, no. 4, pp. $255268,2010$.

[83] International Energy Agency (IEA), "SHC: Task 26 Solar Combisystems." Accessible online at http://archive.iea-shc.org/task26/.

[84] M. Y. Haller, C. A. Cruickshank, W. Streicher, S. J. Harrison, E. Andersen, and S. Furbo, "Methods to determine stratification efficiency of thermal energy storage processes Review and theoretical comparison," Solar Energy, vol. 83, no. 10 , pp. 1847 1860, 2009.

[85] J. Clarke, Energy Simulation in Building Design. Oxford: ButterworthHeinemann, second ed., 2001.

[86] U.S. Department of Energy, "EnergyPlus," 2012. Accessible online at http: //apps1.eere.energy.gov/buildings/energyplus/. 
[87] P. Strachan, G. Kokogiannakis, and I. Macdonald, "History and development of validation with the ESP r simulation program," Building and Environment, vol. 43 , no. 4, pp. $601609,2008$.

[88] J. A. Clarke, Environmental Systems Performance. Ph.D., University of Strathclyde, 2010.

[89] I. Beausoleil-morrison, The adaptive coupling of heat and air flow modelling within dynamic whole-building simulation. Ph.D., University of Strathclyde, 2000.

[90] J. Kopf, Economic potential of residential mirco cogeneration coupled with thermal and electrical storage as a distributed energy resource in Ontario. M.A.Sc., Carleton University, 2012.

[91] B. Lomanowski, Implementation of window shading models into dynamic wholebuilding simulation. M.A.Sc., University of Waterloo, 2008.

[92] J. Anderson, Computational fluid dynamics: the basics with applications. McGraw-Hill, 1995.

[93] J. Crank and P. Nicolson, "A practical method for numerical evaluation of solutions of partial differential equations of the heat-conduction type," Mathematical Proceedings of the Cambridge Philosophical Society, vol. 43, no. 01, pp. $5067,1947$.

[94] American Society of Heating, Refrigeration and Air-Conditioning Engineers, ASHRAE Handbook: Fundamentals. Atlanta, GA: ASHRAE, SI ed., 2009.

[95] J. L. Hensen, On the thermal interaction of building structure and heating and ventilating system of building structure. Ph.D., Technische Universiteit Eindhoven, 1991.

[96] I. Walker and D. Wilson, "The Alberta air infiltration model: Aim-2," tech. rep., The University of Alberta, Edmonton, Canada, 1990.

[97] B. Bradley, "Implementation of the aim-2 infiltration model in hot2000," tech. rep., Unies Ltd., Winnipeg, Canada, 1993.

[98] Office of Energy Efficiency, "Energuide for houses: Energy advisor workshop manual," tech. rep., Natural Resources Canada, Ottawa, Canada, 2005.

[99] W. Wang, I. Beausoleil-Morrison, and J. Reardon, "Evaluation of the Alberta air infiltration model using measurements and inter-model comparisons," Building and Environment, vol. 44, no. 2, pp. 309 -318, 2009.

[100] I. Beausoleil-Morrison, F. Macdonald, M. Kummert, R. Jost, and T. McDowell, "Co-simulation between ESP-r and TRNSYS," Journal of Building Performance Simulation, 2013. DOI: 10.1080/19401493.2013.794864.

[101] S. Klein, P. Cooper, T. Freeman, D. Beekman, W. Beckman, and J. Duffie, "A method of simulation of solar processes and its application," Solar Energy, vol. 17 , no. 1 , pp. $2937,1975$. 
[102] D. E. Bradley, M. Kummert, and T. P. McDowell, "Experiences with and interpretations of standard test methods of building energy analysis tools," in Proceedings of eSim 2004, (Vancouver, BC), pp. 245-252, IBPSA Canada.

[103] D. E. Bradley, M. Kummert, and T. P. McDowell, "Converging on a recommended set of interpretations and assumptions in applying standard tests to energy analysis tools," in First National Conference of IBPSA-USA, (Boulder, CO), IBPSA USA, 2004.

[104] B. Delcroix, M. Kummert, A. Daoud, and M. Hiller, "Conduction transfer functions in TRNSYS multizone building model: current implementation, limitations and possible improvements," in Fifth National Conference of IBPSA-USA, (Madison, WI), pp. 219 226, IBPSA USA, 2012.

[105] "TRNSYS 17: Multizone Building modeling with Type 56 and TRNBuild," Tech. Rep. Volume 5, Solar Energy Laboratory, University of WisconsinMadison, Madison, WI, 2012.

[106] "TRNSYS 17: Mathematical Reference," Tech. Rep. Volume 4, Solar Energy Laboratory, University of Wisconsin Madison, Madison, WI, 2012.

[107] L. Peeters, I. Beausoleil-Morrison, and A. Novoselac, "Internal convective heat transfer modeling: Critical review and discussion of experimentally derived correlations," Energy and Buildings, vol. 43, no. 9, pp. 2227 - 2239, 2011.

[108] M. Trčka, J. L. Hensen, and M. Wetter, "Co-simulation of innovative integrated hvac systems in buildings," Journal of Building Performance Simulation, vol. 2, no. 3, pp. 209 230, 2009.

[109] "TESSLibs 17: Solar Library Mathematical Reference," Tech. Rep. Volume 10, Thermal Energy System Specialists, 2012.

[110] Y. Allard, M. Kummert, M. Bernier, and A. Moreau, "Intermodel comparison and experimental validation of electrical water heater models in TRNSYS," in 12th Conference of International Building Performance Simulation Association, pp. 688 695, IBPSA, 2011.

[111] "TESSLibs 17: Storage Tank Library Mathematical Reference," Tech. Rep. Volume 11, Thermal Energy System Specialists, 2012.

[112] A. Wills, C. A. Cruickshank, and I. Beausoleil-Morrison, "Application of the ESP-r/TRNSYS co-simulator to study solar heating with a single-house scale seasonal storage," Energy Procedia, vol. 30, pp. 715 - 722, 2012.

[113] Trimble Navigation Limited, "Google Sketchup 7," 2013. Accessible online at http://www.sketchup.com/intl/en/.

[114] Office of Energy Efficiency, "Survey of household energy use: Detailed statistical report," tech. rep., Natural Resources Canada, 2007. Accessible online at http: //oee.nrcan.gc.ca/Publications/statistics/sheu07/pdf/sheu07.pdf. 
[115] A. J. Pietila, Reducing the Magnitude and Reshaping the Temporal Distribution of Residential Electrical Loads Purposed to Achieve a Zero Peak House in a Southern Ontario Climate. M.A.Sc., Carleton University, 2011.

[116] L. G. Swan, Residential Sector Energy and GHG Emissions Model for the Assessment of New Technologies. Ph.D., Dalhousie University, 2010.

[117] J. Purdy and I. Beausoleil-Morrison, "The significant factors in modelling residential buildings: Part 1," in 7th International IBPSA Conference: Building Simulation, (Rio de Janeiro, Brazil), IBPSA, Aug. 2001.

[118] M. Sachs, "New R 2000 standard." email correspondence, 2011. Urbandale Construction.

[119] J. Straube and E. Burnett, Building Science for Building Enclosures. Building Science Press, 2005.

[120] American Society of Heating, Refrigeration and Air Conditioning Engineers, "ANSI/ASHRAE/IES Standard 90.1-2010: Energy standard for buildings except low-rise residential buildings," tech. rep., Atlanta, GA, 2010.

[121] "ENERGY STAR ${ }^{\circledR}$ Qualified Windows, Doors \& Skylights." Natural Resources Canada, Office of Energy Efficiency, 2013. Accessible online at http://oee.nrcan. gc.ca/equipment/energystar/16095.

[122] Lawrence Berkeley National Laboratory, "WINDOW 6.3," 2012. Accessible online at http://windows.lbl.gov/software/window/6/.

[123] J. G. Purdy and I. Beausoleil-Morrison, "The Significant Factors in Modelling Residential Buildings," in Proceedings of the 2001 International IBPSA Conference, 2001. CANMET Energy Technology Centre, Natural Resources Canada, Ottawa, Canada.

[124] "Ontario code and construction guide for housing," tech. rep., Ontario Ministry of Municipal Affairs and Housing, Toronto, Ontario, 2010.

[125] Lifebreath ${ }^{\circledR}$ Indoor Air Systems, "Max Series Heat Recovery Ventilators," tech. rep., London, Canada, 2011. Accessible online at http://www.lifebreath.com/ downloads/75/98-MAX-RNC\%20(08-11).pdf.

[126] R. Watson and K. Chapman, Radiant Heating $\mathcal{G}$ Cooling Handbook. McGrawHill Handbooks, McGraw-Hill, 2002.

[127] A. Laouadi, "Development of a radiant heating and cooling model for building energy simulation software," Building and Environment, vol. 39, no. 4, pp. 421 $431,2004$.

[128] M. Manzan, "Subversion commit at revision 5574," 2010. http://espr.svn. cvsdude.com/esp-r/branches/Marco_Manzan/.

[129] IPEX, Manual of Modern Hydronics. second ed., 2004. Accessible online at http://www.builditsolar.com/Projects/SpaceHeating/Manual_of_ Modern_Hydronics_Section_1_4.pdf. 
[130] Radiant Floor Company, Design \& Installation Manual. tenth ed., 2007. Accessible online at http://www.radiantcompany.com/manual/Manual_web-2009. pdf.

[131] Vanguard Radiant Floor Heating, Hydronic Radiant Heating Systems: Installation Manual. Accessible online at http://vanguardproductsolutions.com/ Vanguard_Radiant_Manual.pdf.

[132] American Society of Heating, Refrigeration and Air-Conditioning Engineers, ASHRAE Handbook: HVAC Systems and Equipment. Atlanta, GA: ASHRAE, SI ed., 2008.

[133] B. W. Olesen, "Radiant floor heating in theory and practice," ASHRAE Journal, pp. $19 \quad 24,2002$.

[134] "Products and services." Environment Canada, National Climate Data and Information Archive. Accessible online at http://www.climate.weatheroffice.gc. ca/prods_servs/index_e.html.

[135] J. Purdy and I. Beausoleil-Morrison, "The significant factors in modelling residential buildings: Part 2," in 7th International IBPSA Conference: Building Simulation, (Rio de Janeiro, Brazil), IBPSA, Aug. 2001.

[136] N. Saldanha and I. Beausolcil-Morrison, "Mcasured cnd-use clectric load profiles for 12 Canadian houses at high temporal resolution," Energy and Buildings, vol. 49, pp. 519 530, 2012.

[137] R. Hendron and C. Engebrecht, "Building america house simulation protocols," Tech. Rep. TP-550-49426, National Renewable Energy Laboratory, 2010.

[138] I. Beausoleil-Morrison and G. Mitalas, "BASESIMP: A residential foundation heat loss algorithm for incorporating into whole-building energy analysis programs," in Building Simulation 97, (Prague, Czech Republic), pp. 1-8, IBPSA, 1997.

[139] I. Beausoleil-Morrison. personal communication, 2013.

[140] Bosch Thermotechnology Corp., "Tyfocor ${ }^{\circledR}$ L "G" Propylene Glycol based Solar Fluid: Engineering submittal sheet," tech. rep., 2009. Accessible online at http://www.buderus.us/files/201003042213260.Tyfocor_L_G_HTF\% 20 Specification $\% 20$ ESS.pdf.

[141] American Society of Heating, Refrigeration and Air Conditioning Engineers, "ASHRAE Guideline 12 2000: Minimizing the risk of Legionellosis associated with building water systems," tech. rep., Atlanta, GA, 2000.

[142] J. C. Evarts and L. G. Swan, "Domestic hot water consumption estimates for solar thermal system sizing," Energy and Buildings, vol. 58, no. 0, pp. 58 65, 2013. 
[143] R. Heimrath, "Report on solar combisystems modelled in task 26: Appendix 9: Generic system \# 19: Centralised heat production, distributed heat load," tech. rep., International Energy Agency: Solar Heating \& Cooling Programme, 2003. Accessible online at http://archive.iea-shc.org/publications/downloads/ task26-c-combisystems_modelled-appendix9.pdf.

[144] W. Streicher, R. Heimrath, and B. Chris, "Analysis of system reports of task 26 for sensitivity of parameters: A report of iea shc - task 26," tech. rep., International Energy Agency: Solar Heating \& Cooling Programme, 2007.

[145] F. Incropera and D. DeWitt, Fundamentals of heat transfer. Wiley, 1981.

[146] U. Jordan and K. Vajen, "Realistic domestic hot-water profiles in different time scales," tech. rep., Universität Marburg, 2001.

[147] U. Jordan and K. Vajen, "Influence Of The DHW Load Profile On The Fractional Energy Savings:: A Case Study Of A Solar Combi-System With TRNSYS Simulations," Solar Energy, vol. 69, no. 1 6, pp. 197 208, 2001.

[148] J. Burch and C. Christensen, "Towards development of an algorithm for mains water temperature," in Proceedings of the 2007 ASES Annual Conference, (Cleveland, OH), 2007.

[149] "Phase II environmental site assesment North 20 parcel, Carleton University," Tech. Rep. 10-1122-0176 (2000a), Golder Associates, Ottawa, Canada, 2010.

[150] J. C. Hadorn, ed., Thermal Energy Storage for Solar and Low Energy Buildings - State of the Art. International Energy Agency: Solar Heating \& Cooling Programme, 2005.

[151] F. Ochs, W. Heidemann, and H. Müller-Steinhagen, "Performance of large-scale seasonal thermal energy stores," Journal of Solar Energy Engineering, vol. 131, p. $041005,2009$.

[152] P. Pinel. personal communication, 2012.

[153] S. Patankar, Numerical Heat Transfer and Fluid Flow. Taylor \& Francis, 1980.

[154] J. Côté and J.-M. Konrad, "A generalized thermal conductivity model for soils and construction materials," Canadian Geotechnical Journal, vol. 42, pp. 443 $458,2005$.

[155] J. Côté and J. M. Konrad, "Assessment of structure effects on the thermal conductivity of two-phase porous geomaterials," International Journal of Heat and Mass Transfer, vol. 52, pp. 796 - 804, 2009.

[156] "Solar Collector Test Report," Tech. Rep. 06-08-9133-1, Bodycote Materials Testing Canada Inc., Mississauga, Canada, 2006.

[157] A. Fanney and S. Klein, "Thermal performance comparisons for solar hot water systems subjected to various collector and heat exchanger flow rates," Solar energy, vol. 40, no. I, 1988. 
[158] E. Andersen, Solar combi systems. Ph.D., Technical University of Denmark, 2007.

[159] S. B. Leigh and C. MacCluer, "Comparative study of proportional fluxmodulation and various types of temperature-modulation approaches for radiant floor-heating system control," ASHRAE Transactions, vol. 100, no. 1, pp. 1040-1053, 1994.

[160] C. MacCluer, "Analysis and simulation of outdoor reset control of radiant slab heating systems," ASHRAE Transactions, vol. 96, no. 1, pp. 1283 1287, 1990.

[161] C. MacCluer, "The response of radiant heating systems controlled by outdoor reset with feedback," ASHRAE Transactions, vol. 97, no. 2, pp. 795 799, 1991.

[162] C. S. Barnaby and D. B. Crawley, Building Performance Simulation for Design and Operation, ch. 3. Weather data for building performance simulation. Spon Press, 2011.

[163] C. Edwards, Performance Assessment of Solar Absorption Cooling for Ontario Housing. M.A.Sc., Carleton University, 2009.

[164] U.S. Department of Energy, "EnergyPlus Energy Simulation Software: Weather Data," 2013. Accessible online at http://apps1.eere.energy.gov/ buildings/energyplus/weatherdata_about.cfm?CFID $=5107593 \&$ CFTOKEN $=$ 9c239f92eea2b79-EB810B24-5056-BC19-158E96E935B1303F.

[165] American Society of Heating, Refrigeration and Air Conditioning Engineers, "ANSI/ASHRAE 55-2010: Thermal Environmental Conditions for Human Occupancy," tech. rep., Atlanta, GA, 2004.

[166] F. Ochs, W. Heidemann, and H. Müller-Steinhagen, "Effective thermal conductivity of moistened insulation materials as a function of temperature," International Journal of Heat and Mass Transfer, vol. 51, no. 3-4, pp. 539.552 , 2008.

[167] P. Pinel and I. Beausoleil-Morrison, "Coupling soil heat and mass transfer models to foundations in whole building simulation packages," in ProceedingsofeSim, pp. 557-570, IBPSA, 2012.

[168] Maxxon Canada, "Therma-floor data sheet," 2013. Accessible online at http: //www.maxxon.ca/therma-floor/data.

[169] Vanguard Piping \& Fittings, "CANPEX OXY barrier hydronic radiant heat tubing: Material specification sheet," 2013. Accessible online at http://www. vanguard.ca/upload/TDS_CANPEX\%200xy\%20Barrier\%20Pipe.pdf.

[170] Urecon Pre-Insulated Pipe, "Detailed specifiction PEX-Flex (with diffusion barrier)," 2013. Accessible online at http://www.urecon.com/documents/pdfs/ specs/flexible/PEX-Flex.pdf.

[171] "Development of a plant component model of radiant systems for ESP r/HOT3000 software," Tech. Rep. B3212.2, Institute for Research in Construction, National Research Council Canada, Ottawa, Canada. 


\section{Appendix A}

\section{Numerical Sensitivity Analysis}

This appendix provides the results of the additional numerical sensitivity studies carried out for the C RISE solar thermal energy. Section A.1 describes the results of the discretization study for the solar thermal collector model. Section A.2 then provides the results of the temporal discretization study conducted on the co simulation. Section A.3 discusses the 3-D mesh used in the ground conduction model and the results of the grid dependence study conducted for the mesh. The base parameters of the seasonal solar thermal energy system used in these sensitivity studies may be found in Section 7.2.

The final section in this appendix describes the inter-zonal air flow study conducted in the ESP- $r$ model of the C- RISE house. This study was conducted to help select the fixed air exchange rates between the occupied and basement zones of the C RISE house.

\section{A.1 Collector Discretization Study}

Chapter 4 introduced the Type 539 in the extended component libraries from Thermal Energy System Specialists (TESS) [109]. This was a 1-D multinode model that was used to determine useful solar gains of flat-plate solar collectors at each timestep under specified boundary conditions and flow rates. To determine the sensitivity of the co-simulation results to discretization of the collector, the number of nodes represented in each flat plate collector was varied between 1 and 40 nodes. The annual net energy collected by the seasonal solar thermal energy system, $Q_{\text {coll }}[\mathrm{GJ}]$, is plotted in Figure A.1. 


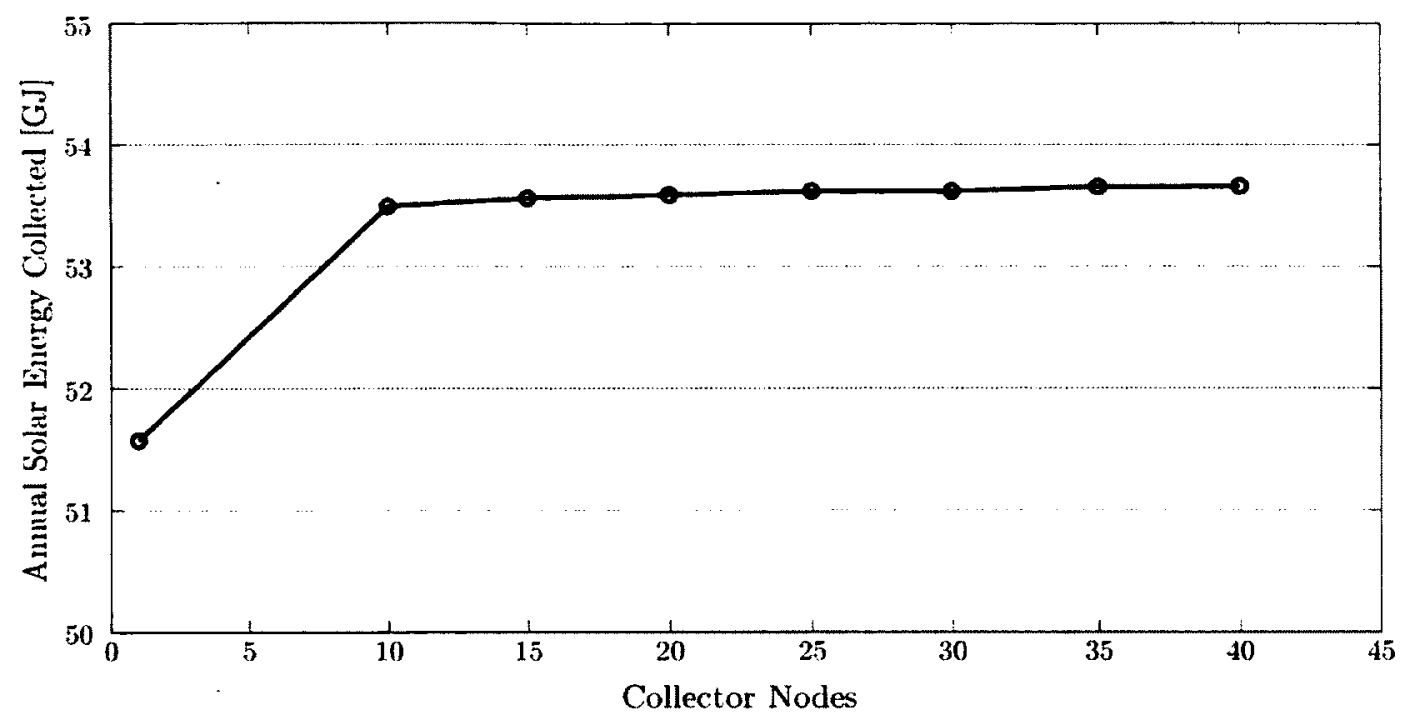

Figure A.1: Annual results of the collector discretization study

When the number of nodes was increased from 1 to $10, Q_{\text {coll }}$ increased by $3.7 \%$. Additional increases in the number of nodes in the model did not show any significant differences in $Q_{\text {coll }}$. The annual energy collected was expected to increase with increasing nodes. For the 1 node case, the entire absorber of the collector was at one average temperature. As the number of nodes were increased, a temperature gradient was able to develop across the collector absorber. The region near the collector inlet had a relatively low temperature compared to the average absorber temperature. This colder region would have a higher collector efficiency compared to the warm region near the collector outlet.

This sensitivity study demonstrated that for the collector and conditions considered in this study, the temperature gradient across the absorber of the collector had little influence on $Q_{\text {coll }}$. Specifying 10 nodes for the collector was found to provide grid independence of the solution. For the parametric study, 15 nodes were used to represent each flat-plate collector. The solution was insensitive to the number of nodes in this region and computational overhead by adding extra nodes was found to be negligible. 


\section{A.2 Temporal Discretization Study}

Stated previously in Chapter 7, the timestep used for all co simulations was 6 minutes. This timestep was chosen to match the time interval of the domestic hot water (DHW) demand profiles used in the coarse parametric study. For this study, hourly DHW profiles were used in this sensitivity study to allow the timestep of the simulation to be varied easily. The Type 9 data reader in TRNSYS required the time interval of the data file be an integer multiplier of the simulation timestep. The time interval of the data file could not be less than the simulation timestep. In this study 2,6 , and 10 minute timesteps were considered. The results of this study are given in Figure A.2.

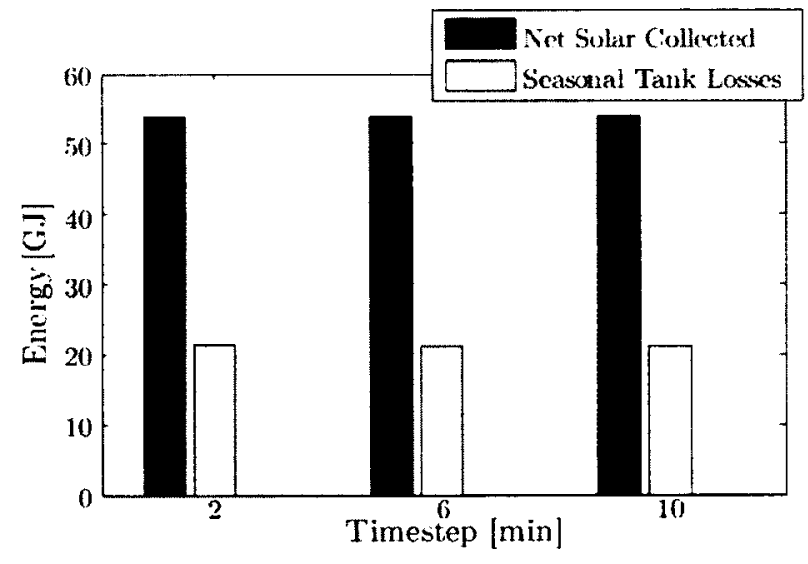

(a)

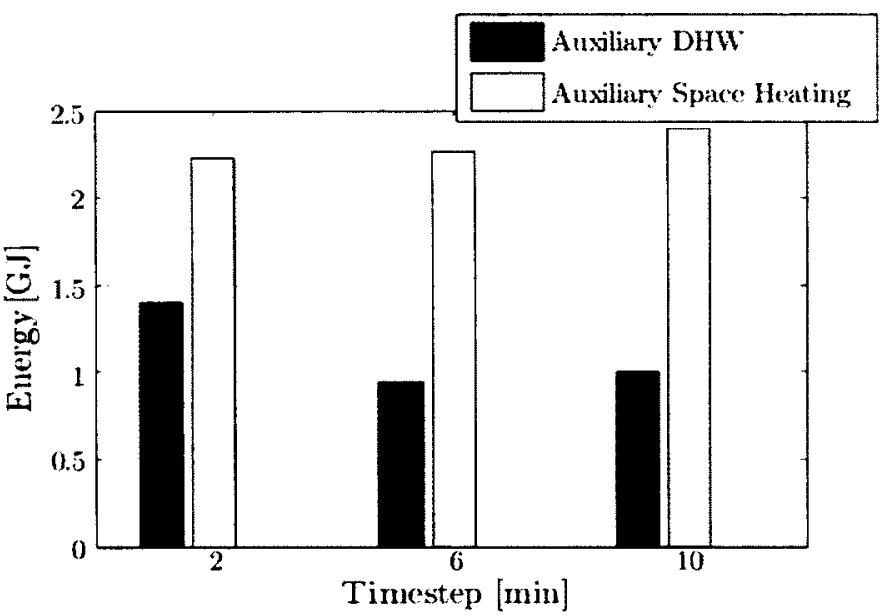

(b)

Figure A.2: Annual results of the temporal discretization study

In Figure A.2a, the annual net solar energy collected $\left(Q_{\text {coll }}\right)$ and annual losses from the seasonal tank are shown. Negligible variation of these performance metrics was observed over the range of timesteps considered. Figure A.2b presents the values of the annual energy supplied to the DHW and space heating loads. The trends for the DHW auxiliary energy appeared to reduce with increasing timestep while the auxiliary, however since an hourly DHW draw profile was used in these co-simulation, the DHW auxiliary energy results weren't considered valuable. The annual auxilary energy for space heating was found to increase with increasing timestep. A $5.8 \%$ increase in space heating auxiliary energy was observed when increasing the timestep 
from 6 to 10 minutes. The increase was less significant between the 2 and 6 minute timestep, representing a $1.7 \%$ increase in auxiliary space heating energy. These results indicated that the 6 minute timestep used in the parametric study was appropriate for grid independence.

\section{A.3 Ground Conduction Model Discretization Study}

This section presents the results of the disceretization study of the ground conduction model 3 D mesh. The solution method for heat conduction in the ground model was based on Patankar [153] and was coded and implemented into TRNSYS by Pinel [152]. There were several parameters that needed to be specified for ground mesh generation. For this study, each parameter was varied independently and the annual losses from the buried seasonal storage was determined.

Section A.3.1 briefly describes the method used to generate the mesh for the ground conduction. Sections A.3.2, A.3.3, A.3.4, and A.3.5 then present the results of the various sensitivity studies which were conducted for the ground conduction model. Finally, in Section A.3.6 the final parameters used for the coarse parametric study are provided.

The configuration and parameters of the C-RISE seasonal solar thermal system used in these studies are the same as the numerical sensitivity analyses described in Chapter 7. The parameters are reiterated in Table A.1 for convenience.

Table A.1: System parameters used for the numerical sensitivity study

\begin{tabular}{lr}
\hline \multicolumn{2}{c}{ Seasonal Storage } \\
\hline Storage volume, $V_{\text {Seas }}\left[\mathrm{m}^{3}\right]$ & 250 \\
Storage height, $h_{\text {Seas }}[\mathrm{m}]$ & 3.5 \\
Insulation thickness, $t_{\text {Seas,ins }}[\mathrm{cm}]$ & 60 \\
\hline \multicolumn{2}{c}{ Solar Collectors } \\
\hline Gross collector area, $A_{c}\left[\mathrm{~m}^{2}\right]$ \\
Collector Tilt, $\beta\left[^{\circ}\right]$ & 34.49 \\
Specific collector flow rate, $\dot{m}_{\text {coll }}^{\prime}\left[\mathrm{kg} / \mathrm{hr} \mathrm{m}^{2}\right]$ & 15 \\
\hline
\end{tabular}




\section{A.3.1 Mesh Generation}

The ground conduction model developed by Pinel [152] was used to simulate buried storage tanks with square or rectangular cross-sections. This type of geometry had two planes of symmetry which were exploited to reduce computational overhead. In this model, only a quarter of the storage tank was considered. The surfaces along the planes of symmetry were set to adiabatic boundary conditions. Figure A.3 illustrates the plan view of the ground mesh.

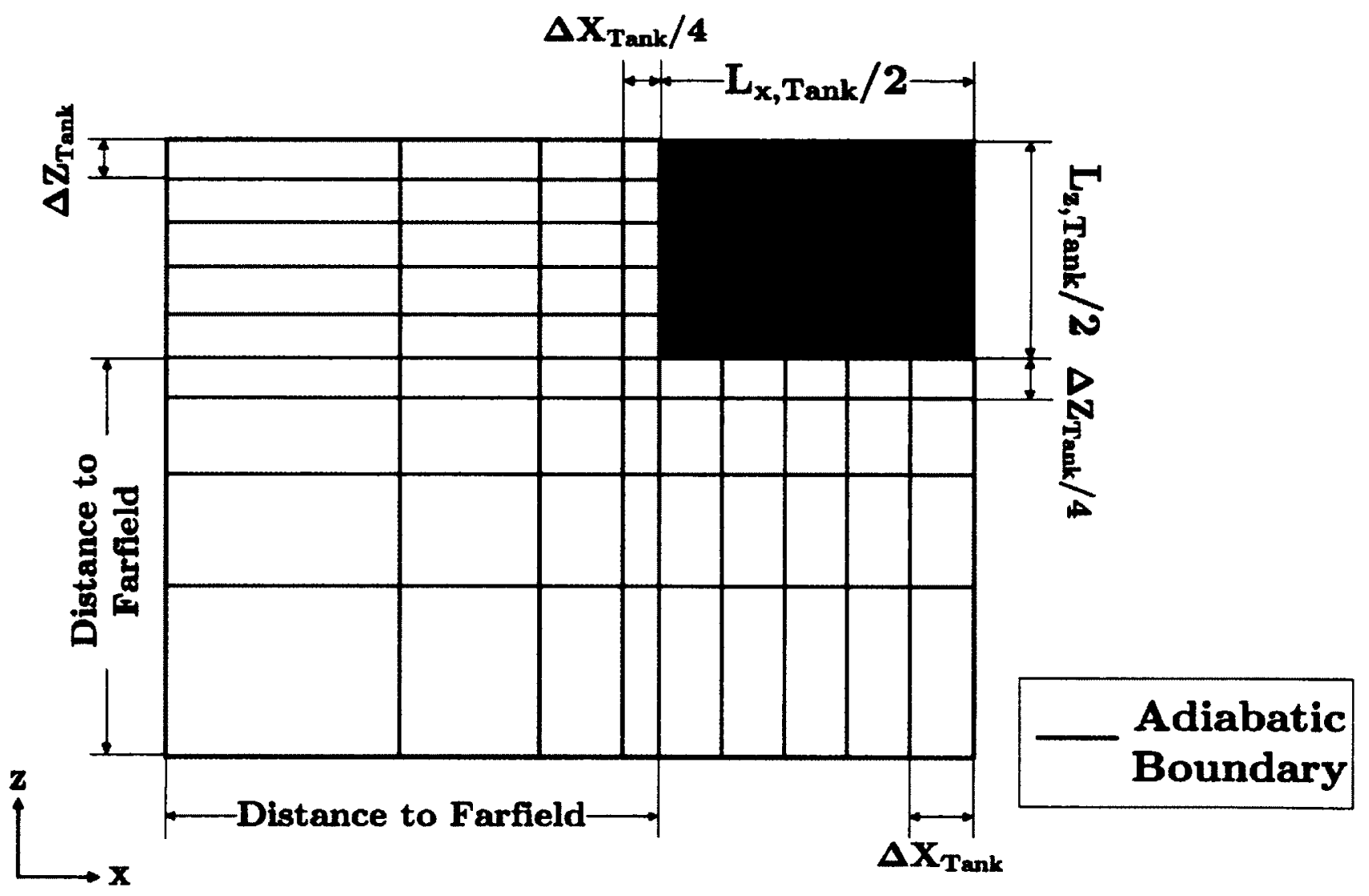

Figure A.3: Plan view of ground conduction model and quarter of buried tank

To generate the mesh in this plane, the user had to specify the side length of the tank in the $\mathbf{x}, \mathrm{L}_{\mathbf{x}, \text { Tank }}[\mathrm{m}]$, and $\mathbf{z}$ direction, $\mathrm{L}_{\mathbf{z}, \text { Tank }}[\mathrm{m}]$. The user then defined the number of nodes along the edge of the tank in the $\mathbf{x}$ and $\mathbf{z}$ directions, $N_{x}$ and $N_{z}$ respectively. The nodes were evenly spaced along the edge of the tank by $\Delta \mathrm{X}_{\text {Tank }}$ and $\Delta Z_{\text {Tank }}[\mathrm{m}]$, shown in Figure A.3. 
A farfield distance was defined for the model, $\mathrm{L}_{\text {farfield }}[\mathrm{m}]$, which represented the length from the edge of the tank to the adiabatic boundary of the mesh [m]. The user specified the number of nodes to the farfield, $N_{\text {farfield }}$, and the nodal spacing was inflated from the edge of the buried tank to the adiabatic boundary at the farfield in the $\mathbf{x}$ and $\mathbf{z}$ directions. The initial spacing from the tank wall to the adjacent soil node was specified as $\Delta \mathrm{X}_{\text {Tank }} / 4$ and $\Delta \mathrm{Z}_{\text {Tank }} / 4$, shown in Figure A.3.

Figure A.4 illustrates the elevation view of the ground conduction model. The user specified the distance from the bottom of the buried tank to the water table, $\mathrm{L}_{\mathrm{wt}}[\mathrm{m}]$, and the distance from the top of the tank to the soil surface, $\mathrm{L}_{\text {surf }}[\mathrm{m}]$. The number of nodes along the edge of the tank in the $y$ direction was equal to the number of nodes specified in the tank, $N_{\text {Seas }}$.

Soil Surface

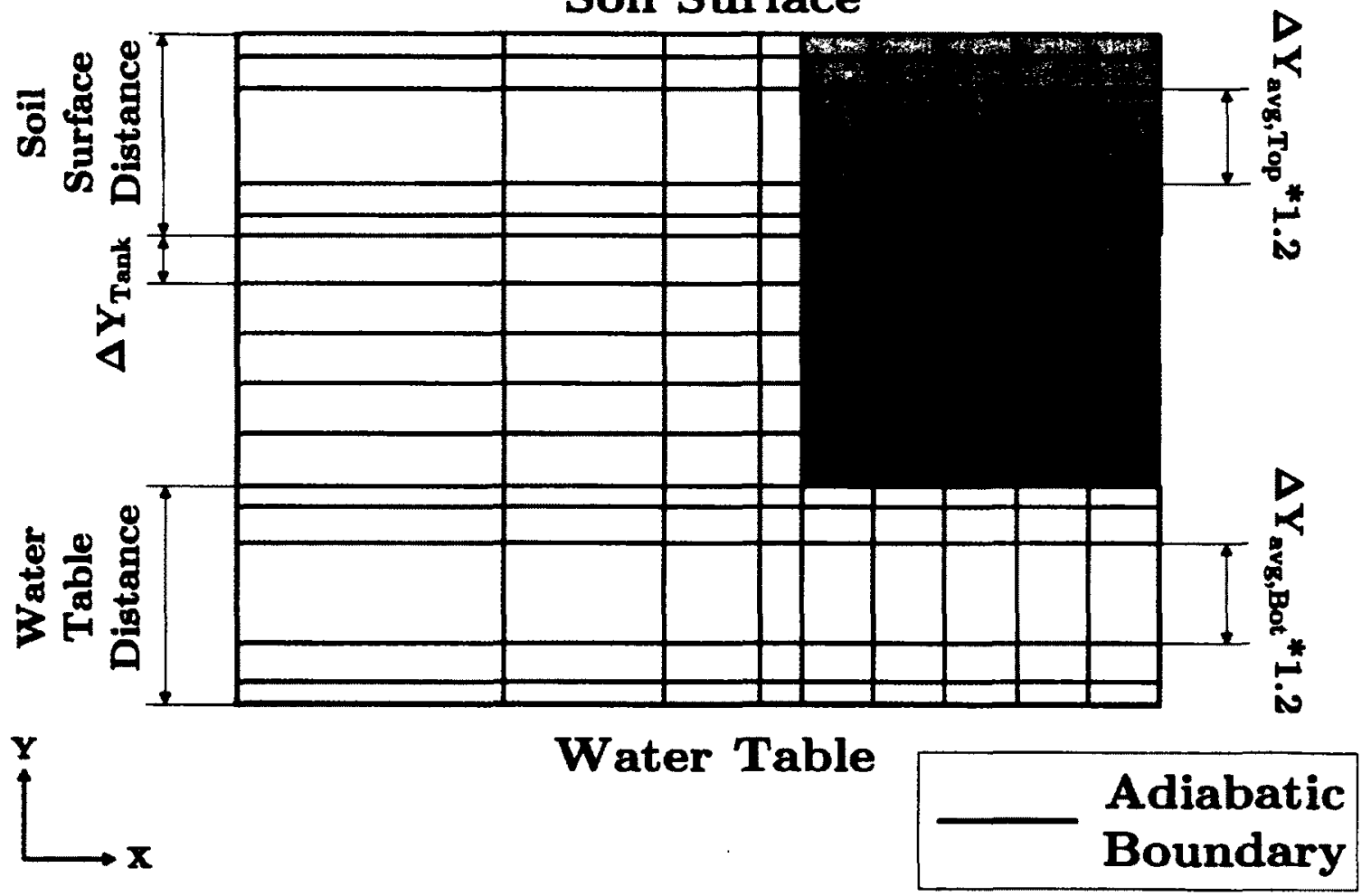

Figure A.4: Elevation view of ground conduction model and quarter of buried tank

The mesh generation between the bottom of the tank and the water table was "center biased", where the nodal spacing inflated from the bottom of the buried tank to the midpoint between the tank bottom and water table. The user specified the 
number of nodes in this region, $N_{B o t}$, and the height of the bottom region, $\mathrm{L}_{\mathrm{Bot}}[\mathrm{m}]$. The average spacing in this region, $\Delta \mathrm{Y}_{\mathrm{avg}, \mathrm{Bot}}[\mathrm{m}]$, was determined by dividing $\mathrm{L}_{\mathrm{Bot}}$ by $N_{B o t}$. This value was used to define the nodal spacing of the bottom region, shown in Figure A.4. A similar meshing procedure was carried out for the back-fill region at the top of the tank, also shown in Figure A.4. The base parameters used in the ground sensitivity study are provided in Table A.2.

Table A.2: Ground conduction model base parameters

\begin{tabular}{|c|c|}
\hline Nodes & \\
\hline Vertical Tank Nodes, $N_{\text {Seas }}$ & 20 \\
\hline Tank Edge Nodes in $\mathbf{x}, N_{x}$ & 5 \\
\hline Tank Edge Nodes in $\mathbf{z}, N_{z}$ & 5 \\
\hline Nodes to Soil Surface, $N_{T o p}$ & 5 \\
\hline Nodes to Water Table, $N_{B o t}$ & 5 \\
\hline Nodes to Farfield, $N_{\text {farfield }}$ & 10 \\
\hline \multicolumn{2}{|l|}{ Tank Dimensions } \\
\hline Tank Height, $h_{\text {Seas }}[\mathrm{m}]$ & 3.5 \\
\hline Tank Edge Length in $\mathbf{x}, \mathrm{L}_{\mathbf{x}, \text { Tank }}[\mathrm{m}]$ & 8.45 \\
\hline Tank Edge Length in $\mathbf{z}, \mathrm{L}_{z, \text { Tank }}[\mathrm{m}]$ & 8.45 \\
\hline \multicolumn{2}{|l|}{ Distance to Boundaries } \\
\hline Distance from Tank Top to Soil Surface, $\mathrm{L}_{\text {Top }}[\mathrm{m}]$ & 0.01 \\
\hline Distance from Tank Bottom to Water Table, $\mathrm{L}_{\text {Bot }}[\mathrm{m}]$ & 0.5 \\
\hline Distance to Farficld, $\mathrm{L}_{\text {farfield }}[\mathrm{m}]$ & 15 \\
\hline
\end{tabular}

The co-simulation timestep was 6 minutes to be consistent with previous simulations. The ground conduction model however, was able to recalculate mesh temperatures after a specified number of co-simulation timesteps. For this study, the temperature field in the ground was recalculated hourly. 


\section{A.3.2 Distance to Farfield Sensitivity}

The first sensitivity study was to vary the location of the farfield in the model. The farfield distance was varied between 2 and $30 \mathrm{~m}$. The results of sensitivity are presented in Figure A.5. Over the range of parameters considered, the annual energy losses of the buried tank were found to relatively insensitive to $\mathrm{L}_{\text {farficld }}$.

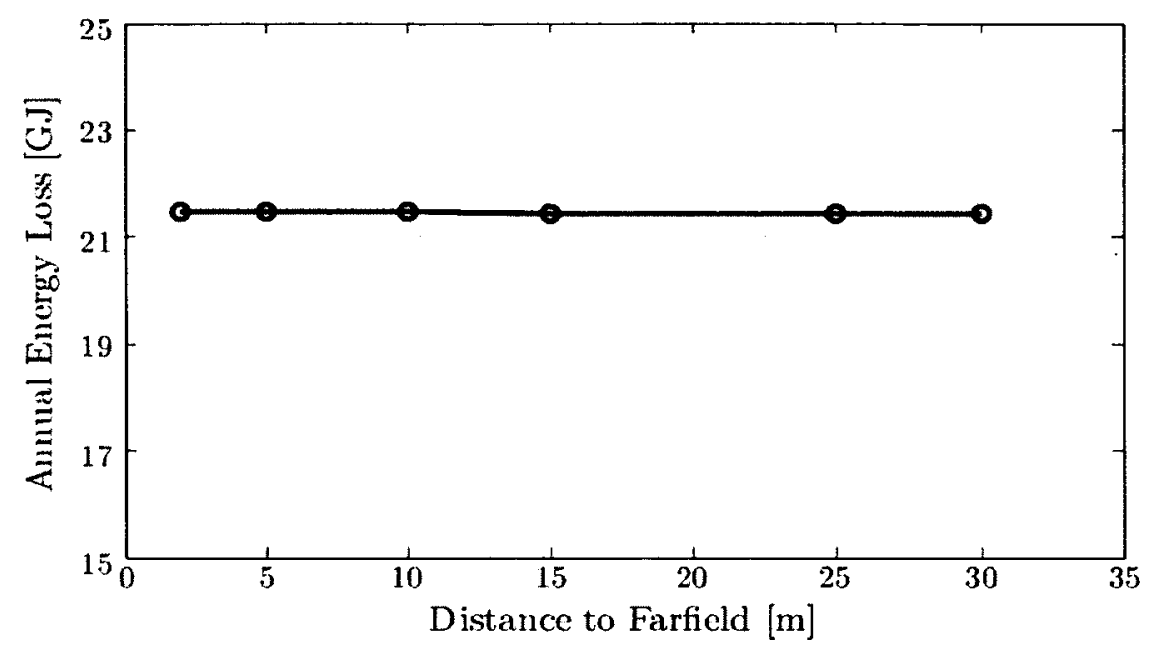

Figure A.5: Annual losses of the buried seasonal storage for the distance to farfield sensitivity study

\section{A.3.3 Nodes to Farfield Sensitivity}

For the $N_{\text {farfield }}$ study, the distance to the farfield was fixed at $15 \mathrm{~m}$. The number of nodes was varied between 2 and 25 nodes. The results of this sensitivity analysis are provided in Figure A.6. When the number of nodes increased from 2 to 5 , the annual tank losses increased by $5.2 \%$. Further increases in $N_{\text {farfield }}$ were observed to have little influence on the annual tank losses. 


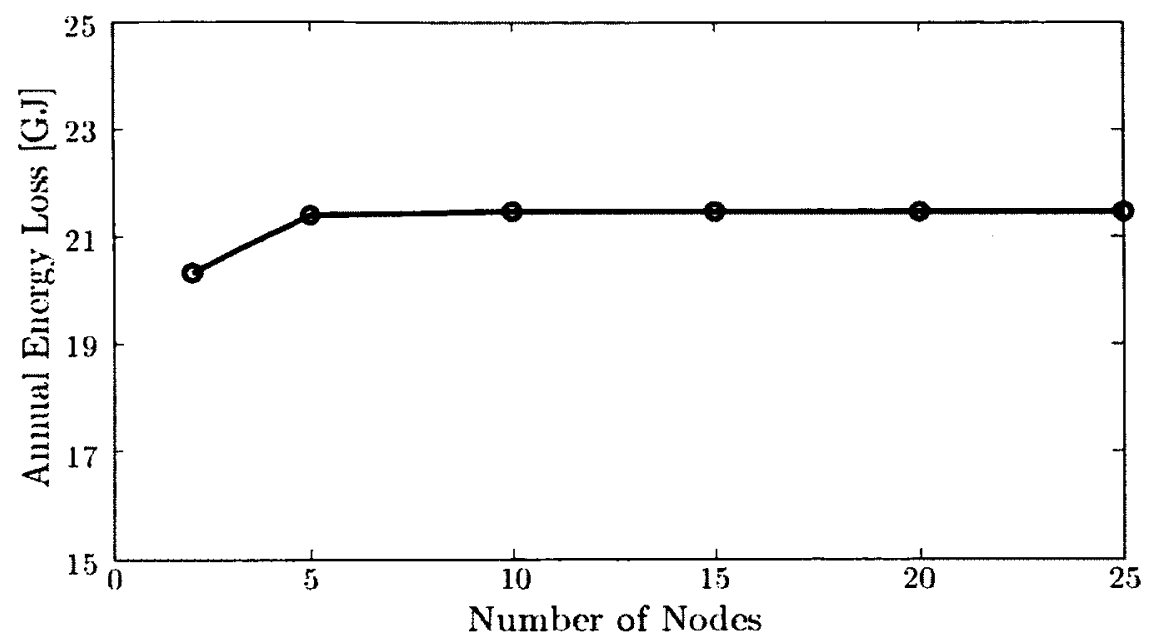

Figure A.6: Annual losses of the buried seasonal storage for the $N_{\text {farfield }}$ sensitivity study

\section{A.3.4 Nodes Along Side of Tank Sensitivity}

For this study, both $N_{x}$ and $N_{z}$ were varied together between 2 and 15. The results of this sensitivity analysis is provided in Figure A.7. Again, the annual tank losses were found to be relatively insensitive to $N_{x}$ and $N_{z}$.

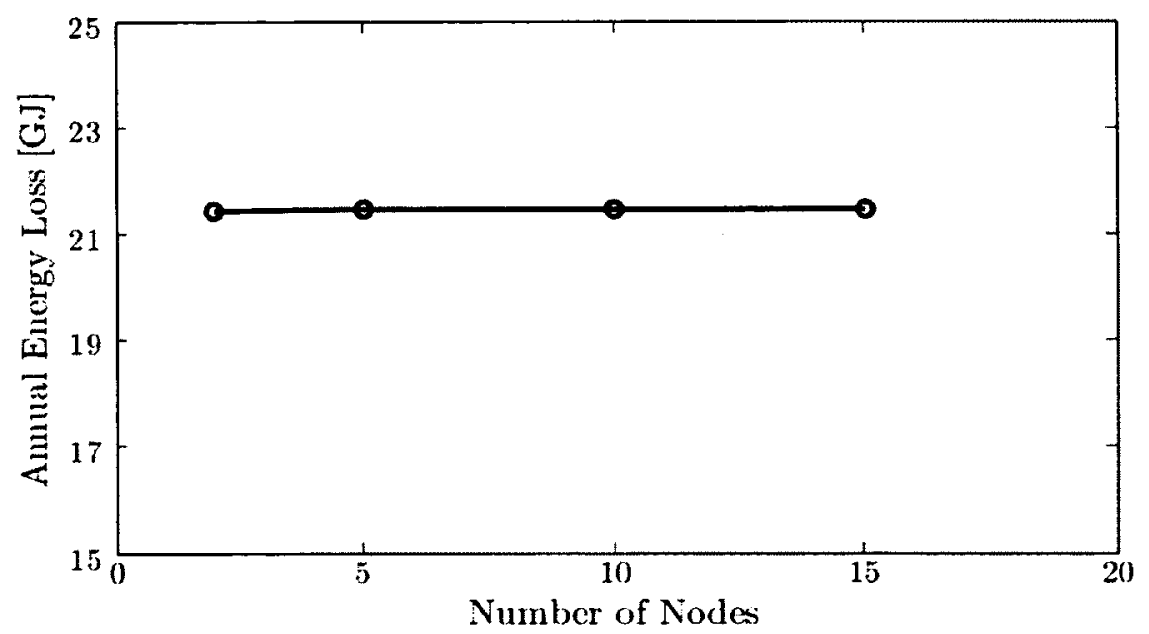

Figure A.7: Annual losses of the buried seasonal storage for the $N_{x}$ and $N_{z}$ sensitivity study 


\section{A.3.5 Nodes Between Tank Bottom and Water Table Sensi- tivity}

The final sensitivity analysis was conducted for the number of nodes between the bottom of the buried tank and the water table. The range of $N_{B o t}$ was limited since there was found to be convergence issues at certain values of $N_{B o t}$. For this study, $N_{B o t}$ was varied between 4 and 6 . The results of this sensitivity study are shown in Figure A.8. Similar to the previous sensitivity studies, the annual tank losses was found to be relatively insensitive to $N_{B o t}$.

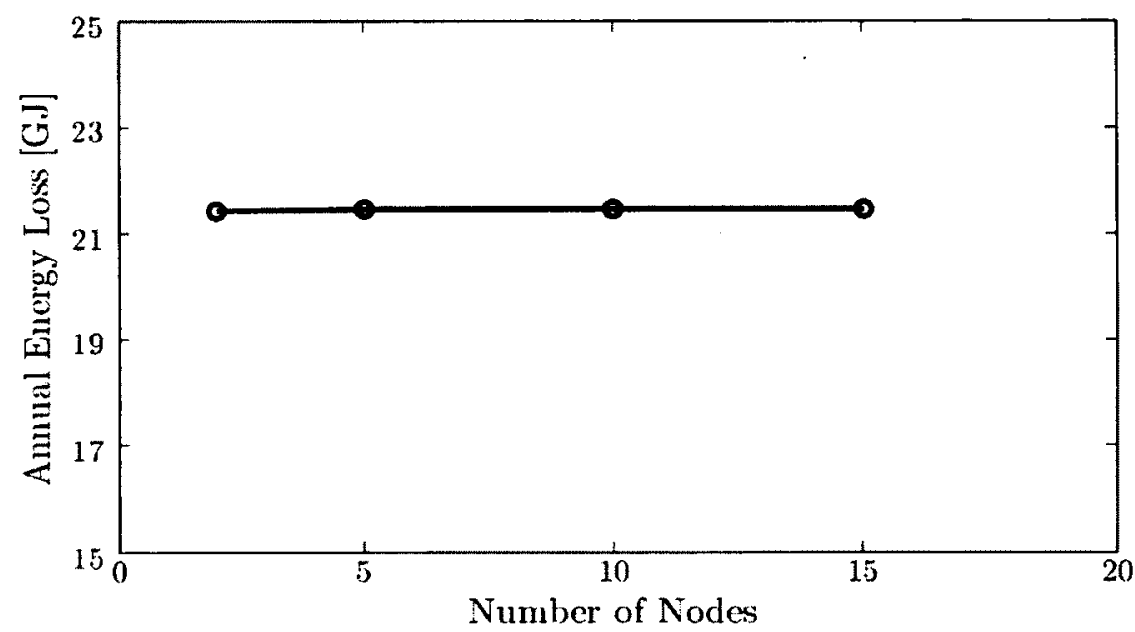

Figure A.8: Annual losses of the buried seasonal storage for the $N_{B o t}$ sensitivity study

\section{A.3.6 Final Parameters used in Ground Conduction Model}

The sensitivity studies conducted above indicated that a coarse mesh could be used to represent the ground surrounding the buried tank. This was beneficial since the ground conduction model had a relatively large amount of computational overhead. Caution had to be taken however, since both the geometry and insulation level of the buried tank was to be varied in the coarse parametric study. At lower insulation levels and higher surface areas, the heat loss to the ground was assumed to become more significant. To address this issue, conservative values were chosen for the ground conduction mesh generation and are provided in Table A.3. 
Table A.3: Ground conduction final discretization parameters

\begin{tabular}{lr}
\hline \multicolumn{2}{c}{ Nodes } \\
\hline Vertical Tank Nodes, $N_{\text {Seas }}$ & 20 \\
Tank Edge Nodes in $\mathbf{x}, N_{x}$ & 5 \\
Tank Edge Nodes in $\mathbf{z}, N_{z}$ & 5 \\
Nodes to Soil Surface, $N_{\text {Top }}$ & 5 \\
Nodes to Water Table, $N_{\text {Bot }}$ & 4 \\
Nodes to Farfield, $N_{\text {farfield }}$ & 10 \\
\hline \multicolumn{2}{c}{ Distance to Boundaries } \\
\hline Distance to Farfield, L Larfield $[\mathrm{m}]$ & 20 \\
\hline
\end{tabular}

\section{A.4 Inter-zonal Air Exchange Study}

Chapter 5 described the air flow that was modelled in the C-RISE house. During operation of the C RISE house, air exchange was expected to occur between occupied zones through openings in partitions and stairwells. At the time of this research there was insufficient data available regarding internal partitions within the C-RISE house or actual measured data for airflow. To address this issue, a method used by Swan [116] was adopted for this work. Swan [116] represented inter-zonal air exchange by specifying fixed flow rates between zones. To determine the magnitude of air flow between the zones, a sensitivity analysis was undertaken.

For this sensitivity study, the main zone was heated to a constant $22^{\circ} \mathrm{C}$ using an ideal heating source. First, the mass flow rate between the main and basement zones was considered. The mass flow rate was varied from 0.1 to $0.4 \mathrm{~kg} / \mathrm{s}$ and the root mean square difference (RMSD) of the basement zone temperatures was calculated for each flow rate increase. Figure A.9 illustrates the results of this sensitivity study. Beyond a mass flow rate of $0.35 \mathrm{~kg} / \mathrm{s}$, the basement zone temperatures were observed to be relatively insensitive to increases in mass flow rate. 


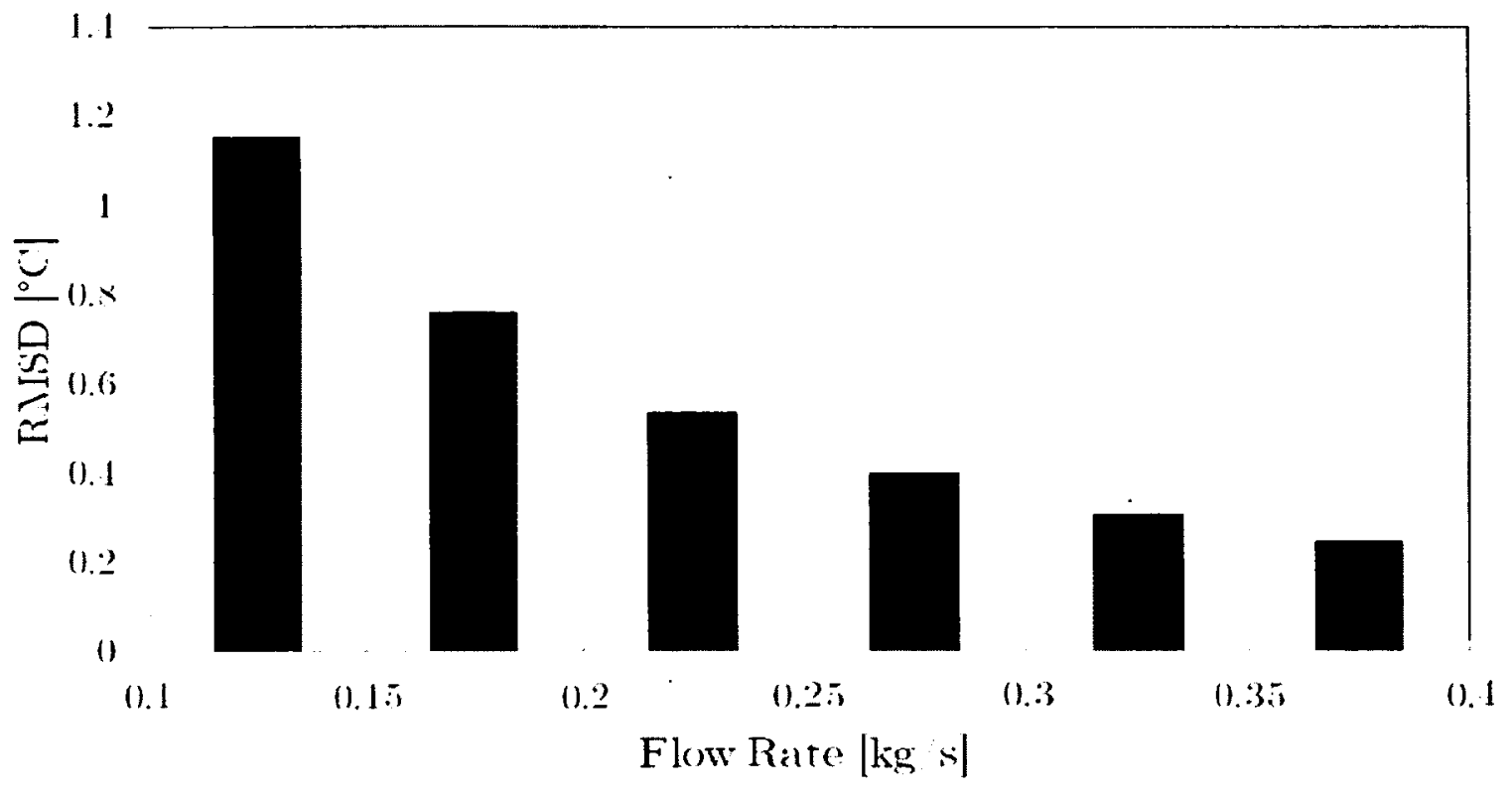

Figure A.9: RMSD of basement zone temperatures with increasing air flow between the basement and main zone

A similar procedure was then carried out for the air mass flow rate between the main and second floor zone. The mass flow rate was varied between 0.1 and $0.6 \mathrm{~kg} / \mathrm{s}$. The results of this sensitivity analysis may be found in Figure A.10. Beyond a mass flow rate of $0.55 \mathrm{~kg} / \mathrm{s}$, the RMSD of the second zone air temperature was found to be relatively insensitive to the mass flow rate between the main and second floor zone.

Thus, the final mass flow rates between the basement and main zone, and main and second zone was 0.35 and $0.55 \mathrm{~kg} / \mathrm{s}$ respectively. This was a coarse treatment of the air exchange between zones, however at the time of the study there was insufficient data regarding the internal partitions of the C-RISE house. In future work, it is recommended that a more rigorous approach is taken to treat the inter-zonal air flow which takes into account partition openings and flow coefficients. 


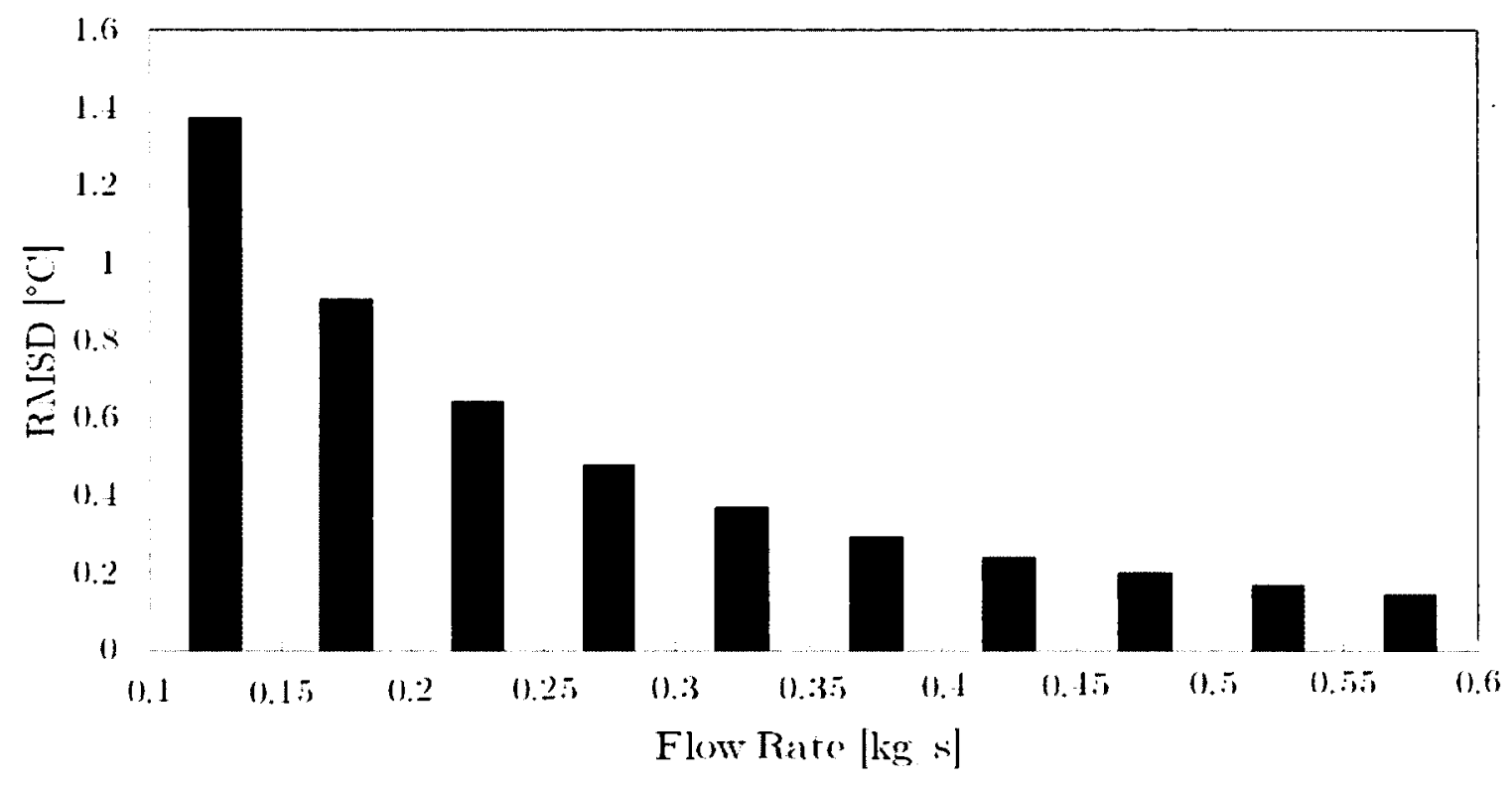

Figure A.10: RMSD of second zone temperatures with increasing air flow between the main and second zone 


\section{Appendix B}

\section{Parametric Study Data}

This appendix provides a portion of the raw data results from the parametric study discussed in Chapter 7. The data shown below is intended to provide additional information to supplement the parametric study contour plots illustrated in Chapter 7. For interested readers who would like to request additional data, they may contact Adam Wills at adamwills@cmail.carleton.ca.

\section{B.1 Combined Space Heating and DHW Solar Fraction}

The combined space heating and domestic hot water (DHW) solar fraction, $\Im_{\text {total }}$, for the different collector areas and seasonal storage volumes considered in the coarse parametric study discussed in Chapter 7 are provided below. The combined solar fraction was calculated using:

$$
\Im_{\text {total }}=\frac{\left(Q_{\text {space }}+Q_{D H W}\right)-\left(Q_{a u x, \text { space }}+Q_{a u x, D H W}\right)}{\left(Q_{\text {space }}+Q_{D H W}\right)}
$$

where $Q_{\text {space }}$ and $Q_{D H W}$ were the total annual space heating and DHW energy delivered to the end load [GJ] respectively, and $Q_{a u x, s p a c e}$ and $Q_{a u x, D H W}$ were the total annual space heating and DHW auxiliary energy delivered to the end load [GJ] respectively [GJ]. 
Table B.1: $30 \mathrm{~cm}$ seasonal storage insulation Table B.2: $45 \mathrm{~cm}$ seasonal storage insulation

\begin{tabular}{|c|c|c|c|c|c|c|c|c|c|}
\hline Storage & \multicolumn{4}{|c|}{ Number of Collectors } & Storage & \multicolumn{4}{|c|}{ Number of Collectors } \\
\hline Vol. $\left[\mathrm{m}^{3}\right]$ & 6 & 8 & 10 & 12 & Vol. $\left[\mathbf{m}^{3}\right]$ & 6 & 8 & 10 & 12 \\
\hline 80 & $58.3 \%$ & $69.3 \%$ & $77.8 \%$ & $83.9 \%$ & 80 & $63.5 \%$ & $75.2 \%$ & $83.7 \%$ & $89.2 \%$ \\
\hline 120 & $57.0 \%$ & $69.1 \%$ & $78.6 \%$ & $85.1 \%$ & 120 & $63.1 \%$ & $76.0 \%$ & $85.1 \%$ & $90.8 \%$ \\
\hline 180 & $53.3 \%$ & $66.0 \%$ & $76.1 \%$ & $83.4 \%$ & 180 & $59.9 \%$ & $73.6 \%$ & $83.4 \%$ & $89.9 \%$ \\
\hline 240 & $49.0 \%$ & $61.8 \%$ & $72.2 \%$ & $80.1 \%$ & 240 & $55.7 \%$ & $69.6 \%$ & $80.0 \%$ & $87.3 \%$ \\
\hline 300 & $45.1 \%$ & $57.4 \%$ & $68.0 \%$ & $76.3 \%$ & 300 & $51.4 \%$ & $65.4 \%$ & $76.0 \%$ & $84.0 \%$ \\
\hline
\end{tabular}

Table B.3: $60 \mathrm{~cm}$ seasonal storage insulation Table B.4: $80 \mathrm{~cm}$ seasonal storage insulation

\begin{tabular}{|c|c|c|c|c|c|c|c|c|c|}
\hline \multirow{2}{*}{$\begin{array}{c}\text { Storage } \\
\text { Vol. }\left[\mathbf{m}^{3}\right]\end{array}$} & \multicolumn{4}{|c|}{ Number of Collectors } & Storage & \multicolumn{4}{|c|}{ Number of Collectors } \\
\hline & 6 & 8 & 10 & 12 & Vol. $\left[\mathbf{m}^{3}\right]$ & 6 & 8 & 10 & 12 \\
\hline 80 & $66.5 \%$ & $78.5 \%$ & $86.8 \%$ & $91.7 \%$ & 80 & $68.6 \%$ & $80.7 \%$ & $88.7 \%$ & $93.2 \%$ \\
\hline 120 & $66.5 \%$ & $79.5 \%$ & $88.3 \%$ & $93.3 \%$ & 120 & $68.8 \%$ & $81.8 \%$ & $90.2 \%$ & $94.7 \%$ \\
\hline 180 & $63.6 \%$ & $77.4 \%$ & $86.9 \%$ & $92.7 \%$ & 180 & $66.0 \%$ & $79.7 \%$ & $88.9 \%$ & $94.2 \%$ \\
\hline 240 & $59.5 \%$ & $73.6 \%$ & $83.7 \%$ & $90.6 \%$ & 240 & $62.0 \%$ & $76.0 \%$ & $85.9 \%$ & $92.4 \%$ \\
\hline 300 & $55.1 \%$ & $69.4 \%$ & $80.0 \%$ & $87.6 \%$ & 300 & $57.6 \%$ & $71.9 \%$ & $82.3 \%$ & $89.7 \%$ \\
\hline
\end{tabular}

\section{B.2 Seasonal Tank Storage Efficiency for Year}

The seasonal tank storage efficiency for year, $\eta_{s, \text { Seas }}[\%]$, represented the ratio of total annual energy extracted from the tank, $Q_{\text {Seas,out }}[\mathrm{GJ}]$, to total energy supplied to the seasonal tank, $Q_{\text {Seas,in }}[\mathrm{GJ}]$. This was expressed mathematically as:

$$
\eta_{s, \text { Seas }}=\frac{Q_{\text {Seas }, \text { out }}}{Q_{\text {Seas }, \text { in }}}
$$

The following tables provide the co simulation results for $\eta_{s, \text { Seas }}$ for the different system configurations considered in the coarse parametric study. 
Table B.5: $30 \mathrm{~cm}$ seasonal storage insulation Table B.6: $45 \mathrm{~cm}$ seasonal storage insulation

\begin{tabular}{|c|c|c|c|c|c|c|c|c|c|}
\hline Storage & \multicolumn{4}{|c|}{ Number of Collectors } & Storage & \multicolumn{4}{|c|}{ Number of Collectors } \\
\hline Vol. $\left[\mathbf{m}^{3}\right]$ & 6 & 8 & 10 & 12 & Vol. $\left[\mathrm{m}^{3}\right]$ & 6 & 8 & 10 & 12 \\
\hline 80 & $46.1 \%$ & $49.0 \%$ & $50.1 \%$ & $50.2 \%$ & 80 & $57.0 \%$ & $59.2 \%$ & $59.6 \%$ & $59.1 \%$ \\
\hline 120 & $40.8 \%$ & $44.7 \%$ & $46.1 \%$ & $46.1 \%$ & 120 & $52.1 \%$ & $55.1 \%$ & $55.4 \%$ & $54.5 \%$ \\
\hline 180 & $33.1 \%$ & $38.1 \%$ & $40.1 \%$ & $40.6 \%$ & 180 & $44.3 \%$ & $48.4 \%$ & $49.3 \%$ & $48.7 \%$ \\
\hline 240 & $26.1 \%$ & $32.1 \%$ & $34.8 \%$ & $35.7 \%$ & 240 & $36.6 \%$ & $41.9 \%$ & $43.6 \%$ & $43.6 \%$ \\
\hline 300 & $20.3 \%$ & $26.7 \%$ & $30.1 \%$ & $31.5 \%$ & 300 & $29.6 \%$ & $36.1 \%$ & $38.5 \%$ & $39.0 \%$ \\
\hline
\end{tabular}

Table B.7: $60 \mathrm{~cm}$ seasonal storage insulation Table B.8: $80 \mathrm{~cm}$ seasonal storage insulation

\begin{tabular}{|c|c|c|c|c|c|c|c|c|c|}
\hline Storage & \multicolumn{4}{|c|}{ Number of Collectors } & Storage & \multicolumn{4}{|c|}{ Number of Collectors } \\
\hline Vol. $\left[\mathrm{m}^{3}\right]$ & 6 & 8 & 10 & 12 & Vol. $\left[\mathrm{m}^{3}\right]$ & 6 & 8 & 10 & 12 \\
\hline 80 & $63.8 \%$ & $65.5 \%$ & $65.5 \%$ & $64.6 \%$ & 80 & $69.3 \%$ & $70.6 \%$ & $70.3 \%$ & $69.3 \%$ \\
\hline 120 & $59.0 \%$ & $61.3 \%$ & $61.0 \%$ & $59.6 \%$ & 120 & $64.6 \%$ & $66.2 \%$ & $65.5 \%$ & $63.9 \%$ \\
\hline 180 & $51.2 \%$ & $54.4 \%$ & $54.6 \%$ & $53.4 \%$ & 180 & $56.5 \%$ & $59.1 \%$ & $58.8 \%$ & $57.2 \%$ \\
\hline 240 & $43.3 \%$ & $47.7 \%$ & $48.7 \%$ & $48.2 \%$ & 240 & $48.3 \%$ & $52.1 \%$ & $52.7 \%$ & $51.8 \%$ \\
\hline 300 & $35.7 \%$ & $41.6 \%$ & $43.4 \%$ & $43.5 \%$ & 300 & $40.4 \%$ & $45.7 \%$ & $47.0 \%$ & $47.0 \%$ \\
\hline
\end{tabular}

\section{B.3 Annual Solar Energy Collected}

The data provided in the tables below represents the total net annual energy collected by the solar thermal collectors for each system considered in the coarse parametric study [GJ]. The term "net" was used when describing then annual solar collected energy since there were timesteps during simulation of the seasonal solar thermal energy system where the solar collectors rejected thermal energy to ambient. This was a control related issue and the quantity of annual energy lost was found to be negligible compared to energy collected. For example, the system configuration with 12 collectors, $80 \mathrm{~m}^{3}$, and $45 \mathrm{~cm}$ of seasonal storage insulation rejected $7.5 \mathrm{MJ}$ annually through the collectors while $7200 \mathrm{MJ}$ of useful gain was collected over the year. 
Table B.9: $30 \mathrm{~cm}$ seasonal storage insulation Table B.10: $45 \mathrm{~cm}$ seasonal storage insulation

\begin{tabular}{|c|c|c|c|c|c|c|c|c|c|}
\hline Storage & \multicolumn{4}{|c|}{ Number of Collectors } & Storage & \multicolumn{4}{|c|}{ Number of Collectors } \\
\hline Vol. $\left[\mathrm{m}^{3}\right]$ & 6 & 8 & 10 & 12 & Vol. $\left[\mathrm{m}^{3}\right]$ & 6 & 8 & 10 & 12 \\
\hline 80 & 30.1 & 36.3 & 41.3 & 45.3 & 80 & 29.3 & 35.0 & 39.6 & 43.0 \\
\hline 120 & 31.8 & 38.7 & 44.5 & 49.3 & 120 & 30.8 & 37.4 & 42.6 & 46.6 \\
\hline 180 & 33.3 & 41.0 & 47.6 & 53.2 & 180 & 32.2 & 39.5 & 45.5 & 50.4 \\
\hline 240 & 34.3 & 42.5 & 49.8 & 56.0 & 240 & 33.1 & 41.0 & 47.6 & 53.1 \\
\hline 300 & 35.1 & 43.7 & 51.4 & 58.2 & 300 & 33.9 & 42.1 & 49.2 & 55.3 \\
\hline
\end{tabular}

Table B.11: $60 \mathrm{~cm}$ seasonal storage insulation Table B.12: $80 \mathrm{~cm}$ seasonal storage insulation

\begin{tabular}{c|cccc}
\hline \multirow{2}{*}{$\begin{array}{c}\text { Storage } \\
\text { Vol. }\left[\mathrm{m}^{3}\right]\end{array}$} & \multicolumn{4}{|c}{ Number of Collectors } \\
$\mathbf{8 0}$ & $\mathbf{6}$ & $\mathbf{8}$ & $\mathbf{1 0}$ & $\mathbf{1 2}$ \\
\cline { 2 - 5 } $\mathbf{1 2 0}$ & 28.7 & 34.3 & 38.5 & 41.4 \\
$\mathbf{1 8 0}$ & 30.2 & 36.5 & 41.4 & 44.9 \\
$\mathbf{2 4 0}$ & 31.5 & 38.5 & 44.1 & 48.6 \\
$\mathbf{3 0 0}$ & 33.4 & 39.9 & 46.2 & 51.2 \\
\hline
\end{tabular}

\begin{tabular}{c|cccc}
\hline \multirow{2}{*}{$\begin{array}{c}\text { Storage } \\
\text { Vol. }\left[\mathbf{m}^{3}\right]\end{array}$} & \multicolumn{4}{|c}{ Number of Collectors } \\
$\mathbf{8 0}$ & $\mathbf{6}$ & $\mathbf{8}$ & $\mathbf{1 0}$ & $\mathbf{1 2}$ \\
\cline { 2 - 5 } $\mathbf{1 2 0}$ & 28.2 & 33.5 & 37.4 & 40.0 \\
$\mathbf{1 8 0}$ & 29.6 & 35.6 & 40.1 & 43.3 \\
$\mathbf{2 4 0}$ & 30.9 & 37.5 & 42.8 & 46.9 \\
$\mathbf{3 0 0}$ & 31.7 & 38.9 & 44.8 & 49.6 \\
\hline
\end{tabular}




\section{Appendix C}

\section{ESP-r Building Constructions}

This appendix provides the major multi layer constructions used in the C-RISE building model. This information is not comprehensive and the interested reader may contact Adam Wills at adamwills@cmail.carleton.ca for further details. Section C.1 provides the constructions for the brick and aluminum siding exterior wall façades. Section C.2 describes the constructions used for the hydronic floors. Finally, Section C. 3 describes the glazing and frame constructions as well as the construction used between the second floor and the attic space. 


\section{C.1 Exterior Walls}

Table C.1: Exterior Brick Wall

\begin{tabular}{lllll} 
Material & $\begin{array}{c}\text { Thickness } \\
{[\mathrm{mm}]}\end{array}$ & $\begin{array}{c}\text { Conductivity } \\
{[\mathrm{W} / \mathrm{m} \mathrm{K}]}\end{array}$ & $\begin{array}{l}\text { Density } \\
{\left[\mathrm{kg} / \mathrm{m}^{3}\right]}\end{array}$ & $\begin{array}{c}\text { Specific Heat } \\
{[\mathrm{J} / \mathrm{kg} \mathrm{K}]}\end{array}$ \\
\hline \hline Lt. Brown Brick & 100 & 0.960 & 2000 & 650 \\
Air & 25 & 0.140 & & \\
EPS & 38 & 0.037 & 25 & 1000 \\
Sheathing & 11 & 0.055 & 290 & 1300 \\
Fibreglass batt. & 111.9 & 0.036 & 100 & 960 \\
Gypsum & 12.5 & 0.160 & 800 & 1090 \\
\hline \multicolumn{5}{l}{} \\
\hline
\end{tabular}

Table C.2: Exterior Siding Wall

\begin{tabular}{lllll} 
Material & $\begin{array}{c}\text { Thickness } \\
{[\mathrm{mm}]}\end{array}$ & $\begin{array}{c}\text { Conductivity } \\
{[\mathrm{W} / \mathrm{m} \mathrm{K}]}\end{array}$ & $\begin{array}{l}\text { Density } \\
{\left[\mathrm{kg} / \mathrm{m}^{3}\right]}\end{array}$ & $\begin{array}{l}\text { Specific Heat } \\
{[\mathrm{J} / \mathrm{kg} \mathrm{K}]}\end{array}$ \\
\hline Aluminium Siding & 38 & 0.018 & 30 & 837 \\
EPS & 38 & 0.037 & 25 & 1000 \\
Sheathing & 11 & 0.055 & 290 & 1300 \\
Fibreglass batt. & 111.9 & 0.036 & 100 & 960 \\
Gypsum & 12.5 & 0.160 & 800 & 1090 \\
\hline
\end{tabular}


Table C.3: Roof Construction

\begin{tabular}{lllll} 
Material & $\begin{array}{c}\text { Thickness } \\
{[\mathrm{mm}]}\end{array}$ & $\begin{array}{c}\text { Conductivity } \\
{[\mathrm{W} / \mathrm{m} \mathrm{K}]}\end{array}$ & $\begin{array}{c}\text { Density } \\
{\left[\mathrm{kg} / \mathrm{m}^{3}\right]}\end{array}$ & $\begin{array}{c}\text { Specific Heat } \\
{[\mathrm{J} / \mathrm{kg} \mathrm{K}]}\end{array}$ \\
\hline \hline \multicolumn{5}{c}{ Exterior } \\
\hline Asphalt & 6 & 1.200 & 2300 & 1700 \\
Sheathing & 11 & 0.055 & 290 & 1300 \\
\hline \multicolumn{5}{c}{ Interior } \\
\hline
\end{tabular}

\section{C.2 Hydronic Floors}

The constructions used for the hydronic floors in the main and second zone of the C-RISE model are described in this section. To simulate the hydronic floor, the plant component in ESP $r$ was linked to a corresponding surface in the building thermal model. The plant component received temperature data from the floor construction and calculated a heat flux injected into the floor at each timestep.

The thermophysical properties of the poured gypsum slab was based on manufacturer data [168]. The details for the piping layout and materials are not included in this section. These parameters were handled by the ESP-r hydronic floor plant component. More information on the hydronic floor piping may be found in Appendix D.

A gypsum board layer was mistakenly omitted from the second zone hydronic floor construction. Under this configuration, the ceiling of the main zone was "unfinished" with exposed insulation. The impact of this omission on simulation results was assumed to be negligible. The percentage difference of the floor RSI-value with and without a $12.5 \mathrm{~mm}$ gypsum board layer was $1.9 \%$. 
Table C.4: Main zone hydronic floor construction

Material Thickness Conductivity Density Specific Heat

\begin{tabular}{lllll} 
& {$[\mathrm{mm}]$} & {$[\mathrm{W} / \mathrm{m} \mathrm{K}]$} & {$\left[\mathrm{kg} / \mathrm{m}^{3}\right]$} & {$[\mathrm{J} / \mathrm{kg} \mathrm{K}]$} \\
\hline \hline Concrete tile & 8 & 1.100 & 2100 & 837 \\
Poured Gypsum & 38.1 & 0.714 & 1840 & 939 \\
Chipboard & 16 & 0.150 & 800 & 2093 \\
Fibreglass batt. & 139 & 0.036 & 100 & 960 \\
\hline \multicolumn{5}{c}{ Basement } \\
\hline
\end{tabular}

Table C.5: Second zone hydronic floor construction

Material Thickness Conductivity Density Specific Heat

\begin{tabular}{lllll} 
& {$[\mathrm{mm}]$} & {$[\mathrm{W} / \mathrm{m} \mathrm{K}]$} & {$\left[\mathrm{kg} / \mathrm{m}^{3}\right]$} & {$[\mathrm{J} / \mathrm{kg} \mathrm{K}]$} \\
\hline \hline Concrete tile & 8 & 1.100 & 2100 & 837 \\
Poured Gypsum & 38.1 & 0.714 & 1840 & 939 \\
Chipboard & 16 & 0.150 & 800 & 2093 \\
Fibreglass batt. & 69.8 & 0.036 & 100 & 960 \\
\hline
\end{tabular}

Main floor

\section{C.3 Ceiling and Glazing Constructions}

Table C.6: Ceiling construction between attic and second floor Material Thickness Conductivity Density Specific Heat

\begin{tabular}{lllll} 
& {$[\mathrm{mm}]$} & {$[\mathrm{W} / \mathrm{m} \mathrm{K}]$} & {$\left[\mathrm{kg} / \mathrm{m}^{3}\right]$} & {$[\mathrm{J} / \mathrm{kg} \mathrm{K}]$} \\
\hline \hline Attic \\
\hline Fibreglass batt. & 324 & 0.036 & 100 & 960 \\
Gypsum & 12.5 & 0.160 & 800 & 1090 \\
\hline \multicolumn{5}{c}{ Second floor } \\
\hline
\end{tabular}


Table C.7: Glazing frame construction

\begin{tabular}{ccccc} 
Material & $\begin{array}{c}\text { Thickness } \\
{[\mathrm{mm}]}\end{array}$ & $\begin{array}{c}\text { Conductivity } \\
{[\mathrm{W} / \mathrm{m} \mathrm{K}]}\end{array}$ & $\begin{array}{c}\text { Density } \\
{\left[\mathrm{kg} / \mathrm{m}^{3}\right]}\end{array}$ & $\begin{array}{c}\text { Specific Heat } \\
{[\mathrm{J} / \mathrm{kg} \mathrm{K}]}\end{array}$ \\
\hline \hline PVC framing & 290.9 & 0.809 & 1379 & 1004 \\
\hline
\end{tabular}

Table C.8: Triple pane double low e argon glazing

\begin{tabular}{|c|c|c|c|c|}
\hline Material & $\begin{array}{c}\text { Thickness } \\
{[\mathrm{mm}]}\end{array}$ & $\begin{array}{c}\text { Exterior Facing } \\
\text { Reflectivity }\end{array}$ & Transmissivity & $\begin{array}{c}\text { Exterior Facing } \\
\text { Reflectivity }\end{array}$ \\
\hline \multicolumn{5}{|c|}{ Exterior } \\
\hline Plate glass & 5.9 & 0.081 & 0.883 & 0.840 \\
\hline Argon & 12.7 & & & \\
\hline Plate glass & 5.6 & 0.108 & 0.819 & 0.157 \\
\hline Argon & 12.7 & & & \\
\hline Plate glass & 6.0 & 0.108 & 0.819 & 0.157 \\
\hline \multicolumn{5}{|c|}{ Interior } \\
\hline
\end{tabular}




\section{Appendix D}

\section{Simulation Input Files}

Both the ESP-r and TRNSYS simulation tools required numerous input files to perform simulations. This appendix provides examples of the key input files required to perform a co-simulation. This appendix is divided into three sections. Section D.1 provides the input file to the Harmonizer for initiating co-simulations. Sections D.2 then provides several of the input files used in the ESP-r C-RISE building model. Finally, Section D.3 provides portions of the input deck file for the TRNSYS model of the seasonal solar thermal system. Attention is drawn to sections of the TRNSYS input file which contained relevant information key parameters of the solar thermal system.

\section{D.1 Harmonizer Input File}

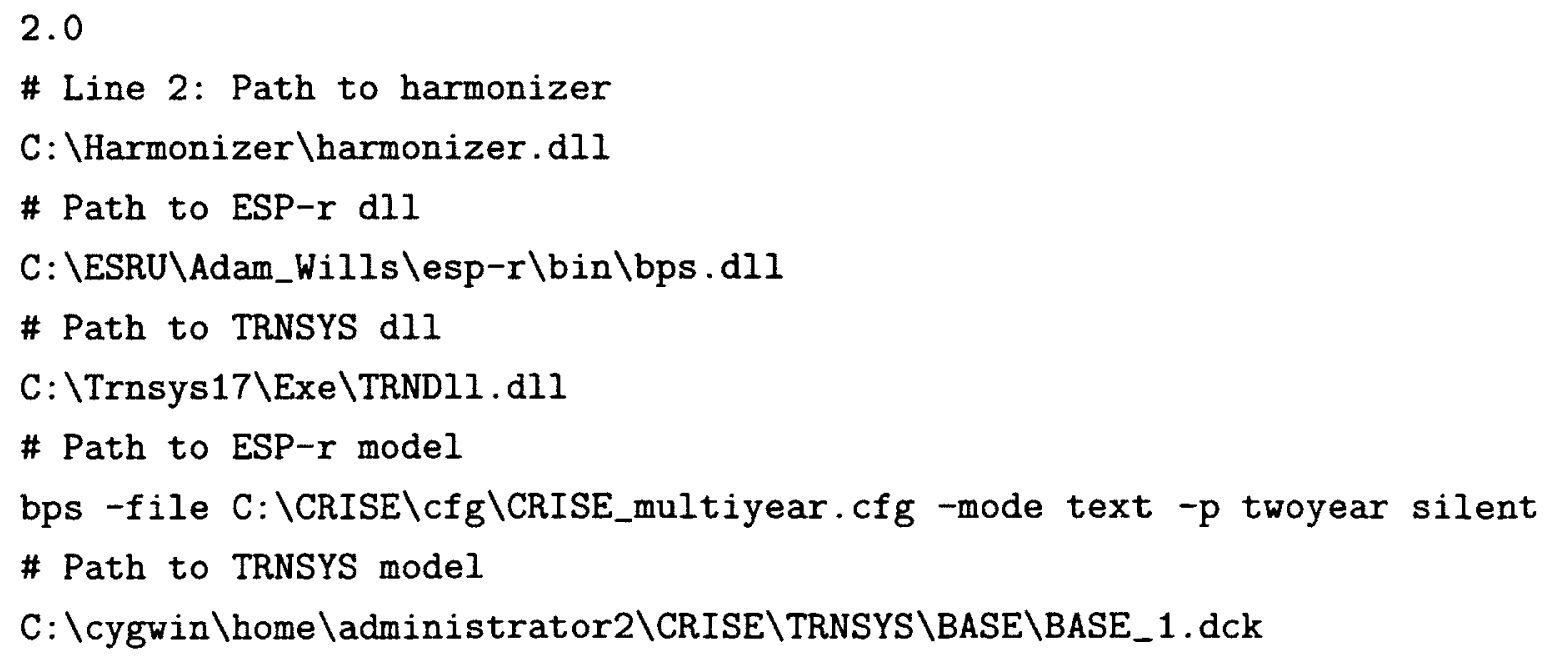


\# Temperature Tol., Mass flow Tol., Moisture flow tol., Max. iterations $0.010,0.010,0.010,100$ 


\section{D.2 ESP-r Input Files}

Models developed in ESP-r required several input files. For clarity, a few key input files are included here. The configuration file was the primary input file for $\mathrm{ESP}-\mathrm{r}$ projects. This file set the paths to databases and other input files associated with the project. Simulation presets such a simulation period and timestep were defined in the configuration file. The plant components associated with an ESP-r model was defined in a separate plant network file. Both of these inputs are provided below. Additional inputs related to air flow, glazing properties, basement heat loss, and controls are also provided.

\section{D.2.1 Configuration File}

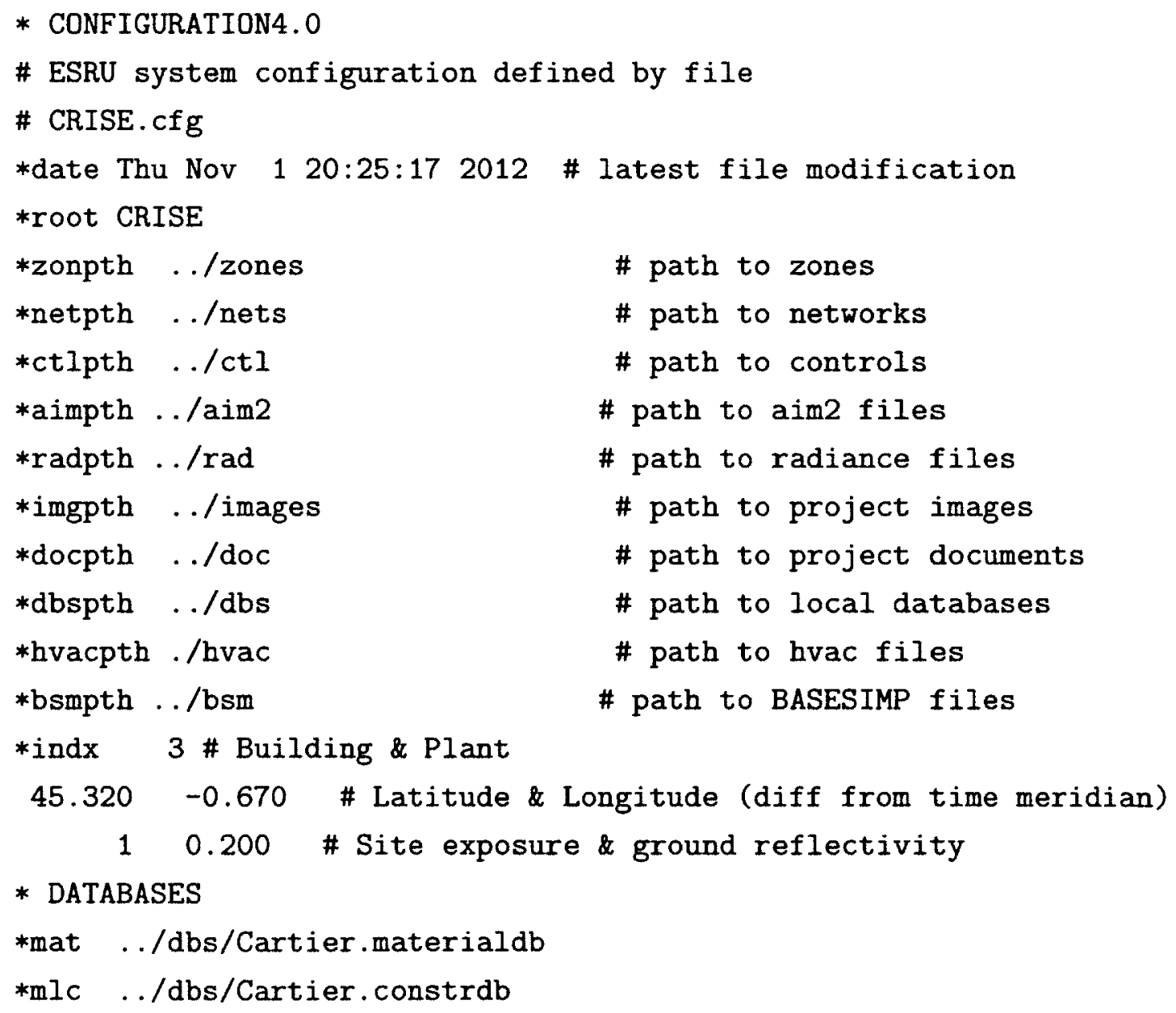


*stdopt optics.db2

*stdprs pressc.db1

*stdevn profiles.db2.a

*clm ../dbs/CRISE. climate

*stdmscldb mscomp.db1

*stdmould mould.db1 \# mould isopleths

$\begin{array}{llllllllllllll}* \text { gref } 2 & 0.20 & 0.20 & 0.20 & 0.20 & 0.20 & 0.20 & 0.20 & 0.20 & 0.20 & 0.20 & 0.20 & 0.20 & 0.70\end{array}$

*snow $26 \begin{array}{lllllllllll}28 & 17 & 1 & 0 & 0 & 0 & 0 & 0 & 1 & 6 & 19\end{array}$

*stdpdb plantc.db1

*stdsbem SBEM.db1

*aim . . /aim2/CRISE. aim

*munt $\quad . /$ mvnt/CRISE.vnt

*slr_half_hr 0 \# solar timing hour centred

*ctl ../ctl/CRISE.ctl

*calename standard weekday Sat \& Sun

*calentag weekdays, weekdays (all year), 260

*calentag saturday, Saturdays (all year), 53

*calentag sunday, Sundays (all year), 52

*list 3

$2,3,1,1,1,1,1,2,3,1,1,1,1,1,2,3,1,1,1,1,1,2,3,1,1,1,1,1,2,3,1,1,1,1,1,2,3$, $1,1,1,1,1,2,3,1,1,1,1,1,2,3,1,1,1,1,1,2,3,1,1,1,1,1,2,3,1,1,1,1,1,2,3,1,1$, $1,1,1,2,3,1,1,1,1,1,2,3,1,1,1,1,1,2,3,1,1,1,1,1,2,3,1,1,1,1,1,2,3,1,1,1,1$, $1,2,3,1,1,1,1,1,2,3,1,1,1,1,1,2,3,1,1,1,1,1,2,3,1,1,1,1,1,2,3,1,1,1,1,1,2$, $3,1,1,1,1,1,2,3,1,1,1,1,1,2,3,1,1,1,1,1,2,3,1,1,1,1,1,2,3,1,1,1,1,1,2,3,1$, $1,1,1,1,2,3,1,1,1,1,1,2,3,1,1,1,1,1,2,3,1,1,1,1,1,2,3,1,1,1,1,1,2,3,1,1,1$, $1,1,2,3,1,1,1,1,1,2,3,1,1,1,1,1,2,3,1,1,1,1,1,2,3,1,1,1,1,1,2,3,1,1,1,1,1$, $2,3,1,1,1,1,1,2,3,1,1,1,1,1,2,3,1,1,1,1,1,2,3,1,1,1,1,1,2,3,1,1,1,1,1,2,3$, $1,1,1,1,1,2,3,1,1,1,1,1,2,3,1,1,1,1,1,2,3,1,1,1,1,1,2,3,1,1,1,1,1,2,3,1,1$, $1,1,1,2,3,1,1,1,1,1,2,3,1,1,1,1,1,2,3,1,1,1,1,1,2,3,1,1,1,1,1,2$

*end_list

*year 1966 \# assessment year

*pnt $\ldots /$ nets/CRISE. enf

\# sim setup: no. sets startup zone_ts plant_ts save_lv Q each ts $\begin{array}{lllllll}* \text { *sps } & 5 & 2 & 10 & 1 & 4 & 0\end{array}$ 


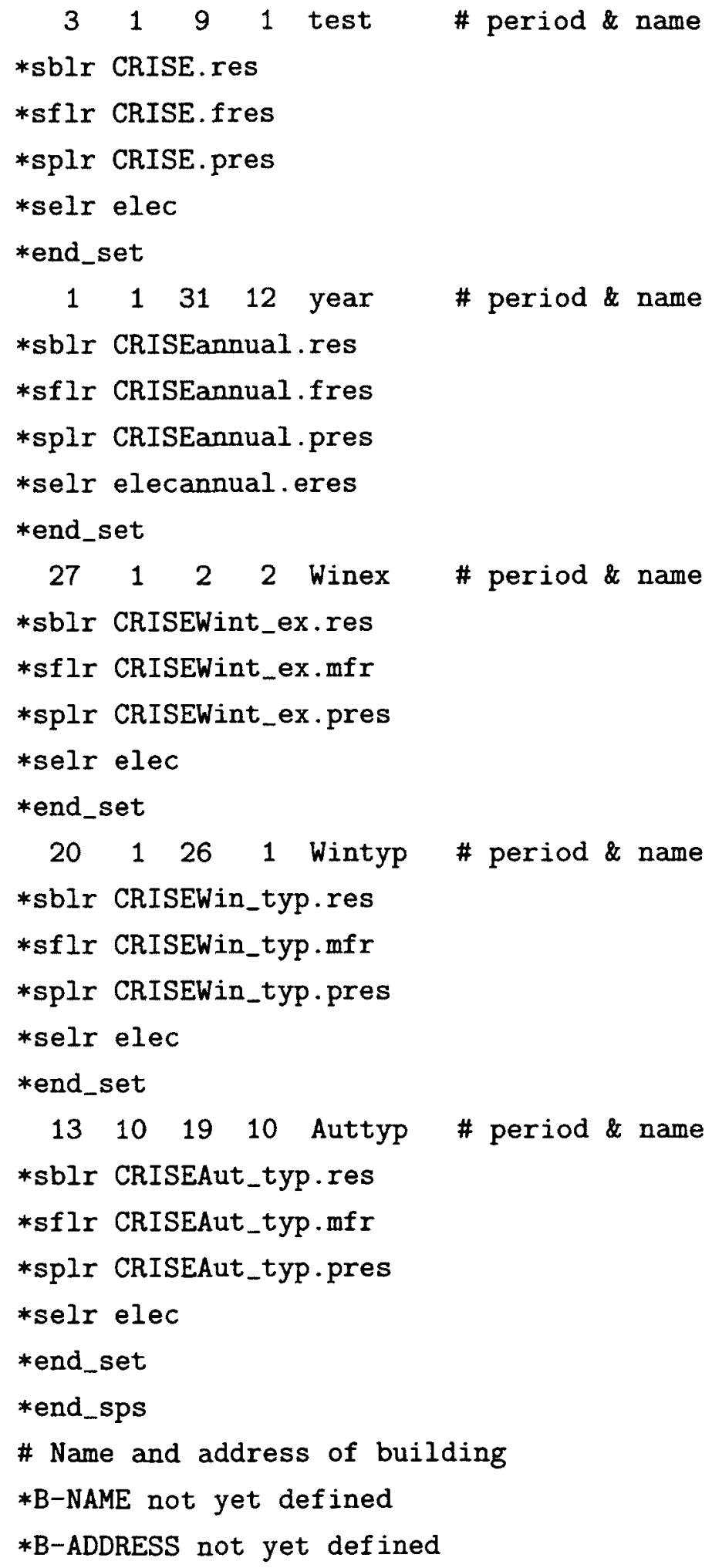


*B-CITY not yet defined

*B-POSTCODE not yet defined

\# Contact information for building owner

*D-NAME not yet defined

*D-ADDRESS not yet defined

*0-CITY not yet defined

*O-POSTCODE not yet defined

*O-TELEPHONE not yet defined

\# Contact information for simulation team

*C-NAME not yet defined

*C-ADDRESS not yet defined

*C-CITY not yet defined

*C-POSTCODE not yet defined

*C-TELEPHONE not yet defined

* PROJ LOG

Cartier.log

* Building

C-RISE Model

5 \# no of zones

*zon 1 \# reference for Main

*opr ../zones/Main.opr \# schedules

*geo ../zones/Main.geo \# geometry

*con ../zones/Main.con \# construction

*cfc ../zones/Main.cfc \# complex fenestration constr

*ivf ../zones/Main.vwf \# viewfactors

*isi ../zones/Main.shd \# shading db

*ihc ../zones/Main.htc \# convective hc coef

*zend

*zon 2 \# reference for Garage

*opr ../zones/Garage.opr \# schedules

*geo .../zones/Garage.geo \# geometry

*con ../zones/Garage.con \# construction

*tmc ../zones/Garage.tmc \# transparent constr

*bsm ../bsm/Garage.bsm \# BASESIMP input 
*zend

*zon 3 \# reference for Basement

*opr .../zones/Basement.opr \# schedules

*geo ../zones/Basement.geo \# geometry

*con ../zones/Basement.con \# construction

*cfc ../zones/Basement.cfc \# complex fenestration constr

*ivf ../zones/Basement.vwf \# viewfactors

*isi ../zones/Basement.shd \# shading db

*bsm ../bsm/Basement999.bsm \# BASESIMP input

*zend

*zon 4 \# reference for Roof

*opr ../zones/Roof.opr \# schedules

*geo .../zones/Roof.geo \# geometry

*con ../zones/Roof.con \# construction

*zend

*zon 5 \# reference for 2nd_floor

*opr ../zones/2nd_floor.opr \# schedules

*geo .../zones/2nd_floor.geo \# geometry

*con ../zones/2nd_floor.con \# construction

*cfc ../zones/2nd_floor.cfc \# complex fenestration constr

*ivf ../zones/2nd_floor.vwf \# viewfactors

*isi ../zones/2nd_floor.shd \# shading db

*ihc ../zones/2nd_floor.htc \# convective hc coef

*zend

*cnn CRISE.cnn \# connections

1 \# fluid flow network:

../nets/CRISE.afn \# leakage description

Main, 0, Basement, 0, 2nd_floor

* Plant

../nets/CRISE.pln \# plant network description 


\section{D.2.2 Plant File}

In this section, the plant configuration file for ESP-r model is presented. The only components of the C-RISE seasonal solar thermal system were the hydronic floors used to supply heat to the main and second floor. The control of fluid temperatures and flow was simulated in TRNSYS.

The embedded pipes in the system were assumed to be cross linked polyethylene (PEX). The thermophysical properties of the PEX piping was determined from manufacturer data $[169,170]$. Two hydronic floor components were created, one for each occupied zone in the C-RISE house model. Two hydronic sending components and two hydronic receiving components were then created and linked to the hydronic floor models to facilitate data exchange with the Harmonizer co- simulation tool.

ESP-r plant file version 2 written on: Sat Oct 6 12:57:28 2012

\# Project title:

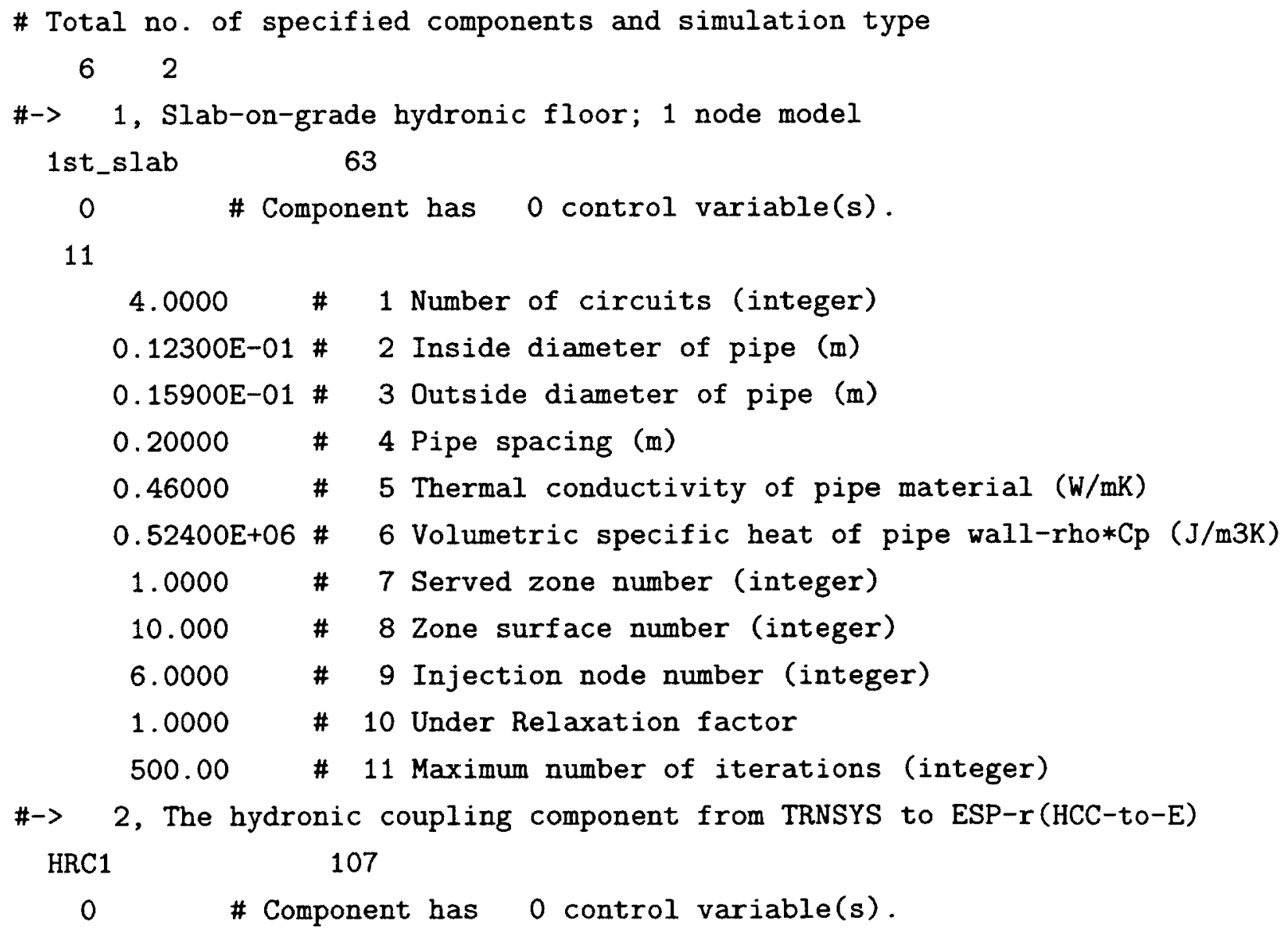


1

$1.0000 \quad$ \# 1 Index of TRNSYS output type

\#-> 3, The hydronic coupling component from ESP-r to TRNSYS(HCC-to-T) HSC1 106

0 \# Component has 0 control variable(s).

1

$1.0000 \quad$ \# 1 Index of TRNSYS coupling

\#-> 4, Slab-on-grade hydronic floor; 1 node model

2nd_slab

63

0 \# Component has 0 control variable(s).

11

$4.0000 \quad \# 1$ Number of circuits (integer)

$0.12300 \mathrm{E}-01$ \# 2 Inside diameter of pipe (m)

$0.15900 \mathrm{E}-01$ \# 3 Outside diameter of pipe (m)

$0.20000 \quad \# 4$ Pipe spacing (m)

$0.46000 \quad \# 5$ Thermal conductivity of pipe material (W/mK)

$0.52400 \mathrm{E}+06$ \# 6 Volumetric specific heat of pipe wall-rho*Cp $(\mathrm{J} / \mathrm{m} 3 \mathrm{~K})$

$5.0000 \quad \# 7$ Served zone number (integer)

$6.0000 \quad \# 8$ Zone surface number (integer)

6.0000 \# 9 Injection node number (integer)

1.0000 \# 10 Under Relaxation factor

500.00 \# 11 Maximum number of iterations (integer)

\#-> 5, The hydronic coupling component from TRNSYS to ESP-r(HCC-to-E) HRC2 107

0 \# Component has 0 control variable(s).

1

$2.0000 \quad \# 1$ Index of TRNSYS output type

\#-> 6, The hydronic coupling component from ESP-r to TRNSYS(HCC-to-T) HSC2 106

0 \# Component has 0 control variable(s).

1

$2.0000 \quad \# 1$ Index of TRNSYS coupling

\# The following is a list of component connections.

6 \# Total number of connections 


\begin{tabular}{|c|c|c|c|c|c|c|}
\hline $\begin{array}{l}\# \text { receiving } \\
\# \text { component }\end{array}$ & node & $\begin{array}{l}\text { conncn } \\
\text { type }\end{array}$ & $\begin{array}{l}\text { sending } \\
\text { component }\end{array}$ & node & $\begin{array}{l}\text { diversion suppli } \\
\text { ratio }\end{array}$ & supp12 \\
\hline 1st_slab & 1 & 3 & HRC1 & 1 & 1.000 & 1 \\
\hline $\mathrm{HSC} 1$ & 1 & 3 & 1st_slab & 1 & 1.000 & 2 \\
\hline HRC1 & 1 & 3 & HSC1 & 1 & 1.000 & 3 \\
\hline 2nd_slab & 1 & 3 & $\mathrm{HRC} 2$ & 1 & 1.000 & $\# 4$ \\
\hline HSC2 & 1 & 3 & 2nd_slab & 1 & 1.000 & $\# 5$ \\
\hline HRC2 & 1 & 3 & HSC2 & 1 & 1.000 & 6 \\
\hline
\end{tabular}

0

\section{D.2.3 AIM-2 Input File}

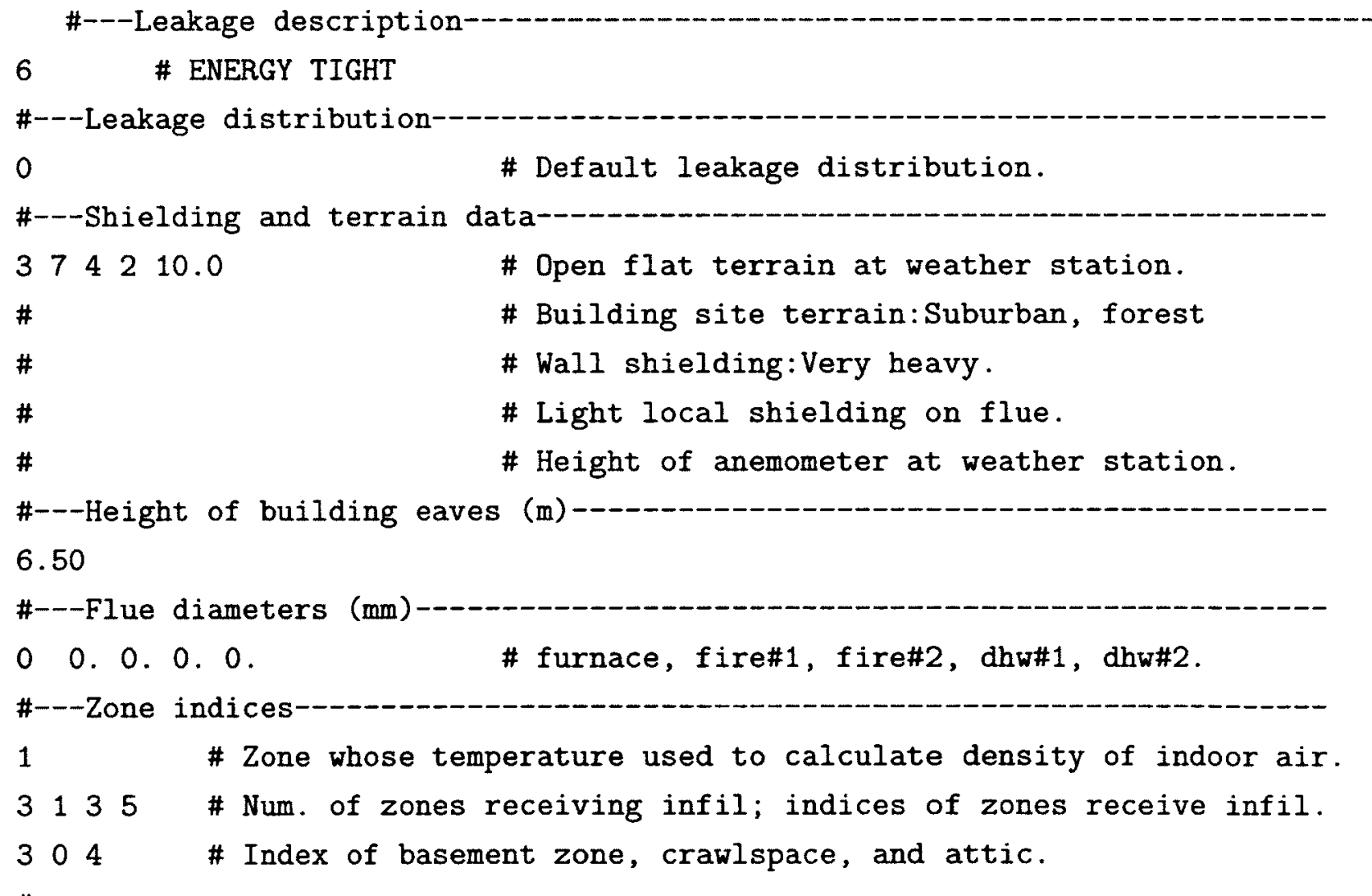




\section{D.2.4 Control File}

This is an ideal zone controller used to cool the building during the summer \# Cooling is only done if the outdoor temperature exceeded 18 oC

\# The cooling setpoint was set to $24 \mathrm{oC}$

* Building

no zone control description supplied

1 \# No. of functions

* Control function 1

\# senses the temperature of the current zone.

$0 \quad 0 \quad 0 \quad 0$ \# sensor data

\# actuates air point of the current zone

000 actuator data

1 \# all daytypes

1365 \# valid Sat-01-Jan - Sat-31-Dec

1 \# No. of periods in day: weekdays

$0 \quad 190.0$ \# ctl type, law (senses ambient dry bulb temp.), start @

13. \# No. of data items

$\begin{array}{lllllllllllllllllllllll}0.0 & 0.0 & 1000000.0 & 0.0 & 0.0 & 24.0 & 1.0 & -3.0 & 0.0 & 0.0 & 0.0 & 0.0 & 18.0\end{array}$

\# Function:Zone links

$1,0,0,0,1$

\section{D.2.5 Ventilation Input File}

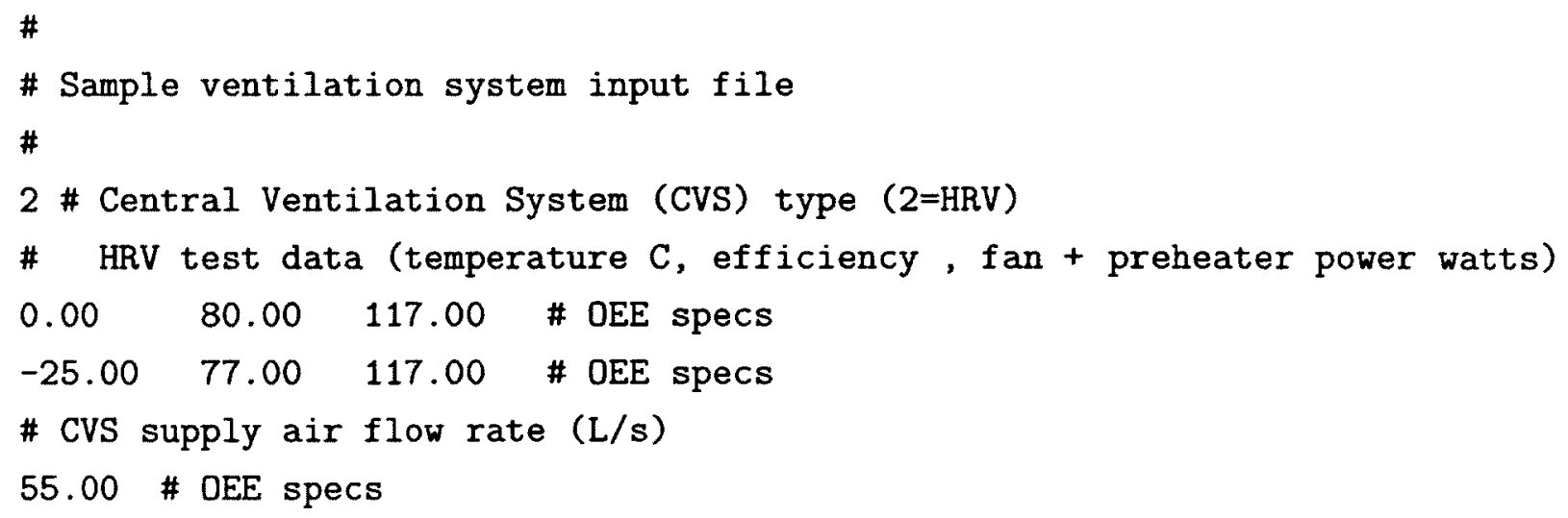


0.00 \# HRV efficiency in cooling mode (used by $\mathrm{A} / \mathrm{C}$ model)

0.00 \# Preheater capacity (watts)

\# CVS temp. control data ( $f l a g$, low temperature trip, high temperature trip)

$70.00 \quad 0.00 \#$ flag $3=$ Temperature controlled, or $1,2,4,5,6,7=\mathrm{N} / \mathrm{A}$

\# HRV duct data

\# Vent. Duct Location: \# of zone in which duct is located

\# Duct Type: \# 1=Flexible, 2=Sheet metal with liner, 3=Ext. ins. Sheet metal

\# Sealing Characteristic: \# 1=Very Tight, 2=Sealed, 3=Unsealed

\#

\# Location, Type, Sealing, Length(m), Diameter (mm), Insul.RSI

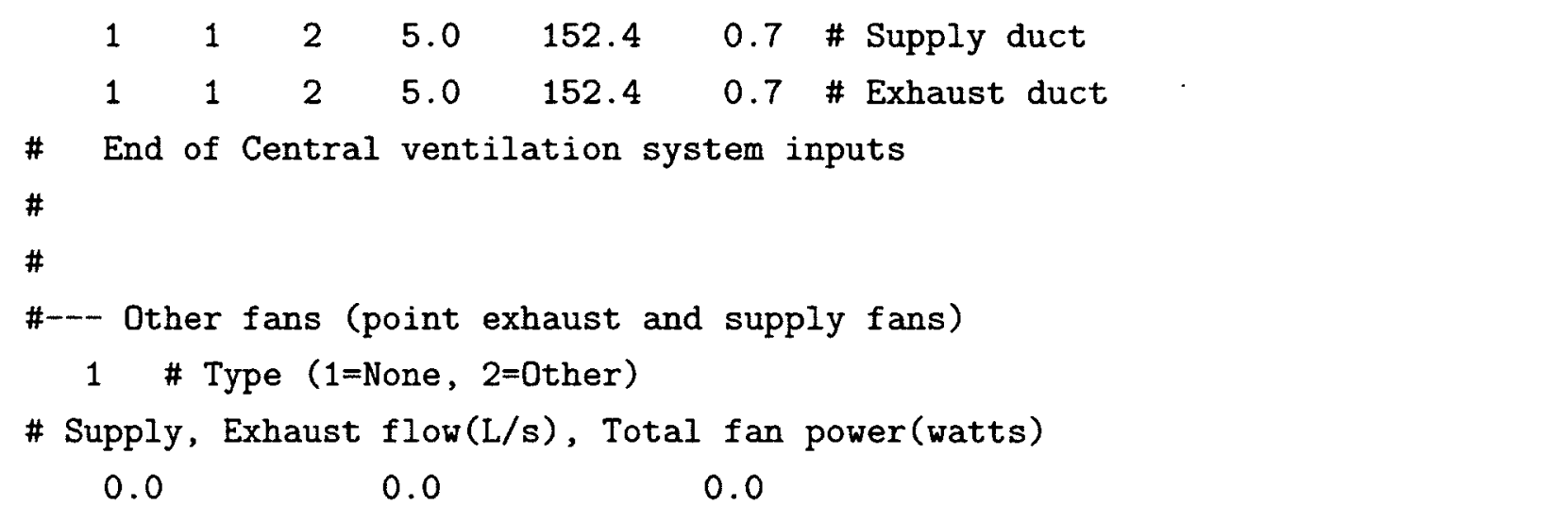

\section{D.2.6 Complex Fenestration Construction File}

\# CFC properties of Main defined in ../zones/Main.cfc

20 \# surfaces

\# CFC index for each surface

$0,0,0,0,0,0,0,0,0,0,0,0,0,1,0,0,2,0,0,1$

5 \# layers in cfc type: 1

\# For each layer: normal solar optical properties - R_fr, R_bk, Tran.
0.072
0.072
0.774
\# glazing
0.000
0.000
0.000
\# gas gap
0.113
0.100
0.662
\# glazing
0.000
0.000
0.000
\# gas gap
0.113
0.100
0.662
\# glazing

\# For each layer: normal visible optical properties - R_fr, R_bk, Tran. 

$0.081 \quad 0.081$
0.883
\# glazing
$0.000 \quad 0.000$
0.000
\# gas gap
0.108
0.102
0.819
\# glazing
0.000
0.000
0.000
\# gas gap
0.108
0.102
0.819
\# glazing

\# For each layer: normal longwave radiative properties - EmisF, EmisB, Tran.
0.840
0.840
0.000
\# glazing
0.000
0.000
0.000
\# gas gap
0.157
0.840
0.000
\# glazing
$0.000 \quad 0.000$
0.000
\# gas gap
0.157
$0.840 \quad 0.000$
\# glazing
3 \# layers in cfc type: 2

\# For each layer: normal solar optical properties - R_fr, R_bk, Tran.
0.085
0.085
0.820
\# glazing
0.000
0.000
0.000
\# gas gap
0.248
0.215
0.293
\# glazing

\# For each layer: normal visible optical properties - R_fr, R_bk, Tran.
0.091
0.091
0.875
\# glazing
0.000
0.000
0.000
\# gas gap
0.045
0.187
0.445
\# glazing

\# For each layer: normal longwave radiative properties - EmisF, EmisB, Tran.
0.836
$0.887 \quad 0.000$
\# glazing
0.000
0.000
0.000
\# gas gap
0.149
0.840
0.000
\# glazing

\# layer type index for cfc type: 1

$1,0,1,0,1$

\# Gas mixture properties for cfc type: 1

\# gas layer 2

$0.399 \mathrm{E}+02$ \# molecular mass of gas mixture (g/gmole)
$0.248 \mathrm{E}-02 \quad 0.507 \mathrm{E}-04$
\# $a$ and $b$ coeffs.- gas conductivity (W/m.K)
$0.362 \mathrm{E}-05 \quad 0.644 \mathrm{E}-07$
\# $a$ and $b$ coeffs. - gas viscosity (N.s/m2)
$0.526 \mathrm{E}+03-0.138 \mathrm{E}-01$
\# $a$ and $b$ coeffs. - specific heat (J/kg.K)

\# gas layer 4

$0.399 \mathrm{E}+02$ \#olecular mass of gas mixture ( $\mathrm{g} / \mathrm{gmole}$ ) 


$$
\begin{array}{rrr}
0.248 \mathrm{E}-02 & 0.507 \mathrm{E}-04 & \# \mathrm{a} \text { and } \mathrm{b} \text { coeffs. - gas conductivity (W/m.K) } \\
0.362 \mathrm{E}-05 & 0.644 \mathrm{E}-07 & \# \mathrm{a} \text { and } \mathrm{b} \text { coeffs. - gas viscosity (N.s/m2) } \\
0.526 \mathrm{E}+03 & -0.138 \mathrm{E}-01 & \# \mathrm{a} \text { and b coeffs. - specific heat (J/kg.K) }
\end{array}
$$

\# layer type index for cfc type: 2

$1,0,1$

\# Gas mixture properties for cfc type: 2

\# gas layer 2

\begin{tabular}{ccc}
$0.399 \mathrm{E}+02$ & \multicolumn{2}{c}{ \# molecular mass of gas mixture (g/gmole) } \\
$0.248 \mathrm{E}-02$ & $0.507 \mathrm{E}-04$ & $\# \mathrm{a}$ and $\mathrm{b}$ coeffs. - gas conductivity (W/m.K) \\
$0.362 \mathrm{E}-05$ & $0.644 \mathrm{E}-07$ & $\# \mathrm{a}$ and $\mathrm{b}$ coeffs. - gas viscosity (N.s/m2) \\
$0.526 \mathrm{E}+03$ & $-0.138 \mathrm{E}-01$ & $\# \mathrm{a}$ and $\mathrm{b}$ coeffs. - specific heat (J/kg.K)
\end{tabular}

\section{D.2.7 BASESIMP Input Files}

Two BASESIMP input files were used in this research. The first was for the basement of the C-RISE house. The second was used for the slab in the garage zone.

\section{D.2.7.1 Basement Zone .bsm File}

*FileVersion 99.0

2.2700

1.7140

12.0654

4.3513

0.0000

3.5200

0.8500

8.0000

8.90

14.2

0.3691

6.651

28.362

11.222

2.697
\# foundation height (m)

\# foundation depth (m)

\# foundation length (m)

\# foundation width (m)

\# insul overlap (for BCCN_1, BCCN_2)

\# insulation in RSI

\# soil conductivity (W/m K)

\# water table (m)

\# $\mathrm{Tg}$, avg

\# $\mathrm{Tg}$, amp

\# Ps (Ground temperature phase angle)

\# Above-grade heat-loss factor (Sag)

\# Below-grade average heat-loss factor (Sbg,avg)

\# Below-grade variable heat-loss factor (Sbg,var)

\# phase angle (phase) 


\section{D.2.7.2 Garage Zone .bsm File}

*FileVersion 1.0

1.0000

\# foundation height (m)

0.7500

\# foundation depth (m)

5.9200

\# foundation length (m)

2.5200

\# foundation width (m)

0.0000

\# insul overlap (for BCCN_1, BCCN_2)

0.0000

\# insulation in RSI

0.8500

\# soil conductivity (W/m K)

8.0000

\# water table (m)

\section{D.3 TRNSYS Input File}

The entire input file for TRNSYS, referred to as a deck file, is omitted here for clarity. Portions of the deck file are included however, to draw attention to important parameters of key types used in modelling the C-RISE seasonal solar thermal system.

\section{D.3.1 TRNSYS Control Cards}

Several variables and equations were defined in the control cards to facilitate easy parameter variation and to ensure that specified relationships between parameters remained constant. For example, the maximum flow rate of the fluid entering the collector array was a function of the array area.

\section{VERSION 17}

*** Control cards

*****************************************************************************

* START, STOP and STEP

CONSTANTS 3

START $=55 * 24$

$\mathrm{STOP}=789 * 24$

STEP $=$ TSTEP 


\author{
SIMULATION START STOP STEP ! Start time End time Time step \\ TOLERANCES 0.0010 .001 ! Integration Convergence \\ LIMITS 5005030 ! Max iterations Max warnings Trace limit \\ DFQ 1 ! TRNSYS numerical integration solver method \\ WIDTH 80 ! TRNSYS output file width, number of characters \\ LIST ! NOLIST statement \\ ! MAP statement \\ SOLVER 011 ! Solver statement Min relax factor Max relax factor \\ NAN_CHECK 0 ! Nan DEBUG statement \\ OVERWRITE_CHECK 0 ! Overwrite DEBUG statement \\ TIME_REPORT 0 ! disable time report \\ EQSOLVER 0 ! EQUATION SOLVER statement \\ ETRACE START STOP ! EQUATION TRACE statement
}

* User defined CONSTANTS

EQUATIONS 21

TSTEP $=1 / 10$ ! Timestep

Parallel_num=6 ! Number of parallel collector branches

Series_num=2 ! Number of collectors per branch

A_collector $=2.874 *$ Series_num ! Total area of collector array [m2]

! Power consumption of solar loop pump [kJ/hr]

P_pumpcoll $=\left(44.6 * E X P\left(0.0181 * A_{-}\right.\right.$collector*Parallel_num $\left.)\right) * 3.6$

! Power consumption of charge circulation pumps $[\mathrm{kJ} / \mathrm{hr}]$

$P_{\text {_pumpsec }}=\left(\left(78.3 * \operatorname{EXP}\left(0.0156 * A_{\text {_collector }} *\right.\right.\right.$ Parallel_num $\left.\left.)\right) * 3.6\right)-\mathrm{P}_{\text {_pumpcoll }}$

M_collflow $12 * A_{\text {_collector }}$ Parallel_num ! Flow rate to collector array $[\mathrm{kg} / \mathrm{hr}]$

UA_HX $=30 * 3.6 * A_{-}$collector $*$ Parallel_num ! UA-value of solar loop HXs [kJ/hr $\left.\mathrm{K}\right]$

V_DHW=0.3 ! Volume of the diurnal tank [m3]

$\mathrm{h}_{-} \mathrm{DHW}=\left(\left(\left(4 * \mathrm{~V}_{-} \mathrm{DHW}\right) *\left(3.5^{\sim} 2\right)\right) / 3.14159\right)^{\wedge}(1 / 3)$ ! Height of the diurnal tank [m]

U_s_ins_side $=0.3167$ ! U-value for side of seasonal tank [kJ/hr m2 K]

U_s_ins_top $=0.3238$ ! U-value for top of seasonal tank [kJ/hr m2 K]

U_s_ins_bot=0.3167 ! U-value for bottom of seasonal tank [kJ/hr m2 K]

U_s_ins_side_P=U_s_ins_side/3.6 ! Unit conversion to [W/m2 k]

U_s_ins_top_P=U_s_ins_top/3.6 ! Unit conversion to [W/m2 k] 
U_s_ins_bot_P=U_s_ins_bot/3.6 ! Unit conversion to $[\mathrm{W} / \mathrm{m} 2 \mathrm{k}]$

V_Seas $=80$ ! Volume of seasonal storage [m3]

h_Seas=3.2 ! Height of seasonal storage [m]

$\mathrm{x}_{-}$Seas $=\left(V_{\text {_Seas }} / \mathrm{h} \text { _Seas }\right)^{-0.5}$ ! side length of square cross-section [m]

P_Seas=4*x_Seas ! Perimeter of seasonal tank cross-section [m]

! Additional conductivity of seasonal tank [kJ/hr m K]

Seas_cond $=6.192 *\left(\left(\left(0.8 * x_{-}\right.\right.\right.$Seas $\left.)+0.16\right) /\left(x_{-}\right.$Seas $\left.\left.^{`} 2\right)\right)$

\section{D.3.2 Weather Reader Type 15}

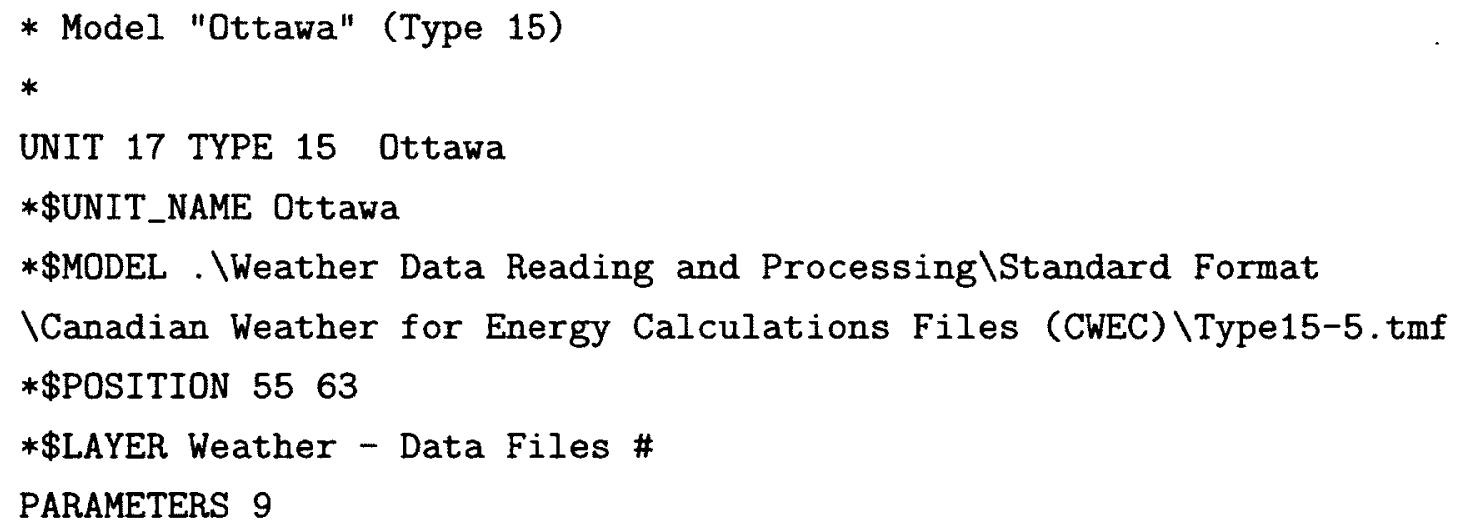




\section{D.3.3 Flat-Plate Collector Type 539}

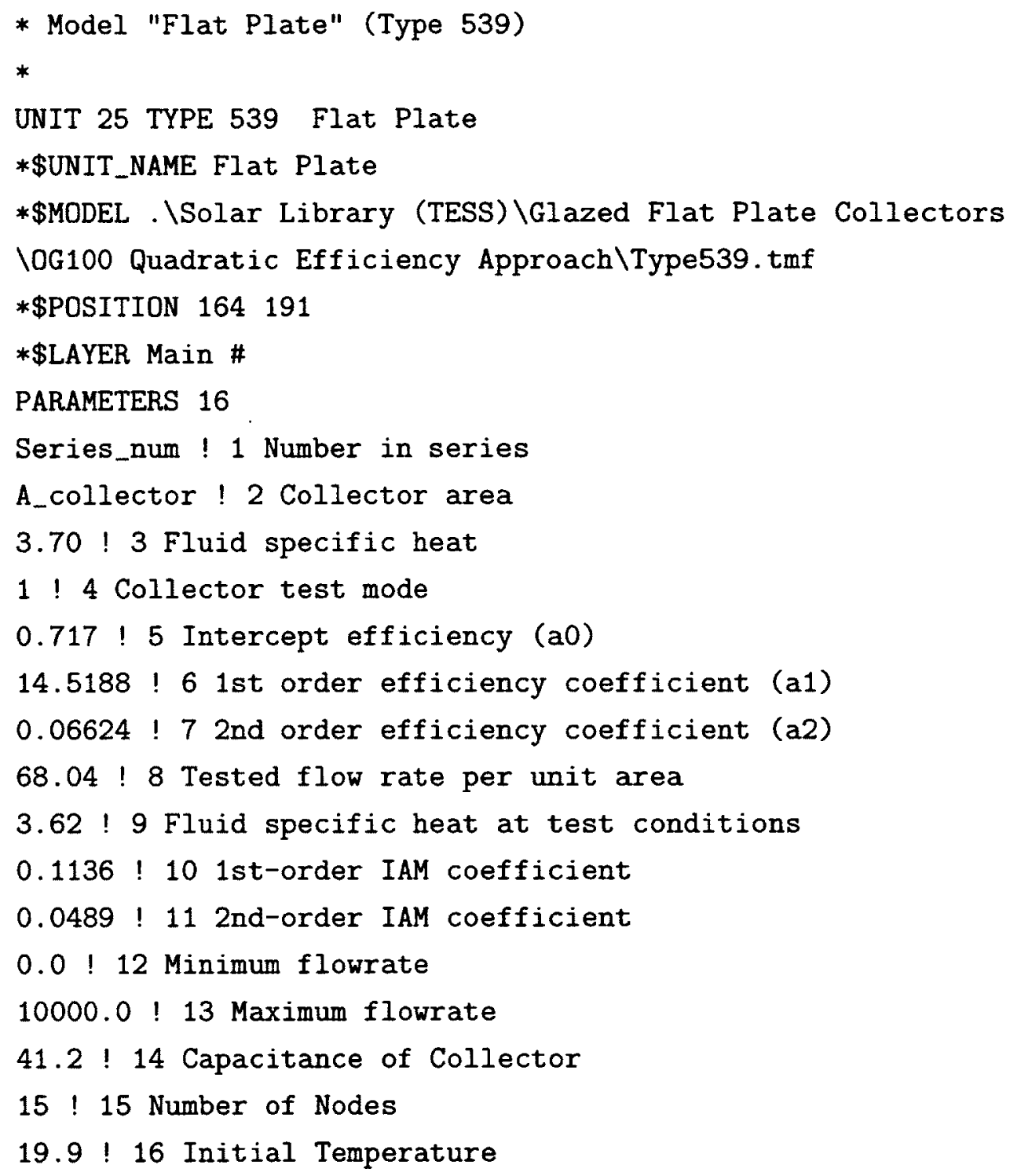

\section{D.3.4 Diurnal Tank Type 534}

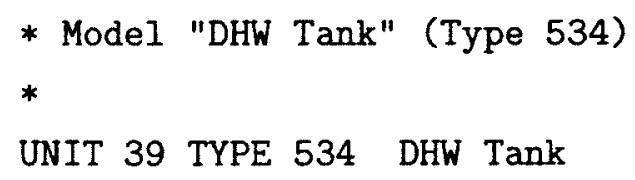


*\$UNIT_NAME DHW Tank

*\$MODEL . \Storage Tank Library (TESS) \Cylindrical Storage Tank

VVertical Cylinder \Version without Plug-In\No HXs \Type534-NoHX.tmf *\$POSITION 735191

*\$LAYER Main \#

*\$\# CYLINDRICAL STORAGE TANK

PARAMETERS 122

-1 ! 1 LU for data file

50 ! 2 Number of tank nodes

2 ! 3 Number of ports

$0 ! 4$ Number of immersed heat exchangers

0 ! 5 Number of miscellaneous heat flows

V_DHW ! 6 Tank volume

h_DHW ! 7 Tank height

0 ! 8 Tank fluid

4.178 ! 9 Fluid specific heat

994 ! 10 Fluid density

2.2428 ! 11 Fluid thermal conductivity

2.592 ! 12 Fluid viscosity

0.000337 ! 13 Fluid thermal expansion coefficient

0.9612 ! 14 Top loss coefficient

1.2384 ! 15 Edge loss coefficient for node-1

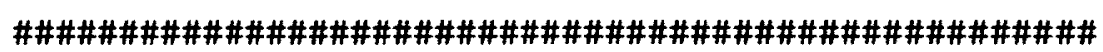

EDGE LOSS COEFFICIENTS OMITTED FOR CLARITY

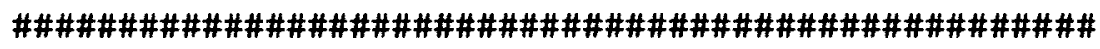

1.2384 ! 64 Edge loss coefficient for node-50

0.9612 ! 65 Bottom loss coefficient

6.0768 ! 66 Additional thermal conductivity

1 ! 67 Inlet flow mode-1

50 ! 68 Entry node-1

1 ! 69 Exit node-1

1 ! 70 Inlet flow mode-2

17 ! 71 Entry node-2

50 ! 72 Exit node-2 


\section{D.3.5 Seasonal Tank Type 531}

* Model "Seasonal Storage" (Type 531)

*

UNIT 19 TYPE 531 Seasonal Storage

*\$UNIT_NAME Seasonal Storage

*\$MDDEL . \Storage Tank Library (TESS) \Flat Bottomed Storage Tank

\Version without Plug-In\Type531-NoPlugIn.tmf

*\$POSITION 658650

*\$LAYER Main \#

$* \$$ \# CYLINDRICAL STORAGE TANK

$* \$ \#$

$* \$ 30 \mathrm{~cm}$ of $0.04 \mathrm{~W} / \mathrm{mK}$ insulation

$* \$$

*\$ Concrete walls $20 \mathrm{~cm}$ thick $\mathrm{k}=1.73 \mathrm{~W} / \mathrm{mK}$ (BASECALC)

PARAMETERS 66

-1 ! 1 LU for data file

20 ! 2 Number of tank nodes

3 ! 3 Number of ports

0 ! 4 Number of immersed heat exchangers

0 ! 5 Number of miscellaneous heat flows

V_Seas ! 6 Tank volume

h_Seas ! 7 Tank height

P_Seas ! 8 Tank perimeter

0 ! 9 Tank fluid

4.181 ! 10 Fluid specific heat

998 ! 11 Fluid density

2.3184 ! 12 Fluid thermal conductivity

1.9692 ! 13 Fluid viscosity

0.000451 ! 14 Fluid thermal expansion coefficient

U_s_ins_top ! 15 Top loss coefficient

U_s_ins_side ! 16 Edge loss coefficient for node-1

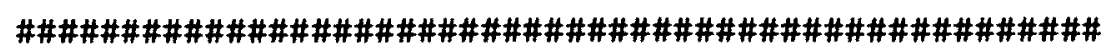

EDGE LOSS COEFFICIENTS OMITTED FOR CLARITY 


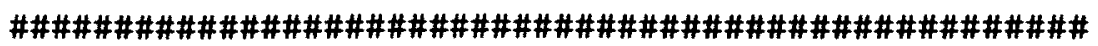

U_s_ins_side ! 35 Edge loss coefficient for node-20

U_s_ins_bot ! 36 Bottom loss coefficient

Seas_cond ! 37 Additional thermal conductivity

1 ! 38 Inlet flow mode-1

1 ! 39 Entry node-1

20 ! 40 Exit node-1

1 ! 41 Inlet flow mode-2

20 ! 42 Entry node-2

1 ! 43 Exit node-2

1 ! 44 Inlet flow mode-3

$20 ! 45$ Entry node-3

1 ! 46 Exit node-3 


\section{Appendix E}

\section{Hydronic Slab Model in ESP-r}

This appendix provides a brief introduction to the hydronic slab model created and implemented into ESP-r by Laouadi [127]. The discussion here is not meant to be exhaustive, merely to introduce the model and describe the modifications made to the model for this research. For further details on the solution procedure of the model, the interested reader is directed to Laouadi [127].

The hydronic floor model was 2-D semi-analytical model which was designed for integration into the 1 D modelling method used in in building simulation tools for heat transfer in building envelope fabrics. The model was only capable of representing serpentine piping arrangements for the floor and was originally intended for slab-ongrade systems only. Section E.2 describes the modification made in the source code to allow for simulation of hydronic systems located on subfloors.

\section{E.1 Assumptions and Modelling}

Laouadi [127] stated three assumptions used to develop the mathematical model of the radiant floor:

- The temperature gradients along the axis of the embedded piping was negligible compared to the temperature gradients in the plane of the tubing cross-section. Laouadi [127] stated that this assumption was valid as long as the ratio of the spacing between the serpentine tubes and the length of the entire circuit was much less than 1.

- The edges of the radiant system were well insulated (adiabatic). 
Figure E.1 illustrates the 2-D calculation domain of the hydronic floor, encompassed by the bold black line. The spacing between the embedded pipes is $M$, the slab thickness is $S$, the vertical distance from the axis of the embedded pipe to the floor surface is $x_{p}$.

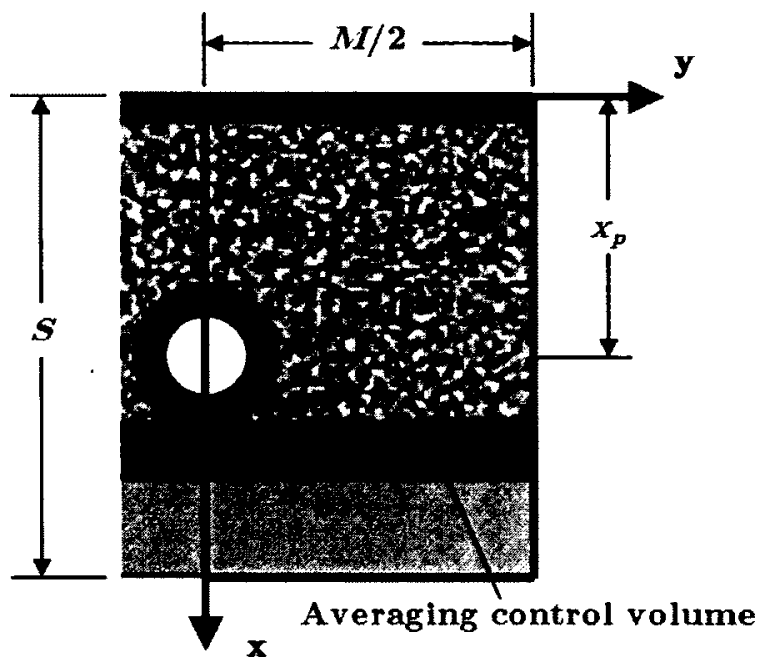

Figure E.1: Hydronic floor calculation domain, adapted from Laouadi [127]

The boundary conditions of the calculation domain were given as [127]:

$$
\begin{gathered}
x=0: \quad-k \frac{\partial T}{\partial x}=q_{\text {floor }} \\
x=S: \quad T=T_{g}(t) \\
y=0, M / 2: \quad \frac{\partial T}{\partial y}=0
\end{gathered}
$$

where $k$ is the average conductivity of the slab material $[\mathrm{W} / \mathrm{m} \mathrm{K}], T_{g}(t)$ is the temperature of the ground in contact with slab on grade system at time $t\left[{ }^{\circ} \mathrm{C}\right]$, and $q_{\text {floor }}$ is the heat flux lost at the floor surface $\left[\mathrm{W} / \mathrm{m}^{2}\right]$.

The heat transfer in the slab medium is governed by the fundamental equation given in Equation E.4.

$$
\rho c_{p} \frac{\partial T}{\partial t}=\frac{\partial}{\partial x}\left(k \frac{\partial T}{\partial x}\right)+\frac{\partial}{\partial y}\left(k \frac{\partial T}{\partial y}\right)+q
$$


where $\rho$ is the average density of the slab $\left[\mathrm{kg} / \mathrm{m}^{3}\right], c_{p}$ is the specific heat of the slab $[\mathrm{J} / \mathrm{kg} \mathrm{K}]$, and $q$ is the heat generation rate per unit volume $\left[\mathrm{W} / \mathrm{m}^{3}\right]$ which occurs within the volume occupied by the pipe.

Laouadi [127] pointed out that the analytical solution of Equation E.4 was non trivial. To solve the system, Laouadi [127] employed a 1 D numerical method to solve for $\mathbf{y}$-averaged temperatures over the averaging control volume shown in Figure E.1. The Equation E.4 may be re written as [127]:

$$
\rho c \frac{\partial \bar{T}}{\partial t}=\frac{\partial}{\partial x}\left(k \frac{\partial \bar{T}}{\partial x}\right)+\bar{q}(x, t)
$$

where $\bar{T}$ and $\bar{q}$ are the $\mathrm{y}^{-}$averaged temperature and heat generation rate. These values are determined from [127]:

$$
\begin{aligned}
& \bar{T}(x, t)=\frac{2}{M} \int_{0}^{M / 2} T(x, y, t) d y \\
& \bar{q}(x, t)=\frac{2}{M} \int_{0}^{M / 2} q(x, y, t) d y
\end{aligned}
$$

The solution for the temperature $T(x, y, t)$ in Equation E.4 was then expressed as the sum of the mean temperature $\bar{T}$ and a perturbation $\Phi$, shown in Equation E.8 [127].

$$
T(x, y, t)=\bar{T}(x, t)+\Phi(x, y, t)
$$

The $\bar{T}(x, t)$ is typically solved within the building simulation tool within the $1 \mathrm{D}$ model for building constructions layers [171]. The 2-D perturbation $\Phi$ could then be solved for analytically. For details on this analytical solution, the interested reader is directed to Laouadi [127].

Figure E.2 illustrates the energy balance over a differential length of embedded pipe. The differential fluid element is at temperature $T_{f}\left[{ }^{\circ} \mathrm{C}\right]$ and is receiving and inlet energy rate of $\mathrm{dQ}_{b}[\mathrm{~W}]$. The inside of the pipe wall is at temperature $T_{t i}\left[{ }^{\circ} \mathrm{C}\right]$ and the outside of the wall is at $T_{t o}\left[{ }^{\circ} \mathrm{C}\right]$. Heat is transferred from the fluid to the tube wall at a rate of $\mathrm{dQ}_{f}[\mathrm{~W}]$ over the differential length and heat was transferred from the tube wall to the slab at a rate of $\mathrm{dQ}_{c}[\mathrm{~W}]$. 


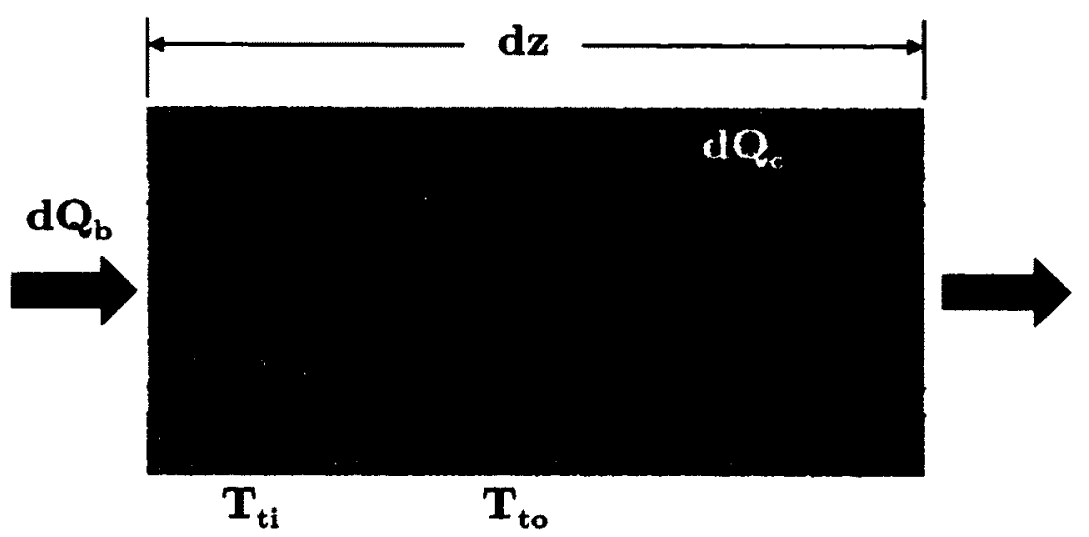

Figure E.2: Energy balance for tube element, adapted from Laouadi [127]

The energy balance expression for this differential element is provided in Equation E.9 [127]:

$$
\dot{m} c_{f} \frac{\partial T_{f}}{\partial z}=-\left[U P\left(T_{f}-T_{t o}\right)+(\rho c A)_{f} \frac{\partial T_{f}}{\partial t}+U P R_{c}(\rho c A)_{t} \frac{\mathrm{d} T_{t o}}{\mathrm{~d} t}\right]
$$

where $\dot{m}$ was the mass flow rate of the fluid through the element $[\mathrm{kg} / \mathrm{s}], c$ was the specific heat of the material $[\mathrm{J} / \mathrm{kg} \mathrm{K}], \mathrm{U}$ was the overall heat conductance of the pipe wall and heat transfer coefficient between the fluid and pipe wall $\left[\mathrm{W} / \mathrm{m}^{2} \mathrm{~K}\right], P$ is the perimeter of the pipe cross-sectional surface $[\mathrm{m}], R_{c}$ is the conductive thermal resistance of the tank wall per unit length $[\mathrm{m} \mathrm{K} / \mathrm{W}], A$ was the cross-sectional area $\left[\mathrm{m}^{2}\right]$, and the subscripts $f$ and $t$ referred to the fluid and the pipe wall respectively.

Further details of the solution method are omitted here for clarity. The intention of this section was to introduce the model, assumptions, and boundary conditions used for the hydronic floor model. For complete details on the solution method, the interested reader is directed to Laouadi [127]. 


\section{E.2 Modification to the Source Code}

In the original implementation to ESP $r$, the user was required to specify the zone, surface, and node number which received or sent heat flux from the hydronic slab model. Since the model was developed for slab on grade systems, the heat injection from the hydronic floor was only included in the specified energy balance expressions for the user specified surface. If the surface receiving the hydronic system flux was adjacent to a surface in another zone, the energy balance expressions for the adjacent zone did not include the flux from the plant component. This lead to unrealistic results for the system.

To illustrate the original limitation on the hydronic floor model, a two zone model shown in Figure E. 3 was created. The common surface between the two zones was a single layer mass partition which by default was discretized into three nodes. A hydronic plant component was specified for the system and associated with the floor surface of Zone 2. The flux gain from the hydronic floor model was injected into the middle node of the construction.

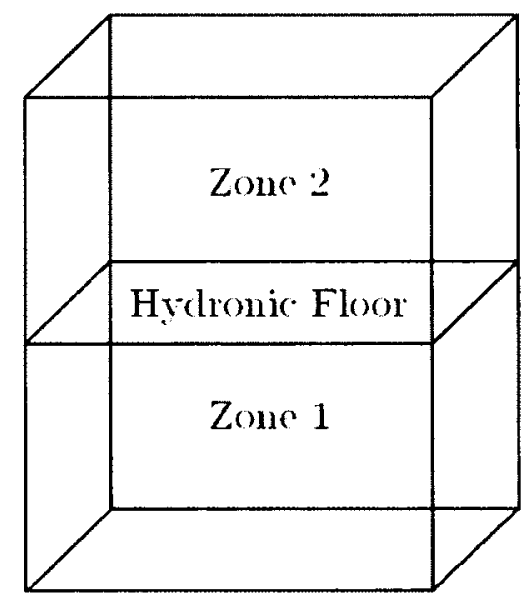

Figure E.3: Simple 2 zone hydronic floor example model

The hydronic floor had a simple on-off control with a constant temperature source to supply the system. Two simulations were performed to demonstrate the limitation of the hydronic floor model. For the first simulation, the ESP-r development branch source code from revision 8808 was used. This was the revision immediately preceding the addition of the hydronic floor model modification. A one week simulation was performed and the middle node temperatures of the Zone 1 ceiling and Zone 2 floor 
were recorded. Since these two nodes are conflated in the model, the temperature of the two nodes should be identical at every timestep. The results of the first simulation are given in Figure E.4.

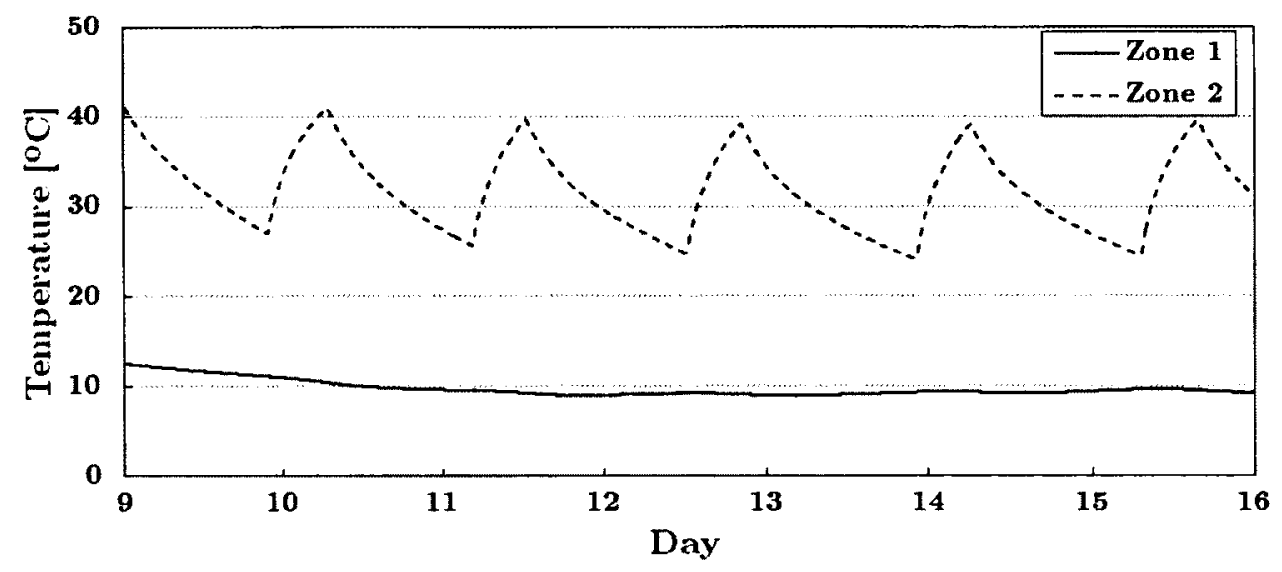

Figure E.4: Temperature of node receiving flux from hydronic floor model using ESP r @r8808

It can be seen that the energy balance of the surface between the zones had become de coupled. From the perspective of Zone 2, the middle node temperature of the hydronic floor increased and decreased with plant flux injection as expected. From the perspective of Zone 1 however, the middle node of the ceiling observed to be largely insensitive to the operation of the hydronic floor and was at a consistently lower temperatures than it's corresponding node in Zone 2. The results obtained here were unrealistic since both nodes considered here represented the same discrete volume of building fabric. The issue was that only the energy balance expressions for Zone 2 received the hydronic floor flux. This flux was not included in the energy balance expressions of Zone 1.

A modification to the source code was introduced by Manzan [128] to correct this decoupling. The modified source code determined if the hydronic floor surface was linked to another zone. If it was, flux from the plant network was injected to the corresponding node in the adjacent zone surface. This modification has been recently implemented into the ESP $r$ development branch source code. To illustrate the modification, a second simulation was run using development branch at revision 9155. The temperature node of the middle of the hydronic slab from the perspective of both Zone 1 and Zone 2 is provided in Figure E.5. 


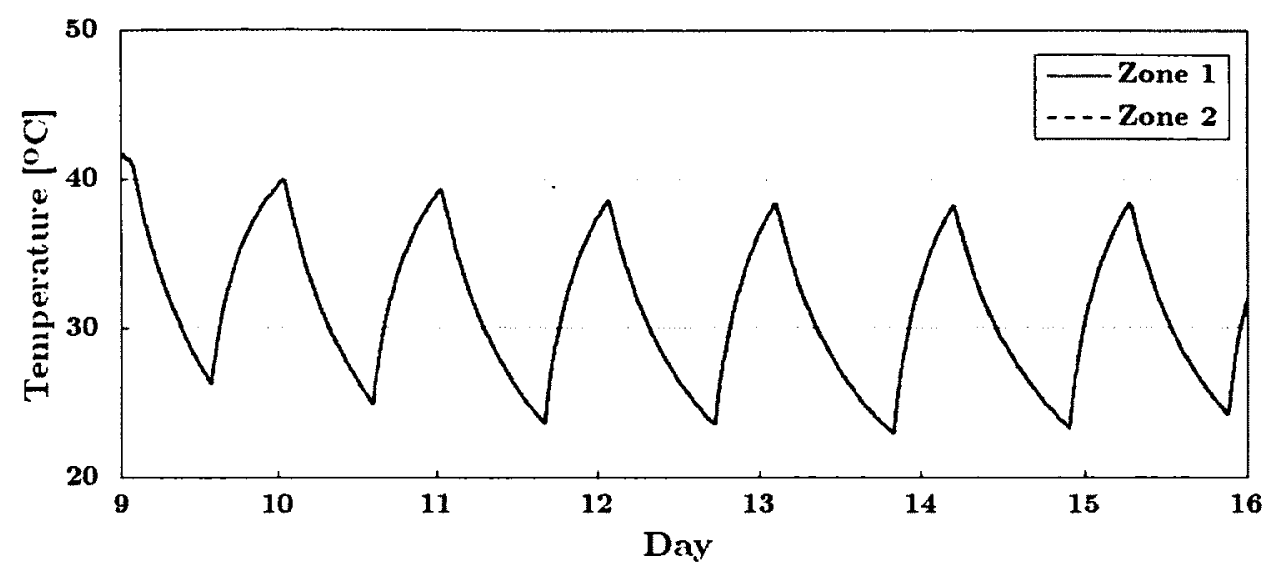

Figure E.5: Temperature of node receiving flux from hydronic floor model using ESP-r @ $\mathrm{r} 9155$

The system now appeared to behave as expected. Both nodes were calculated to have nearly identical temperatures. These results made sense since both nodes represented the same discrete volume of building fabric.

It was previously mentioned that the lower boundary condition of the hydronic slab model was assumed to be a uniform temperature equal to the ground boundary temperature. A uniform temperature boundary was assumed to be valid for hydronic subfloor systems where there was sufficient insulation provided on the underside of the system. The criteria for minimum insulation levels under the floor to ensure model validity was not determined however, and further research on the modelling of subfloor hydronic systems is encouraged. 


\section{Appendix F}

\section{Custom TRNSYS Types}

One of the strengths of the TRNSYS tool was the ease in which new control or component models could be implemented into the software. Discussed in Chapter 4 , the structure of the TRNSYS software was modular. A new TRNSYS type could be coded in a stand alone dynamic linking library (DLL) and loaded at runtime.

Below is the source code for the outdoor reset control (ORC) that was written for this research. This control scheme was based on the ORC with indoor feedback studied by MacCluer [161]. This controller was able to run in 2 modes. In the first mode, indoor feedback with offset modulation was used. Under this control setup the reset curve is translated vertically based on feedback from the indoor zone. In the second mode, indoor feedback with slope modulation was used. Here the slope of the reset curve was adjusted based on indoor feedback. This controller could also function as a simple ORC if the first mode was used with zero thermostat gain.

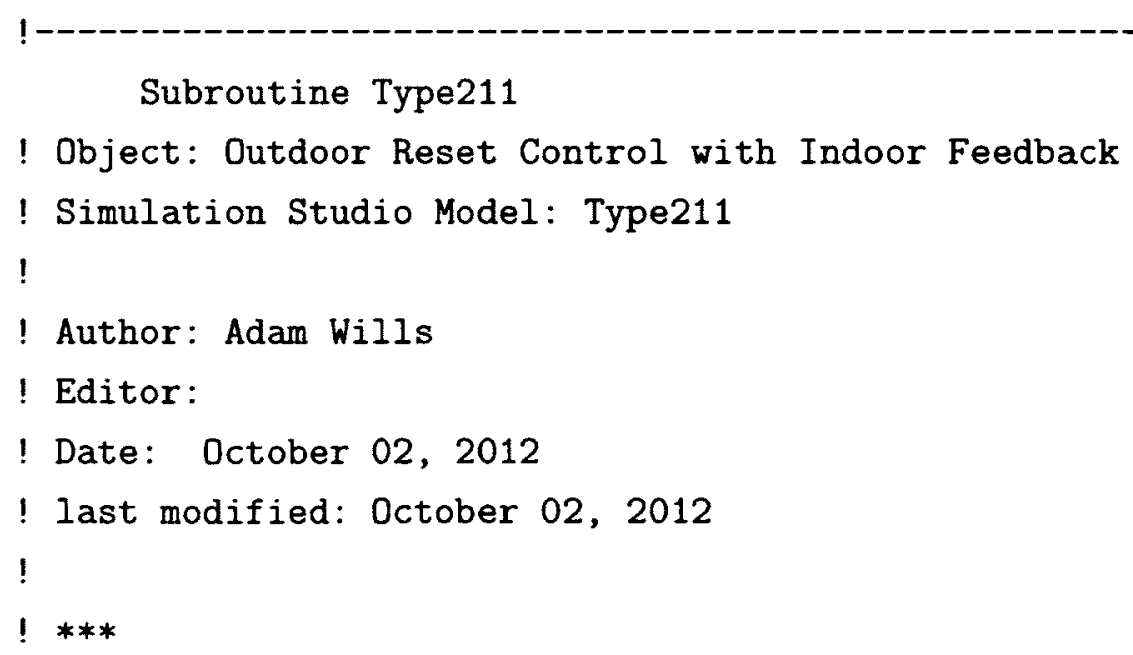




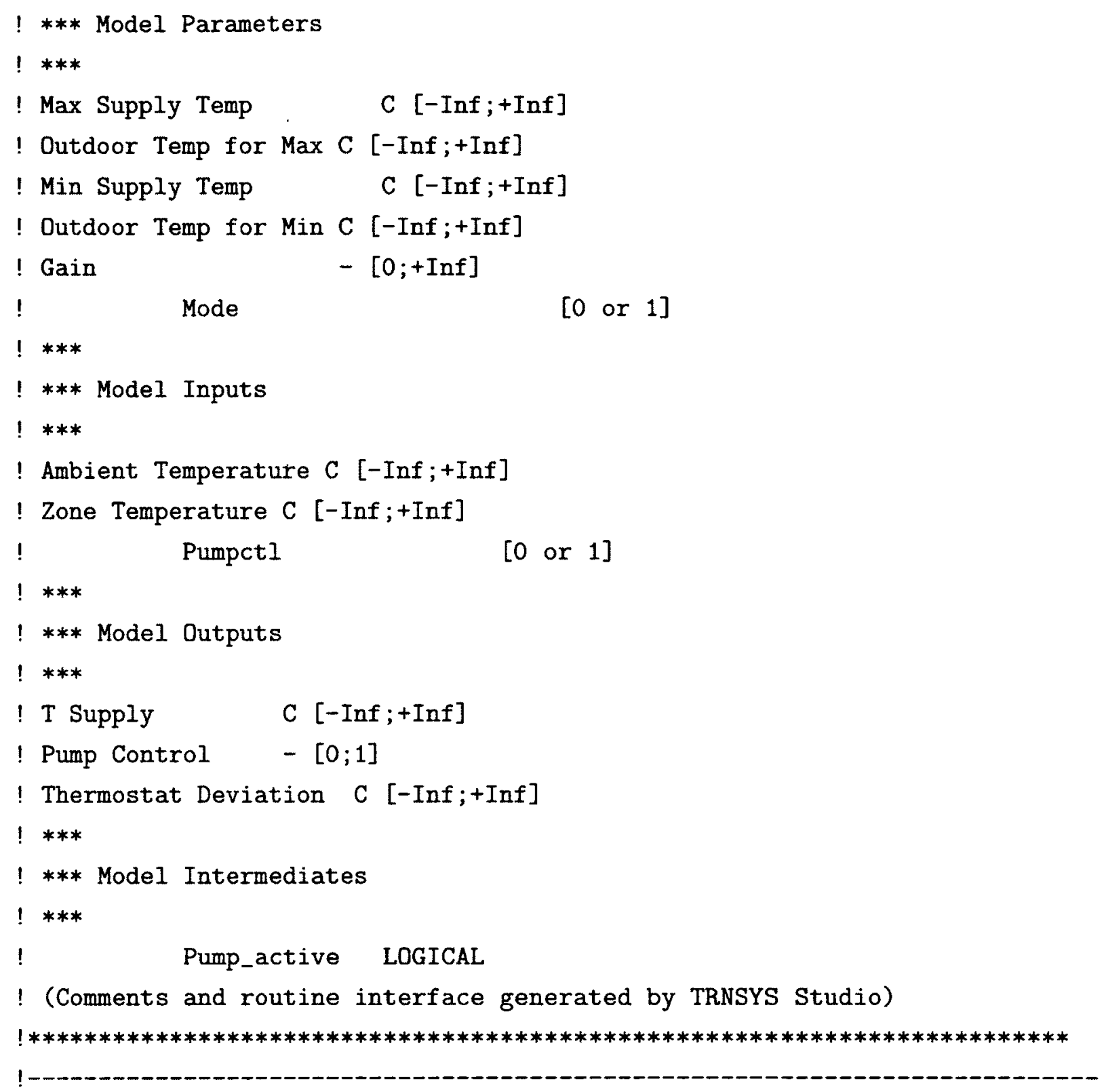

! This TRNSYS component skeleton was generated from the TRNSYS studio based ! on the user-supplied parameters, inputs, outputs, and derivatives. The ! user should check the component formulation carefully and add the content ! to transform the parameters, inputs and derivatives into outputs.

! Remember, outputs should be the average value over the timestep and not

! the value at the end of the timestep; although in many models these are ! exactly the same values. Refer to existing types for examples of using 
! advanced features inside the model (Formats, Labels etc.)

!-------

Use TrnsysConstants

Use TrnsysFunctions

!DEC\$Attributes DLLexport :: Type211

!-

! Trnsys Declarations

Implicit None

Double Precision Timestep, Time

Integer CurrentUnit, CurrentType

! PARAMETERS

DOUBLE PRECISION Tmaxsup

DOUBLE PRECISION Toutmax

DOUBLE PRECISION Tminsup

DOUBLE PRECISION Toutmin

DOUBLE PRECISION Tsetter

DOUBLE PRECISION Gain

DOUBLE PRECISION Mode

$! \quad$ INPUTS

DOUBLE PRECISION Tamb

DOUBLE PRECISION Tzone

DOUBLE PRECISION Pumpctl

$!$ INTERMEDIATES

LOGICAL Pump_active

DOUBLE PRECISION slope

$1 \quad$ OUTPUTS

DOUBLE PRECISION TsuP

DOUBLE PRECISION Pump_over 
DOUBLE PRECISION deviate

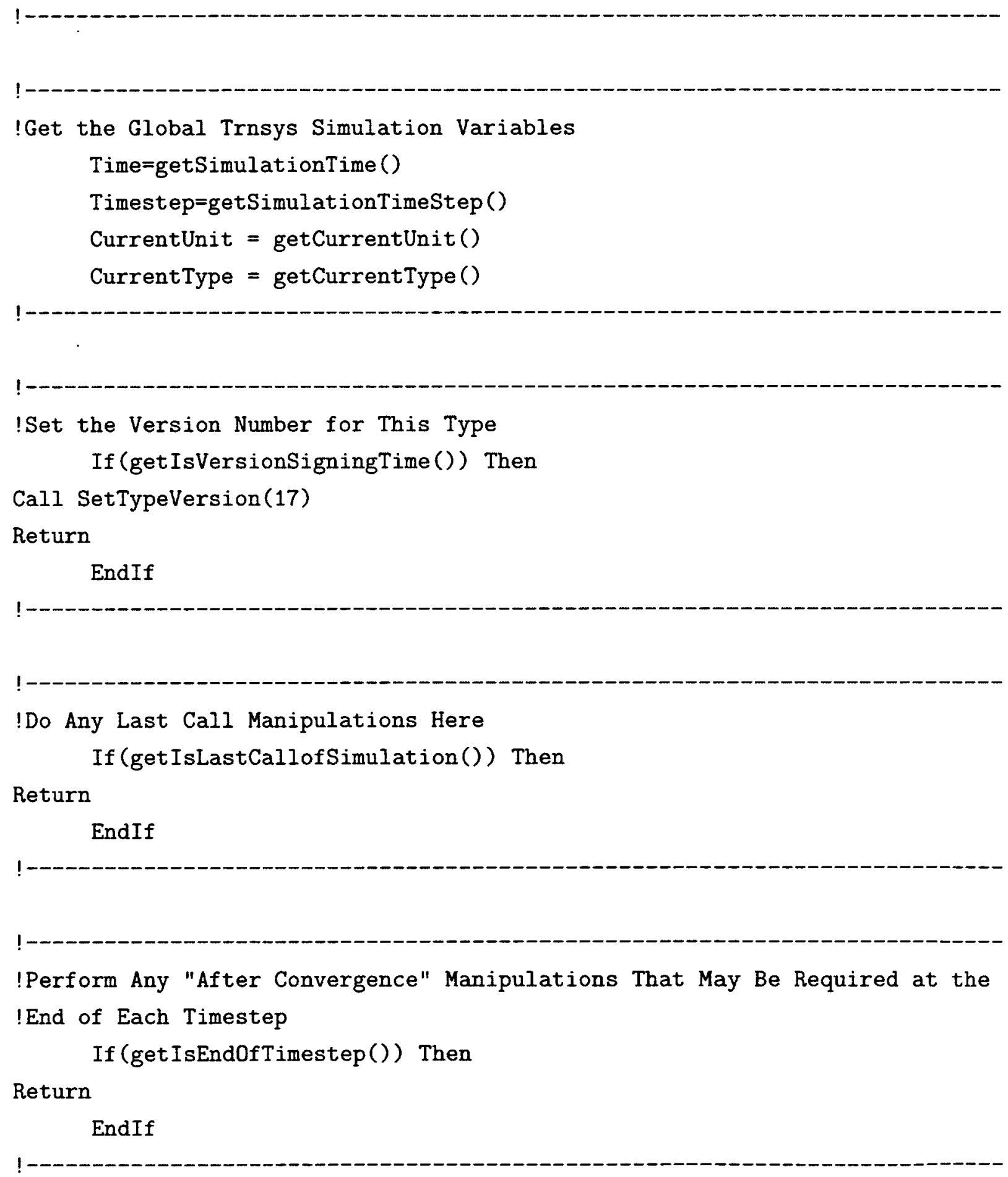


!Do All of the "Very First Call of the Simulation Manipulations" Here If (getIsFirstCallofSimulation()) Then

! Tell the TRNSYS Engine How This Type Works

! The number of parameters that the the model wants

Call SetNumberofParameters (7)

! The number of inputs that the the model wants

Call SetNumberofInputs (3)

!The number of derivatives that the the model wants

Call SetNumberofDerivatives (0)

!The number of outputs that the the model produces

Call SetNumberofOutputs(3)

! An indicator for the iteration mode (default=1).

Call SetIterationMode(1)

!The number of static variables that the model wants stored in the !global storage array and the number of dynamic variables that the !model wants stored in the global storage array

Call SetNumberStoredVariables $(0,0)$

!The number of discrete control functions set by this model (a !value greater than zero requires the user to use Solver 1d)

Call SetNumberofDiscreteControls (0)

Return

EndIf 
!Do All of the First Timestep Manipulations Here - There Are No Iterations !at the Intial Time

$$
\begin{aligned}
& \text { If (getIsStartTime()) Then } \\
& \text { Tmaxsup = getParameterValue(1) } \\
& \text { Toutmax = getParameterValue (2) } \\
& \text { Tminsup = getParameterValue (3) } \\
& \text { Toutmin = getParameterValue (4) } \\
& \text { Tsetter = getParameterValue(5) } \\
& \text { Gain = getParameterValue (6) } \\
& \text { Mode = getParameterValue(7) } \\
& \text { Tamb = GetInputValue(1) } \\
& \text { Tzone = GetInputValue(2) } \\
& \text { Pumpctl = GetInputValue(3) }
\end{aligned}
$$

!Set the Initial Values of the Outputs (\#,Value)

Call SetOutputValue (1, 0) ! T Supply

Call SetOutputValue $(2,0)$ ! Control to pump

Call SetOutputValue $(3,0)$ ! Thermostat Deviation

Return

EndIf

$1-$

$!-$

!ReRead the Parameters if Another Unit of This Type Has Been Called Last If (getIsReReadParameters()) Then

! Read in the Values of the Parameters from the Input File

Tmaxsup = getParameterValue(1)

Toutmax $=$ getParameterValue (2)

Tminsup $=$ getParameterValue (3) 


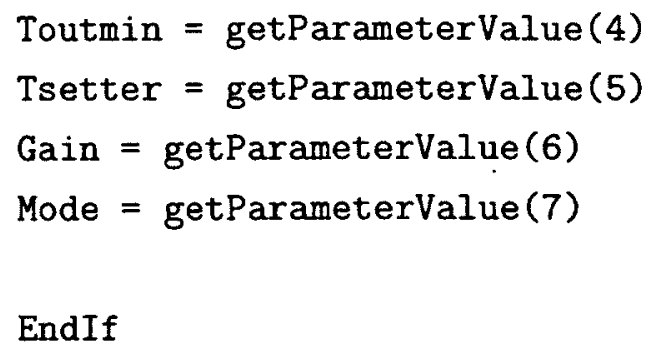


If (Pump_active) Then

! Calculate reset slope slope $=(($ Tminsup-Tmaxsup $) /($ Toutmin-Toutmax $))$

If (Mode $==0$ ) Then

! Indoor feedback using offset modulation

! Begin calculating the supply temp from the main reset curve Tsup $=($ slope* $($ Tamb-Toutmax $))+$ Tmaxsup

! If there is indoor feedback, adjust the supply temp accordingly

! Add in the gain

$$
\text { Tsup }=\text { Tsup }+(\text { deviate*Gain })
$$

Else

! Mode 1. Indoor feedback using slope modulation

! Modify slope based on thermostat deviation

! Zone above setpoint, decrease negative slope

! Zone below setpoint, increase negative slope

$$
\text { slope }=\text { slope }-(\text { deviate } * \text { Gain })
$$

! Calculate Supply Temperature with new slope of curve passing

! through point of minumum supply at maxoutdoor temperature

$$
\text { Tsup }=\text { Tminsup }+(\text { slope } *(\text { Tamb-Toutmin }))
$$

\section{Endif}

! Make sure the determined supply is within the operable range ! If calculated supply temperature is too high, reset to max If (Tsup > Tmaxsup) Tsup = Tmaxsup

! Set output pump signal

Pump_over $=$ Pumpct 1 
! If calculated supply temperature is too low, outside

! operating range. Turn off pumps

If (Tsup < Tminsup) Then

!Override pump signal

Pump_over $=0 . \mathrm{do}$

Tsup = Tminsup

EndIf

Else

! Radiant floor system is not active, no pumps

Pump_over $=$ Pumpct 1

Tsup $=0 . \mathrm{dO}$

EndIf

!Set the Outputs from this Model (\#,Value)

Call SetOutputValue(1, Tsup) ! T Supply

Call SetOutputValue(2, Pump_over) ! Pump Control

Call SetOutputValue(3, deviate) ! Thermostat Deviation

Return

End 